\title{
Refinery Integration of By-Products from Coal-Derived Jet Fuels
}

\section{SEMI-ANNUAL PROGRESS REPORT}

September 18, 2005 - March 17, 2006

Caroline E. Burgess Clifford, André Boehman, Chunshan Song,

Bruce Miller, Gareth Mitchell

Date Issued: May 17, 2006

Grant DE-FC26-03NT41828

The Pennsylvania State University

The Energy Institute

C205 Coal Utilization Laboratory

University Park, PA 16802 


\section{Disclaimer}

This report was prepared as an account of work sponsored by an agency of the United States Government. Neither the United States Government nor any agency thereof, nor any of their employees, makes any warranty, express or implied, or assumes any legal liability or responsibility for the accuracy, completeness, or usefulness oof any information, apparatus, product, or process disclosed, or represents that its use would not infringe privately owned rights. Reference herein to any specific commercial product, process, or service by trade name, trademark, manufacturer, or otherwise does not necessarily constitute or imply its endorsement, recommendation, or favoring by the United States Government or any agency thereof. The views andd opinions of authors expressed herein do not necessarily state or reflect those of the United States Government or any agency thereof. 


\section{Abstract}

This report summarizes the accomplishments toward project goals during the first six months of the third year of the project to assess the properties and performance of coal based products. These products are in the gasoline, diesel and fuel oil range and result from coal based jet fuel production from an Air Force funded program. Specific areas of progress include generation of coal based material that has been fractionated into the desired refinery cuts, acquisition and installation of a research gasoline engine, and modification of diesel engines for use in evaluating diesel produced in the project. Characterization of the gasoline fuel indicates a dominance of single ring alkylcycloalkanes that have a low octane rating; however, blends containing these compounds do not have a negative effect upon gasoline when blended in refinery gasoline streams. Characterization of the diesel fuel indicates a dominance of 3-ring aromatics that have a low cetane value; however, these compounds do not have a negative effect upon diesel when blended in refinery diesel streams. The desulfurization of sulfur containing components of coal and petroleum is being studied so that effective conversion of blended coal and petroleum streams can be efficiently converted to useful refinery products. Equipment is now in place to begin fuel oil evaluations to assess the quality of coal based fuel oil. Combustion and characterization of fuel oil indicates that the fuel is somewhere in between a No. 4 and a No. 6 fuel oil. Emission testing indicates the fuel burns similarly to these two fuels, but trace metals for the coal-based material are different than petroleum-based fuel oils. Co-coking studies using cleaned coal are highly reproducible in the pilot-scale delayed coker. Evaluation of the coke by Alcoa, Inc. indicated that while the coke produced is of very good quality, the metals content of the carbon is still high in iron and silica. Coke is being evaluated for other possible uses. Methods to reduce metal content are being evaluated. 


\section{TABLE OF CONTENTS}

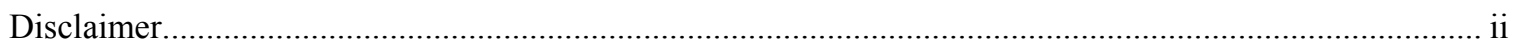

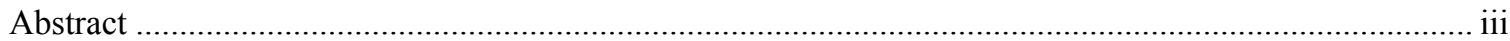

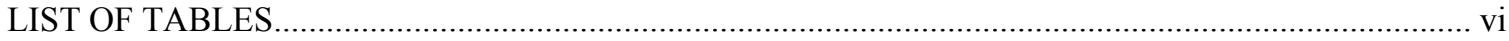

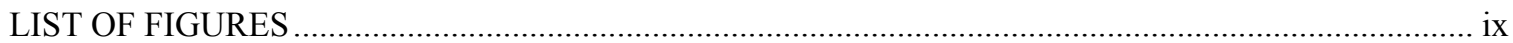

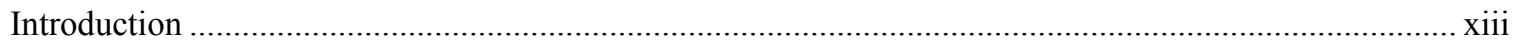

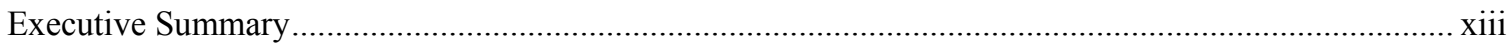

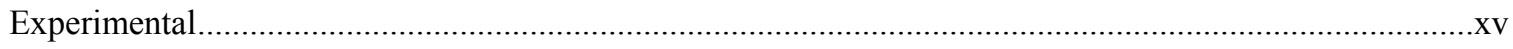

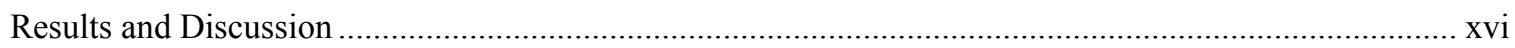

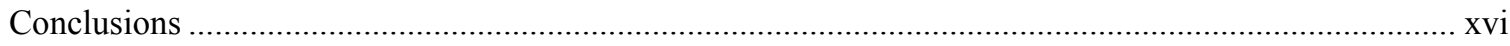

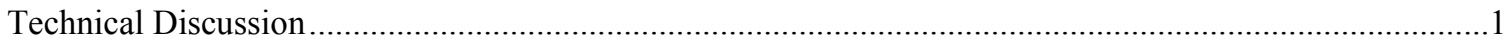

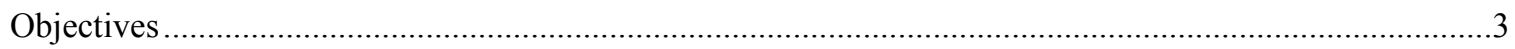

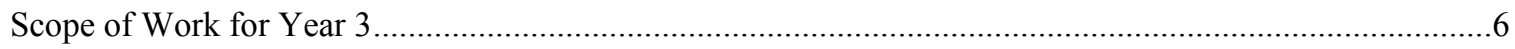

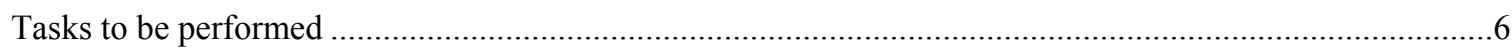

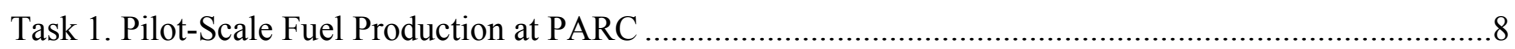

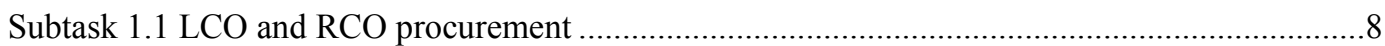

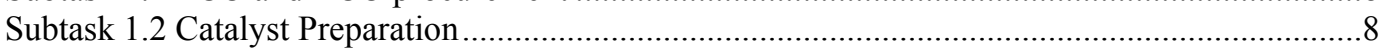

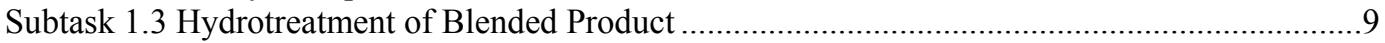

Subtask 1.4 Fractionation into Refinery Product Slate................................................................12

Task 2. Evaluation of Coal-Based Gasoline and Diesel Products in IC Engines and Related Studies ..........13

Subtask 2.1 Impact on Gasoline Quality and Performance ...........................................................13

2.1.1 Preparation of Laboratory and Instrumentation .....................................................14

2.1.2 Impact on Chemical and Physical Properties ............................................................18

2.1.3 Impact on SI Engine Emissions and Performance ................................................18

Subtask 2.2 Impact on Diesel Fuel Quality and Performance .......................................................22

2.2.1 Acquisition, Installation, and Instrumentation of Ignition Test Equipment ..............23

2.2.2 Development of Analytical Methods and Test Procedures ......................................23

2.2.3 Evaluation of Capabilities and Needs for Supplemental Measurements and

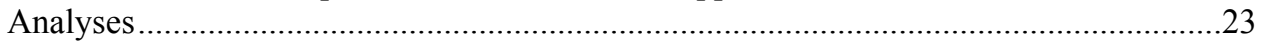

2.2.4 Impact on Chemical and Physical Properties ..........................................................24

2.2.5 Impact on CI Engine Emissions and Performance ..............................................27

Task 3. Desulfurization, Denitrogenation, Saturation of Aromatics, Chemicals from Coal...........................44

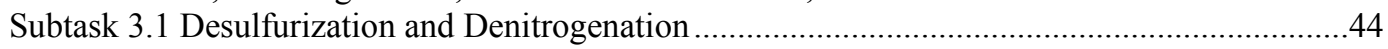

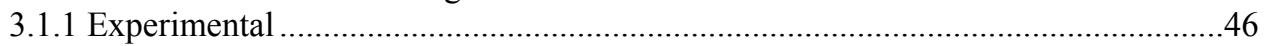

3.1.1.1 Preparation of high active unsupported NiMo sulfide catalysts ..........................46

3.1.1.2 Direct measurement of active sites on HDS catalysts ........................................47

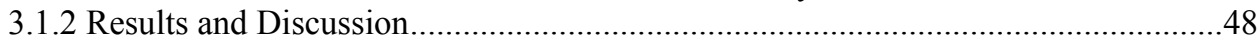

3.1.2.1 Preparation of high active unsupported NiMo sulfide catalysts .............................48

3.1.2.1.1 Comparison of Unsupported NiMoS with Commercial NiMoS/ $\mathrm{Al}_{2} \mathrm{O}_{3}$ Catalyst 48 
3.1.2.1.2 Effects of pressure and temperature in catalyst preparation on HDS .................50

3.1.2.1.3 Effects of organic solvent in catalyst preparation on HDS ...............................53

3.1.2.1.4 Effect of $\mathrm{Ni} /(\mathrm{Mo}+\mathrm{Ni})$ ratio on DBT and 4,6-DMDBT HDS.............................. 55

3.1.2.2 Direct measurement of active sites on HDS catalysts ...........................................56

3.1.2.2.1 Simultaneous adsorption of DBT and 4,6-DMDBT on HDS catalysts ..............57

3.1.2.2.2 Sequential adsorption of DBT and 4,6-DMDBT on HDS catalysts ...................59

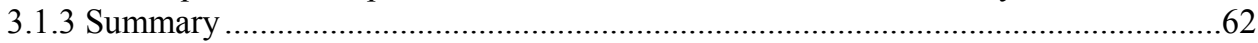

3.1.3.1 Preparation of high active unsupported NiMo sulfide catalysts ............................62

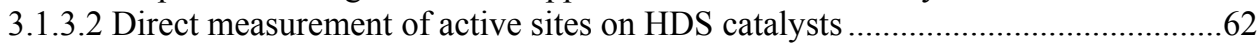

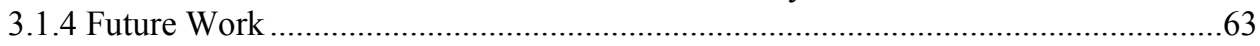

Subtask 3.2 Saturation of Two-Ring Aromatics............................................................................63

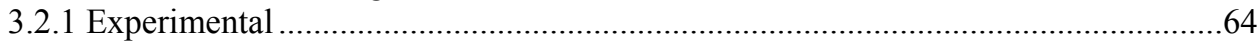

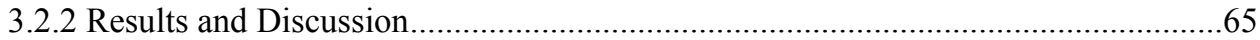

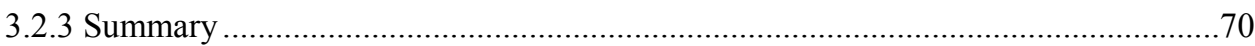

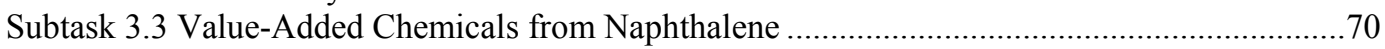

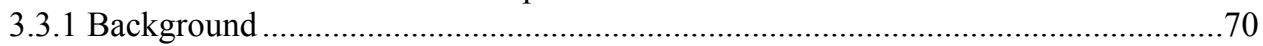

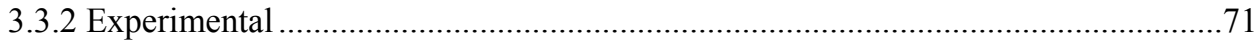

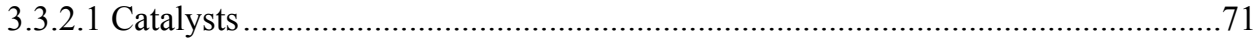

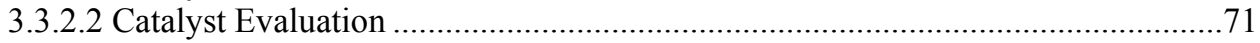

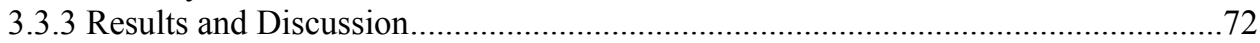

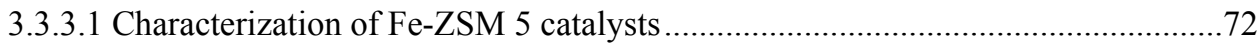

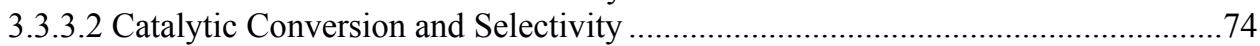

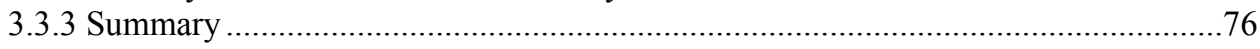

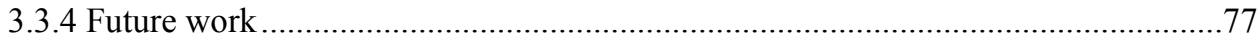

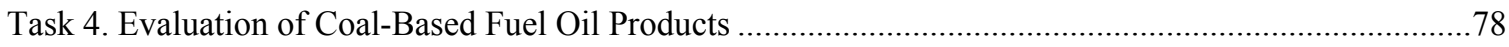

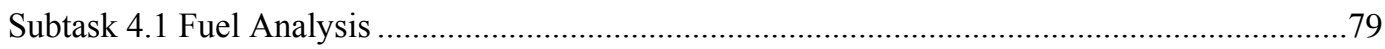

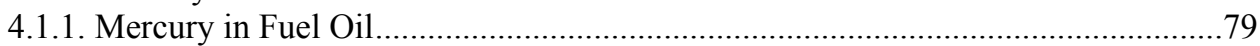

4.1.1.1 Evaluation of LECO Mercury Analyzer for Liquid Hydrocarbons.......................83

4.1.1.2 Other Techniques for Analysis of Trace Metals in Liquid Hydrocarbons .............85

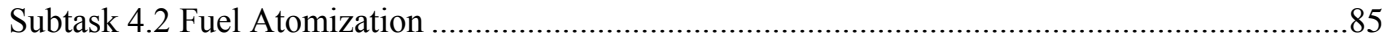

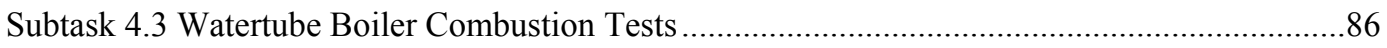

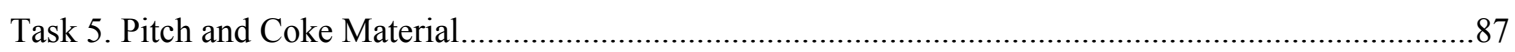

Subtask 5.1 Sample Procurement and Preparation ................................................................... 87

Subtask 5.2. Examine the Residue from Fractionation of the Deeply-Hydrotreated RCO/LCO

as a pitch material .....................................................................................................99

Subtask 5.3 Co-Coking of Coal and Heavy Petroleum Stream .....................................................105

Subtask 5.3.1 Reproducibility of the Products from the Delayed Coker........................................106

Subtask 5.3.2 Production of Coal Tar from Coal Extraction..........................................................128

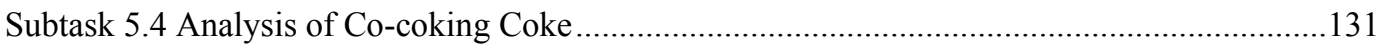

Subtask 5.5 Analysis of Co-Coking Binder Pitch ..........................................................................139

Subtask 5.6 Manufacture and Testing of Carbon Artifacts ..........................................................160

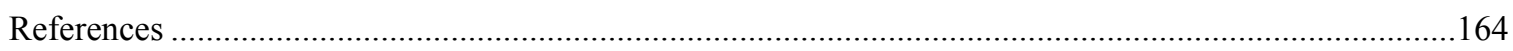

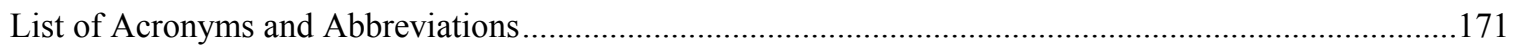

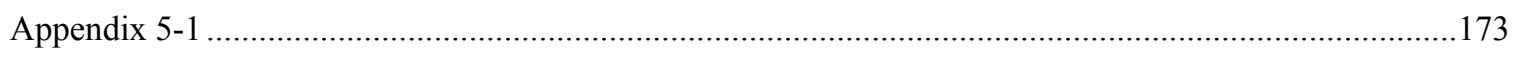

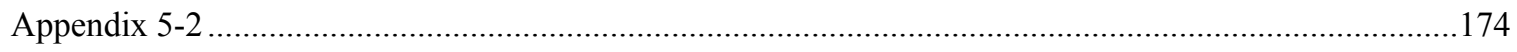




\section{List of Tables}

Table 1-1. United LCO and Koppers RCO Simulated Distillations ..............................................................

Table 2-1. CFR Engine Operation Conditions for Previous and Current Autoignition Study .......................17

Table 2-2. Fuel Properties of Ultra Low Sulfur Diesel Fuel Doped with Three-Ringed Aromatics..............25

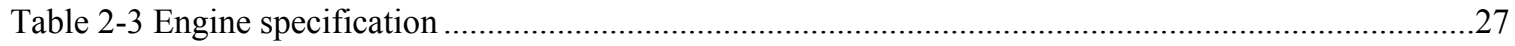

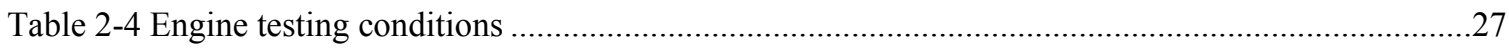

Table 3-1. Rate constants of HDS of DBT and 4,6-DMDBT over unsupported NiMo sulfide and commercial sulfide catalysts

Table 3-2. The effects of preparation condition on HDS of DBT and 4,6-DMDBT over unsupported

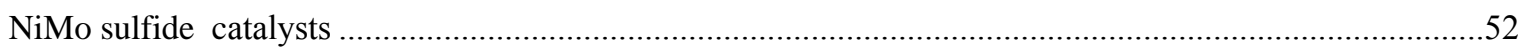

Table 3-3. The effects of preparation temperature on HDS of DBT and 4,6-DMDBT over unsupported NiMo sulfide catalysts .53

Table 3-4. The effects of solvent amount on HDS of DBT and 4,6-DMDBT over unsupported NiMo sulfide catalysts

Table 3-5. The effect of $\mathrm{Ni} /(\mathrm{Mo}+\mathrm{Ni})$ ratio on HDS of 4,6-DMDBT and DBT over NiMo sulfide catalyst .56

Table 3-6. Amount of adsorbed sulfur compounds on NiMo and CoMo sulfide catalysts from simultaneous adsorption ... .59

Table 3-7. Amount of adsorbed sulfur compounds on NiMo and CoMo sulfide catalysts from sequential adsorption

Table 3-8. Turnover frequency of DBT and 4,6-DMDBT HDS over commercial NiMo and CoMo sulfide catalysts on the basis of simultaneous adsorption 61

Table 3-9. Characterization of Pd, Pt and Pd-Pt catalysts supported on CBV720*

Table 3-10. Binding Energies from XPS analysis for Pd, Pt and Pd-Pt catalysts. .68

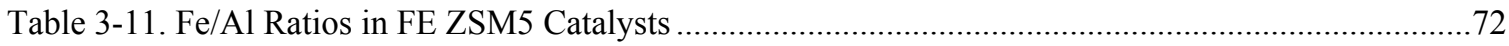

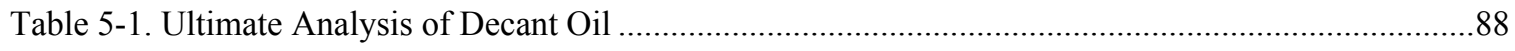

Table 5-2. Product Distribution by Weight for Vacuum Distillation..............................................................8

Table 5-3. Comparison of the Clean Coal Frother Cell Effluent with Run-of-Mine Pittsburgh Seam Coal 
Table 5-4. Elemental Analysis and Simulated Boiling Point for Hydrotreated Decant Oils

Table 5-5. Proximate and Ultimate Analysis of the Feeds Used in this Study ..... .107

Table 5-6. Conditions and Product Distributions for co-coking experiments. 115

Table 5-7. Distribution of ${ }^{1} \mathrm{H}$ NMR signals as a function of time of delayed co-coking of Pittsburg Seam coal with decant oil (4:1 Ratio) 116

Table 5-8. Distribution of ${ }^{13} \mathrm{C}$ NMR signals as a function of time of delayed co-coking of Pittsburg Seam coal with decant oil (4:1 Ratio) 117

Table 5-9. Boiling point distributions by simulated distillation gas chromatography 120

Table 5-10. Simulated distillation boiling point distributions of coker distillates. 121

Table 5-11. Product distributions by weight from simulated distillation. 122

Table 5-12. Product distributions by weight from vacuum distillation .123

Table 5-13. Distribution of ${ }^{1} \mathrm{H}$ NMR signals of delayed co-coking of Pittsburgh seam coal with decant oil 125

Table 5-14 Distribution of ${ }^{13} \mathrm{C}$ NMR signals of delayed co-coking of Pittsburgh seam coal with decant oil

Table 5-15 Chemical compositions of vacuum fractions based on semi-quantitative GC/MS results ........128

Table 5-16. Conditions and Yields from the Experimental Delayed Coker 132

Table 5-17. Petrographic Analysis of Carbon Textures in Coker Sample \#55 by Size and Origin, Vol. \% 136

Table 5-18. Proportion of Textures Derived from Pittsburgh Seam Coal and Decant Oil Compared with The Normalized Concentration of Decant Oil Textures in Coke from Run \#55, Vol. \% 136

Table 5-19. Proximate Analysis of Run \#55 from Different Levels above Inlet Compared with the Green and Calcined Coke Composite Provided by A.J. Edmond

Table 5-20. Petrographic Analysis of Carbon Textures in a Composite of Twelve Coker Runs

Provided by A.J. Edmond, both green and Calcined Coke by Size and Origin, Vol. \% 137

Table 5-21. Proportion of Textures Derived from Coal and Decant Oil Compared with the Normalized Concentration of Decant Oil Textures in Composite Coke Green and Calcined Cokes, Vol.\% 137

Table 5-22. Spectrochemical Analysis of Ash Derived from Green and Calcined Coke Composites Provided by A.J. Edmond Compared with the Coal (EI-186) .138 
Table 5-23. Heat Soaking Conditions of Co-coking Liquid Distillate Run \#50

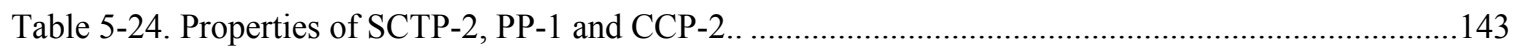

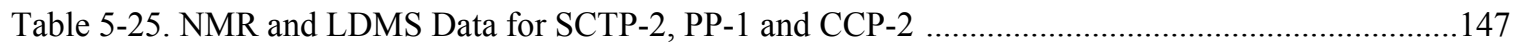

Table 5-26. Number of Various Atoms in Average Molecular and Structural Parameters for SCTP-2, PP-1 and CCP-2 Derived from Solution State NMR and LDMS ......

Table 5-27. Comparison of Results from ${ }^{13} \mathrm{C}$ Solid State $\left(\mathrm{CP}\right.$ and SPE) and ${ }^{13} \mathrm{C}$ Solution State NMR For SCTP-2 and PP-1

Table 5-28. Conditions of Heat Soaked and Visual Observation of Reacted Material as Compared to The Original Run \#50 (360 C-FBP), SCTP-2 and PP-1 .154

Table 5-29. Mass Distribution of SCTP-2, PP-1, Run \#50 and Its Derivatives. 155

Table 5-30. Number and Weight Averages of SCTP-2, PP-1 and Run \#50 and Its Derivatives 156

Table 5-31. Samples of Manufacturing of Carbon Artifacts. .163 


\section{List of Figures}

Figure 1-1 Possible Integration of Coal into Existing Refineries .....................................................................

Figure 1-2. Schematic of Fuel Hydrotreating and Hydrogenation to Take Place at PARC ...........................10

Figure 2-1 Ion probe equipped head gasket for the Hydra engine ...........................................................15

Figure 2-2. Optic-fiber Spark Plug for the CFR Octane Rating Engine …….............................................16

Figure 2-3 Close-up of the Electrodes and Eight Optical Openings ..............................................................16

Figure 2-4 Heat release and cylinder temperature of methylcyclohexane during cool flame combustion ....19

Figure 2-5. Concentrations of $\mathrm{O}_{2}, \mathrm{CO}$, and $\mathrm{CO}_{2}$ vs. compression ratio by TCD. ......................................21

Figure 2-6 Concentration of $\mathrm{CH}_{4}, \mathrm{C}_{2} \mathrm{H}_{4}+\mathrm{C}_{2} \mathrm{H}_{6}, \mathrm{C}_{3} \mathrm{H}_{6}$, and methylcyclohexane vs. compression ratio

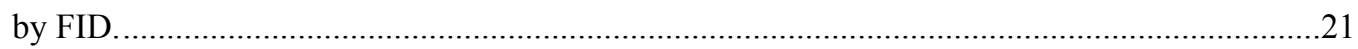

Figure 2-7 Photograph of the Ingnition Quality Tester (IQT) at the Penn State Energy Institute ................26

Figure 2-8 Sample data readout from the IQT. Needle lift is displayed in yellow and combustion

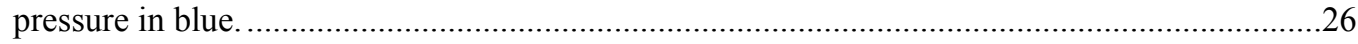

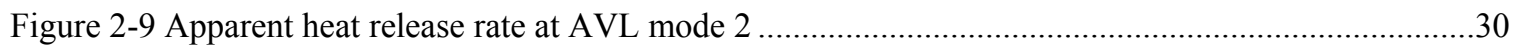

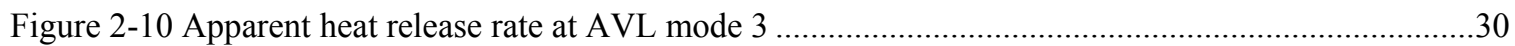

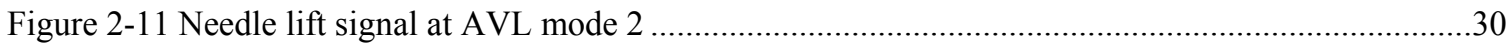

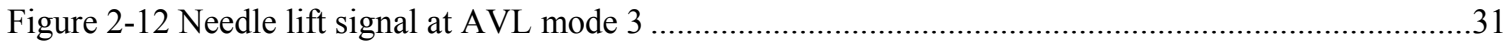

Figure 2-13 Bulk cylinder gas temperature at AVL mode 2 ........................................................................

Figure 2-14 Bulk cylinder gas temperature at AVL mode 3 .....................................................................

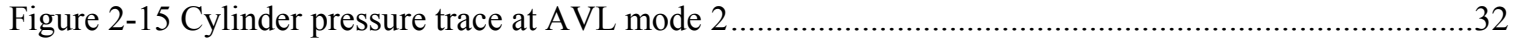

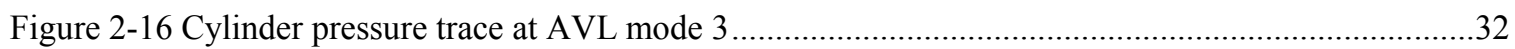

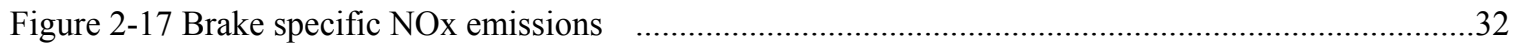

Figure 2-18 Brake specific unburned hydrocarbon emissions ...........................................................................32

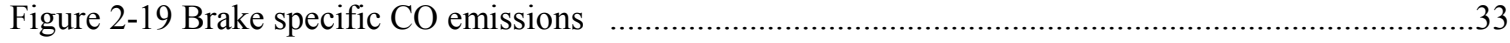

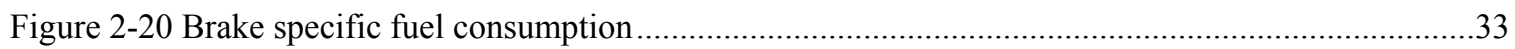

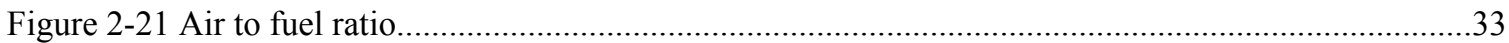

Figure 2-22 Digital Photograph of (a) Optically Accessible Cylinder Head and (b) Navistar 7.3 L Engine.34

Figure 2-23 (a) Isothermal profiles at $475^{\circ} \mathrm{C}$ under air ; $0,3,6$, and 9 correspond to the concentrations of $\mathrm{CO}_{2}$ injected to engine intake (b) Weight loss profiles of $\mathrm{S} 0$ and $\mathrm{S} 9$..........41

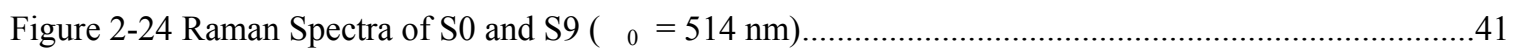

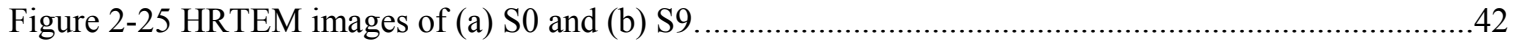


Figure 3-1. HDS rate constants for simultaneous HDS of DBT and 4,6-DMDBT over the laboratory-prepared unsupported NiMoS and a commercial supported $\mathrm{NiMoS} / \mathrm{Al}_{2} \mathrm{O}_{3}$ Catalyst (CR424) at $300^{\circ} \mathrm{C}$ under initial $\mathrm{H}_{2}$ of 300 pressure psi for 28 mins. 50

Figure 3-2. The effect of preparation pressure of $\mathrm{H}_{2}$ on HDS of 4,6-DMDBT and DBT over NiMo sulfide catalysts.

Figure 3-3. The effect of preparation temperature on HDS of 4,6-DMDBT and DBT over NiMo sulfide catalyst .53

Figure 3-4. The effect of solvent amount on HDS of 4,6-DMDBT and DBT over NiMo sulfide catalyst...54 Figure 3-5. Breakthrough curve of DBT and DMDBT on (a) CoMo and (b) NiMo sulfide catalysts at 25 and $300^{\circ} \mathrm{C}$ from simultaneous adsorption. .58

Figure 3-6. Breakthrough curve of DBT and DMDBT on (a) CoMo and (b) NiMo sulfide catalysts at $300^{\circ} \mathrm{C}$ from sequential adsorption.. 61

Figure 3-7. Conversion vs. TOS for the hydrogenation of tetralin over bimetallic catalysts at $225^{\circ} \mathrm{C}$ and $600 \mathrm{psig}$ hydrogen pressure in the presence of $100 \mathrm{ppm}$ sulfur as BT.

Figure 3-8. t-DHN/c-DHN ratios for the hydrogenation of tetralin at $225^{\circ} \mathrm{C}$ and $600 \mathrm{psig}$ hydrogen pressure in the presence of $100 \mathrm{ppm}$ sulfur as BT. .66

Figure 3.9. XPS Spectra of Pd $3 \mathrm{~d}_{5 / 2}$ for Pd/CBV720* .68

Figure 3-10. XPS Spectra of Pd $3 d_{5 / 2}$ for Pd-Pt(4:1)/CBV720*. .69

Figure 3-11. XPS Spectra of Pt $4 \mathrm{f}_{7 / 2}$ for Pt/CBV720*..... .69

Figure 3-12. Spectra of $\mathrm{Pt} 4 \mathrm{f}_{7 / 2}$ for $\mathrm{Pd}-\mathrm{Pt}(4: 1) / \mathrm{CBV} 720^{*}$. .70

Figure 3-13. $\mathrm{NH}_{3}-$ TPD profiles of HZSM 5 and Iron modified ZSM 5 after reaction at $300 \mathrm{deg}$ C Reaction conditions: temperature: $300{ }^{\circ} \mathrm{C}$; Feed (2-MN:methanol: mesitylene=1:5:5 mol ratio): $1.98 \mathrm{ml} / \mathrm{hr}$; Catalyst: 0.3 gram; Gas flow: $20 \mathrm{ml} / \mathrm{min}$ .73

Figure 3-14. The Mass spectroscopy data indicating the peak for water after the $\mathrm{NH}_{3}$ desorption strong acid and weak acid sites. 74

Figure 3-15. Comparison of the Conversion of 2-MN over Fe ZSM 5 catalysts.Reaction conditions: temperature: $300{ }^{\circ} \mathrm{C}$; Feed (2-MN:methanol: mesitylene=1:5:5 mol ratio): $1.98 \mathrm{ml} / \mathrm{hr}$; Catalyst: 0.3 gram; Gas flow: $20 \mathrm{ml} / \mathrm{min}$. 
Figure 3-16. Comparison of the selectivity of 2,6DMN over Fe ZSM 5 catalysts.Reaction conditions: temperature: $300{ }^{\circ} \mathrm{C}$; Feed (2-MN:methanol: mesitylene $\left.=1: 5: 5 \mathrm{~mol} \mathrm{ratio}\right): 1.98 \mathrm{ml} / \mathrm{hr}$; Catalyst: 0.3 gram; Gas flow: $20 \mathrm{ml} / \mathrm{min}$ .75

Figure 3-17. Conversion vs Comparison of the selectivity of 2,6DMN/2,7 DMN over Fe ZSM 5 catalysts.Reaction conditions: temperature: $300{ }^{\circ} \mathrm{C}$; Feed (2-MN:methanol: mesitylene=1:5:5 mol ratio): $1.98 \mathrm{ml} / \mathrm{hr}$; Catalyst: 0.3 gram; Gas flow: $20 \mathrm{ml} / \mathrm{min}$ . .76

Figure 5-1. Tubing Bomb Apparatus .92

Figure 5-2. Yields from Coking Original Decant Oil (DO107) Under Autogenous Pressure at $465^{\circ} \mathrm{C}$, wt. \% .95

Figure 5.3. Distribution of Carbon Textures in Cokes Derived from DO107, vol. \% .96

Figure 5.4. Yields from Coking a Blend of Decant Oil (DO107) and Powellton Coal Under Autogenous Pressure at $465^{\circ} \mathrm{C}$, wt. $\%$ . .97

Figure 5.5. Distribution of Coal-derived Textures in Cokes from Decant Oil/Coal Blends, vol. \%.................98

Figure 5.6. Distribution of Petroleum-derived Textures in Cokes from Decant Oil/Coal Blends, vol. \% .........98

Figure 5.7. Comparison of Yields of Gas, Oil and THF-Soluble Fractions from Experiments Using DO107 Alone and Blends with Coal under Autogenous Pressure, wt. \% . .99

Figure 5.8. Total Insoluble Yield for DO107 Alone and Blends with Coal under Autogenous

Pressure, wt. \% 100

Figure 5.9. Carbon Texture Comparison for Domain and Flow Domain, vol. \% 101

Figure 5.10. Carbon Texture Comparison for Small Domain and Mosaic, vol. \%. 101

Figure 5.11. Carbon Texture Comparison for Isotropic, vol. \% . 102

Figure 5.12. Gas Yield from Three Hydrotreated Decant Oils 103

Figure 5.13. Oil Yield from Three Hydrotreated Decant Oils ..... 104

Figure 5.14. THF-Insoluble Yield from Three Hydrotreated Decant Oils. 104

Figure 5.15. THF-Soluble from Three Hydrotreated Decant Oils .104

Figure 5-16. (a) Picture of delayed coking unit, (b) schematic of the unit in the delayed coker........ 109

Figure 5-17. ${ }^{1} \mathrm{H}$ NMR spectra of vacuum distillation fractions. 126

Figure 5-18. ${ }^{13} \mathrm{C}$ NMR spectra of vacuum distillation fractions. 127

Figure 5-19. Schematic of 2-stage coal extraction reactor, with hot in-line filter. 130 
Figure 5-20 Mass Distribution of SCTP-2, PP-1, and CCP-2 Analyzed by LDMS

Figure 5-21. Average Structures for SCTP-2, PP-1 and CCP-2 Suggested by the Solution State NMR

Analyses

Figure 5-22. LDMS Spectra of Original Run \#50 and Its Derived Materials HT02, HT04, HT06, HT07 and HT08 153

Figure 5-23. Mass Distribution of SCTP-2, PP-1, Run \#50 and Its Derivatives 155

Figure 5-24. Number and Weight Averages of SCTP-2, PP-1, Run \#50 and Its Derivatives. 156

Figure 5-25. Comparison of a Mass Distribution of Run \#50-HT02 to that of SCTP-2 and PP-1

Figure 5-26. Comparison of a Mass Distribution of the 320-360 Fraction and Its Derived Materials HT10, HT11 and HT12 159

Figure 5-27. Comparison of the Mass Distribution of HT02 and HT10. A Possibility of Mixing These Two Samples at a Specific Ratio to Obtain a More Continuous Mass Distribution. .160 


\section{Refinery Integration of By-Products from Coal-Derived Jet Fuels}

\section{Introduction}

This program is investigating the fate of each major product from a refinery complex, except jet fuel, resulting from the refinery integration of coal-derived jet fuel production via a combined RCO/LCO strategy by studying the physical and chemical nature of all products that are perturbed by introduction of coal components into the refinery.

The impact of the proposed research is to provide the scientific and fundamental engineering basis to integrate the production of coal-based jet fuel into existing refinery operations in a time frame consistent with availability and economic forecasts related to petroleum-derived as opposed to coal-based feedstocks. The results of these studies lead to the integration of all non-jet-fuel streams into current refinery operations in concert with desired production of coal-based jet fuel engine testing toward the end of the first decade of the new century. For successful utilization of coal-based jet fuels all non-jet-fuel components must fit existing and future product stream specifications.

\section{Executive Summary}

Penn State has been working for more than a decade on the development of an advanced, thermally stable, coal-based jet fuel, JP-900. Two process routes to JP-900 have been identified, one involving the hydrotreating of blends of refined chemical oil (RCO, a by-product of the coal tar industry) with light cycle oil (LCO), and the other involving the addition of coal to delayed cokers. However, no refinery is operated for the primary purpose of making jet fuel. The conversion of the jet fuel section of a refinery to production of coal-based JP-900 would necessarily impact the quantity and quality of the other refinery products, such as gasoline, diesel fuel, fuel oil, and coke. The overall objective of this project is to examine the characteristics and quality of the streams other than the jet fuel, and to determine the effect those materials would have on other unit operations in the refinery.

The present report documents the activities of the first six months of year three of what is envisioned to be a four-year program. Our collateral work on jet fuel, funded by the Air Force Office of Scientific Research, is focused exclusively on that product. Thus as we branch out into the study of the other refinery streams, under this present contract, much of the effort in the last year has been devoted to the evaluation of product streams to streamline operations. 
The overall project involves pilot-scale production of materials at Intertek PARC Technical Services (Harmarville, PA). The coal-based gasoline and diesel fuel is being evaluated in appropriate internal combustion engines. Desulfurization, denitrogenation, and saturation of aromatics are being tested. There is also a component to examine the production of high-value aromatic compounds. The coal-based fuel oil was tested in a research boiler, although not enough fuel was available to do complete characterization. The pitch and coke from initial runs has been characterized. These interrelated activities are designed to evaluate the full range of products from coal-based thermally stable jet fuel production and to lead toward process integration in existing refineries.

The first run for hydrotreatment of blends of refined chemical oil and light cycle oil, followed by fractionation of the total product, was performed at PARC. The various distillation cuts have been provided to the researchers at Penn State for analytical characterization and for use in the appropriate evaluation tests. In addition, decant oil was hydrotreated at several levels of severity for use in the co-coking work. In this report period, PARC has been acquiring new samples of RCO and LCO, and is preparing to hydrotreat in the next six months.

For evaluation of gasoline quality and performance, we have acquired and installed a Ricardo Hydra single-cylinder research engine. The engine can now operate under load and on fuels of interest. Work is continuing on instrumentation and facilities hook-up to the engine test stand. The gasoline obtained from PARC had a CFR octane rating of 61.4, which is low compared to standard gasolines. One of the main components of the gasoline is methylcyclohexane, which will lower the octane rating of a fuel. Therefore, the work done in the first six months of Year 3 relates to fundamentally understanding how methylcyclohexane reacts during combustion so performance may be enhanced.

To assess the impact on diesel fuel quality and performance, two existing engine test stands, using Navistar and DCC turbodiesel engines were enhanced. In addition, new instrumentation for testing ignition quality was purchased and is being installed. The ignition quality test has recently become an ASTM method; we will participate in a round-robin evaluation of this test, which will provide a useful external comparison of data on the coal-based fuels at no additional cost to the project. The diesel fuel from PARC has been characterized. The two major components of coal-derived diesel fuel are fluorene $(3.0 \mathrm{wt} \%)$ and phenanthrene (1.5 wt\%). To evaluate how these compounds might impact a diesel engine, each was blended with an ultra-low sulfur diesel fuel (BP-15) at various concentrations. Details of the results of these tests are discussed within the report.

The desulfurization of 4,6-dimethyldibenzothiophene and of dibenzothiophene in decalin was studied over commercial cobalt-molybdenum and nickel-molybdenum catalysts. Quinoline was used as a model compound to investigate the effect of the presence of nitrogen compounds of the desulfurization process. The desulfurization can be explained by pseudo-first-order kinetics, and is strongly inhibited by the presence of quinoline. An unsupported NiMo catalyst was produced in organic solvent and found to more active than the commercial catalysts. A flow reactor was designed and constructed for saturation of aromatics. The first series of experiments involved palladium on various supports as the catalysts for saturation. The Pd-Pt bimetallic catalysts are more active and sulfur-resistant than the $\mathrm{Pd}$ monometallic catalysts. Selective methylation of 2-methylnaphthalene with methanol has been studied for the production of 2.6dimethylnaphthalene, which would be a value-added coal-based by-product for the petrochemical industry. The conversion and selectivity are higher for iron-modified ZSM 5 
when compared to the $\mathrm{ZSM} 5\left(\mathrm{SiO}_{2} / \mathrm{Al}_{2} \mathrm{O}_{3}=50\right)$. This means that the conversion and selectivity increase with the decrease in acidity.

In the previous report, for fuel-oil evaluation, the combustion performance and trace element emissions of PARC produced fuel oil were measured in Penn State's watertube research boiler. The performance was measured compared to a commercial/petroleum-based No. 6 fuel oil. Work for the next six months will continue with this testing, using a new batch of fuel from PARC so that additional testing can be completed.

About $19 \mathrm{~kg}$ of coke was produced from 12 consecutive runs using 20 weight percentage of the clean Pittsburgh FCE (EI-186) and 80\% United Refining decant oil (EI-107) in our laboratory-scale delayed coker. The coke product was provided to A.J. Edmond Co. for calcinations at $1275^{\circ} \mathrm{C}$ and evaluated as a petroleum coke product. A.J. Edmond was able to make a calcined coke of superior density, but determined that the content of silicon and iron were too high to meet the requirements of Alcoa. However, Alcoa performed an initial investigation of the Pittsburgh co-coke, by preparing laboratory-scale anodes to test the apparent baked density and electrical resistivity. This preliminary evaluation suggested that the co-coke anode had superior properties to those of their standard petroleum coke.

In addition, work continued on processing the non-distillable liquids from the co-coking runs using Pittsburgh coal into a useful binder pitch product. Characterization of these materials in comparison to a standard coal-tar and petroleum pitches, suggested that an increase in the concentration of condensed aromatic-fused-ring compounds would be necessary to match the properties of the standard pitches. An experimental program was designed to heat treat several of the heavier, higher boiling point liquid fractions from one of the test runs used to make the coke sample discussed above. Preliminary results show that some combination of treatment temperature and time effectively increased their molecular weight into the range of the standard petroleum pitch, but revealed that too severe reaction conditions would result in the formation of solids. Work will continue to refine the technique to determine the best set of conditions and liquids fraction to employ to produce a suitable binder pitch.

Finally, on-going studies into the influence of hydrotreated decant oil on the gas and liquid product quality has been completed and the additional question about what influence there might be on coke quality is being addressed in laboratory-scale experiments. To-date heat treatment of the original and hydrotreated decant oils have been conducted using different reaction times and under autogenous pressure individually as well as in the presence of $20 \mathrm{wt} \%$ Powellton/Eagle column flotation cell effluent. Although the impact of hydrotreatment was to increase liquids yield and reduce coke yields, when combined with coal a greater amount of solids were formed and those cokes appeared to much more homogeneous, i.e., more enhanced vitrinite carbon textures.

\section{Experimental}

The respective experimental details for each of the tasks of this project are described within the individual Tasks I - V detailed later in this report. 


\section{Results and Discussion}

The results of each task of this project are documented and discussed within the appropriate Task I - V detailed later in this report.

\section{Conclusions}

Each of the individual tasks of this project has progressed as proposed or to a greater extent than originally proposed. Each task individually contributes to the ultimate goal of refinery integration. This report describes the procurement of equipment into the appropriate laboratories, the establishment of experimental procedures and the generation of results that indicate the relevance and feasibility of the proposed work.

Progress has been made to produce hydrotreated products, differing from conventional refinery products but also compatible with conventional materials. Specific areas of progress include generation of coal based material that has been fractionated into the desired refinery cuts, acquisition and installation of a research gasoline engine, and modification of diesel engines for use in evaluating diesel produced in the project. Characterization of the gasoline fuel indicates a dominance of single ring alkylcycloalkanes that have a low octane rating; however, blends containing these compounds do not have a negative effect upon gasoline when blended in refinery gasoline streams. Characterization of the diesel fuel indicates a dominance of 3-ring aromatics that have a low cetane value; however, these compounds do not have a negative effect upon diesel when blended in refinery diesel streams. For both the gasoline and diesel fuels, the performance of the engine will continue to be evaluated. The desulfurization of sulfur containing components of coal and petroleum is being studied so that effective conversion of blended coal and petroleum streams can be efficiently converted to useful refinery products. The 
development of a finely dispersed Ni/Mo catalyst prepared in house shows increased sulfur removal compared to commercial Ni/Mo catalyst. Equipment is now in place to begin fuel oil evaluations to assess the quality of coal based fuel oil. It was reported in the last report that combustion and characterization of fuel oil indicates that the fuel is somewhere in between a No. 4 and a No. 6 fuel oil. Emission testing indicates the fuel burns similarly to these two fuels, but trace metals for the coal-based material are different than petroleum-based fuel oils. Testing of this fuel will continue when a new sample of fuel oil is produced in the summer. Co-coking studies using cleaned coal are highly reproducible in the pilot-scale delayed coker. Evaluation of the coke indicated that while the coke produced is of very good quality, the metals content of the carbon is still high in iron and silica. Coke is being evaluated for other possible uses. Methods to reduce metal content are being evaluated. 


\section{Technical Discussion}

\section{Background}

Penn State has been involved in a multi-phase fifteen-year program to develop an advanced thermally stable jet fuel for the Air Force [1-1 -1-4]. This fuel would resist breaking down at high temperatures $\left(900^{\circ} \mathrm{F}\right)$, so it could be used for cooling sensitive parts on highperformance aircraft, as well as providing the propulsion. It is provisionally called JP-900.

At its inception, the JP-900 program presumed that this new fuel would be made entirely or substantially from coal. There are three reasons for this.

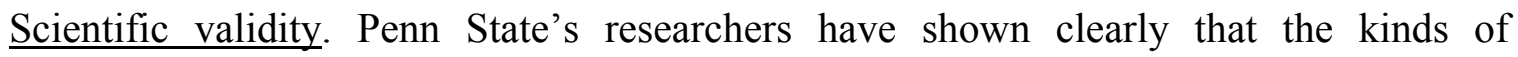
chemicals in the fuel that make it stable at $900^{\circ} \mathrm{F}$ (hydroaromatics and naphthenes) can be derived in abundant amounts from coal. This has been demonstrated in numerous peerreviewed publications [1-5 - 1-10].

Long-term security. Unlike petroleum, coal is a secure, domestic energy resource, for which centuries' worth of reserves remain in the U.S.

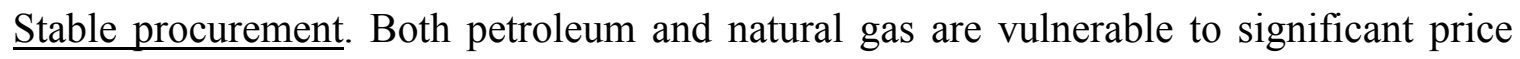
spikes. In contrast, coal companies are willing to write twenty-year delivery contracts at a guaranteed stable price. In turn, this would help stabilize the price of military fuel for decades to come. 
To ultimately produce an advanced thermally stable coal-based jet fuel a practical and economically viable process, compatible with current refinery practice, is necessary. The evaluation of this scenario is the subject of this proposal. No refinery is operated for the specific purpose of making jet fuel. Furthermore, refineries are highly integrated, in that many of the individual operations are dependent on, or use streams from, other operations. Therefore, in order to insure that the production of coal-based JP-900 in the jet fuel section of a refinery is acceptable to refinery operators, it is crucial to have data showing the effect of the by-products from coal-based JP-900 production (i.e., the $<180^{\circ} \mathrm{C}$ and the $>270^{\circ} \mathrm{C}$ fractions) on the quantity and quality of the other refinery products: gasoline, diesel, fuel oil, pitch, and coke.

Options for integrating coal, or a coal liquid product that is currently available commercially (a by-product coal tar distillate from the metallurgical coke industry) into existing refineries are illustrated in Figure 1-1. With respect to the first two options, coal can either be added to the coker directly or be co-processed with the resid. Of these, addition of the coal to coker has been selected - in consultation with our refinery partner - as the better option to produce sufficient quantities of coal-based fuel for thermal stability and combustion testing. Each of these approaches has a unique set of technical challenges in terms of specifying the proper feedstocks (for both petroleum- and coal-based components), process conditions (temperature and pressure) and processing approaches.

Previous work at Penn State has resulted in significant progress in identifying the remaining critical barriers to realization of coal-based fuels [1-11 - 1-20]. 


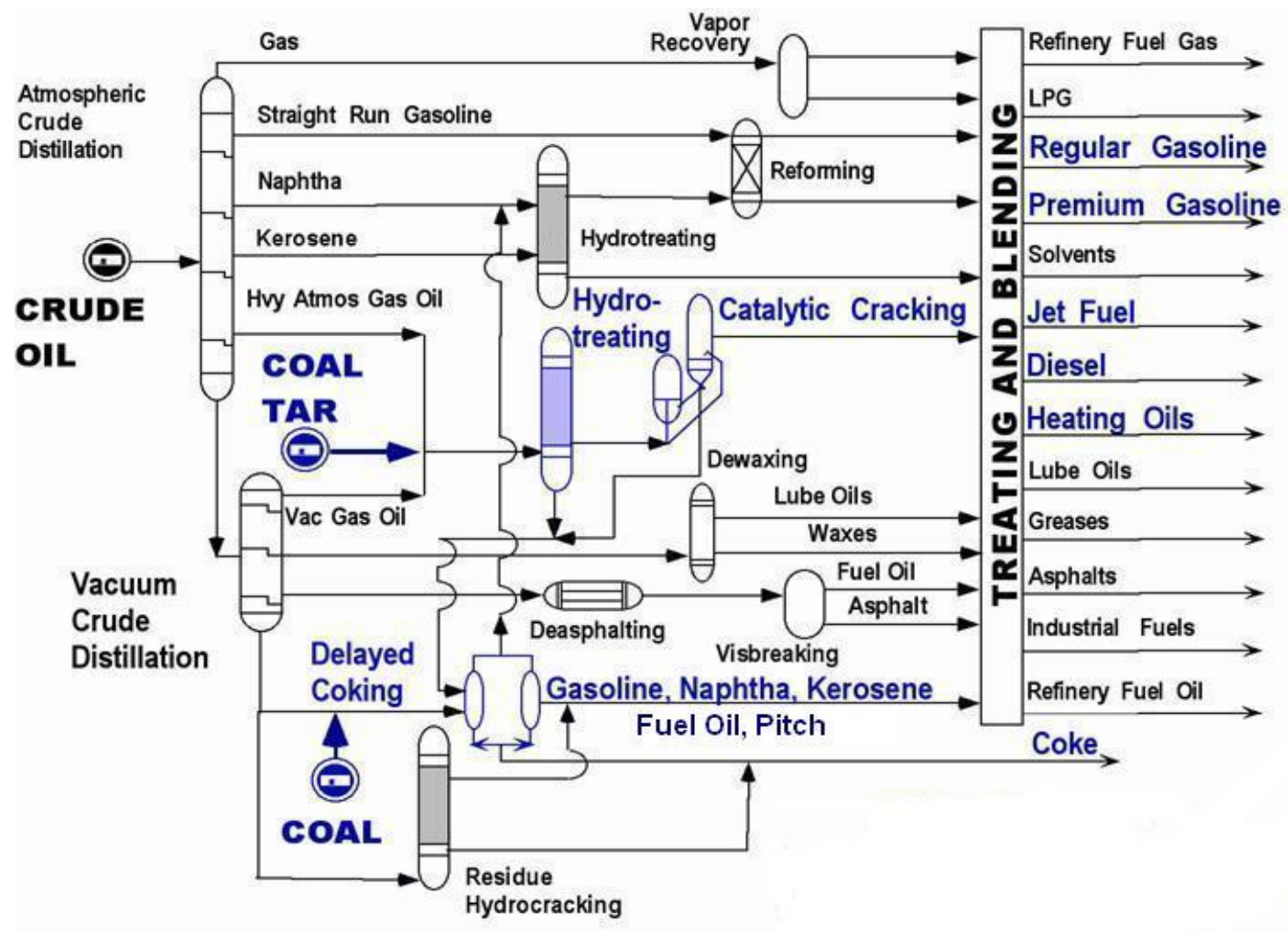

Figure 1-1. Possible Integration of Coal into Existing Refineries.

\section{Objectives}

A number of potential JP-900-type jet fuels have been produced by Pennsylvania Applied Research Corporation (PARC) from the hydrotreatment of a coal-derived refined chemical oil (RCO) and its mixture with a petroleum-derived light cycle oil (LCO).

The overall objective of this project is to examine the characteristics and quality of the streams other than the jet fuel, and what effect those materials would have on the other unit operations in the refinery, the quality and value of the other products. Broadly, these additional by-products are the liquids lighter and heavier than jet fuel itself, i.e., the $<180^{\circ} \mathrm{C}$ and the $>270^{\circ} \mathrm{C}$ 
fractions produced after hydrotreating the $\mathrm{RCO} / \mathrm{LCO}$ blend and fractionating to recover the jet fuel and other refinery streams.

Prior to the beginning of this project, virtually all work was focused on the jet fuel. However, as we have noted above, no refinery is run for the specific purpose of making jet fuel. Therefore, to make these processes acceptable for adoption in refineries, it is vital to assess their impact on the other major operations and products in a refinery. The acquisition of that knowledge is the basis of this project.

These studies will impact all of the major product streams in a conventional petroleumbased refinery. Therefore, replacing petroleum feedstock with domestic coal, gasoline, diesel, fuel oil and pitch components will favorably impact reducing dependence on, and security of supply of, foreign petroleum resources.

The objectives of the project are to:

- Investigate and develop an understanding of the most promising refinery integration of all process streams resulting from the production of coal-based jet fuel.

- Demonstrate the quality of each of the process streams in terms of refinery requirements to maintain a stable, profitable refinery operation.

- Demonstrate the performance of key process streams in practical testing used for application of these streams.

This fundamental research was proposed as a four-year program. In this document we report activities and accomplishments for the first half of the second contract year. The approach chosen draws on previous work that has now successfully produced a coal-based JP-900 fuel at pilot-plant scale for initial investigations in the fuel stabilization and combustion studies [1-21 - 
1-23]. In that work, it has been shown that hydrotreated blends of light cycle oil and refined chemical oil (a coal-derived liquid) resulted in the most thermally stable product to date.

This program is investigating the fate of each major product from a refinery complex, except jet fuel, resulting from the refinery integration of coal-derived jet fuel production via a combined RCO/LCO strategy by studying the physical and chemical nature of all products that are perturbed by introduction of coal components into the refinery.

The impact of the proposed research is to provide the scientific and fundamental engineering basis to integrate the production of coal-based jet fuel into existing refinery operations in a time frame consistent with availability and economic forecasts related to petroleum-derived as opposed to coal-based feedstocks. The results of these studies lead to the integration of all non-jet-fuel streams into current refinery operations in concert with desired production of coal-based jet fuel engine testing toward the end of the first decade of the new century. For successful utilization of coal-based jet fuels all non-jet-fuel components must fit existing and future product stream specifications.

Coal tar fractions have been successfully demonstrated to be suitable feedstocks for the production of jet fuels for high-speed aircraft [1-22, 1-23]. The jet fuel, as prepared and evaluated in our Air Force project, is a $180-270^{\circ} \mathrm{C}$ product, cut from a mixture of RCO/LCO total liquid product. Of this product the $<180^{\circ} \mathrm{C}$ cut represents $\sim 4 \%$ of the total product and the $>270^{\circ} \mathrm{C}$ fraction represents just over $40 \%$ of the total liquid product [1-24]. These streams must either be blended as is, chemically converted and then blended, converted to chemicals, or used as feed to the coker. 


\section{Scope of Work for Year 3}

The technical approach consists of five carefully planned goals whose successful completion will lead to the achievement of the project objectives. These goals include:

- pilot-scale fuel production at PARC,

- evaluation of coal-based gasoline and diesel products in internal combustion engines,

- desulfurization, and denitrogenation of coal-based fuels, the saturation of aromatics to improve stability and the development of chemicals from coal,

- evaluation of coal-based fuel oil, and

- evaluation of pitch and coke materials from coal-based fuel production.

These interrelated goals are designed to evaluate the full utilization of products from coal-based thermally stable jet fuel production and lead toward process integration into existing refineries.

\section{Tasks to be Performed}

We are critically analyzing the performance and value of the streams produced from combination of coal-derived components and normal refinery process streams.

The critical analyses include:

- evaluation of gasoline range material in spark-ignited gasoline engines

- evaluation of diesel-range product for use in compression-ignited diesel engines

- evaluation of heavier range materials as heating oils and boiler fuels

- evaluation of products from co-coking strategies as precursors to higher value cokes and carbons. 
The following summarizes the technical achievements for the first six months of the third project year. 


\section{Task 1. Pilot-Scale Fuel Production at PARC}

C. Burgess Clifford (PSU), L. Rudnick, G. Wilson (PARC)

\section{Subtask 1.1 LCO and RCO Procurement}

Intertek PARC prepared to do a new run of blended light cycle oil (LCO) and refined chemical oil (RCO); the new LCO was procured from United Refining Company in Warren, PA. The new RCO was procured from Koppers, Inc., Harmarville, PA. These materials were blended to provide a feedstock RCO/LCO blend that will be upgraded by deep hydrotreatment and fractionated in the second six months of Year 3. In previous work, a simulated distillation (D2887) of LCO and RCO samples was done, and is shown in Table 1-1. [1-25] Intertek PARC is sending LCO and RCO samples of the run to be done in the summer, and will be compared to the previous analyses.

\section{Subtask 1.2 Catalyst Preparation}

Catalyst, necessary for the deep hydrotreating of total liquid product (TLP), was obtained in this task. In previous work [1-1, 1-24], PARC has identified a Criterion Syncat-3 cobaltmolybdenum or Syncat 37, nickel-molybdenum catalysts as effective in converting the coalbased blend to a deeply hydrotreated total liquid product. This product has been found to be rich in hydroaromatic components and as a result the jet fuel is thermally very stable. These catalysts must be activated by presulfiding after drying in a flow of hydrogen. The SYNCAT catalyst is received by PARC pre-impregnated with a sulfur compound, however, PARC employs a treatment with kerosene containing $0.25 \mathrm{wt} \%$ dimethyldisulfide to ensure proper sulfiding prior to use. 
Table 1-1 United LCO and Koppers RCO Simulated Distilllations

\begin{tabular}{cccc} 
SAMPLE & LCO & RCO & 1:1 RCO:LCO \\
& PR 1244 & PR 1238 & PR 1251 \\
Instrument & 5880 & 5880 & 5880 \\
IBP & 350 & 335 & 341 \\
$5 \%$ & 451 & 390 & 396 \\
$10 \%$ & 485 & 429 & 431 \\
$20 \%$ & 516 & 433 & 436 \\
$30 \%$ & 533 & 435 & 440 \\
$40 \%$ & 553 & 437 & 486 \\
$50 \%$ & 570 & 438 & 534 \\
$60 \%$ & 593 & 451 & 551 \\
$70 \%$ & 618 & 500 & 577 \\
$80 \%$ & 651 & 545 & 625 \\
$90 \%$ & 684 & 598 & 667 \\
$95 \%$ & 705 & 650 & 704 \\
$\mathrm{FBP}$ & 771 & 894 & 813 \\
& & & \\
$\%$ at $356^{\circ} \mathrm{F}\left(180^{\circ} \mathrm{C}\right)$ & 0.15 & 1.91 & 1.36 \\
$\%$ at $518^{\circ} \mathrm{F}\left(270^{\circ} \mathrm{C}\right)$ & 31.2 & 74.0 & 45.5 \\
\hline $572^{\circ} \mathrm{F}\left(300^{\circ} \mathrm{C}\right)$ & 50.9 & 85.1 & 68.1
\end{tabular}

\section{Subtask 1.3 Hydrotreatment of Blended Product}

Production of deeply hydrotreated total liquid product (TLP) to provide material for other tasks in this project by large-scale production of TLP is necessary. The full description of the previous runs is provided in previous semi-annual reports. [1-25] The production of drum quantities of liquid products is described below, including information for the hydrotreatment, hydrogenation and fractionation of total liquid product into fractions to be evaluated in this program. The non-jet-fuel components co-produced with the jet fuel were isolated by fractional distillation for further characterization and testing at Penn State University. 
The scope of this project was to produce hydrogenated total liquid products (TLP) to generate $180^{\circ} \mathrm{C}$ - naphtha, $180-270^{\circ} \mathrm{C}$ high stability jet fuel that meet the tentative specifications set for JP-900, $270-343^{\circ} \mathrm{C}$ diesel and $343^{\circ} \mathrm{C}+$ fuel. The jet fuel target production of this project was 500 gallons. Figure 1-2 is a schematic of the process that is expected to be used for the next batch of fuels.

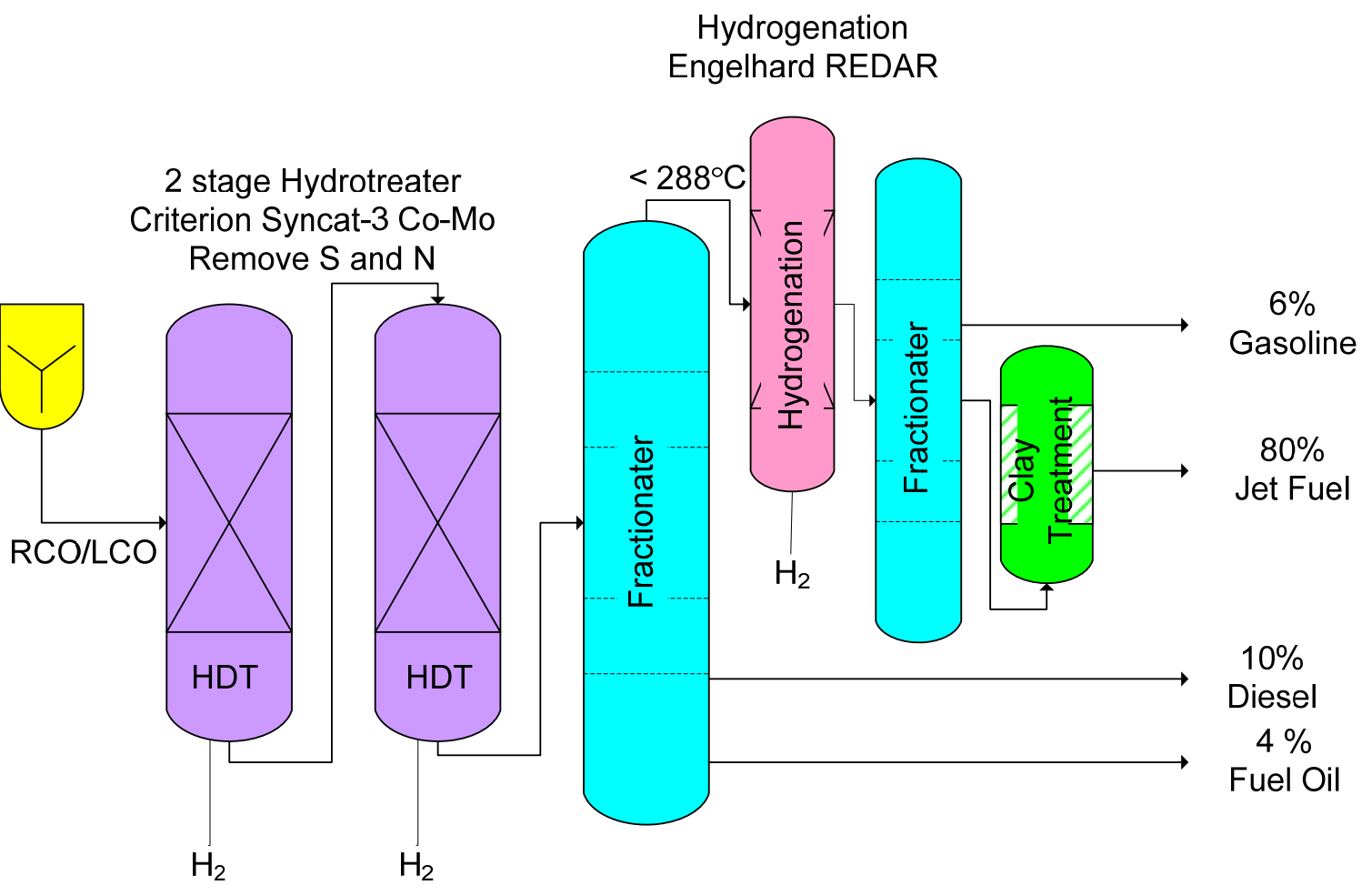

Figure 1-2: Schematic of Fuel Hydrotreating and Hydrogenation to Take Place at PARC, Harmaville, PA.

The hydrogenation catalyst used in this project was Engelhard's REDAR catalyst. The charge for the unit was as follows:

Hydrogenation Reactor $12251 \mathrm{cc}, 1657 \mathrm{gm}$, Engelhard REDAR (PC-765) 
Reactor 2832 cc, 2084 gm, Engelhard REDAR (PC-765)

Intertek PARC is now in the process of fractionating and treating a new batch of fuel for Year 3, and description of the feeds will be included in the next report.

In the course of this study jet fuel samples with varying smoke points and related aromatics contents were sampled to Penn State for determination of their thermal stability. It was determined that for the jet fuel to meet the smoke point specification of JP5, JP-8 and therefore JP-900 the residual aromatics content must be reduced to a very low level, probably $<2$ wt $\%$.

Work at Penn State had also determined that a final treatment of the jet fuel over a bed of either activated alumina or activated clay improved the thermal stability even further than hydrogenation alone. Consequently it was decided to blend all of the hydrogenated jet fuel and subject it to clay treatment using Engelhard F-24 clay. This treatment changed the visual color from amber to water white and decreased the amount of carbon produced in the thermal stability test.

For the last run, a detailed description of Intertek PARC's Pilot Scale Unit is provided. The unit is being prepared for a new run in May/June 2006. The new run will be described in detail in the next report. 


\section{Subtask 1.4: Fractionation into Refinery Product Slate}

No additional work has been done on this part of the project with regards to the liquids production. Analysis of the cokes generated from co-coking of hydrotreated decant oils with coal is described in Task 5 of the report. 


\section{Task 2. Evaluation of Coal-based Gasoline and Diesel Products in IC Engines and}

Related Studies (A. Boehman, Y. Yang, S. Kirby, Y. Zhang)

By introducing coal-derived streams into the refinery, several perturbations to the quality and quantity of refinery streams may result and directly impact vehicular fuels production. The coal contribution to the refinery streams will affect the quality, composition and performance of the resulting vehicular fuels. The fraction of the hydrotreated streams that boils below $180^{\circ} \mathrm{C}$ will be directed to the gasoline pool. Having components from coal is expected to boost octane number and aromatic content, and therefore, boost value. The $>270^{\circ} \mathrm{C}$ cut of the hydrotreated stream would be low in sulfur due to the severe hydrotreatment. The effect on flash point will need to be determined if this stream is sent to the fuel oil pool and/or diesel pool. If this stream is combined with diesel fuel, it will add cycloparaffins, which will increase energy density and boost value. However, the impact on cetane number and sooting tendency is unclear. The following task structure will permit assessment of the impact of refinery integration of JP-900 production on gasoline and diesel fuel.

\section{Subtask 2.1: Impact on Gasoline Quality and Performance}

Under this subtask, our efforts have consisted of continuing preparation and refinement of facilities for the SI engine testing activity and ignition studies of relevant compounds to understand the impact of the coal-derived compounds on knocking and flame propagation. 


\section{Subtask 2.1.1 Preparation of Laboratory and Instrumentation}

Combustion and emission properties of the coal-based gasoline in SI engine application will be studied in a single-cylinder Ricardo Hydra research engine and a single-cylinder Waukesha CFR octane rating engine. Under this subtask, we acquired and installed the Ricardo Hydra single-cylinder research engine for use under Task 2.1.2 and developed instrumentation for combustion analysis. And we modified the fuel delivery system on a CFR Octane Rating engine for ignition quality and reaction pathway tests.

GC-MS result has shown that the major components in the coal-based gasoline samples are cycloalkanes, whose octane ratings are lower than that of the commercialgrade gasoline and therefore may cause knocking in SI engine combustion. Flame propagation across the combustion chamber and the auto-oxidation chemistry of the unburned mixture (end gas) have been identified as the two determining factors in engine knock [2-1]. The auto-oxidation chemistry of the end gas is being performed at a Waukesha CFR octane rating with modified intake system and running at the motoring mode. To date, our examination of the decomposition chemistry of methyl cyclohexane (a model for coal-derived gasoline) has resulted in an ACS preprint [2-2].

A head gasket equipped with 6 ion probes (Figure 2-1) has been designed and fabricated for the Hydra engine which enables detecting the flame arrival along the plane of head gasket. The related signal conditioning board has been build and data acquisition boards have been purchased. Another in-cylinder flame detector, optical sensor equipped spark plug, has also been obtained (Figures 2-2 and 2-3) which allows the flame detection on the top of the combustion chamber. 
The two devices designed for studying the flame propagation in SI engine have been obtained. Description for the ion-probe head gasket was included in the previous annual report. The recently received fiber-optic spark plugs (Figures 2-2 and 2-3) utilize eight optical probes installed on the plug rim (Figure 2-2) to "see" the flame propagation during engine combustion. Two such spark plugs were obtained and will be installed in the Ricardo Hydra engine and CFR octane rating engine. The signal conditioning and data acquisition system are being built.

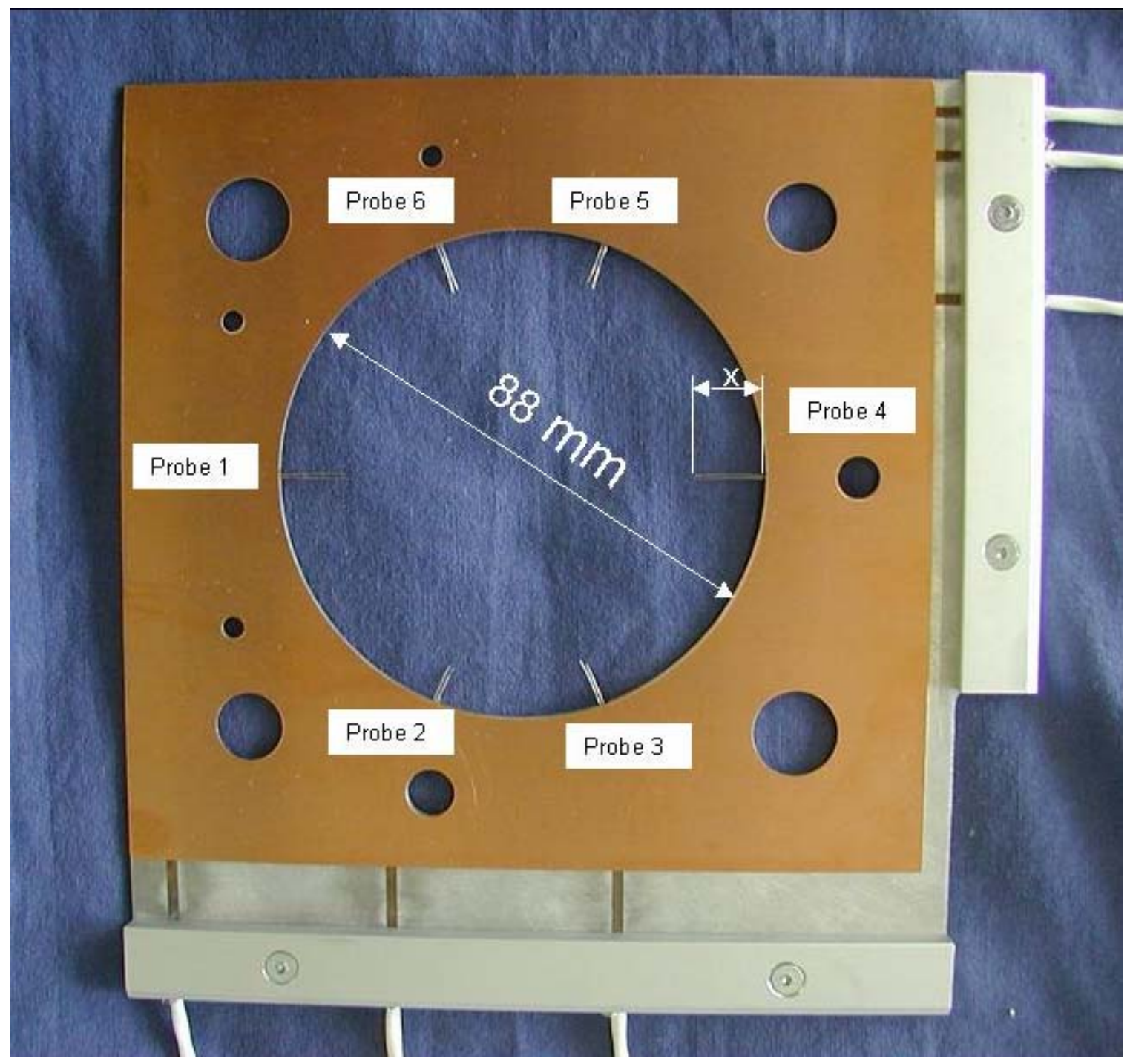

Figure 2-1 Ion probe equipped head gasket for the Hydra engine 


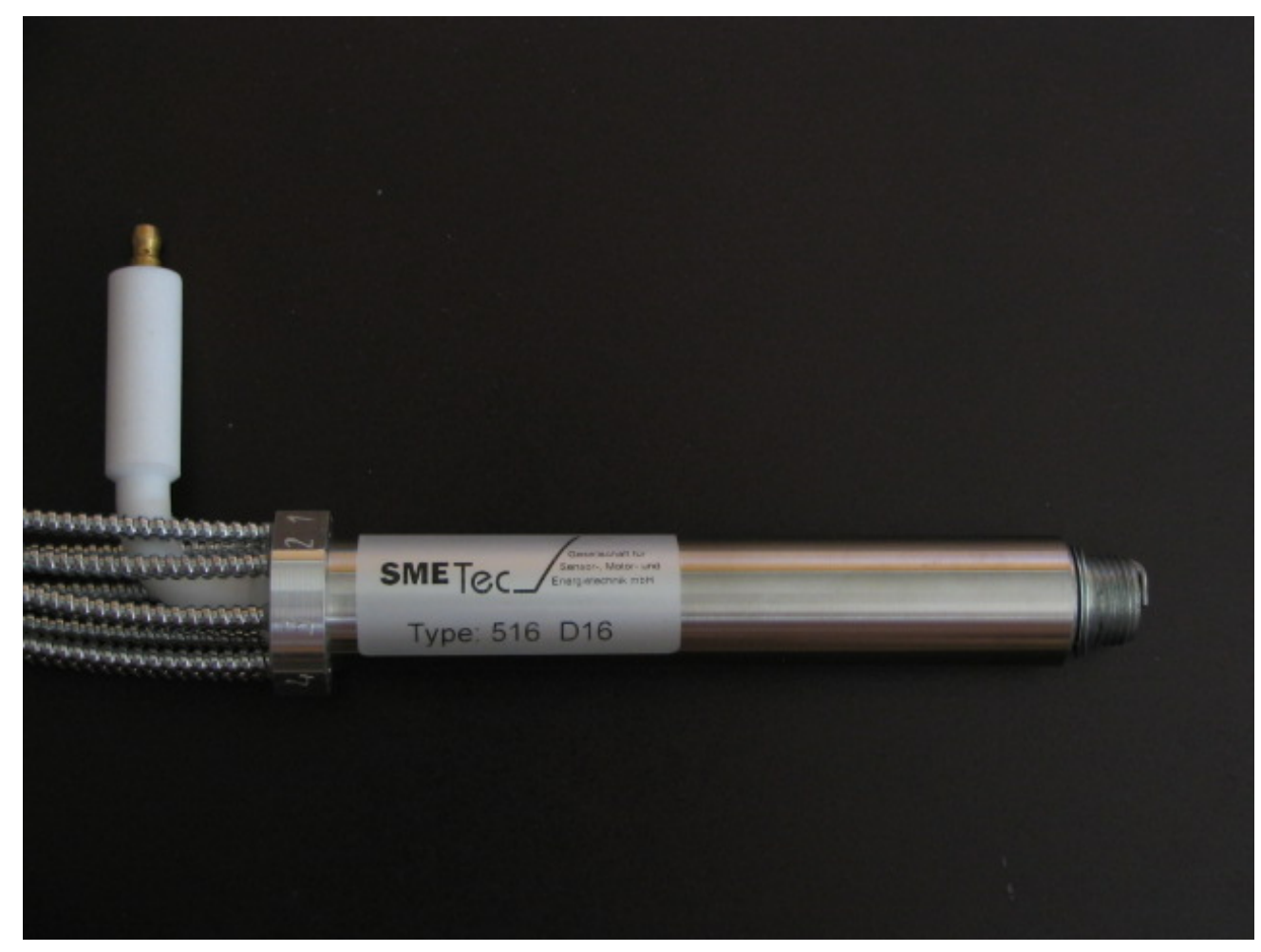

Figure 2-2 Optic-fiber Spark Plug for the CFR Octane Rating Engine

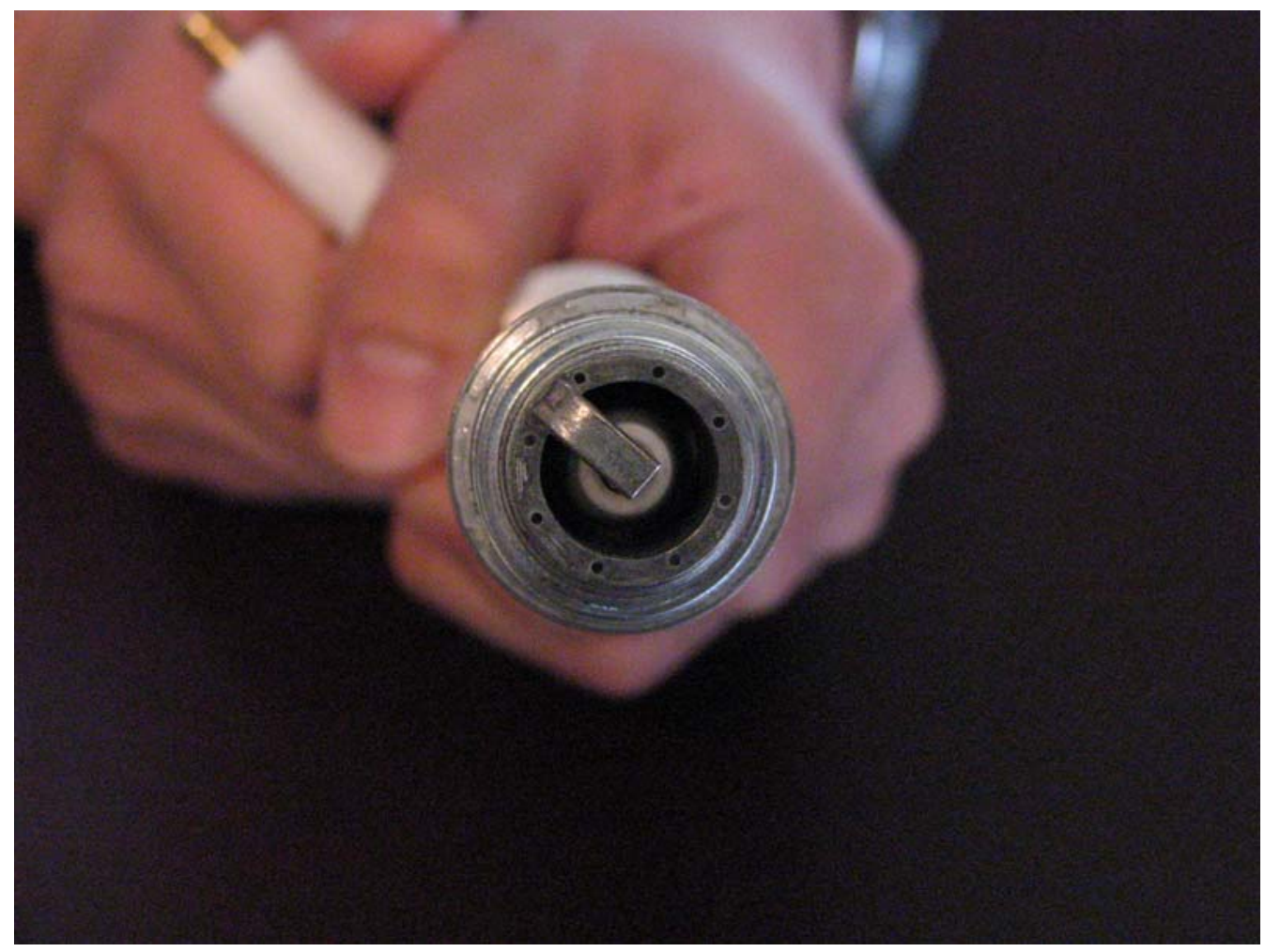

Figure 2-3 Close-up of the Electrodes and Eight Optical Openings 
Low temperature heat release during the oxidation of model compound methylcyclohexane was observed with modified operation conditions. Two-stage ignition of methylcyclohexane was also detected. This is in contrast to previous tests where no heat release was detected prior to the sudden autoignition (knocking). Comparison of the operation condition is listed in Table 2-1. The decreased engine speed gives more time for the low temperature oxidation to occur. Lowered intake temperature shifts the reaction from the intermediate region that has the negative temperature dependence (heat release is inhibited) to the low temperature region where heat release can be easily detected.

Table 2-1 CFR Engine Operation Conditions for Previous and Current Autoignition Study

\begin{tabular}{|l|l|l|}
\hline & Previous & Current \\
\hline Engine speed (RPM) & 900 & 600 \\
\hline Intake Temperature (K) & 533 & 393 \\
\hline
\end{tabular}

Finally, the method has been upgraded for condensing products from the low temperature oxidation. A dry-ice/acetone bath replaced the previous ice/water bath. A gas bubbler containing a known volume of dichloromethane is immersed in the bath. Gas flow rate into the bubbler is regulated and measured, which enables the quantification of the condensed species. The obtained dichloromethane solution is then directly analyzed by GC-MS without water extraction. Non-condensed gases after the cold trap are collected in Tedlar bags and analyzed by GC-FID/TCD. With these improvements, a much more complete picture of methylcyclohexane low temperature oxidation was obtained. 


\section{Subtask 2.1.2 Impact on Chemical and Physical Properties}

Under this subtask, we have performed detailed chemical analyses and physical analyses of fuel samples. From several runs at PARC, fuel fractions were provided representing the gasoline and diesel fuel cuts. To date the primary fuel characterization for the gasoline cut has been through ignition studies which are presented under Subtask 2.1.3 below. Octane rating measurements of the coal-derived gasoline, blends of the coal-derived gasoline in a reference gasoline ("UTG 96," 96 RON fuel provided by ConocoPhillips in support of this project) and blends of model compounds in the reference gasoline are ongoing. The research octane number of one coal-based gasoline (EI-174, the latest from JP-900 production) was measured on the CFR octane rating engine according to the ASTM D2699 standard. The research octane number obtained is 61.4

\section{Subtask 2.1.3 Impact on SI Engine Emissions and Performance}

The low temperature oxidation of methylcyclohexane has been successfully achieved in the CFR engine with the recent modifications on engine operation conditions.

Heat release from the low temperature oxidation is shown in Figure 2-4. This low temperature heat release does not lead to main combustion because reaction is quenched during the expansion stroke. Note the maximum temperature during this cycle is only 886 $\mathrm{K}$, well below the normal combustion temperature (>1800K). The start of cool flame ignition, which is defined as the point where heat release rate turns from negative to positive, occurs at 1.8 crank angles after TDC with the temperature of $831 \mathrm{~K}$ and pressure 
of $1314 \mathrm{kPa}$. The ignition temperature of methylcyclohexane is comparable with the $1^{\text {st }}$ stage ignition of $\mathrm{n}$-heptane $(\sim 780 \mathrm{~K}$, in the last report) under similar conditions. However, the cool flame combustion of methylcyclohexane occurs at a much later timing than that of $\mathrm{n}$-heptane which is well before TDC. This is consistent with the longer ignition delay of methylcyclohexane observed in rapid compression machine studies [23]. The later-than-TDC ignition timing also implies that two-stage ignition, which is commonly observed for $\mathrm{n}$-heptane and other straight-chain alkanes, occurs only under a narrow range of conditions for methylcyclohexane. Later tests at high compression ratios confirmed this speculation.

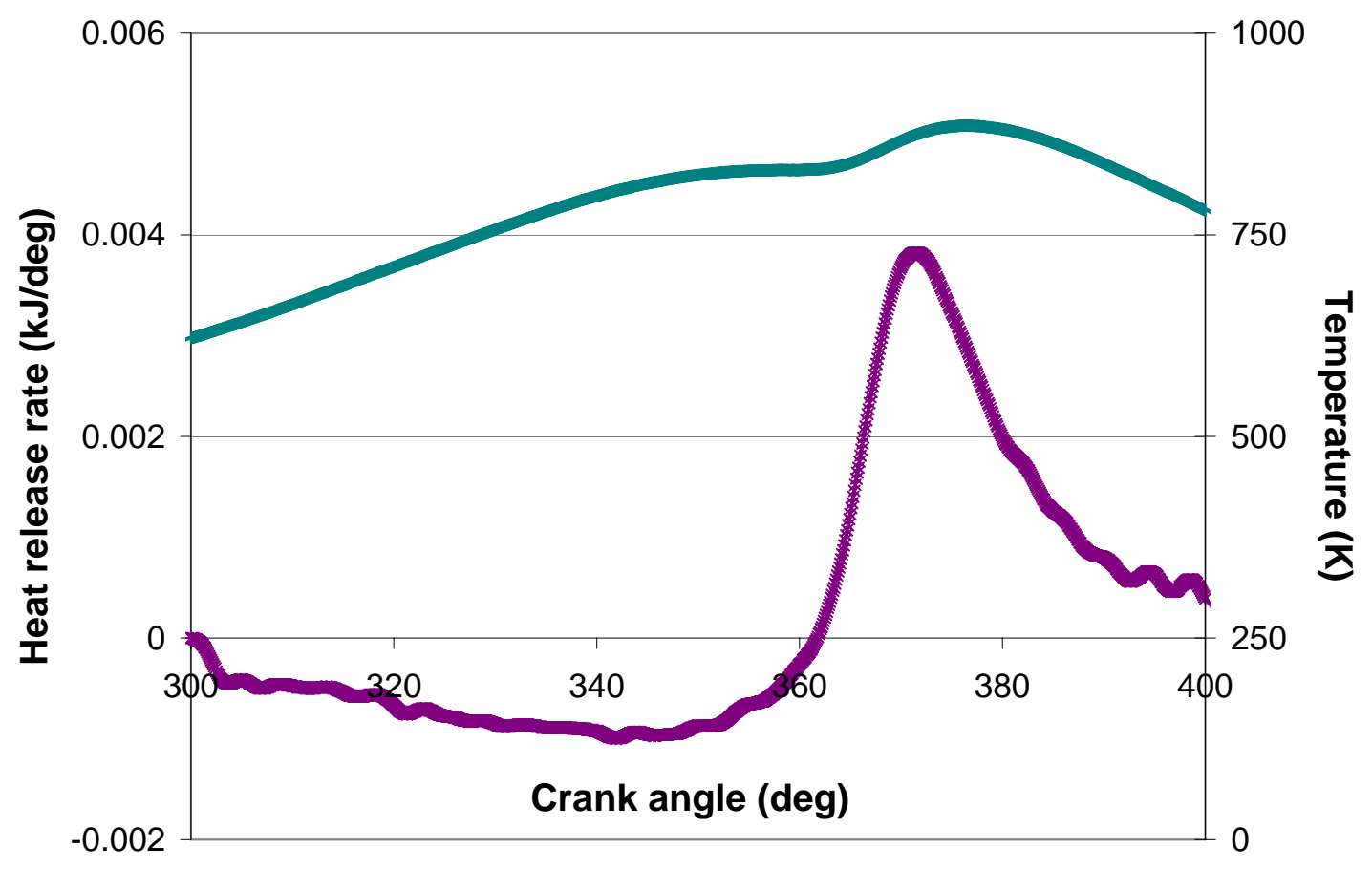

Figure 2-4 Heat release and cylinder temperature of methylcyclohexane during cool flame combustion. Condition: intake $120^{\circ} \mathrm{C}, 600 \mathrm{rpm}$, compression ratio 7.47, equivalence ratio 0.13 (nitrogen $50 \mathrm{SCFH}$ ). 
To further investigate methylcyclohexane oxidation in an SI engine, especially the formation of aromatic compounds, a series of tests were conducted. While the other conditions are kept constant, the engine compression ratio was increased so that the transition from low temperature heat release to the major combustion can be studied.

The oxidation products were collected and analyzed by the methods described above. GC results of non-condensable species after the cold trap have been studied. Figure 2-5 shows the concentration variation of $\mathrm{O}_{2}, \mathrm{CO}$, and $\mathrm{CO}_{2}$ with compression ratio detected by TCD. Figure 2-6 shows the concentration variations of methane, ethane \& ethylene, propylene, and unreacted methylcyclohexane with compression ratio by FID. Note that except methylcyclohexane, all species in Figures 2-5 and 2-6 are only present in the gas phase. Most methylcyclohexane is absorbed by the cold dichloromethane liquid and appears on GC-MS spectra. It is seen that as compression ratio increases, fuel consumption increases as indicated by the steady decrease of $\mathrm{O}_{2}$ and fuel concentrations. Significant amount of $\mathrm{CO}$, methane, ethane and ethylene are formed as compression ratio increases. They are relatively stable comparing to other intermediates and can be consumed if the combustion is complete. The build-up of $\mathrm{CO}$ concentration retards $\mathrm{CO}_{2}$ formation, therefore the $\mathrm{CO}_{2}$ concentration stays at low concentration $(<0.5 \%)$ during the course of the test. A considerable amount of propylene is also formed whose concentration increases at early stage (lower compression ratio) and decreases at late stage. This means that propylene is a relatively reactive intermediate and is converted to other species at higher temperature. 


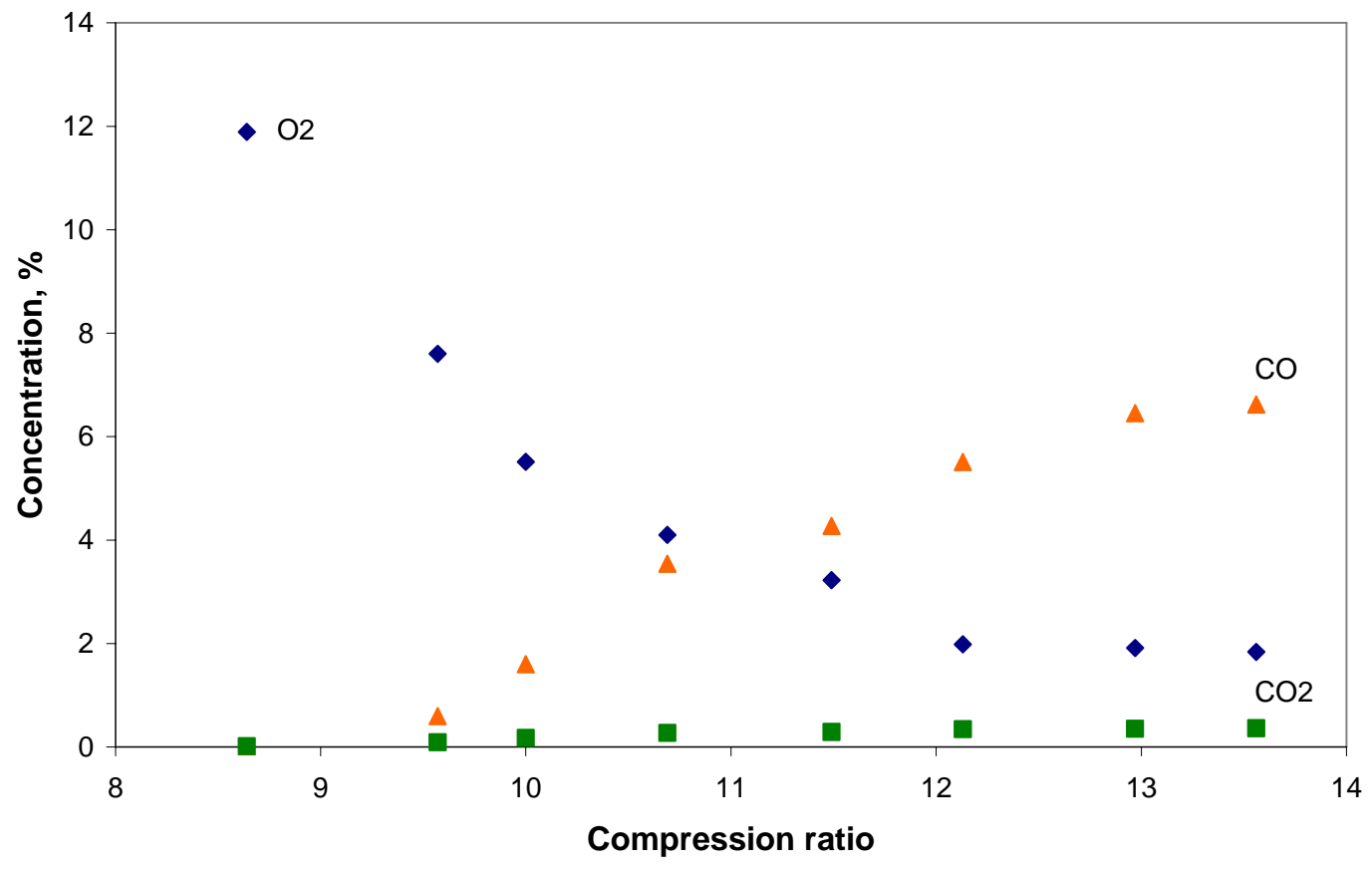

Figure 2-5 Concentrations of $\mathrm{O}_{2}, \mathrm{CO}$, and $\mathrm{CO}_{2}$ vs. compression ratio by TCD. Condition: intake $120^{\circ} \mathrm{C}, 600 \mathrm{rpm}$, equivalence ratio 1.2 (nitrogen $125 \mathrm{SCFH})$.

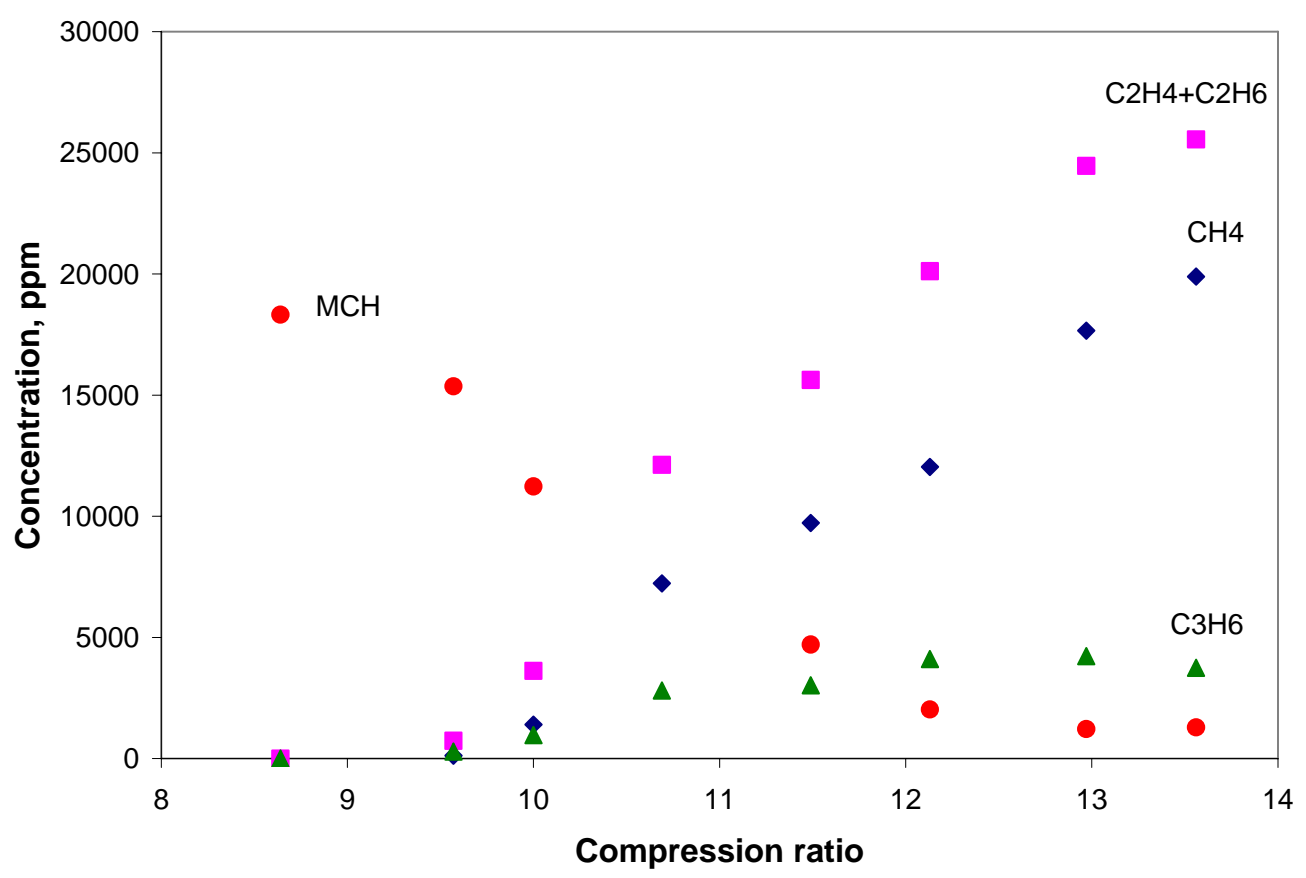

Figure 2-6 Concentration of $\mathrm{CH}_{4}, \mathrm{C}_{2} \mathrm{H}_{4}+\mathrm{C}_{2} \mathrm{H}_{6}, \mathrm{C}_{3} \mathrm{H}_{6}$, and methylcyclohexane vs. compression ratio by FID. Conditions are same as in Figure 25 . 
GC-MS results of the condensable species are still being analyzed. A preliminary result suggests that the intermediate species are formed via two pathways: dehydrogenation and partial oxidation. Methylcyclohexenes are the major products at low compression ratio while benzene and toluene are the major products at high compression ratio, indicating that the dehydrogenation is the dominant reaction path. Benzene formation is directly from such dehydrogenation reactions. On the other hand, partial oxidation products, such as cycloketones and cycloepoxides, are observed at low compression ratio but disappeared at high compression ratio, which suggests these early formed intermediates are consumed at high temperature.

Note that the previous results only reported the oxygen-containing species in the condensed phase because the gas-collecting method was not able to effectively condense the unreacted fuel and related dehydrogenation products. The new method will enable us to study the complete product compositions (in both liquid and gas) of many hydrocarbons from the current system.

\section{Subtask 2.2 Impact on Diesel Fuel Quality and Performance}

Under this subtask, we continue to focus on facility development activities, but have also made great strides in fuel and combustion characterization. The facilities work has been refinement and enhancement of two existing engine test stands, one housing a Navistar V-8 7.3L turbodiesel engine and the other housing a DDC 4-cylinder 2.5L turbodiesel engine. 


\subsubsection{Acquisition, Installation and Instrumentation of Ignition Test Equipment}

This work has been completed, with some updated information on configuration and procedures given in Section 2.1.1. The equipment was applied to ignition studies of diesel and other fuels and has resulted in the submission of a manuscript to Combustion \& Flame [2-4].

\subsubsection{Development of Analytical Methods and Test Procedures}

The modification of the CFR Octane Rating engine to serve as a rapid compression machine for ignition studies represents a unique adaptation of a standard instrument and will provide a means of comparing experimental data with kinetic models of the ignition process.

\subsubsection{Evaluation of Capabilities and Needs for Supplemental Measurements and}

\section{Analyses}

The analytical methods developed for the characterization of the fuel cuts from the PARC runs can now serve as the basis for subsequent fuel and SOF chemical analyses. We have developed procedures for use of an existing FTIR spectrometer to speciate the products of our ignition tests, which has already highlighted significant differences in the intermediate species present as we pass through first and second stage ignition for different fuels. We have also developed a plan for upgrading an existing gas chromatograph for hydrocarbon speciation from engine exhausts. We intend to perform the upgrade of the GC (from packed to capillary columns) and use a method that is the same as in the Shimadzu GC-MS. This will allow the GC results to be interpreted through the species identification capabilities of the GC-MS. 


\subsubsection{Impact on Chemical and Physical Properties}

We have completed tests on the impact of coal-derived compounds on the DCN of base diesel fuels. This work resulted in the preparation of an ACS preprint [2-5].

Two major components of coal-derived diesel fuel (cut \#3) were identified by GC-MS. Fluorene and phenanthrene were found to be present in sample \# EI 175 in concentrations of $3 \mathrm{wt} \%$ and $1.5 \mathrm{wt} \%$, respectively. These compounds were used as representatives for similar compounds, such as hydrophenanthrenes, that form a large portion of the coal-derived diesel.

Physical property analyses were performed on solutions of various concentrations of fluorene, or phenanthrene, in an ultra low-sulfur diesel fuel (BP15). BP15 is petroleum-derived and primarily comprises of long chain aliphatic compounds ( $\mathrm{C} 8$ to C13). Both fluorene and phenanthrene are already present in BP15 at concentrations of $<1 \mathrm{wt} \%$. Solubility issues arose at concentrations greater than $5 \mathrm{wt} \%$ for fluorene, in all likelihood due to the aliphatic nature of BP15.

Evaluation of combustion characteristics of doped BP15 will be performed. To remove the influence of ignition delay ethyl hexyl nitrate (EHN) was added to 5\% phenanthrene doped BP15 at 250,500, and $750 \mathrm{ppm}$. The ignition delay of these mixtures was determined using the IQT and results are presented in Table 2-2. 
Table 2-2 Fuel Properties of Ultra Low Sulfur Diesel Fuel Doped with Three-Ringed Aromatics

\begin{tabular}{|c|c|c|c|c|c|}
\hline Fuel & BP15 & \multicolumn{4}{|c|}{ BP15/5\%Phenathrene/EHN } \\
\hline $\begin{array}{c}\text { Additive } \\
(\mathrm{ppm})\end{array}$ & - & 0 & 250 & 500 & 750 \\
\hline DCN & 47.2 & 46.7 & 50.8 & 50.2 & 49.9 \\
\hline
\end{tabular}

The derived cetane number (DCN) for each of the fuel blends was measured in accordance with ASTM D6890-03a. A correlation has been developed to convert the measured ignition delay into a $\mathrm{DCN}$, which is correlated with the $\mathrm{CN}$ measured by ASTM D613 (CFR Cetane Rating engine). The ignition delay (defined as the elapsed time from injection to where the chamber pressure reaches $\mathrm{P}_{\text {initial }}+50 \mathrm{psi}$ ) under specified conditions is measured using the Ignition Quality Tester (IQT) (Figure 2-7). The system is fully automated and an experiment consists of 15 pre-injections (to equilibrate system temperatures) followed by 32 injections. The reported DCNs are the averages of these 32 injections of pre-filtered fuels. A sample of data from a single injection is presented as a screen shot in Figure 2-8.

Very little affect on DCN was observed with the addition of varying concentrations of EHN. This result is confusing and work is continuing to determine what might be neutralizing the affect of the EHN. Similar trends, or lack thereof, in fuel properties related to phenanthrene-doped BP15 have been presented in previous reports. Methods used in sample preparation are being examined. 


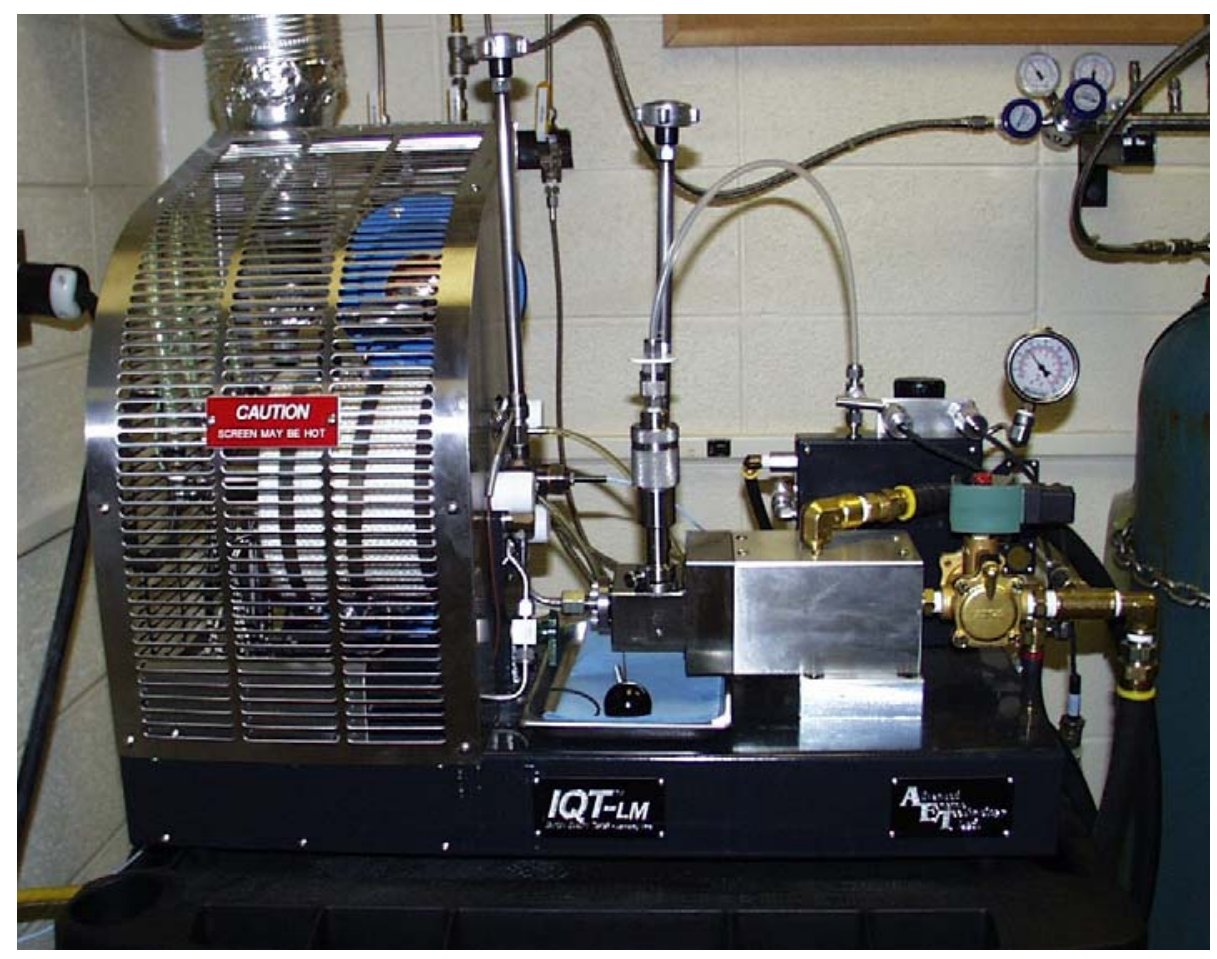

Figure 2-7 Photograph of the Ignition Quality Tester (IQT) at the Penn State Energy Institute

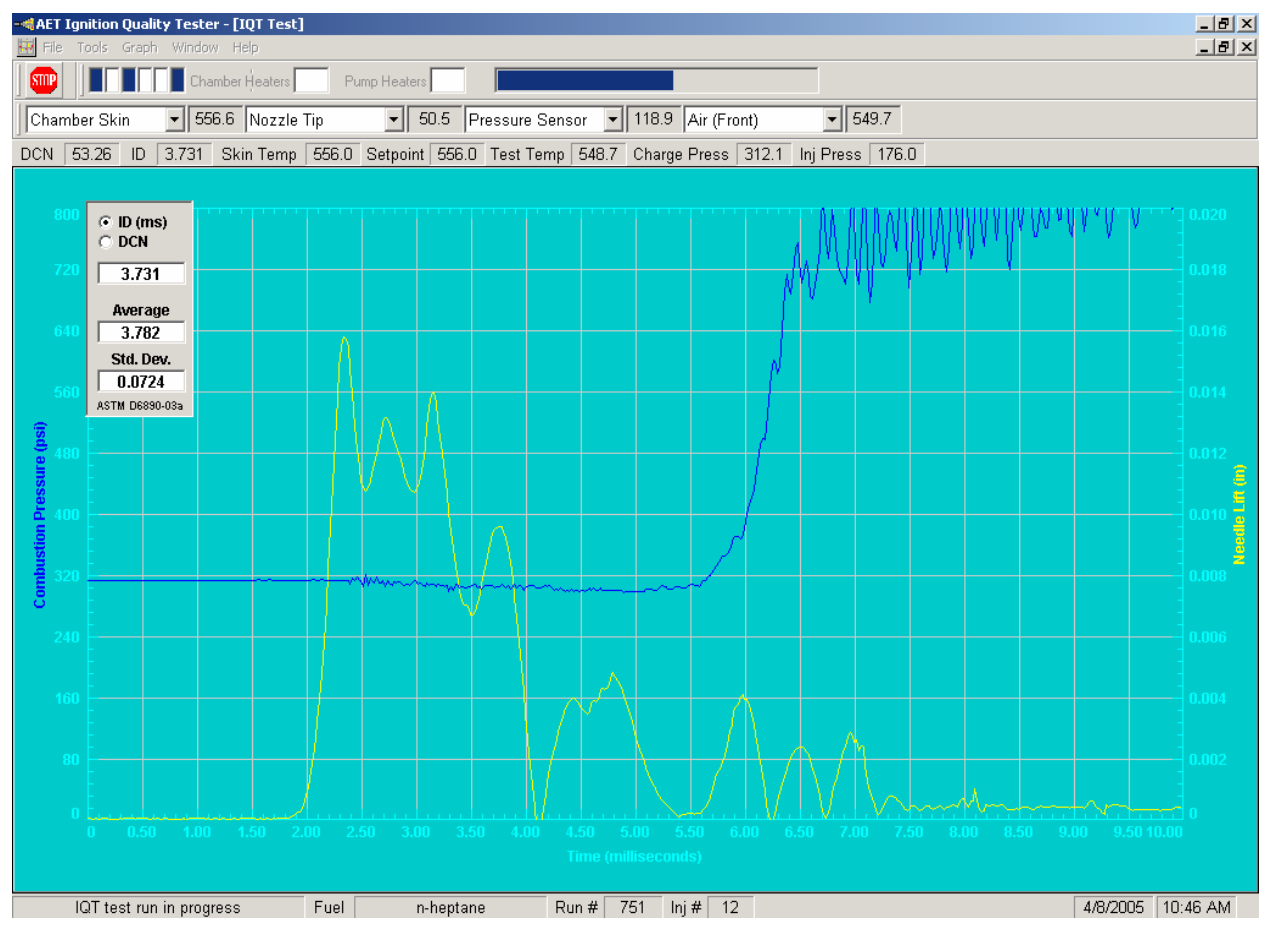

Figure 2-8 Sample data readout from the IQT. Needle lift is displayed in yellow and combustion pressure in blue. 


\subsubsection{Impact on CI Engine Emissions and Performance}

The engine testing was performed on a DDC/VM $2.5 \mathrm{~L}$ common-rail diesel engine. Engine specifications are listed in Table 2-3. 5\% volume of coal derived diesel fuel blended with BP15 (CDD5) was selected for the engine testing with BP15 performed as the baseline fuel. AVL mode 2 and mode 3 represent the low load and medium load conditions with low engine speeds. Theses two modes were chosen as the engine testing conditions at this stage. Detailed engine testing conditions can be seen in Table 2-4.

Table 2-3 Engine specification

\begin{tabular}{|l|l|}
\hline Engine & $\begin{array}{l}\text { DDC 2.5L TD DI-4V } \\
\text { automotive diesel engine }\end{array}$ \\
\hline Displacement & $2.5 \mathrm{~L}$ \\
\hline Bore & $92 \mathrm{~mm}$ \\
\hline Stroke & $94 \mathrm{~mm}$ \\
\hline Compression Ratio & 17.5 \\
\hline Connecting rod length & $159 \mathrm{~mm}$ \\
\hline Rated Power & $103 \mathrm{KW} @ 4000 \mathrm{RPM}$ \\
\hline Peak Torque & $340 \mathrm{Nm} @ 1800 \mathrm{RPM}$ \\
\hline Injection system & $\begin{array}{l}\text { Electronically controlled } \\
\text { common-rail(Bosch) }\end{array}$ \\
\hline Valve train & 4 valves/cylinder \\
\hline
\end{tabular}

Table 2-4 Engine testing conditions

\begin{tabular}{|c|c|c|c|c|c|}
\hline Mode & $\begin{array}{c}\text { Speed } \\
(\mathrm{rpm})\end{array}$ & $\begin{array}{c}\text { Load } \\
(\mathrm{ft} . \mathrm{lb})\end{array}$ & $\begin{array}{c}\text { BMEP } \\
(\mathrm{MPa})\end{array}$ & $\begin{array}{c}\text { Pilot SOI } \\
(\text { Deg BTDC) }\end{array}$ & $\begin{array}{c}\text { Main SOI } \\
(\text { Deg BTDC) }\end{array}$ \\
\hline AVL2 & 1330 & 46.5 & 0.32 & 22 & -4 \\
\hline AVL3 & 1630 & 153.8 & 1.05 & 34 & 3 \\
\hline
\end{tabular}

As shown in Figure 2-9 and Figure 2-10, there were no observably significant differences can be found in the bulk overall combustion characteristics between coal derived diesel blend and BP15 under both AVL mode2 and mode 4 conditions. As the engine condition was changed from AVL mode 2 to mode 3 , both pilot injection and main injection were advanced. As a result, reduction of premixed heat release due to main 
injection was observed. As to the heat release due to pilot injection, when the pilot injection timing was advanced from AVL mode 2 to mode 3 , a small amount of low temperature heat release prior to the main premixed heat release was found. Also, there was a significantly increase in the diffusion combustion fraction as the engine load was increased with the change of injection timings.

From the needle lift characteristics shown in Figures 2-11 and 2-12, there was no injection timing difference observed between coal derived diesel blend and BP15 under both of the engine conditions despite that there was a bulk modulus difference between these two fuels. In conventional pump-line-nozzle diesel engines, there was a fuel pressure propagation speed difference due to the different fuel bulk modulus. However, in the common-rail diesel engines, bulk modulus effect can be eliminated due to different fuel injection system features.

Also, as shown from Figures 2-13 to 2-16, almost the same pressure traces and bulk cylinder temperature profiles were observed between coal derived diesel blend and baseline BP15. Although, 5\% coal derived diesel fuel blend and baseline BP15 shared almost same injection and overall combustion characteristics, there were emissions results differences found between these two fuels. Error bars in the testing results represent the $95 \%$ confidence interval for random error and $1 \%$ full-scale system calibration error.

NOx emissions were found higher for the coal derived diesel blend consistently through the increased engine load conditions (Figures 2-17). A $0.9 \%$ Nox increase at mode 2 conditions and 3.8\% NOx increase at mode 3 for $5 \%$ coal derived diesel blend were observed. Since there was no injection timing and overall combustion 
characteristics difference, adiabatic flame temperature difference between these two fuels were expected to be the reason causing the increased NOx emissions for coal derived diesel blend. It is known that the addition of aromatic content will increase the adiabatic flame temperature and NOx emission is very sensitive to the flame temperature and produced in the local high flame temperature regions. Coal derived diesel fuel has a significantly higher aromatic content than normal diesel fuel, therefore the addition of coal derived diesel fuel in the baseline fuel will increase the adiabatic flame temperature and NOx emissions. Under this condition, although there was no difference in the bulk cylinder gas temperature profile, there were locally higher flame temperature regions formed for the coal derived diesel fuel blend.

As engine load was increased, significantly decrease in the total unburned hydrocarbon and carbon monoxide emissions were observed (Figures 2-18 and 2-19). This decrease is mainly due to the significant increase in the combustion temperature when the engine load was increased. This increase facilitates more complete oxidation for hydrocarbon and carbon monoxide. Also, under low load condition, coal derived diesel fuel was observed to produce more carbon monoxide emissions. This can be explained by the lower air-fuel ratio for the coal derived diesel fuel blend as shown in Figures 2-21. Also, the addition of coal derived diesel fuel increases the quantity of ring structures in the fuel, which will tend to increase the unburned hydrocarbon emissions.

Finally, a slightly higher brake specific fuel consumption for coal derived diesel blend was observed throughout the engine testing conditions as shown in Figures 2-20. 


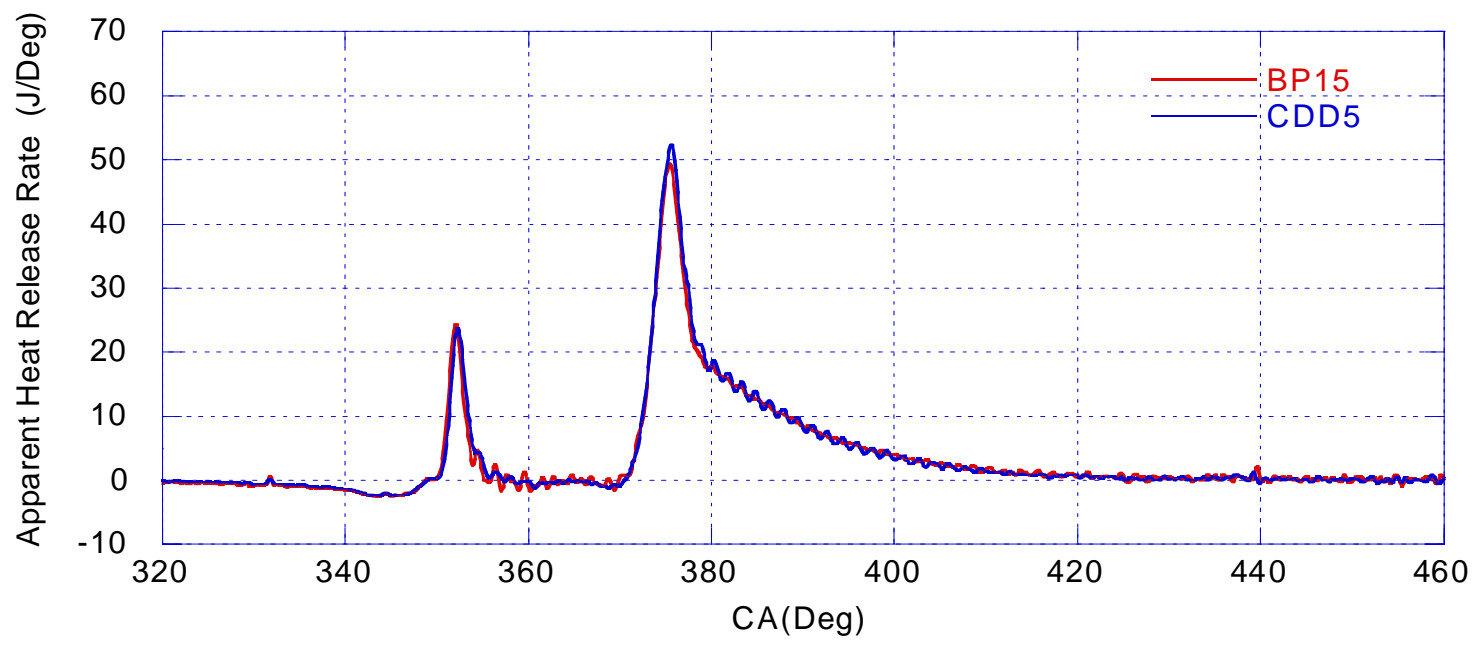

Figure 2-9 Apparent heat release rate at AVL mode 2

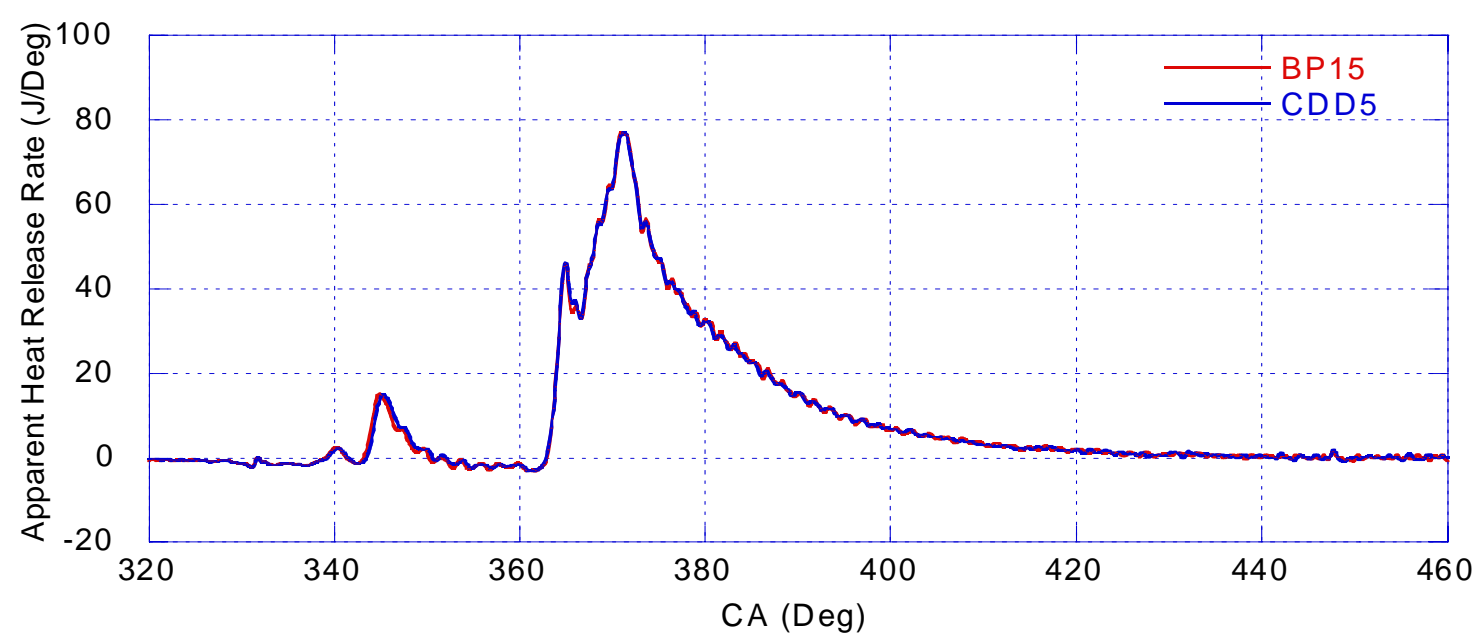

Figure 2-10 Apparent heat release rate at AVL mode 3

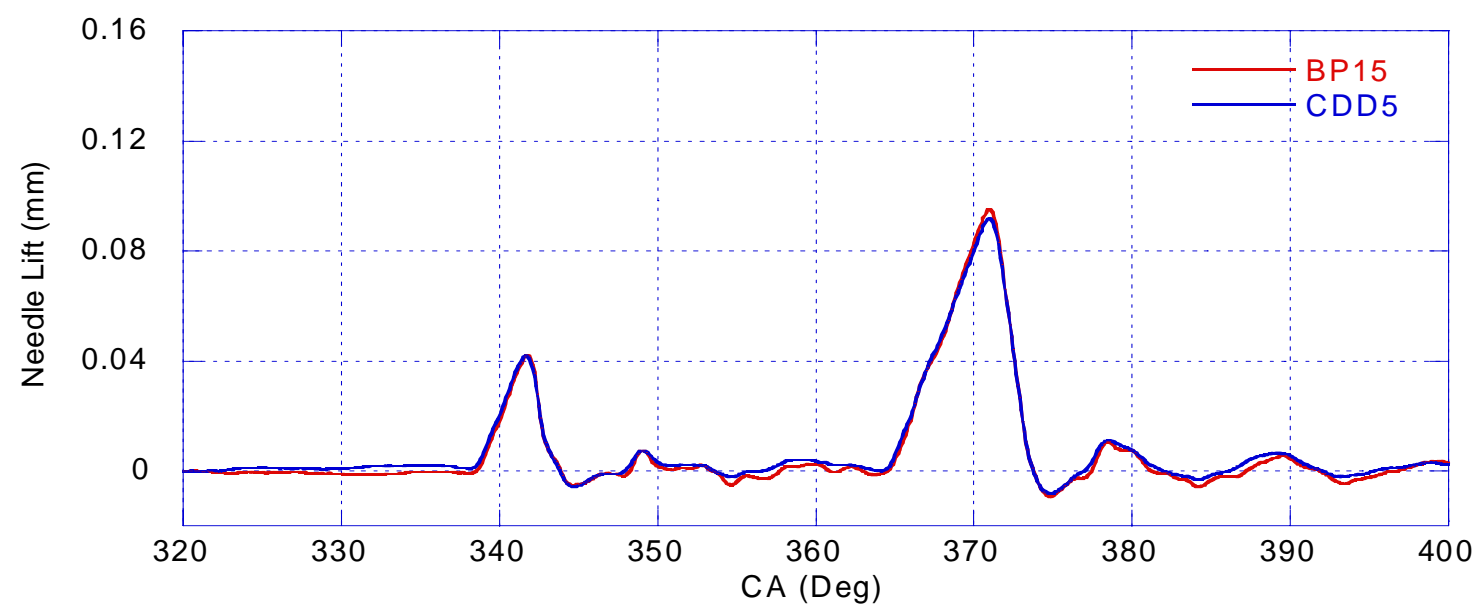

Figure 2-11 Needle lift signal at AVL mode 2 


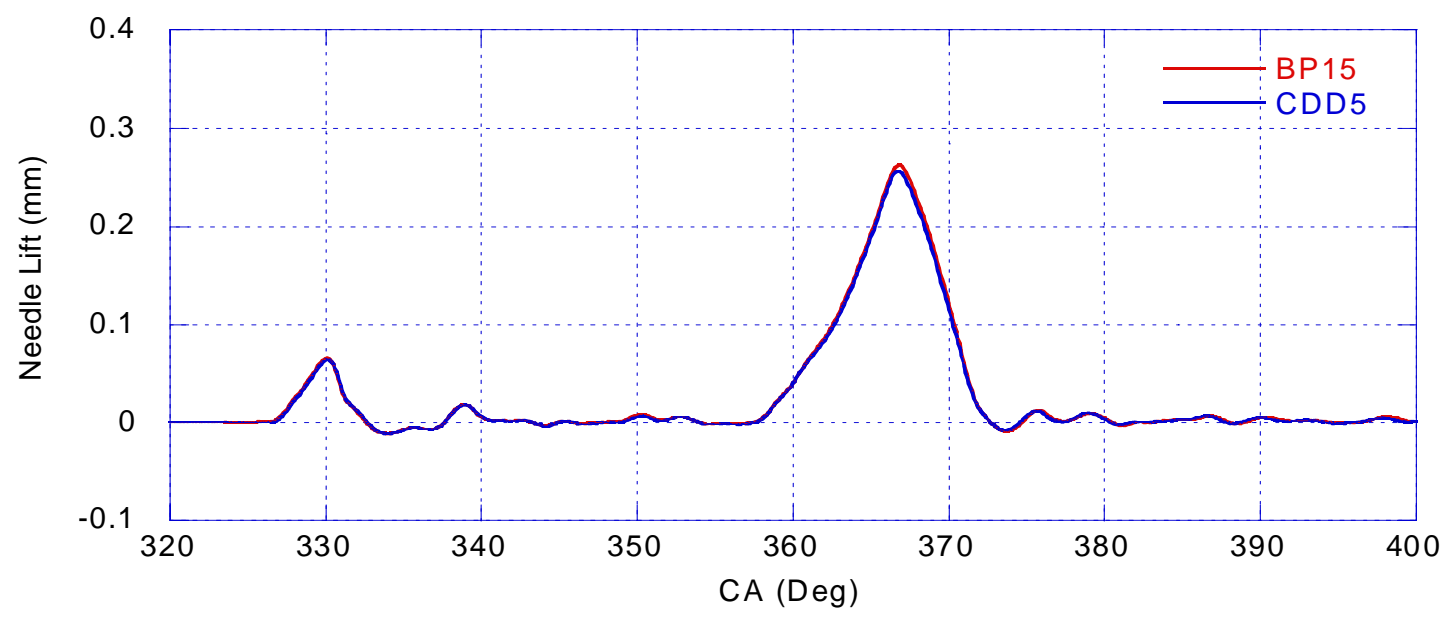

Figure 2-12 Needle lift signal at AVL mode 3

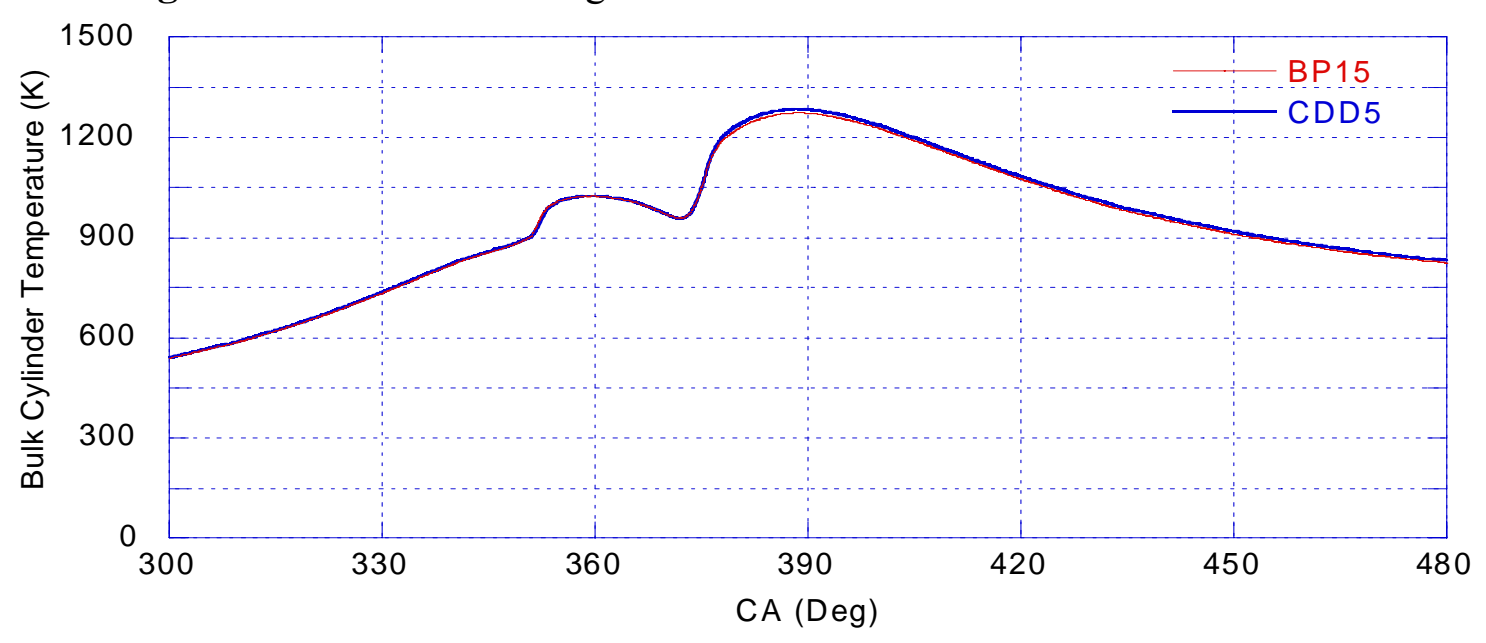

Figure 2-13 Bulk cylinder gas temperature at AVL mode 2

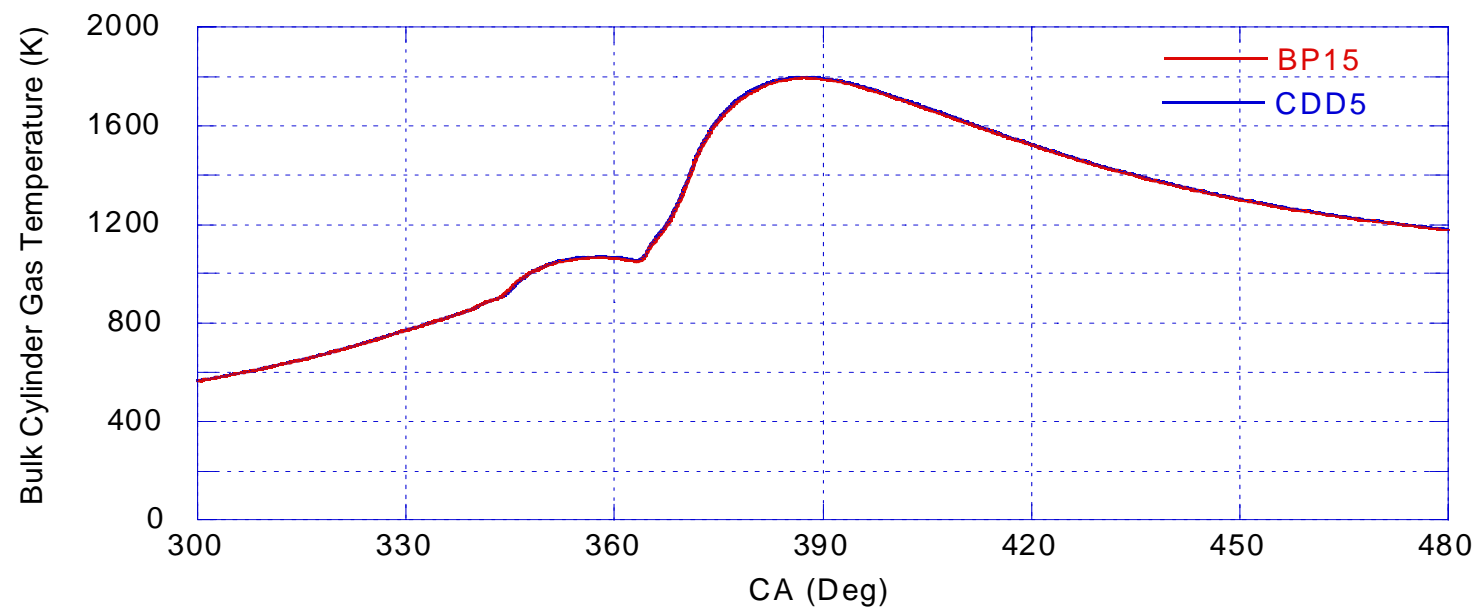

Figure 2-14 Bulk cylinder gas temperature at AVL mode 3 


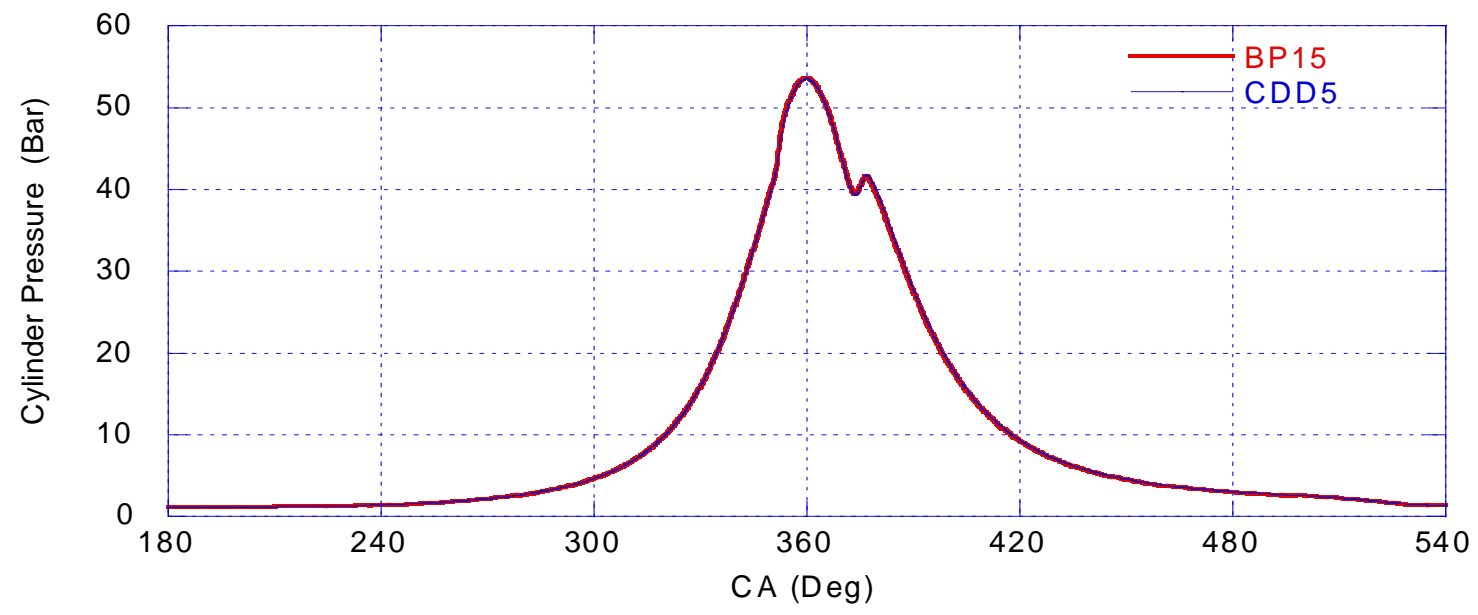

Figure 2-15 Cylinder pressure trace at AVL mode 2

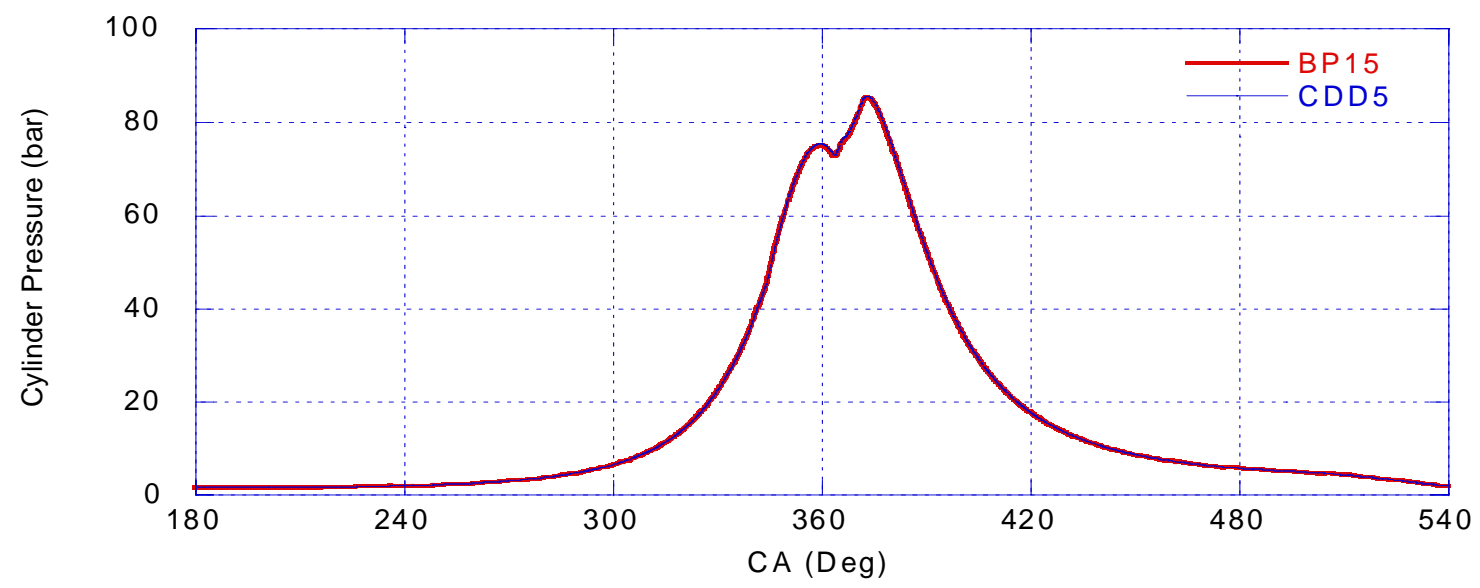

Figure 2-16 Cylinder pressure trace at AVL mode 3

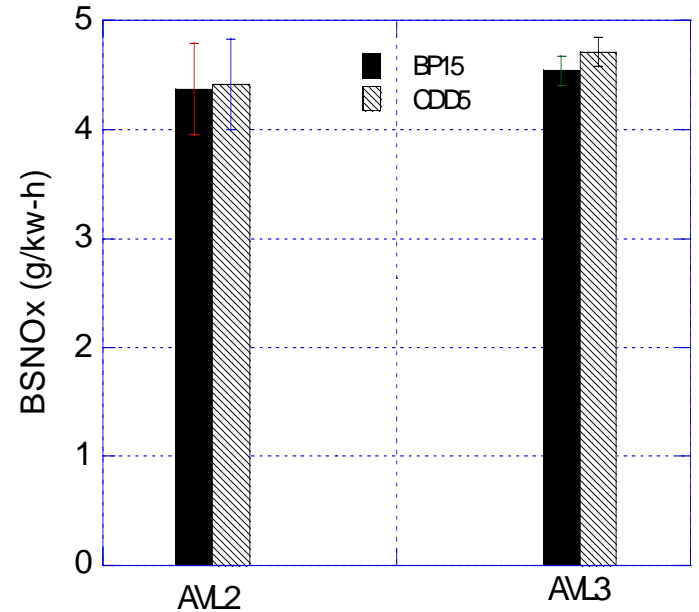

Figure 2-17 Brake specific NOx emissions

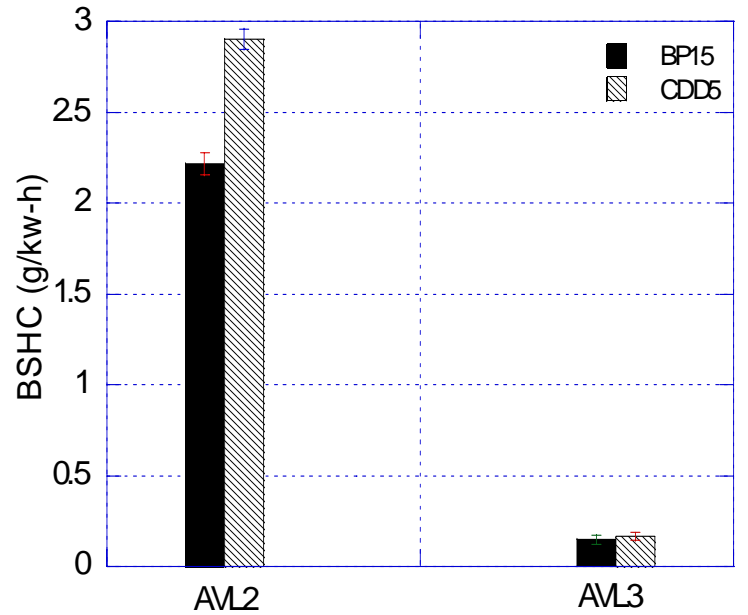

Fig. 2-18 Brake specific unburned hydrocarbon emissions 

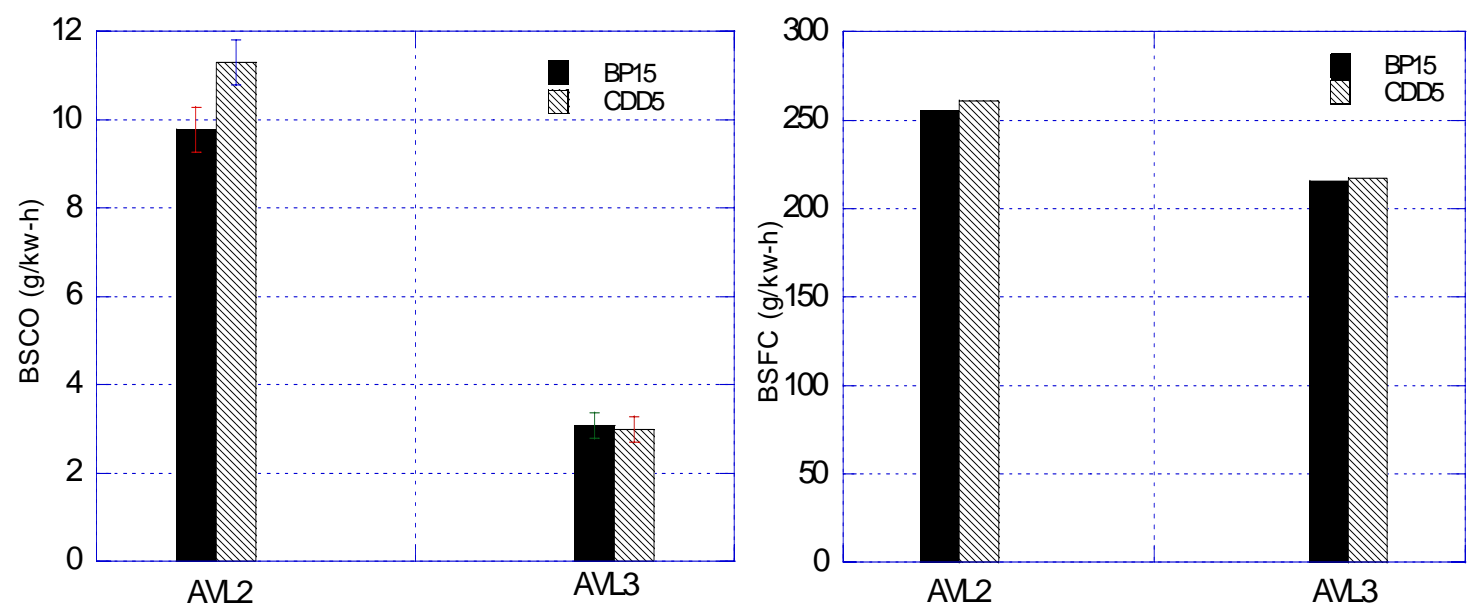

Figure 2-19 Brake specific CO emissions Figure 2-20 Brake specific fuel consumption

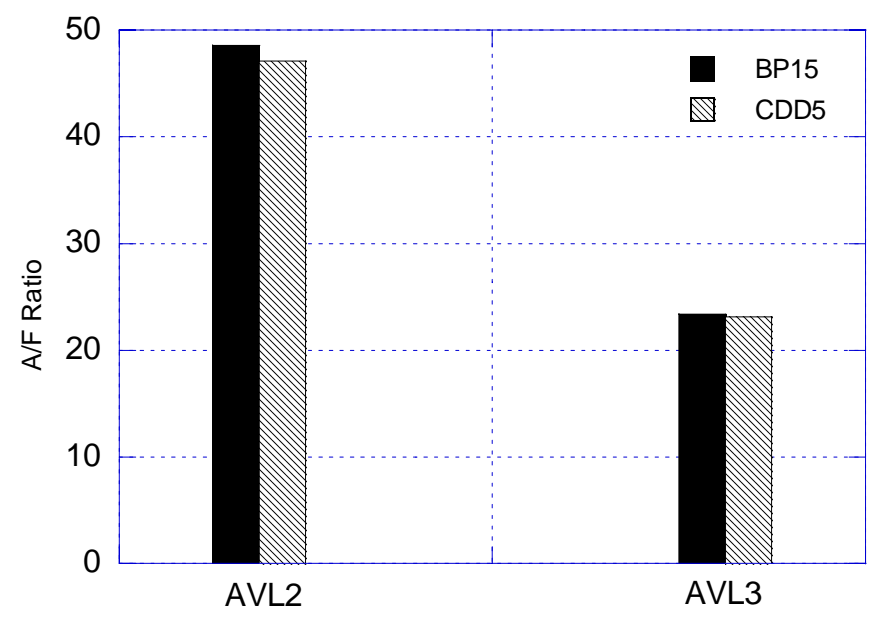

Figure 2-21 Air to fuel ratio

\section{In-Cylinder Imaging of Coal-Derived Diesel Combustion}

For the purpose of better understanding the impact of the coal-derived compounds on the injection, ignition and combustion of diesel fuels in a practical engine, we have developed an installation of an existing AVL 513D Engine Videoscope (purchased under an NSF Research Equipment Grant, \# CTS-0079073) in our Navistar V-8 7.3L turbodiesel engine. This required design and machining access for an endoscope probe and a light guide to visualize the fuel spray and the spray flame. The modified cylinder head is ready for use and will be implemented after some other preliminary emissions studies are completed. 


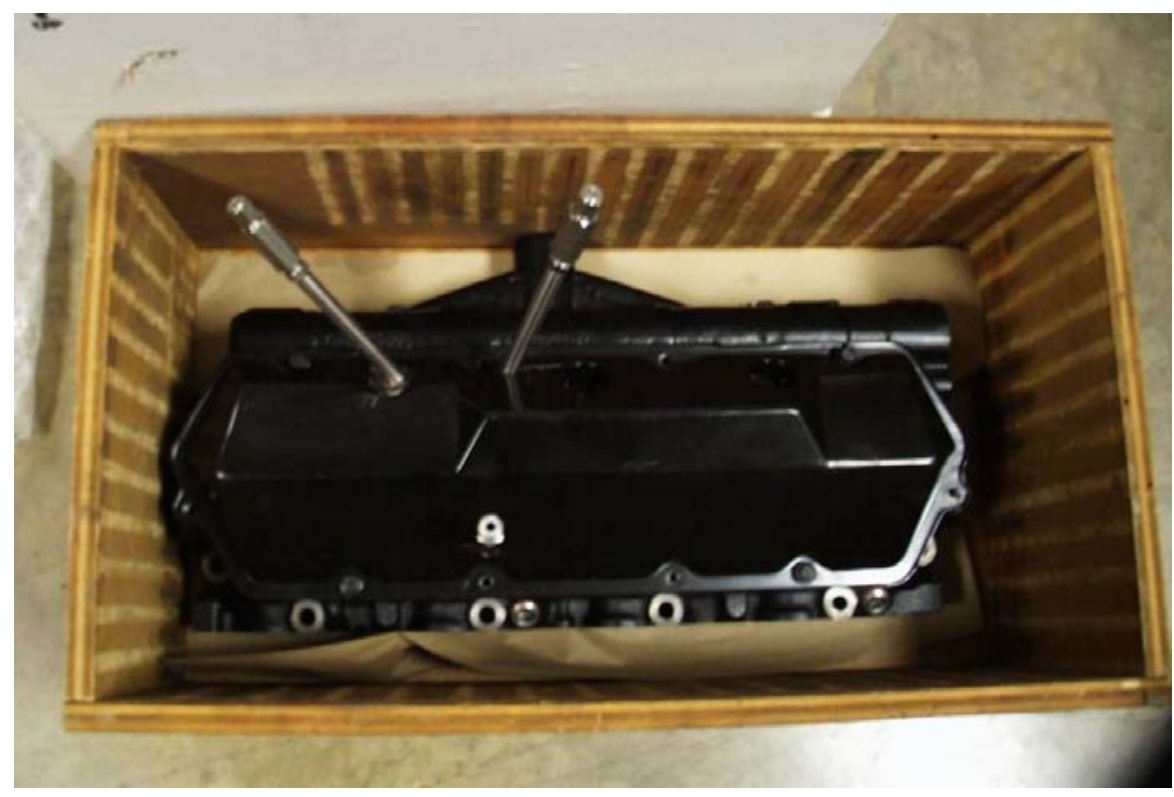

(a)

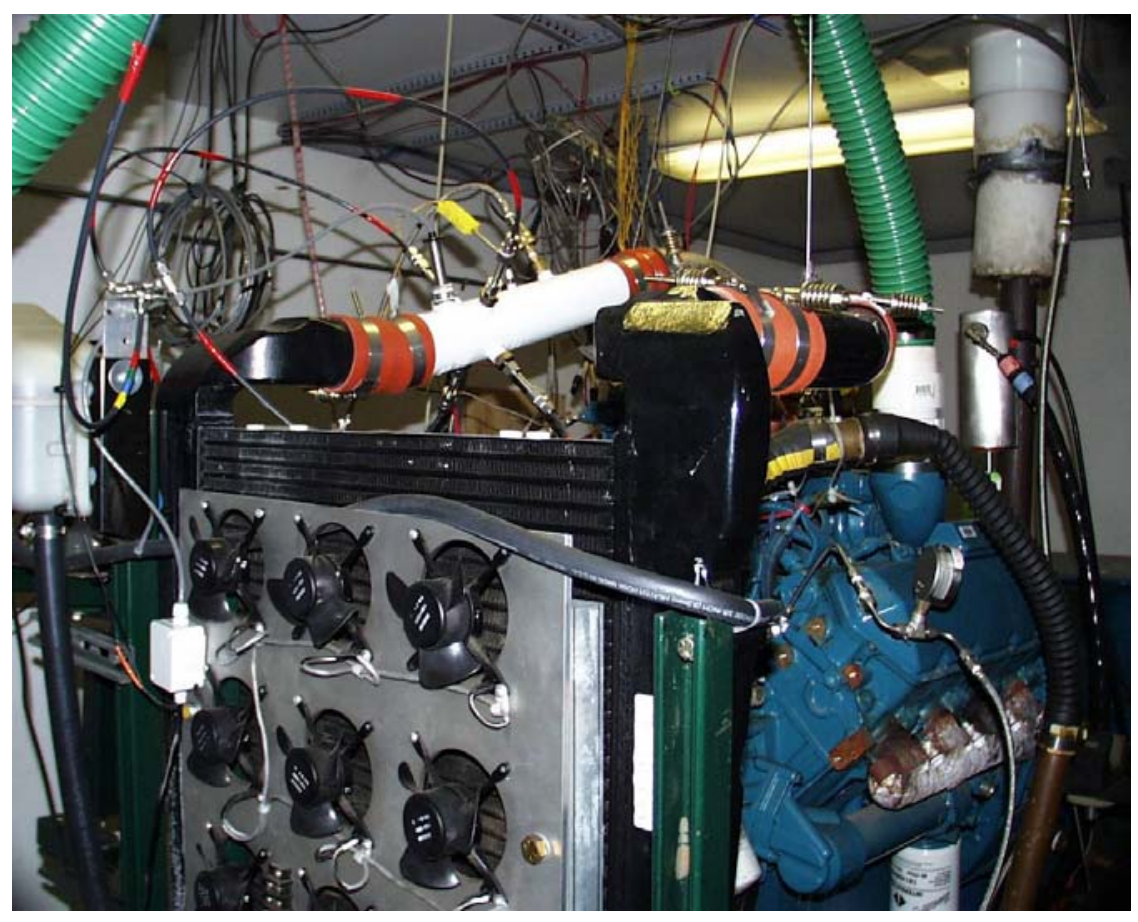

(b)

Figure 2-22 Digital Photograph of (a) Optically Accessible Cylinder Head and (b) Navistar 7.3L Turbodiesel Engine 


\section{Impact of Fuel Composition on Properties of Diesel Soot}

Previously in the Year 2 Annual Report we presented a comparison between BP15, $10 \% \mathrm{CDD}$, and 20\%CDD. Emission data was obtained for BP15 and 20\%CDD fuels [2-6]. The oxidation behavior of the soot from engine combustion of BP15 and 10\%CDD was determined by using the thermogravimetric and Differential Scanning Calorimetry (TGADSC). The engine used in this experiment is a single cylinder DI diesel engine operated at $75 \%$ load and $3600 \mathrm{rpm}$. In the Year 2 Annual Report for future work, we proposed to examine the impacts of engine operating conditions such as EGR, injection timing and injection strategies on soot oxidative reactivities. Bulk soot samples were to be collected from the raw exhaust of the DDC engine. Experiments were to be conducted on the TGA-DSC to obtain the oxidation kinetics of diesel soot and various characterization techniques were to be applied to these soot samples, for comparison with the fuel effects. This work has seen tremendous progress in the past 6 months as evidenced by the results and discussion below.

Recent findings in our laboratory have shown that fuel formulation can affect the oxidative reactivity of the soot (see for instance the Year 2 Annual Report) [2-6]. The inclusion of biodiesel in the fuel lowers the ignition temperature of soot and consequently lowers the temperature required for regeneration of the diesel particulate filter (DPF) and this was attributed to the high surface oxygen content of biodiesel soot. In addition, the oxidation rate of biodiesel was found to be two times faster than that of diesel soot [2-7].

Here, we present a potential method to improve the regenerability of the DPF by enhancing the oxidative reactivity of diesel soot. We show that EGR can be utilized to generate more reactive soot. Carbon dioxide $\mathrm{CO}_{2}$ was used to simulate particle free and 
cold EGR, which is proposed as a possible pathway to generate soot that is more prone to oxidize in DPF.

Soot Origin and Sampling. A highly instrumented single cylinder direct injection diesel engine was used to produce the soot samples. The engine was running under fixed load (75\%) and speed (3600 rpm). Diesel particulate matter samples were collected from the raw exhaust of the engine on teflon filters. The diesel particulate matter was subsequently removed from the filters and thermally treated under UHP nitrogen at $500^{\circ} \mathrm{C}$ to remove volatile compounds. Thus, the soot considered in this work is the volatile-free fraction of the diesel particulate. Simulated EGR (SEGR) was introduced to the engine intake system from high pressure cylinders of $\mathrm{CO}_{2}$ at different concentrations: $0,3,6$, and 9 vol.\%. The fuel considered was an ultra low sulfur diesel with 15 ppm sulfur content (BP15).

Soot Oxidative Reactivity. A Thermogarvimetric Analyzer (TGA) was used to investigate the difference in reactivity between the soot samples. Two experiments were considered to elucidate the soot reactivity: (1) the isothermal in which the soot was heated in air $(100 \mathrm{cc} / \mathrm{min})$ at $475^{\circ} \mathrm{C}$ and, (2) the nonisothermal in which the soot was heated in air $(100 \mathrm{cc} / \mathrm{min})$ from $30^{\circ} \mathrm{C}$ to $600^{\circ} \mathrm{C}$ at a heating rate of $2.5^{\circ} \mathrm{C} / \mathrm{min}$. The kinetic parameters of soot oxidation were derived from the nonisothermal profiles [2-8].

Raman Spectroscopy. A visible Renishaw spectroscopy was used to determine the degree of graphitization of the soot samples. The excitation laser was an Ar ion laser $\left(\lambda_{0}=514 \mathrm{~nm}\right.$, source power $\left.10 \mathrm{~mW}\right)$. The laser was focused on the sample through a microscope with 100X objective lens. Two soot samples, designated as S0 and S9 were considered, where 0 and 9 correspond to the $\mathrm{CO} 2$ concentrations under which the soot 
was formed. The integrated intensity ratio IG/ID was used to investigate the degree of graphitization of the soot samples and Tuinstra and Koenig (TK) expression was used to determine the crystallite width (La) [2-8].

X-Ray Diffraction (XRD). The XRD investigation was done using a Philips MPD instrument. The XRD spectra of S0 and S9 were recorded and the interlayer spacing (d002) was calculated according to Bragg's equation [2-9], the stacking height (Lc) and the crystallite width (La) were calculated according Scherrer's equation [2-9].

Soot Nanostructure Imaging. To investigate the nanostructure of the diesel soot, the high resolution transmission electron microscopy (HRTEM) images were recorded using a Joel $2010 \mathrm{~F}$ instrument operated at $200 \mathrm{kV}$ and equipped with a field emission gun. A small amount of the sample was suspended and sonicated in ethanol. A drop of the solution was then transferred to a copper grid coated with a lacy carbon film for analysis.

Soot Reactivity. $\quad$ Figure 2-23a shows the isothermal TGA profiles for S0 and S9. The impact of $\mathrm{CO} 2$ is obvious. Increasing the $\mathrm{CO} 2$ enhances the oxidation behavior of the soot. Figure 2-23a also shows that by increasing the $\mathrm{CO} 2$ concentration in the engine intake, further increase in the reactivity is observed. The oxidation rate of S9 was found to be two times faster than that of S0. The results here suggest that low temperature combustion via high EGR level is advantageous.

Figure 2-23b shows the nonisothermal and differential TGA (DTG) profiles of S0 and S9. Compared to S0, S9 exhibits a lower ignition temperature by about $50^{\circ} \mathrm{C}$. The oxidation time was cut nearly by $50 \%$. The activation energies were estimated to be $145 \mathrm{~kJ} / \mathrm{mol}$ and $105 \mathrm{~kJ} / \mathrm{mol}$ for S0 and S9, respectively. The reported activation energies 
were independent of gas flow rate and sample mass and therefore free from heat and mass transfer limitations. From the DTG, it can be seen that the reaction rate of S0 increases with temperature as expected, is higher than the reaction rate of S0 and reaches a maximum at lower temperature than S0.

XRD. From the XRD patterns (not shown), the key structural parameters can be determined. The d002 results obtained from Bragg's equation [Chen and Dobbins, 2000] were calculated as $0.345 \mathrm{~nm}$ and 0.354 for S0 and S9, respectively. Using Scherrer's equation [2-9], Lc values were found to be $1.19 \mathrm{~nm}$ and $1.15 \mathrm{~nm}$ for $\mathrm{S} 0$ and $\mathrm{S} 9$, respectively. The crystallite width (La) was determined as $2.24 \mathrm{~nm}$ and $1.65 \mathrm{~nm}$ for S0 and S9, respectively. From these data it can be seen that the difference in reactivities between S0 and S9 is not explained by the d002 or Lc. The crystallite width, on the other hand, is shorter for S9. It is well-known that soot with short fringes is more prone to oxidation because of the increase in the ratio between edge carbon and basal plane carbon [2-10]. Accordingly, it is expected that the number of active sites in S9 is higher than those in S0. This speculation can be proved by performing oxygen chemisorption analysis on both samples.

Raman Spectroscopy. $\quad$ Figure 2-24 shows the Raman spectra obtained for S0 and S9. Two distinct peaks are shown: the G peak $(1580 \mathrm{~cm}-1)$, which is referred to the graphitic band, and the D peak (1350 cm-1), which can be assigned to the disordered band. The integrated intensity ratio IG/ID can be used as a reactivity index. The IG/ID for S0 and S9 was found to be 0.443 and 0.375 , respectively. These values indicate that S0 has more graphitic structure than S9 in agreement with the TGA data. According to the Tuinstra and Koenig (TK) expression [2-8], the crystallite width (La) is found to be 
$1.95 \mathrm{~nm}$ and 1.65 for $\mathrm{S} 0$ and S9, respectively. Despite the fact that the TK expression holds well only for La between 2.5 and $250 \mathrm{~nm}$ [2-11], the values of La from the Raman spectra agrees with those from XRD.

Soot Nanostructure. The HRTEM investigations were conducted in order to obtain information about soot structure at the atomic level. The HRTEM images of S0 and S9 are shown in Figure 2-25. Both soots have a classic core/shell structure. S0 soot is characterized by a small disordered core which was estimated to be about $2-3 \mathrm{~nm}$. The outermost part is built of straight fringes arranged concentrically and parallel to the particle perimeter. On the other hand, S9 soot has a larger disordered core of about 9-10 $\mathrm{nm}$. The core is characterized by randomly oriented short fringes. The outermost regions of the primary particles are characterized by wavy-long graphene layers. The coexistence of the wavy layers and short fringes in S9 are partly responsible for the observed higher reactivity.

The results presented here show that changing the combustion conditions via $\mathrm{CO} 2$ alters the soot properties. EGR can be utilized to enhance the oxidative reactivity of diesel soot. We employed $\mathrm{CO}_{2}$ to simulate cold and particle free EGR; a condition that can be achieved in real world engines by recirculation of the EGR from downstream of the DPF (particle free EGR) and to increase the cooling of the EGR (cold EGR).

It is well-known that $\mathrm{CO}_{2}$ suppresses the soot formation through its dilution, thermal, and chemical effects [2-12, 2-13]. It can be speculated that adding $\mathrm{CO}_{2}$ results in different pyrolysis chemistry. The nature of the pyrolysis species and the way they contribute to soot formation and growth are altered. Due to its higher heat capacity (the thermal effect of $\mathrm{CO}_{2}$ ), incorporating $\mathrm{CO}_{2}$ into the combustion process results in lowering 
the flame temperature. Therefore, one can expect that the degree of carbonization/graphitization of the soot is lowered and less mature soot is produced. The chemical effect of $\mathrm{CO}_{2}$, on the other hand, is believed to also influence the soot reactivity. The dissociation of $\mathrm{CO}_{2}$ leads to an increase in $\mathrm{O}$ atoms and the reaction of $\mathrm{CO}_{2}$ with $\mathrm{H}$ atoms results in increasing the $\mathrm{OH}$ and decreasing the $\mathrm{H}$ concentration [2-12]. Hence, the oxidation rates increase as a result of high $\mathrm{O}$ and $\mathrm{OH}$ concentrations and the formation of large $\mathrm{PAH}$ is suppressed due to the lack of $\mathrm{H}$ atoms, the key component for soot formation via the HACA mechanism [2-14]. Accordingly, small particle size, and hence higher surface area, and short fringe length are formed; the characteristics of more oxidatively reactive soot. However, further work is necessary to determine the mechanism by which $\mathrm{CO}_{2}$ influences the soot reactivity. 

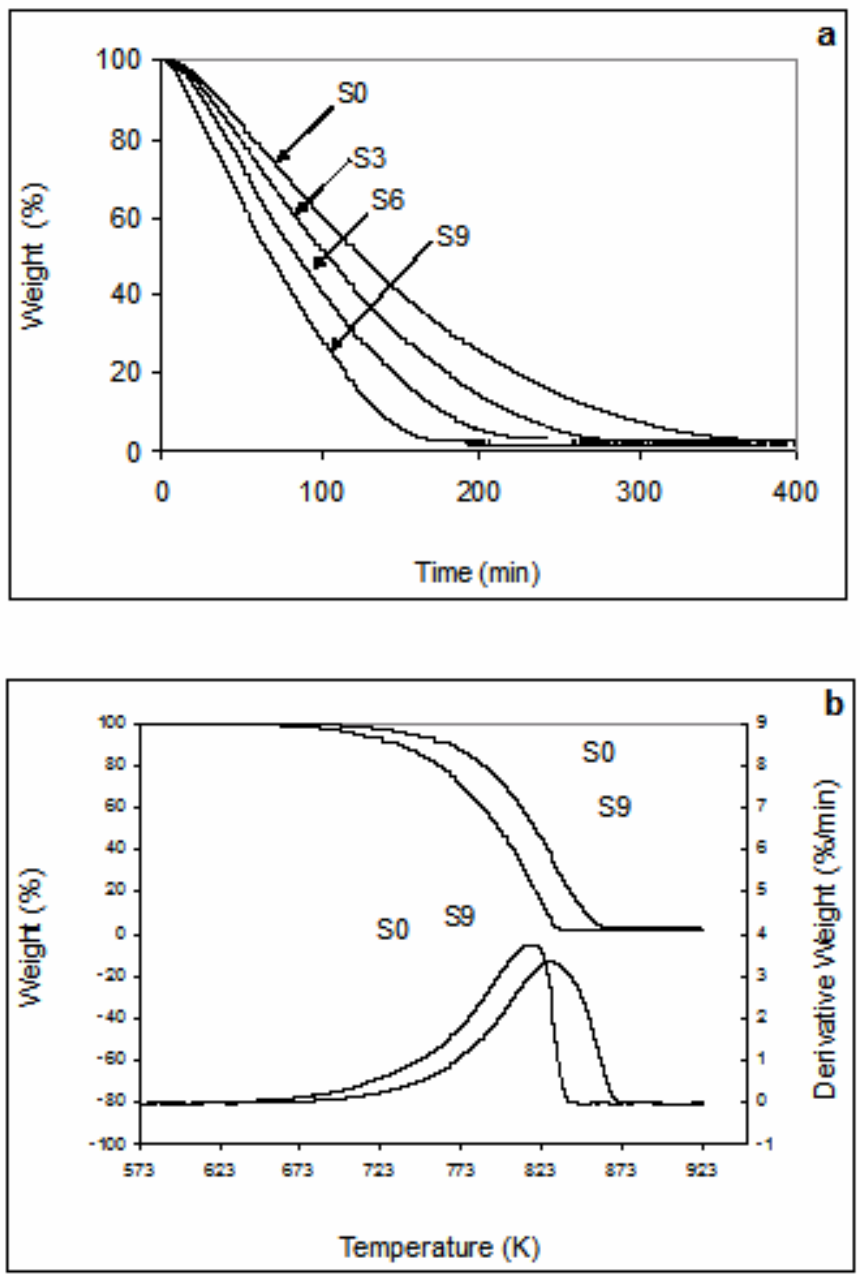

Figure 2-23 (a) Isothermal profiles at $475^{\circ} \mathrm{C}$ under air ; 0, 3, 6, and 9 correspond to the concentrations of $\mathrm{CO}_{2}$ injected to engine intake (b) Weight loss profiles of $\mathrm{S} 0$ and $\mathrm{S} 9$.

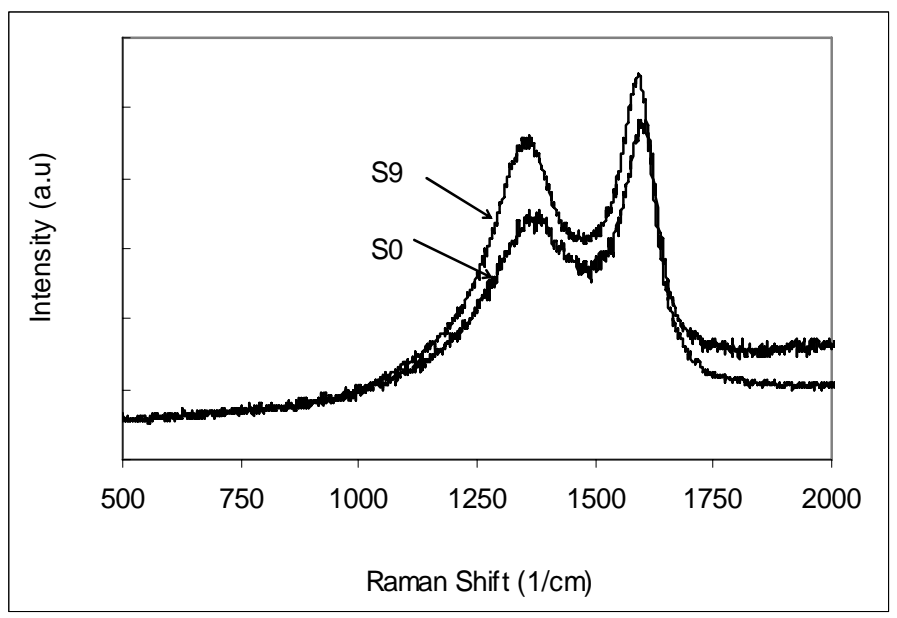

Figure 2-24. Raman spectra of S0 and S9 $\left(\lambda_{0}=514 \mathrm{~nm}\right)$. 


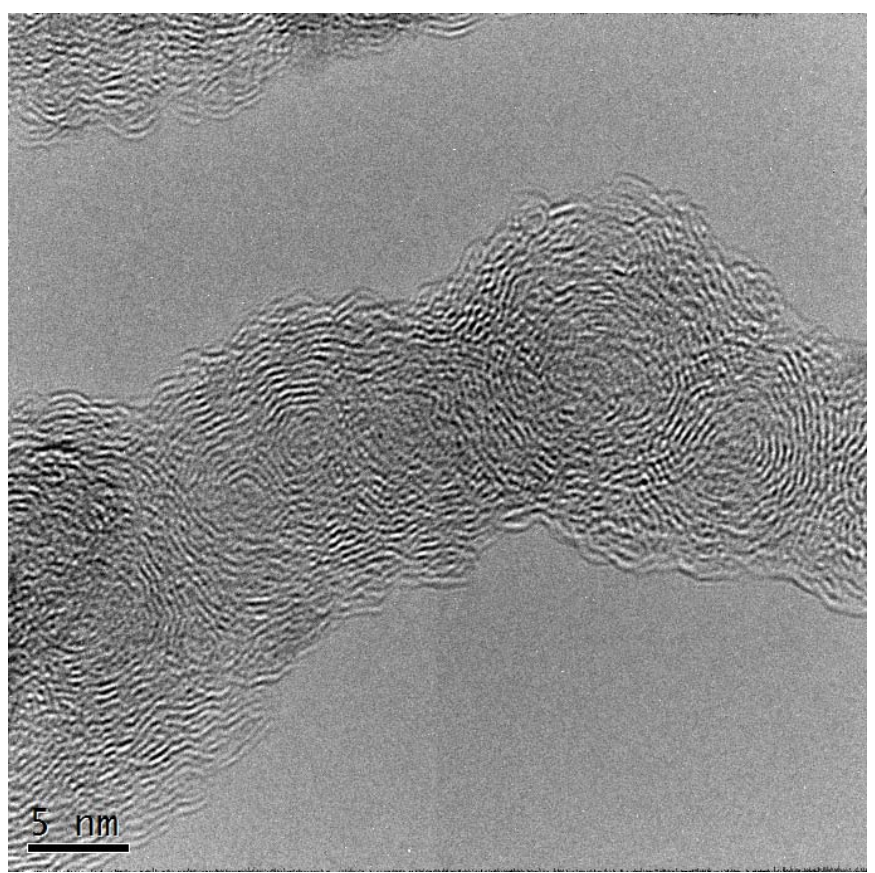

(a)

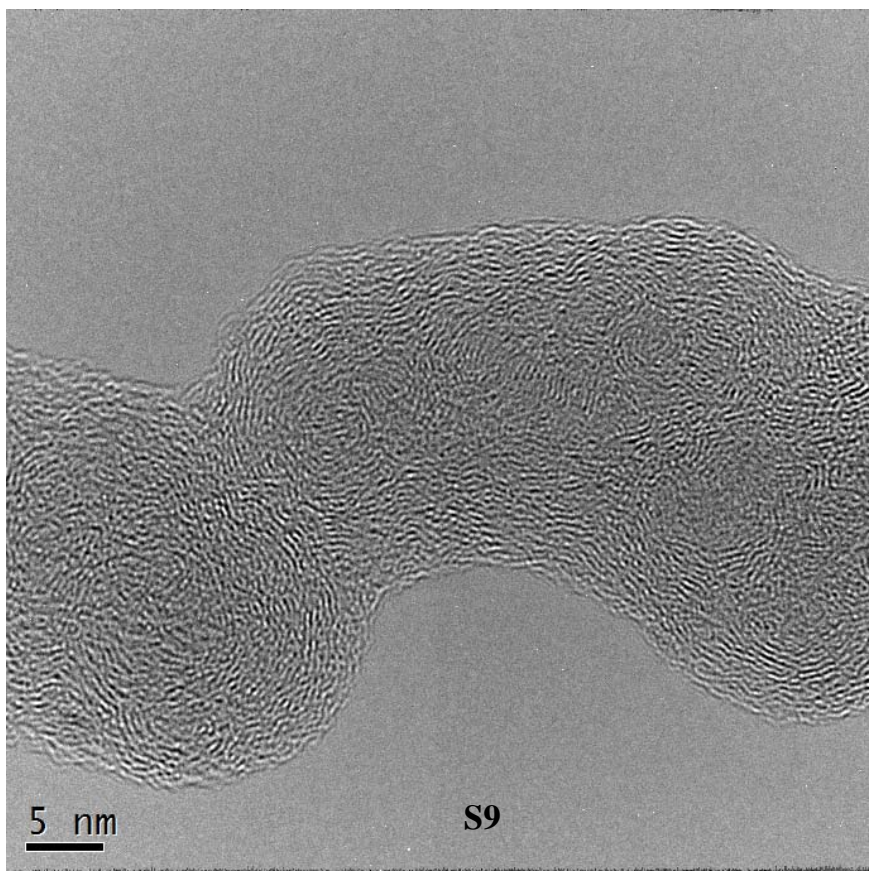

(b)

Figure 2-25. HRTEM images of (a) S0 and (b) S9.

A Santoro-type diffusion flame will be used to assess the impacts of aromatics on soot reactivity by examining the role that the polyaromatic hydrocarbon (PAH) compounds play during the inception and growth stages of soot formation. Two aromatic compounds 
are of particular interest: Phenanthrene $\left(\mathrm{C}_{14} \mathrm{H}_{10}\right)$ and fullerene $\left(\mathrm{C}_{13} \mathrm{H}_{10}\right)$. These compounds will be heated in a vaporizer to temperatures above the respective melting points, and their vapors will be entrained into the flowing burner fuel (ethylene). Soot will then be collected from the resulting sooting flame. 


\section{Task 3. Desulfurization, Denitrogenation, Saturation of Aromatics, Chemicals from Coal}

Jae Hyung Kim, Boonyawan Yoosuk, Vasudha Dhar, Brian Senger, Xiaochun Xu, Xiaoliang Ma, and Chunshan Song

\section{Subtask 3.1: Desulfurization and Denitrogenation}

Deep desulfurization and denitrogenation in a part of the DOE refinery integration project has been performed to obtain ultra-clean fuels containing very low sulfur and nitrogen. Ultradeep hydrodesulfurization (HDS) of fuels has become an important research area because of increasingly stringent environmental regulations on sulfur content in fuel [3-1]. The diesel containing high sulfur compounds leads to higher levels of $\mathrm{SO}_{\mathrm{x}}$ in the exhaust, which results in acid rain and poisons catalysts in catalytic converters that reduce $\mathrm{CO}$ and $\mathrm{NO}_{\mathrm{x}}$ [3-2]. Consequently, the sulfur level in diesel fuel must be reduced to 15 ppmw by June 2006 in the US. Hydrodesulfurization is currently a major process in petroleum refineries to reduce the sulfur in the liquid hydrocarbon fuels. However, several researchers have found that the nitrogen compounds coexisting in middle-distillate oil inhibit the deep hydrodesulfurization and the removal of such nitrogen compounds from the middle-distillate oil can improve significantly the deep hydrodesulfurization performance [3-3,3-4,3-9].

A new process, called PSU-SARS, is being explored in our laboratory. The idea in this process is to remove sulfur and nitrogen compounds in the fuels by selective adsorption. The major advantages of this process are that the process can run at ambient temperature and pressure without flowing hydrogen gas and the spent adsorbents can be regenerated either by solvent washing or by oxidation using air. The PSU-SARS can be also applied to pre-denitrogenation of the middle-distillate oil to improve the deep hydrodesulfurization performance. 
In previous reports, we focused on the adsorptive desulfurization (ADS) and denitrogenation $(\mathrm{ADN})$ of basic or very reactive nitrogen compounds such as quinoline or indole, which strongly influences hydrodesulfurization. These nitrogen compounds were removed easily by adsorption as compared with sulfur compounds because they are much more reactive than sulfur compounds in hydrotreating process. Also, we have reported adsorption of LCO (light cycle oil) on activated carbon, which showed the highest capacity of nitrogen and sulfur in the adsorption of a model fuel. The removal of nitrogen from LCO was performed successfully and the feed product containing low nitrogen $(<10 \mathrm{ppm})$ was obtained.

During this project period, we have tried to develop new HDS catalysts for LCO and adsorption treated LCO. In refinery industries, supported Mo sulfide catalysts have been widely used for hydrotreating processes, and more effective catalysts and processes for deep hydrodesulfurization have been investigated in academia and industry. The synergetic effects of promoters such as $\mathrm{Ni}$ and $\mathrm{Co}$ on the catalytic activity of the Mo sulfides have been reported in the literature. Generally, Mo sulfide catalysts are prepared from impregnation of precursors in aqueous solution, followed by drying, calcination and pre-sulfidation. Some researchers have proposed more effective preparation of Mo sulfide catalysts with different precursors such as ammoniun tetrathiomolybdate (ATTM). These Mo sulfide catalysts can be synthesized directly from ATTM by a thermal decomposition method and do not need further presulfidation of catalysts. Devers and coworkers observed more specific activity of Mo sulfide catalysts prepared hydrothermally in thiophene HDS and compared them with Mo sulfide catalysts prepared by thermal decomposition [3-16]. Yoneyama and Song [3-11] reported on a new method for preparing highly dispersed and unsupported Mo sulfide catalyst from aqueous ATTM solution mixed with an organic solvent in hydrothermal synthesis under hydrogen. At the conditions, the 
use of organic solvent helps to improve the dispersion of precursor molecules. In this study, a new hydrothermal preparation method was used for the preparation of Mo sulfide catalysts with both water and organic solvent were used under hydrogen and also Ni addition to them was investigated.

\subsubsection{Experimental}

\subsubsection{Preparation of high active unsupported NiMo sulfide catalysts}

Unsupported NiMo sulfide catalysts were synthesized by the hydrothermal method using enough water at high temperature and pressure. The catalyst synthesis was carried out in a batch reactor with a volume of $25 \mathrm{ml}$. The ammonium tetrathiomolybdate (ATTM, $\left.\left(\mathrm{NH}_{4}\right)_{2} \mathrm{MoS}_{4}\right)$ and nickel nitrate hexahydrate $\left(\mathrm{Ni}\left(\mathrm{NO}_{3}\right)_{2} \cdot 6 \mathrm{H}_{2} \mathrm{O}\right)$ were dissolved in aqueous solution with a variety of $\mathrm{Ni} /(\mathrm{Mo}+\mathrm{Ni})$ ratios and then decalin as an organic solvent was added. The reactor was purged several times with hydrogen before being pressurized with hydrogen to the desired initial pressure and placed in a preheated fluidized sand bath. Following the synthesis, the reactor was removed from the sand bath and immediately quenched in a water bath. The unsupported sulfide catalysts synthesized were separated and stored in an organic solvent.

All synthesized catalysts were evaluated by simultaneous HDS of DBT and 4,6-DMDBT. The reactant chemicals, DBT, 4,6-DMDBT and decahydronaphthalene (decalin, used as solvent), were obtained from Aldrich Chemical Co., and were used without further purification. The HDS of DBT and 4,6-DMDBT was carried out in a horizontal tubing micro reactor. The reactor was loaded with $0.023 \mathrm{~g}$ of synthesized catalysts and $4 \mathrm{~g}$ of reactant mixture $(0.4 \mathrm{~mole} \%$ of $4,6-$ DMDBT and $0.4 \mathrm{~mol} \%$ of DBT in decalin). The sealed reactor was purged with hydrogen and then pressurized with 400 psi of $\mathrm{H}_{2}$ and put in fluidized sand bath preheated to 300 or $350^{\circ} \mathrm{C}$. 
After the reactor is placed in the sand bath, the reactor was agitated at 200 strokes/min. Liquid products and the catalysts were separated and collected from the reactor after HDS reaction. The products were analyzed by Shimadzu GC/MS (GC12A/QP-500) for identification and HewlettPackard GC (HP5890) with XTI-5 column (Restek) for quantification.

\subsubsection{Direct measurement of active sites on HDS catalysts}

Direct measurement of active sites on metal sulfide catalysts for HDS of dibenzothiophenetype sulfur compounds is very important research for analyzing the properties of catalysts. In this study, it was performed with adsorption of these sulfur compounds in liquid phase. This is one of PSU-SARS applications under dynamic flow conditions. Three model fuels were prepared and one contained the equal amount of DBT and 4,6-DMDBT dissolved in the mixed solvent of decane and hexadecane. Fuels were also prepared with DBT alone and 4,6-DMDBT alone, so that the total sulfur concentration was $687 \mathrm{ppmw} \mathrm{S}$. Two commercial catalysts, $\mathrm{CoMo} / \mathrm{Al}_{2} \mathrm{O}_{3}$ (Cr344) and $\mathrm{NiMo} / \mathrm{Al}_{2} \mathrm{O}_{3}(\mathrm{Cr} 424)$, were used for the liquid-phase adsorption and HDS of DBT and 4,6-DMDBT. The catalysts were ground and sieved to $125-250 \mu \mathrm{m}$, and were presulfided at $350^{\circ} \mathrm{C}$ for $4 \mathrm{~h}$ in a flow of $5 \mathrm{vol} \% \mathrm{H}_{2} \mathrm{~S}-\mathrm{H}_{2}$ at a flow rate of $200 \mathrm{ml} / \mathrm{min}$; they were subsequently stored in hexane to minimize oxidation. The presulfided catalysts were packed in a stainless steel column having a bed dimension of $4.6 \mathrm{~mm}$ ID and $150 \mathrm{~mm}$ length. The packed column was placed in a convection oven. Before introducing the feed, the adsorbent bed was treated further with $\mathrm{H}_{2}$ gas at a flow rate of $100 \mathrm{ml} / \mathrm{min}$, heated up to $300^{\circ} \mathrm{C}$ and kept at this temperature for about $1 \mathrm{~h}$ to remove hexane in the catalysts and to produce sulfur vacancies on the sulfide catalysts. After the pretreatment, the temperature of the adsorbent bed was reduced to $25^{\circ} \mathrm{C}$ or maintained at $300^{\circ} \mathrm{C}$ for the subsequent adsorption experiments. In the adsorption, the model 
fuels were delivered into the sulfide catalyst column by a HPLC pump, flowed up through the catalyst bed at a liquid hourly space velocity (LHSV) of $4.8 \mathrm{~h}-1$. The effluent from the top of the column was collected periodically for analysis. Oxygen chemisorption was done on both sulfide catalysts in our previous study and described in detail. The HDS reaction data which were performed in previous work were used for turnover frequency (TOF) with the adsorption results. [3-15] A GC-MS (Shimadzu GC17A/QP-500) was used for identification of the products, while a gas chromatograph (SRI 8610C), equipped with an FID detector, was used for quantitative analysis of the products.

\subsubsection{Results and discussion}

\subsubsection{Preparation of high activity unsupported NiMo sulfide catalysts}

\subsection{Comparison of Unsupported NiMoS with Commercial $\mathrm{NiMoS} / \mathrm{Al}_{2} \mathrm{O}_{3}$ Catalyst}

The unsupported NiMo sulfide catalyst synthesized in this study was compared kinetically in simultaneous hydrodesulfurization of DBT and 4,6-DMDBT with a sulfided commercial NiMo catalyst (NiMo/ $/ \mathrm{Al}_{2} \mathrm{O}_{3}, \mathrm{Cr} 424$ from Criterion). In general, HDS of individual sulfur compounds follows the pseudo-first-order kinetics, thus:

$$
\begin{aligned}
& \ln \left(C_{\text {DMDBT }} / C_{\text {DMDBT0 }}\right)=-\left(k_{1}+k_{2}\right) \cdot t \\
& \frac{k_{1}}{k_{2}}=\frac{[\text { Initial Selectivity of HDMDBT }]}{[\text { Initial Selectivity of DMBP }]}
\end{aligned}
$$

where $k_{1}$ is the pseudo first-order rate constant for the hydrogenation pathway, and $k_{2}$ is the pseudo first-order rate constant for the hydrogenolysis pathway. The value of $\left(k_{1}+k_{2}\right)$, the overall 
rate constant, can be calculated from experimental data. The individual rate constants for each reaction pathway were calculated by using the method suggested in our previous work. In this method, the ratio of $k_{1} / k_{2}$ was calculated by the ratio of the initial selectivity of primary products.

Figure 3-1and Table 3-1 show the rate constants for simultaneous HDS over both sulfide catalysts. The unsupported NiMo sulfide catalyst was prepared with $1 \mathrm{~g}$ of solvent and $10 \mathrm{~g}$ of water at $350^{\circ} \mathrm{C}$ under 450 psi $\mathrm{H}_{2}$ for 2 hours; the ratio of $\mathrm{Ni} /(\mathrm{Ni}+\mathrm{Mo})$ was 0.43 . The HDS reaction over both catalysts was conducted at $300{ }^{\circ} \mathrm{C}$ and $300 \mathrm{psi} \mathrm{H}_{2}$.

The unsupported NiMo sulfide catalyst was very active in both HDS of DBT and 4,6DMDBT; it has much higher activity for direct desulfurization (DDS), which is represented by the rate constant $k_{2}$, and for hydrogenation (HYD), which is represented by $k_{1}$, than the commercial catalyst Cr424. Specifically, it has higher HYD activity than Cr424 and, for 4,6DMDBT HDS, it had much higher HYD activity. Therefore, the unsupported NiMo sulfide is suitable for deep HDS of jet and diesel range fuels. Along with these kinetic data, the investigation of preparation conditions on unsupported NiMo sulfide catalysts has been performed with their effects on HDS reactions. 


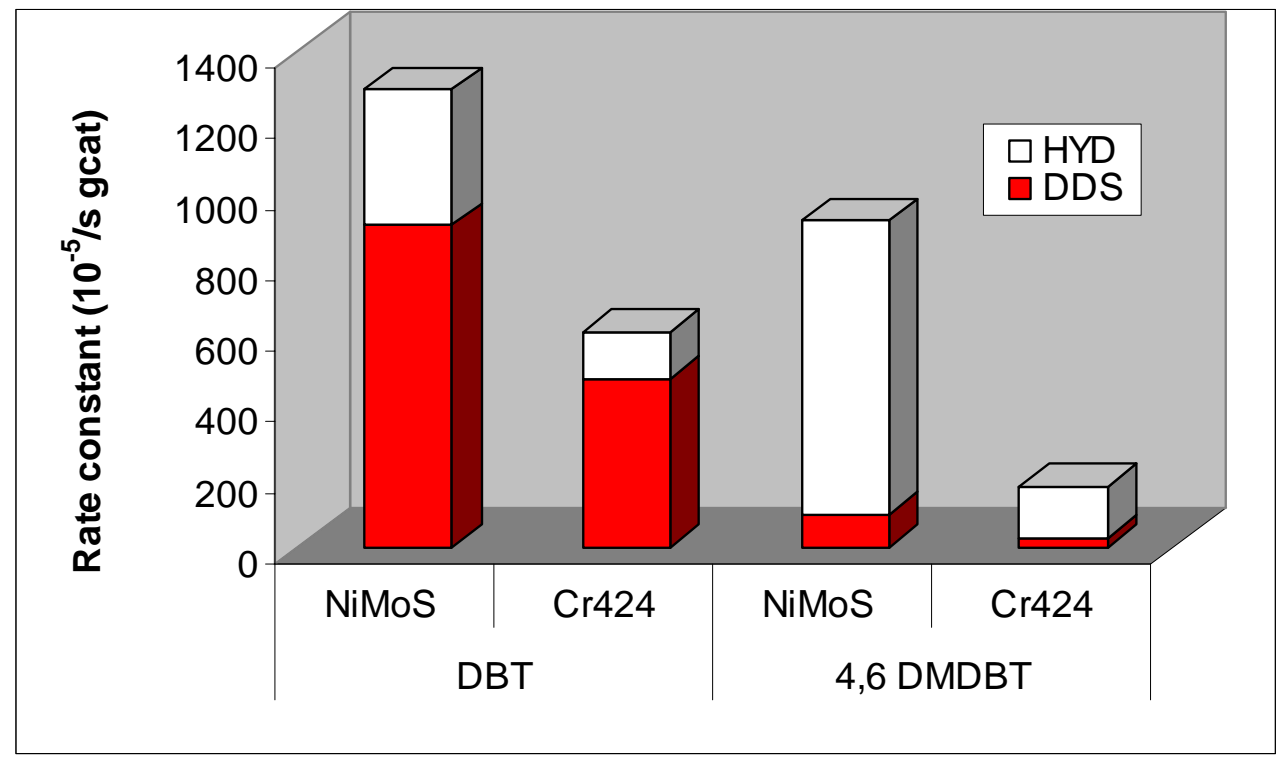

Figure 3-1. HDS rate constants for simultaneous HDS of DBT and 4,6-DMDBT over the laboratory-prepared unsupported $\mathrm{NiMoS}$ and a commercial supported $\mathrm{NiMoS} / \mathrm{Al}_{2} \mathrm{O}_{3}$ Catalyst (CR424) at $300^{\circ} \mathrm{C}$ under initial $\mathrm{H}_{2}$ pressure of 300 psi for 28 mins.

Table 3-1. Rate constants of HDS of DBT and 4,6-DMDBT over unsupported NiMo sulfide and commercial sulfide catalysts

\begin{tabular}{|l|c|c|c|c|}
\hline Rate constant & \multicolumn{2}{|c|}{ DBT } & \multicolumn{2}{c|}{4,6 DMDBT } \\
\hline $10^{-5} / \mathrm{s}$ gcat & NiMoS & Cr424 & NiMoS & Cr424 \\
\hline$k_{1}+k_{2}$ & 1290.0 & 609.4 & 920.5 & 169.9 \\
\hline$k_{1} / k_{2}$ & 0.42 & 0.29 & 8.76 & 5.59 \\
\hline$k_{1}$ & 381.9 & 135.9 & 826.2 & 144.1 \\
\hline$k_{2}$ & 908.1 & 473.5 & 94.3 & 25.8 \\
\hline
\end{tabular}

\subsection{Effects of pressure and temperature in catalyst preparation on HDS}

Figure 3-2 and Table 3-2 show the effect of catalyst preparation $\mathrm{H}_{2}$ pressure on HDS of DBT and 4,6-DMDBT at $350^{\circ} \mathrm{C}$. A gradual increase was observed in the conversion of both sulfur compounds with increasing $\mathrm{H}_{2}$ pressure of catalyst preparation conditions. In the pressure range of 200 to $400 \mathrm{psi}, \mathrm{H}_{2}$ pressure affected strongly the HDS activity of synthesized catalysts. However, when the pressure was increased to $500 \mathrm{psi}$, the increase of HDS activity was not significant on both sulfur compounds. In DBT HDS, generally, BP (biphenyl) is a major product from DDS pathway and a small amount of CHB (cyclohexylbenzene) is detected from HYD 
pathway with traceable amount of $\mathrm{BCH}$ (bicylcohexane). In this study, however, it was very interesting that the major product was $\mathrm{CHB}$ over the unsupported NiMo sulfide and $\mathrm{BCH}$ was also detected around $10 \%$. Consequently, HYD/DDS ratio was over 1.0 on all of them prepared in this study except that over NiMo sulfide prepared at 200 psi of $\mathrm{H}_{2}$ pressure, which had HYD/DDS ratio of 0.9. These values are much higher than those over the commercial CoMo sulfide and even NiMo sulfide catalysts which are 0.12 and 0.56 , respectively. Based on these results, the $\mathrm{H}_{2}$ pressure significantly affected the preparation of NiMo sulfide catalysts and provided higher HYD activity. Lower $\mathrm{H}_{2}$ pressure might not provide enough hydrogen to help the decomposition of ATTM and formation of NiMo sulfide while higher $\mathrm{H}_{2}$ pressure may help ATTM to be converted and synthesized to small and active NiMo sulfide particles for HDS of DBT and 4,6-DMDBT.

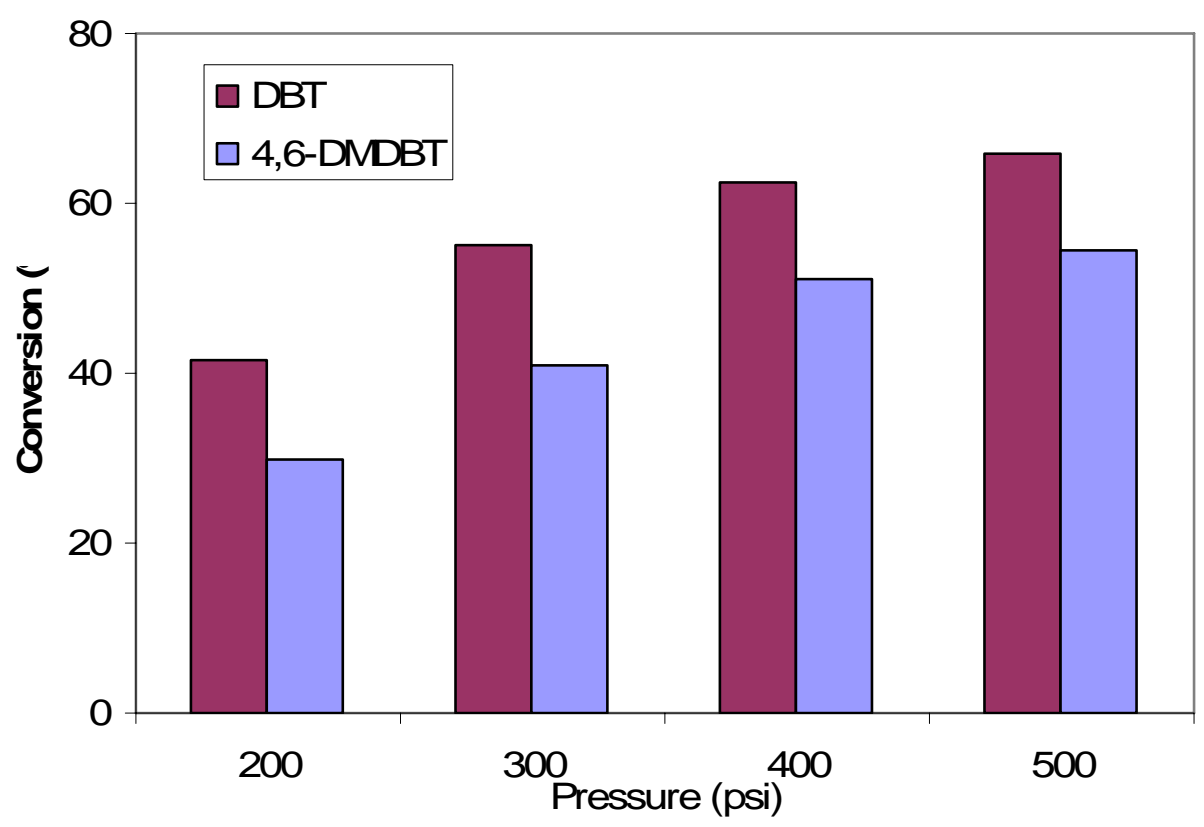

Figure 3-2. The effect of preparation pressure of $\mathrm{H}_{2}$ on HDS of 4,6-DMDBT and DBT over NiMo sulfide catalysts. Temperature $350^{\circ} \mathrm{C}$, Solvent: $1 \mathrm{~g}$ and $\mathrm{Ni} /(\mathrm{Ni}+\mathrm{Mo})=0.43$ 
Table 3-2. The effects of preparation condition on HDS of DBT and 4,6-DMDBT over unsupported NiMo sulfide catalysts

\begin{tabular}{|c|c|c|c|c|c|c|c|c|c|c|}
\hline \multirow[b]{2}{*}{$\begin{array}{c}\text { Pressure } \\
\text { (psi) }\end{array}$} & \multirow{2}{*}{$\frac{\text { CONV }}{\text { DBT }}$} & \multicolumn{4}{|c|}{ SELECTIVITY } & CONV & \multicolumn{4}{|c|}{ SELECTIVITY } \\
\hline & & THDBT & BP & CHB & $\mathrm{BCH}$ & $\begin{array}{c}4,6- \\
\text { DMDBT }\end{array}$ & $\begin{array}{c}\text { 4HDM } \\
\text { DBT }\end{array}$ & $\begin{array}{c}3,3^{\prime}- \\
\text { DMBP }\end{array}$ & MCHT & $\mathrm{DMBCH}$ \\
\hline 200 & 39.8 & 10.9 & 51.4 & 31.6 & 6.1 & 29.4 & 45.6 & 29.4 & 21.7 & 3.4 \\
\hline 300 & 54.2 & 9.5 & 37.4 & 43.1 & 10.0 & 40.4 & 41.9 & 31.4 & 24.5 & 2.2 \\
\hline 400 & 58.5 & 6.2 & 41.1 & 42.6 & 10.1 & 47.3 & 37.8 & 33.2 & 27.0 & 2.0 \\
\hline 500 & 63.4 & 5.6 & 45.0 & 40.8 & 8.6 & 50.5 & 35.3 & 32.8 & 28.8 & 3.0 \\
\hline
\end{tabular}

Figure 3-3 and Table 3-3 show the effects of catalyst preparation temperature on the HDS of DBT and 4,6-DMDBT. The conversions of DBT and 4,6-DMDBT increased gradually with increasing of preparation temperature. In product distribution, DMBP, a product from DDS pathway, decreased with increasing preparation temperature while products from HYD pathway increased. Consequently, the HYD/DDS ratio increased from 1.13 to 1.52 with increasing preparation temperature. It has been reported that the catalytic activity of Mo based sulfide catalyst is related to the coexistence of two different sites in HDS of DBTs and each site drives HDS reaction through DDS pathway and HYD pathway. A predominant pathway may be directly dependent upon the relative concentrations of theses active sites. According to the result of preparation temperature effects, it seems that the higher preparation temperature provides higher HYD activity than DDS activity for synthesized unsupported catalysts. This result correlates with the ratio of HYD/DDS in the product selectivity and the ratio was higher at higher preparation temperature. 


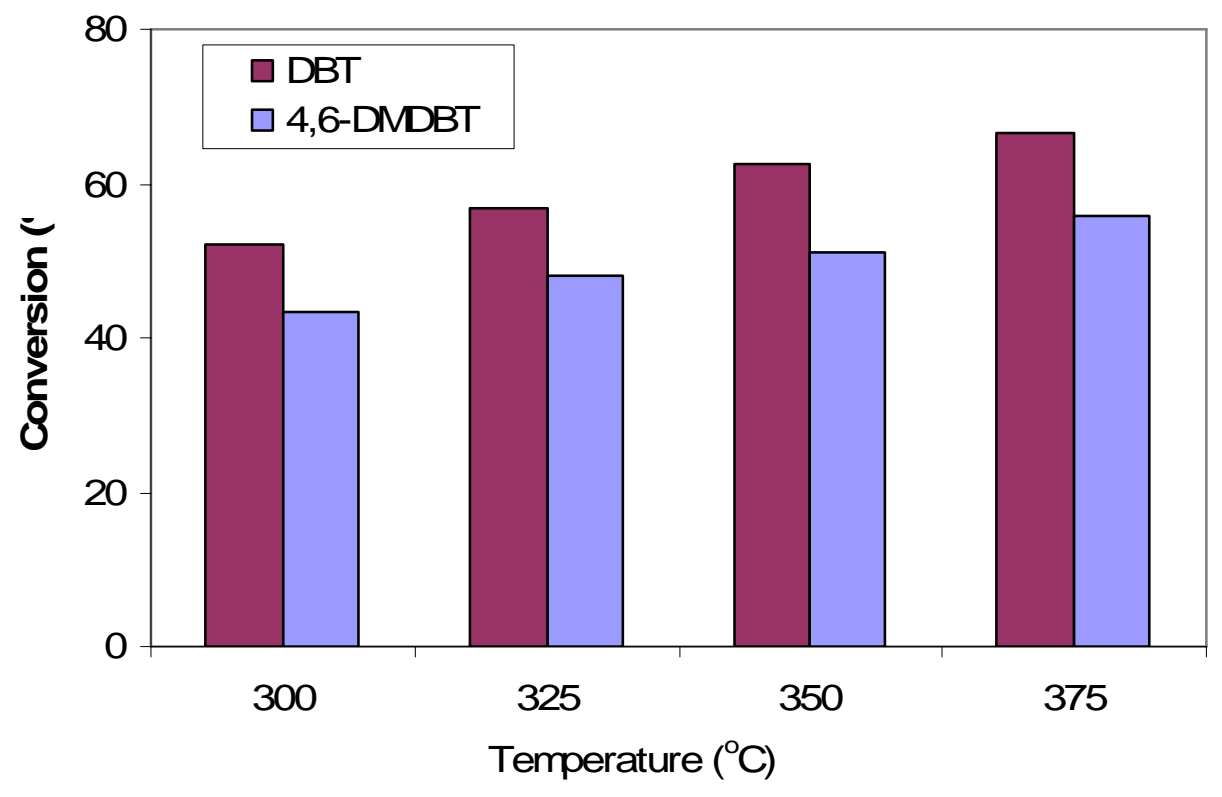

Figure 3-3. The effect of preparation temperature on HDS of 4,6-DMDBT and DBT over NiMo sulfide catalyst. $\mathrm{H}_{2}$ pressure: $400 \mathrm{psi}$, Solvent: $1 \mathrm{~g}$ and $\mathrm{Ni} /(\mathrm{Ni}+\mathrm{Mo})=0.43$.

Table 3-3. The effects of preparation temperature on HDS of DBT and 4,6-DMDBT over unsupported NiMo sulfide catalysts

\begin{tabular}{|c|c|c|c|c|c|c|c|c|c|c|}
\hline \multirow[b]{2}{*}{$\begin{array}{c}\text { Temp. } \\
\left({ }^{\circ} \mathrm{C}\right)\end{array}$} & \multirow{2}{*}{$\begin{array}{c}\text { CONV } \\
\text { DBT }\end{array}$} & \multicolumn{4}{|c|}{ SELECTIVITY } & CONV & \multicolumn{4}{|c|}{ SELECTIVITY } \\
\hline & & THDBT & $\mathrm{BP}$ & $\mathrm{CHB}$ & $\mathrm{BCH}$ & $\begin{array}{c}4,6- \\
\text { DMDBT }\end{array}$ & $\begin{array}{c}4 \mathrm{HDM} \\
\text { DBT }\end{array}$ & $\begin{array}{c}3,3^{\prime}- \\
\text { DMBP }\end{array}$ & MCHT & DMBCH \\
\hline 300 & 50.3 & 5.1 & 46.5 & 39.6 & 8.7 & 41.6 & 33.7 & 40.6 & 24.0 & 1.7 \\
\hline 325 & 53.8 & 5.4 & 43.4 & 42.0 & 9.2 & 44.8 & 35.6 & 37.1 & 25.8 & 1.5 \\
\hline 350 & 58.5 & 6.2 & 41.1 & 42.6 & 10.1 & 47.3 & 37.8 & 33.2 & 27.0 & 2.0 \\
\hline 375 & 63.9 & 4.9 & 38.7 & 47.1 & 9.3 & 51.9 & 41.8 & 25.4 & 31.0 & 1.8 \\
\hline
\end{tabular}

\subsection{Effects of organic solvent in catalyst preparation on HDS}

An organic solvent (decalin, decahydronaphthalene) was added to the aqueous solution of ATTM and Ni precursor, and its effects were investigated by varying its amount in this study. Figure 3-4 and Table 3-4 illustrate the effect of organic solvent amount used in preparation on the activity of unsupported NiMo sulfide catalysts for HDS of DBT and 4,6-DMDBT. Both DBT and 4,6-DMDBT conversions increased significantly with the addition of organic solvent and their increase was 18 and $22 \%$, respectively. The results indicated that the presence of organic 
solvent in the catalyst preparation step promoted the activity of unsupported NiMo catalysts and this coincides with the results reported by Yoneyama and Song [3-11]. They reported the addition of organic solvent to the preparation $\mathrm{MoS}_{2}$ from ATTM provided high activity for cleavage of $\mathrm{C}-\mathrm{C}$ bond and hydrogenation of naphthalene, and additional water led to much higher activity. Probably the presence of the organic solvent helps to disperse ATTM containing water droplets during preparation reaction with vigorous agitation. This results in fine molecular dispersion of precursor molecules in aqueous solution isolated by organic solvent prior to and during their decomposition and hydrogen reduction. In the DBT HDS, BP was predominant over the NiMo catalyst prepared without organic solvent. With increasing amounts of organic solvent, however, it decreased slightly and gradually. Similar trends were observed in the 4,6-DMDBT HDS.

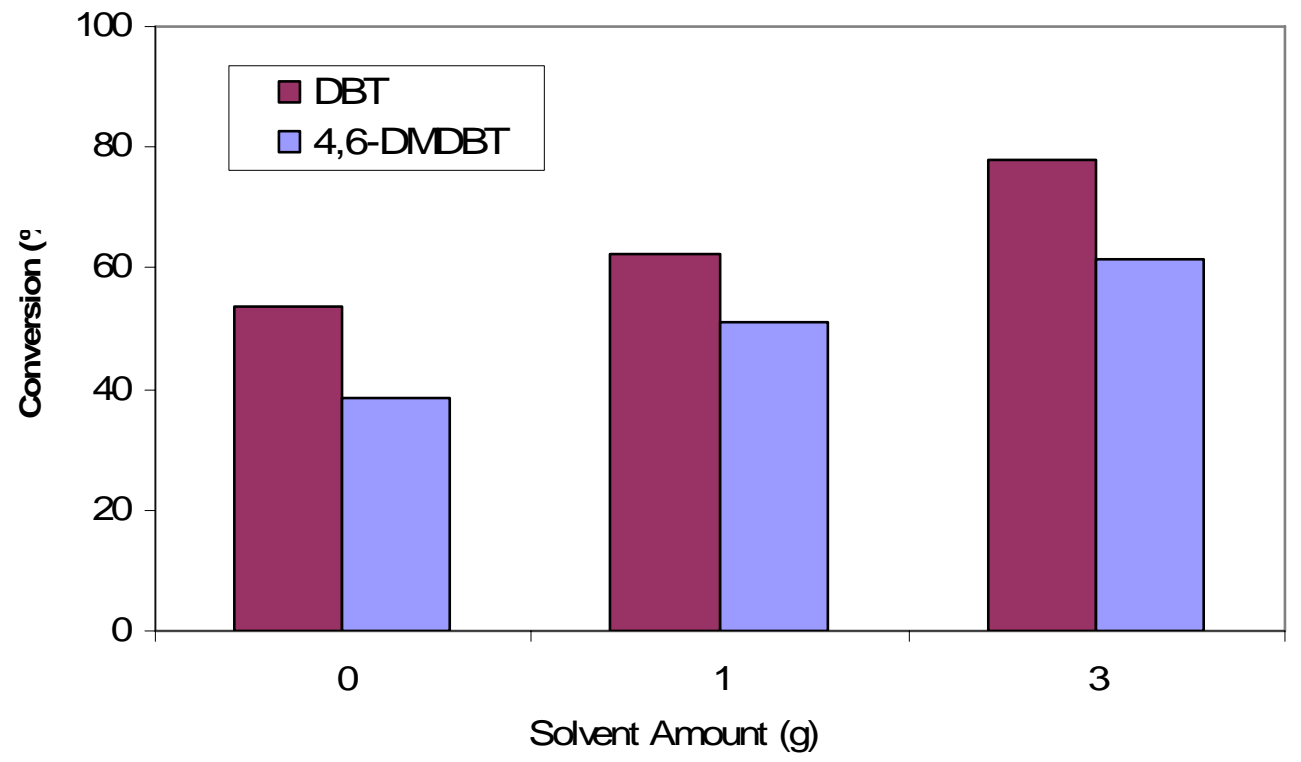

Figure 3-4. The effect of solvent amount on HDS of 4,6-DMDBT and DBT over NiMo sulfide catalyst. Temperature: $350^{\circ} \mathrm{C}, \mathrm{H}_{2}$ pressure: $400 \mathrm{psi}$ and $\mathrm{Ni} /(\mathrm{Ni}+\mathrm{Mo})=0.43$ 
Table 3-4. The effects of solvent amount on HDS of DBT and 4,6-DMDBT over unsupported NiMo sulfide catalysts

\begin{tabular}{|c|r|r|r|r|r|r|r|r|r|r|}
\hline \multirow{2}{*}{$\begin{array}{c}\text { Solvent } \\
(\mathrm{g})\end{array}$} & \multicolumn{1}{|l|}{ CONV } & \multicolumn{2}{|c|}{ SELECTIVITY } & \multicolumn{1}{c|}{ CONV } & \multicolumn{4}{|c|}{ SELECTIVITY } \\
\cline { 2 - 11 } & DBT & THDBT & BP & CHB & BCH & $\begin{array}{c}4,6- \\
\text { DMDBT }\end{array}$ & $\begin{array}{c}\text { 4HDM } \\
\text { DBT }\end{array}$ & $\begin{array}{c}3,3 '- \\
\text { DMBP }\end{array}$ & MCHT & DMBCH \\
\hline 0 & 52.4 & 7.7 & 46.7 & 38.4 & 7.2 & 35.8 & 46.2 & 31.2 & 20.9 & 1.7 \\
\hline 1 & 58.5 & 6.2 & 41.1 & 42.6 & 10.1 & 47.3 & 37.8 & 33.2 & 27.0 & 2.0 \\
\hline 3 & 73.5 & 3.4 & 40.7 & 46.2 & 9.8 & 59.3 & 30.9 & 36.0 & 31.1 & 1.9 \\
\hline
\end{tabular}

\subsection{Effect of $\mathrm{Ni} /(\mathrm{Mo}+\mathrm{Ni})$ ratio on $\mathrm{DBT}$ and 4,6-DMDBT HDS}

Based on catalysts preparation in previous chapters, an unsupported NiMo sulfide synthesized at $350^{\circ} \mathrm{C}$ and 400 psi $\mathrm{H}_{2}$ pressure with $1 \mathrm{~g}$ of organic solvent was selected as a standard catalyst and conditions for the effects of Ni ratio on Mo sulfide catalyst. As shown in Table 3-5, unsupported NiMo sulfides had higher conversion of DBT and 4,6-DMDBT than unsupported Mo sulfide, Ni sulfide and a commercial Ni sulfide (Aldrich). The unsupported Mo sulfide was prepared by the same method as NiMo sulfide was, but without Ni precursor. The Ni sulfide was also prepared by the same procedure without ATTM. The conversion of DBT and 4,6-DMDBT increased with increasing $\mathrm{Ni}$ amount, reached a maximum at 0.5 of the ratio and decreased at higher ratio of Ni to Mo. Alumina-supported Mo catalysts with Ni or Co promoter are used widely in industries and these active metals are impregnated on the support with the $\mathrm{Ni} / \mathrm{Mo}$ atomic ratio of $0.2 \sim 0.3$. In the present study, however, the activity of the catalyst with $\mathrm{Ni} / \mathrm{Mo}$ atomic ratio of $0.25(\mathrm{Ni} /(\mathrm{Ni}+\mathrm{Mo})$ ratio $=0.2)$ was higher than that of Mo alone sulfide catalyst, but the unsupported NiMo sulfide had highest activity at the ratio of 1.00 among the catalysts tested. This ratio is much higher than that on conventional supported NiMo catalysts.

It has been reported that $\mathrm{Ni}$ atoms may be placed at the edge of $\mathrm{MoS}_{2}$ crystallites and form Ni-Mo-S structure which is considered as a major HDS active site. The hydrothermal preparation helps unsupported NiMo sulfide catalysts to form very small size (nano size) of NiMo sulfide cluster. It may be because organic solvent is finely dispersed in aqueous solution 
(under close super critical conditions) of ATTM and Ni precursor in high $\mathrm{H}_{2}$ pressure and this helps ATTM to be decomposed completely and to be formed very fine particle of NiMo sulfide. In addition, $\mathrm{Ni}$ atoms would incorporate into smaller crystallites of Mo sulfide and it would be possible for more Ni atoms to incorporate into smaller Mo sulfide crystallites and form smaller and more NiMoS phases. The conversion of both sulfur compounds increased until the Ni/Mo atomic ratio of 1.0 as shown in Table 3 - because more active phase might be formed after more Ni atoms incorporate into the small crystallites of Mo sulfide. In higher Ni/Mo atomic ratio, however, the conversion of sulfur compounds decreased. Possibly, excess Ni atom may occupy active phase of NiMoS and cause deactivation.

Table 3-5. The effect of Ni/(Mo+Ni) ratio on HDS of 4,6-DMDBT and DBT over NiMo sulfide catalyst

\begin{tabular}{ccccc}
\hline \multirow{2}{*}{$\mathrm{Ni} /(\mathrm{Ni}+\mathrm{Mo})$} & DBT & \multicolumn{2}{c}{4,6 DMDBT } \\
& Conv. & HYD/DDS & Conv. & HYD/DDS \\
\hline $0.00^{1}$ & 27.5 & 2.95 & 35.2 & 12.96 \\
0.20 & 40.8 & 1.13 & 31.1 & 2.78 \\
0.33 & 46.1 & 1.18 & 36.3 & 2.88 \\
0.43 & 54.6 & 1.37 & 43.5 & 2.02 \\
0.50 & 63.8 & 1.46 & 49.9 & 2.02 \\
0.56 & 55.4 & 1.11 & 42.4 & 2.25 \\
$1.00^{2}$ & 8.3 & 0.28 & 5.1 & 12.86 \\
$1.00^{3}$ & 11.3 & 0.70 & 12.7 & 0.27 \\
$\mathrm{Cr} 344$ & 44.3 & 0.13 & 17.8 & 2.14 \\
$\mathrm{Cr} 424$ & 53.6 & 0.56 & 26.0 & 2.07 \\
\hline
\end{tabular}

${ }^{1}$ Mo sulfide prepared from ATTM, ${ }^{2}$ Ni sulfide prepared from Ni nitrate ${ }^{3}$ Commercial Ni sulfide

\subsubsection{Direct measurement of active sites on HDS catalysts}

The measurement of active sites is very important research because it may provide very significant information of catalysts about the properties of adsorption and activity. The measurement of active sites on HDS sulfide catalysts has been performed with adsorption (or chemisorption) of probe molecules such as $\mathrm{O}_{2}$ and NO. Tauster et al. [3-13] and Burch and 
Collins [3-14] conducted pulse $\mathrm{O}_{2}$ chemisorption at room temperature and low temperature ($78^{\circ} \mathrm{C}$ ) and then both reported that oxygen is chemisorbed on the edge sites of the $\mathrm{MoS}_{2}$ crystallites, which are regarded as anion vacancies (or coordinative unsaturated sites (CUS)) on edges and corners of the $\mathrm{MoS}_{2}$ crystallites. It is widely accepted that these sites are directly related to catalytic active sites on HDS of sulfur compounds containing aromatic rings. In NO adsorption, Topsøe and Topsøe reported that NO most probably adsorbs on the edge or corner sites of $\mathrm{MoS}_{2}$-like structures and the adsorption therefore reflects the edge dispersion of these structures [3-17]. Hong and Regalbuto [3-18] suggested that Mo-S sites with unsaturated coordination located in S-Mo-S layers are adsorption sites for probe molecules $\mathrm{H}_{2} \mathrm{~S}, \mathrm{CO}, \mathrm{O}_{2}$ and NO, while $\mathrm{S}$ sites located in S-S layers only adsorb $\mathrm{O}_{2}$ and NO. Through these adsorption examinations, it has also been acquired that the overall $\mathrm{NO} / \mathrm{Mo}$ and $\mathrm{O}_{2} / \mathrm{Mo}$ ratios and the variation in these ratios are quite similar and these means that $\mathrm{NO}$ and $\mathrm{O}_{2}$ chemisorb on similar sites. However, the adsorption properties and amounts of sulfur compounds, specifically DBTtype compounds, may be quite different from the conventional adsorption methods with simple probe molecules. Therefore, the adsorption of DBT and 4,6-DMDBT in liquid phase was studied in this study and provided significant information of active sites on HDS sulfide catalysts.

\subsection{Simultaneous adsorption of DBT and 4,6-DMDBT on HDS catalysts}

Figure 3-5 and Table 3-6 show the results of simultaneous adsorption of DBT and 4,6DMDBT on the commercial CoMo and NiMo sulfides. At room temperature, $25^{\circ} \mathrm{C}$, the replacement phenomena of DMDBT by DBT were observed on the both sulfide catalysts. As reported at the previous DOE report [3-15], stronger adsorbents may replace weaker adsorbents on active sites on which both adsorbents share or compete when stronger adsorbents saturate 
them. However, the replaced amount of 4,6-DMDBT by DBT was only $0.002 \mathrm{mmol} / \mathrm{g}(4 \%$ of saturation amount) and even the phenomena were not observed at high temperature, $300^{\circ} \mathrm{C}$, as shown in Table 3-6. It means that DBT and 4,6-DMDBT may adsorb and share on same adsorption (active) sites, which are only little on metal sulfide catalysts. Also, an interesting thing has been observed in this experiment is that the adsorption amount of 4,6-DMDBT was larger at $300^{\circ} \mathrm{C}$ than that of DBT. This might be considered that no steric hindrance of two methyl group at 4 and 6- position of DBT (dibenzothiophene). However, the replacement phenomena were not observed at those conditions and this means that DBT and 4,6-DMDBT may not share the same active sites. Therefore, it is sure that this steric hindrance is affecting on the adsorption of 4,6-DMDBT which adsorbs different active sites on metal sulfide catalysts.

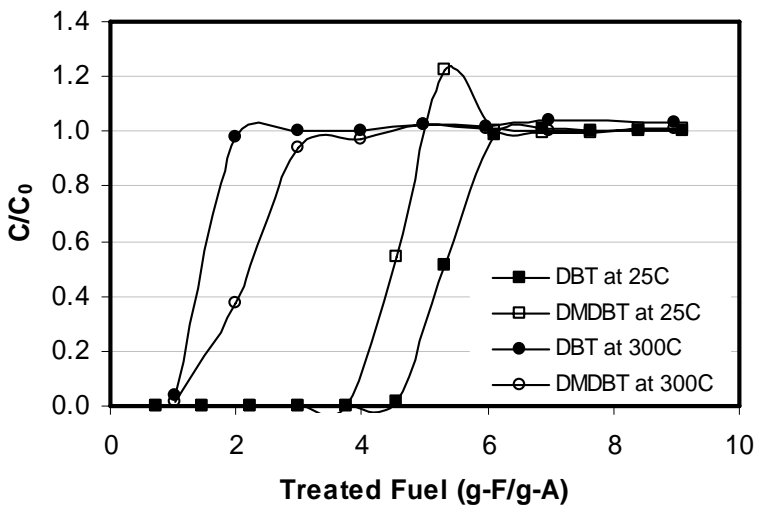

(a)

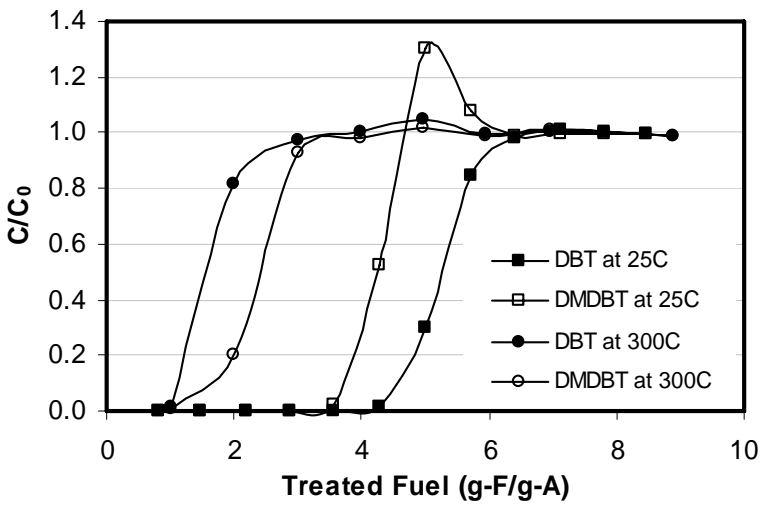

(b)

Figure 3-5. Breakthrough curve of DBT and DMDBT on (a) CoMo and (b) NiMo sulfide catalysts at 25 and $300^{\circ} \mathrm{C}$ from simultaneous adsorption. 
Table 3-6. Amount of adsorbed sulfur compounds on NiMo and CoMo sulfide catalysts from simultaneous adsorption

\begin{tabular}{|l|c|c|c|c|c|c|c|}
\hline Amount $(\mathrm{mmol} / \mathrm{g})$ & $\mathrm{O}_{2}$ Chem & \multicolumn{6}{|l|}{ Adsorption of DBT and 4,6-DMDBT } \\
\hline Temperature & $-78.5^{\circ} \mathrm{C}$ & $25^{\circ} \mathrm{C}$ & & & $300^{\circ} \mathrm{C}$ & & \\
\hline CoMoS & & Total & DBT & DMDBT & Total & DBT & DMDBT \\
\hline & 0.086 & 0.103 & 0.057 & 0.046 & 0.039 & 0.016 & 0.023 \\
\hline NiMoS & & & & $0.048^{1}$ & & & \\
\hline & 0.095 & 0.099 & 0.056 & 0.043 & 0.044 & 0.018 & 0.026 \\
\hline
\end{tabular}

${ }^{1}$ The adsorption amount at the saturation point by 4,6-DMDBT

\subsection{Sequential adsorption of DBT and 4,6-DMDBT on HDS catalysts}

In order to investigate replacement of adsorbents in more detail, another adsorption experiment was performed at $300^{\circ} \mathrm{C}$, which is named sequential adsorption and at which 4,6 DMDBT alone fuel was fed and followed by DBT alone fuel and also the adsorption sequence was changed. Figure 3-6 shows the breakthrough curves of each DBT and 4,6-DMDBT when each compound alone fuel was flew into adsorbents. Based on this experiment, the adsorption amount of each compound was calculated and shown in Table 3-7. First and second adsorption amounts of 4,6-DMDBT were larger than those of DBT and the desorption amount of a sulfur compound was calculated during second adsorption of the other compound. Therefore, each sulfur compounds may replace the other sulfur compounds preoccupied on metal sulfides, but it was observed that the former compound cannot be removed entirely from the latter compound. Based on these results, irreversible amounts of DBT and 4,6-DMDBT were able to be calculated by the subtraction of desorption amount from adsorption amount and are shown in Table 3-7. Interestingly, the irreversible amount of DBT and 4,6-DMDBT are 0.010 and $0.023 \mathrm{mmol} / \mathrm{g}$ on CoMo sulfide and 0.018 and $0.027 \mathrm{mmol} / \mathrm{g}$ on NiMo sulfide and quite similar to the adsorption amounts from simultaneous adsorption shown in Table 3-6. The numbers of total active sites for DBT and 4,6-DMDBT on the sulfide catalysts is considered as the sum of irreversible amount of 
DBT and 4,6-DMDBT. The number on CoMo sulfide is $0.033 \mathrm{mmol} / \mathrm{g}$ and that on NiMo sulfide is $0.45 \mathrm{mmol} / \mathrm{g}$. These are very similar to the adsorption amount (the number of active sites) from simultaneous adsorption. The consistent results can be obtained from both simultaneous and sequential absorption experiments.

Based on the simultaneous adsorption and HDS of DBT and 4,6-DMDBT shown in Table 3-5Table 3-, turnover frequency (TOF) of each sulfur compounds on metal sulfide catalysts was calculated and shown in Table 3-8. TOF based on the total adsorption amount at $25^{\circ} \mathrm{C}$ is quite similar to that based on $\mathrm{O}_{2}$ chemisorption, but that based on the total adsorption amount at $300^{\circ} \mathrm{C}$ is much higher than the latter. The adsorption results enable calculation of TOF based on the adsorption of each sulfur compound while $\mathrm{O}_{2}$ chemisorption could not provide this number because it cannot provide information of each sulfur compound adsorption. This TOF is much higher than that calculated on the basis of total amount as shown in Table 3-8.

Table 3-7. Amount of adsorbed sulfur compounds on NiMo and CoMo sulfide catalysts from sequential adsorption

\begin{tabular}{|c|c|c|c|c|}
\hline \multirow{2}{*}{$\begin{array}{c}\text { Amount } \\
(\mathrm{mmol} / \mathrm{g})\end{array}$} & \multicolumn{2}{|c|}{ Adsorption } & \multirow{2}{*}{ Desorption } & \multirow{2}{*}{ Irreversible $^{1}$} \\
\cline { 2 - 3 } Experiment I & DMDBT & DBT & DMDBT & DMDBT \\
\hline CoMoS & 0.055 & 0.023 & 0.032 & 0.023 \\
\hline NiMoS & 0.050 & 0.017 & 0.023 & 0.027 \\
\hline Experiment II & DBT & DMDBT & DBT & DBT \\
\hline CoMoS & 0.035 & 0.036 & 0.025 & 0.010 \\
\hline NiMoS & 0.037 & 0.028 & 0.019 & 0.018 \\
\hline
\end{tabular}

${ }^{1}$ Irreversible amount is calculated by subtraction of desorption amount from adsorption amount 
Feed switched
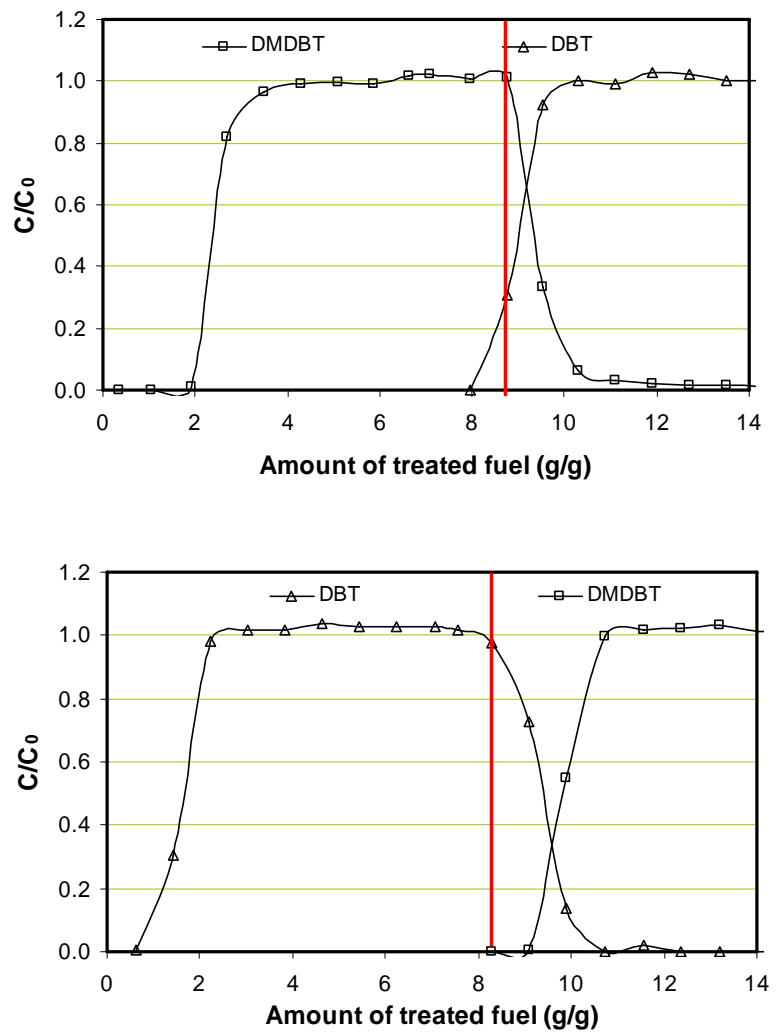

(a) $\mathrm{CoMo} / \mathrm{Al}_{2} \mathrm{O}_{3}$
Feed switched
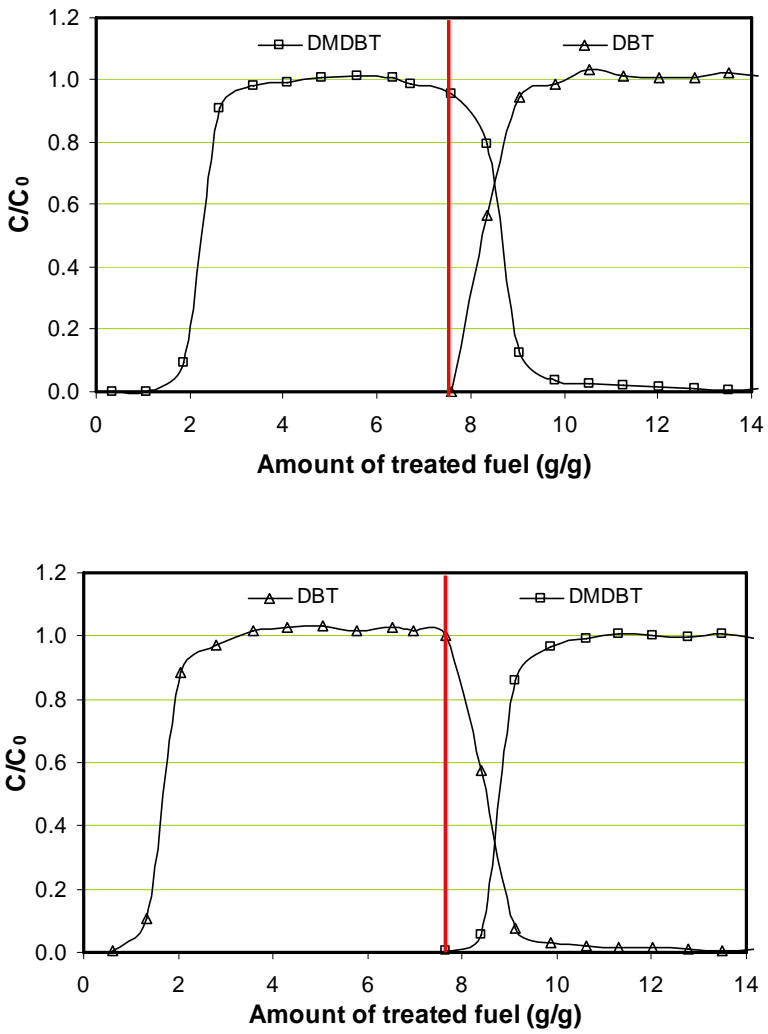

(b) $\mathrm{NiMo} / \mathrm{Al}_{2} \mathrm{O}_{3}$

Figure 3-6. Breakthrough curve of DBT and DMDBT on (a) CoMo and (b) NiMo sulfide catalysts at $300^{\circ} \mathrm{C}$ from sequential adsorption.

Table 3-8. Turnover frequency of DBT and 4,6-DMDBT HDS over commercial NiMo and CoMo sulfide catalysts on the basis of simultaneous adsorption

\begin{tabular}{|c|c|c|c|c|c|c|c|}
\hline \multirow{2}{*}{$\operatorname{TOF}\left(\mathrm{h}^{-1}\right)$} & & DBT & & & DMDBT & & \\
\hline & & $\mathrm{O}_{2}$ Chem & Ads $25^{1}$ & Ads $300^{2}$ & $\mathrm{O}_{2}$ Chem & Ads $25^{1}$ & Ads $300^{2}$ \\
\hline \multirow{2}{*}{$\begin{array}{l}\text { Cr344 } \\
\text { (CoMoS) }\end{array}$} & Total & 19.5 & 16.3 & 42.8 & 91.7 & 40.6 & 106.6 \\
\hline & Each & & 36.3 & 71.7 & & 73.7 & 264.1 \\
\hline \multirow{2}{*}{$\begin{array}{l}\mathrm{Cr} 424 \\
\text { (NiMoS) }\end{array}$} & Total & 25.9 & 24.8 & 56.4 & 100.3 & 51.2 & 116.3 \\
\hline & Each & & 57.6 & 96.5 & & 90.1 & 280.1 \\
\hline
\end{tabular}




\subsubsection{Summary}

\subsubsection{Preparation of high active unsupported NiMo sulfide catalysts}

1) Organic solvent addition in catalyst synthesis was effective for generation of highly active NiMo unsupported catalyst. Probably the presence of the organic solvent helps to disperse ATTM containing water droplet during preparation reaction with vigorous agitation. This results in fine molecular dispersion of precursor molecules in aqueous solution isolated by organic solvent prior to and during their decomposition and hydrogen reduction.

2) The preparation conditions $\left(\mathrm{H}_{2}\right.$ pressure, temperature and solvents) have significant effects on activity of unsupported NiMo sulfide catalyst. Higher temperature and pressure provided high activity for HYD pathway of both DBT and 4,6-DMDBT HDS. It is because the conditions employed in this study may provide specific environments to form very small (nano) size of NiMo sulfide clusters.

\subsubsection{Direct measurement of active sites on HDS catalysts}

1) At simultaneous adsorption, the replacement phenomena of DMDBT by DBT were observed on CoMo and NiMo sulfide catalysts because the former adsorbs more weakly on catalytic surface than the latter. However, the replaced amount of 4,6-DMDBT by DBT was very little and only $4 \%$ of saturation amount $(0.002 \mathrm{mmol} / \mathrm{g})$ and even the phenomena were not observed at high temperature, $300^{\circ} \mathrm{C}$,

2) The direct adsorption method successfully showed adsorption properties of DBT and 4,6DMDBT on sulfide catalysts and provided significant information about adsorption (active) sites for HDS of both sulfur compounds at the conditions employed in this study. Based on adsorption 
conditions which are closer to HDS reaction conditions, this method is more reasonable and viable as compared with conventional methods (chemisorption).

3) It was observed irreversible DBT and 4,6-DMDBT adsorbed on sulfide catalysts which could not be replaced by each other. It means that there are separate adsorption sites on sulfide catalysts. One is for only DBT, another for only 4,6-DMDBT and the other for both compounds which may share and compete, but is very little.

\subsubsection{Future work}

1) Improving the capacity and selectivity of sulfur and nitrogen of activated carbon to other aromatic compounds and contaminant will be performed after investigation of fuel composition of light cycle oil (LCO) and its mixture with refined chemical oil (RCO).

2) Adsorptive denitrogenation of LCO and RCO will be performed on activated carbon and modified carbon adsorbents and the hydrodesulfurization of the denitrogenated LCO and its mixture with RCO will also be performed over new developed unsupported sulfide catalysts and other type of catalysts (noble metals, eg.; $\mathrm{Pd}, \mathrm{Pt}$ and $\mathrm{Pd} / \mathrm{Pt}$ ) with different pretreatment (presulfidation, reduction and etc.)

3) HDS of LCO and its mixture with RCO over commercial catalysts and new developed catalysts will be performed before/after adsorptive denitrogenation/desulfurization.

\section{Subtask 3.2. Saturation of Two-Ring Aromatics}

As a part of the DOE refinery integration project, this sub-task aims at saturating aromatics for high-quality diesel and distillate fuels. High aromatics content in distillate fuels is undesirable since it lowers the fuel quality and contributes to the formation of environmentally 
harmful emissions. In general, lower aromatics content leads to increased thermal stability, improved combustion characteristics and less soot formation. The conventional method of dearomatization is by aromatics saturation (hydrogenation). Typically, sulfided $\mathrm{Co}-\mathrm{Mo} / \mathrm{Al}_{2} \mathrm{O}_{3}$ or $\mathrm{Ni}-\mathrm{Mo} / \mathrm{Al}_{2} \mathrm{O}_{3}$ catalysts are employed for hydrogenation. However, these catalysts are most active at higher temperatures where equilibrium limitations may prevent complete hydrogenation. Noble-metal catalysts are active at lower temperatures, where equilibrium limitations can be overcome, however sulfur-tolerance is a major obstacle to their commercial application.

To meet the fuel performance and compositional specifications for diesel fuel, it is necessary for both RCO and LCO to be hydrogenated. This work focuses on the development of increasingly sulfur-tolerant, noble-metal catalysts for the low-temperature hydrotreating and dearomatization (LTHDA) of distillate fuels for the production of ultra-clean and low-aromatic diesel fuels.

In this reporting period, the influence of adding Pt to Pd on the property of the catalysts and the surface characteristics of the bimetallic catalysts were examined.

\subsubsection{Experimental}

The general experimental procedure and the procedure for catalyst preparation are the same as in our previous semi-annual report [3-15]. 


\subsubsection{Results and Discussion}

A series of Pd-Pt bimetallic catalysts with different ratios of Pd to Pt were prepared, characterized and tested in order to determine the effect of combining Pd with Pt in different ratios. The results are presented in Figure 3-7 and Figure 3-8.

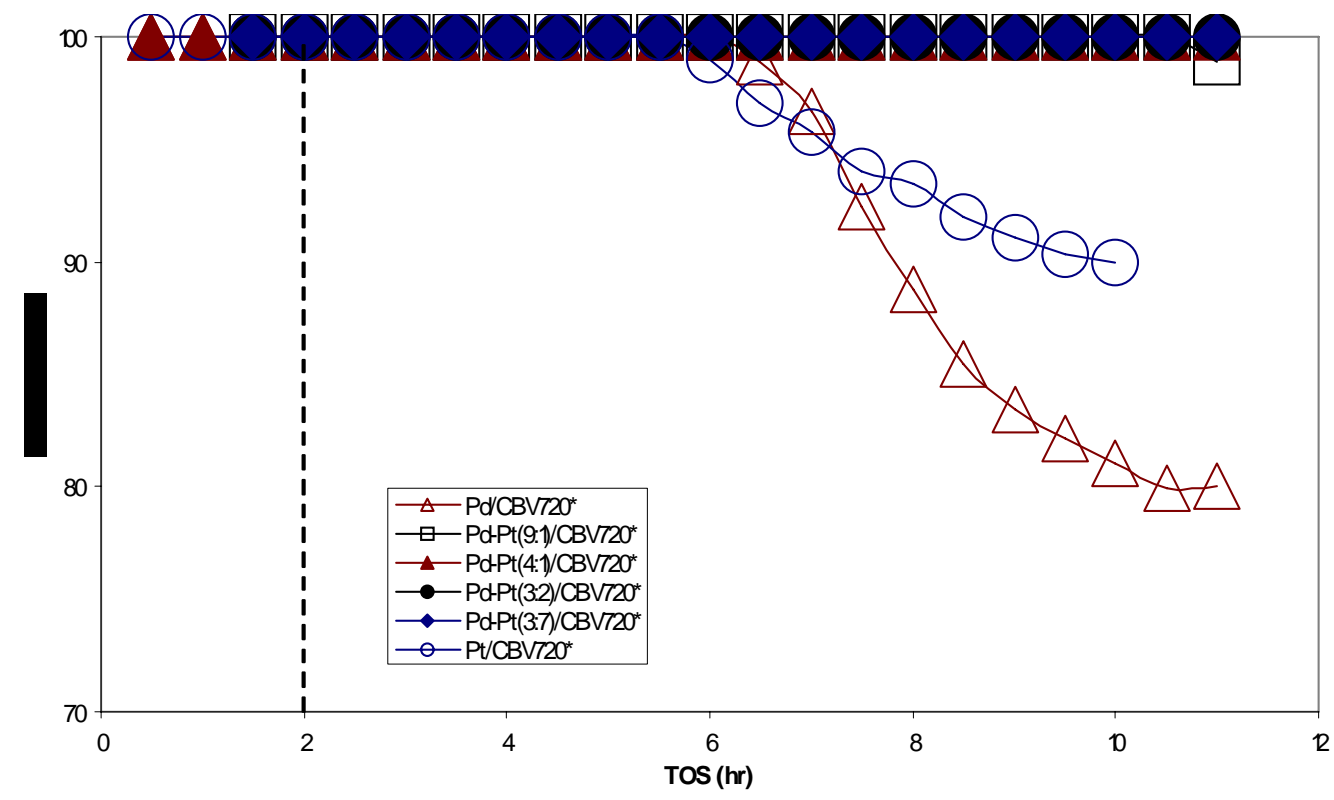

Figure 3-7. Conversion vs. TOS for the hydrogenation of tetralin over bimetallic catalysts at $225^{\circ} \mathrm{C}$ and 600 psig hydrogen pressure in the presence of $100 \mathrm{ppm}$ sulfur as BT. 


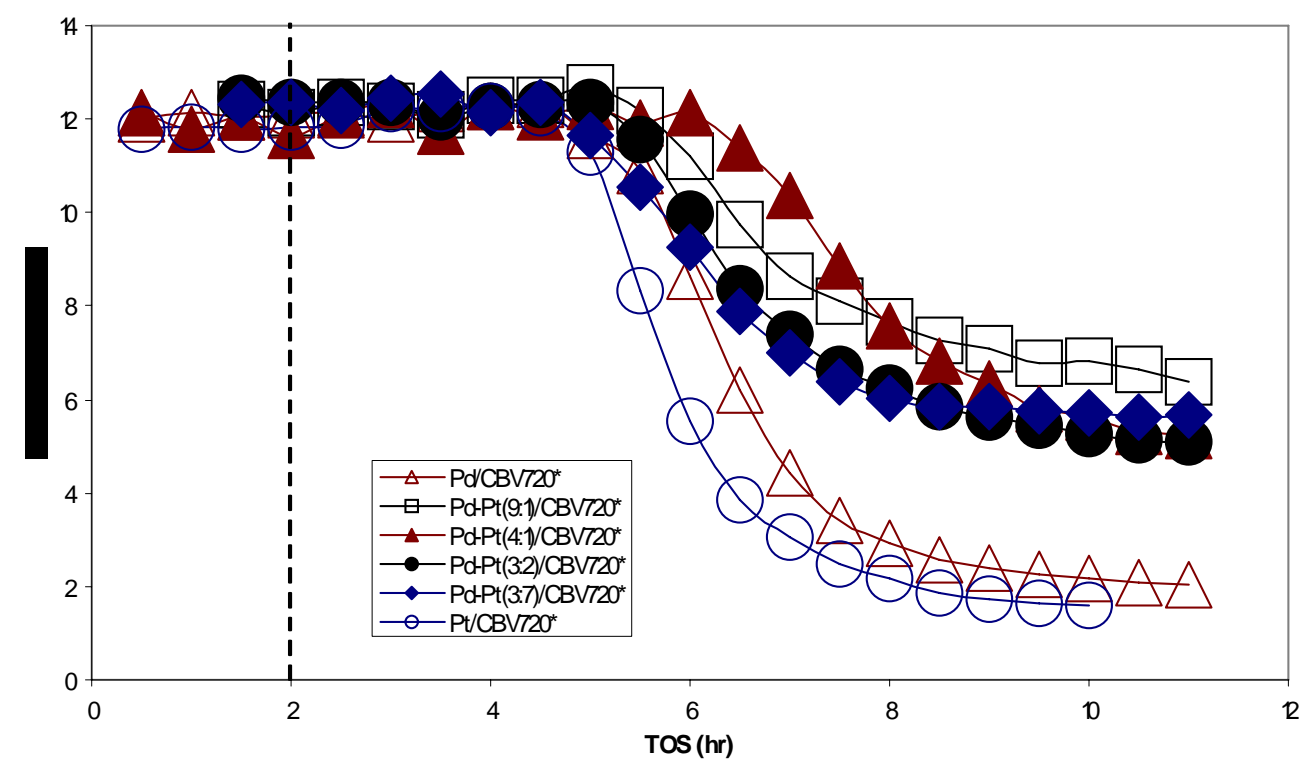

Figure 3-8. t-DHN/c-DHN ratio for the hydrogenation of tetralin over bimetallic catalysts at $225{ }^{\circ} \mathrm{C}$ and 600 psig hydrogen pressure in the presence of $100 \mathrm{ppm}$ sulfur as BT.

As shown in Figure 3-7, the Pd-Pt/CBV720* catalysts maintained 100\% tetralin conversion well after both $\mathrm{Pd} / \mathrm{CBV} 720 *$ and $\mathrm{Pt} / \mathrm{CBV} 720 *$ catalysts began to show deactivation due to sulfur poisoning. Additionally, for the bimetallic catalysts, the trans-/cis-decalin ratio resisted initial deactivation for a slightly longer period of time and was maintained at a higher level, as seen in Figure 3-8. This indicates that the bimetallic combinations provided an enhancement in sulfur tolerance, as compared with the monometallic catalysts. Little difference, however, can be observed amongst the series of bimetallic catalysts. Except for the $\operatorname{Pd}-\operatorname{Pt}(9: 1) / \mathrm{CBV} 720^{*}$, which began to show some deactivation at eleven hours time on stream (TOS), all the bimetallic combinations maintained $100 \%$ tetralin conversion for the duration of the experiment. The trans-/cis-decalin ratio data also does not provide much information to distinguish any of the bimetallic catalysts. It appears as though the $\mathrm{Pd}-\mathrm{Pt}(4: 1) / \mathrm{CBV} 720^{*}$ catalyst resisted decline in trans-/cis-decalin ratio for 0.5 hours TOS longer than $\operatorname{Pd}-\operatorname{Pt}(9: 1) / \mathrm{CBV} 720^{*}$ and one hour TOS 
longer than $\operatorname{Pd}-\operatorname{Pt}(3: 2) / C B V 720 *$ or $\operatorname{Pd}-\operatorname{Pt}(3: 7) / C B V 720 *$ So Pd-Pt(4:1) may be the most sulfur tolerant of the Pd-Pt combinations tested; however, further study with these bimetallic combination are recommended. It should be noted that other work on the hydrogenation of $\mathrm{LCO} / \mathrm{SRLGO}$ over Pd-Pt/ $\mathrm{SiO}_{2}-\mathrm{Al}_{2} \mathrm{O}_{3}$ and the hydrogenation of tetralin over Pd-Pt supported on ultra-stable $\mathrm{Y}$ zeolite $\left(\mathrm{USY}, \mathrm{SiO}_{2} / \mathrm{Al}_{2} \mathrm{O}_{3}=680\right.$ ) have concluded that the optimum mole ratio of Pd to Pt was 4:1. This work may confirm this result, however, as stated previously, further study is recommended.

The characterization of the Pd, Pt and Pd-Pt catalysts is presented in Table 3-9.

Table 3-9 Characterization of Pd, Pt and Pd-Pt catalysts supported on CBV720*.

\begin{tabular}{|c|c|c|c|}
\hline Catalyst & BET Surface Area $\left(\mathrm{m}^{2} / \mathrm{g}\right)$ & Dispersion (CO) & Dispersion $\left(\mathrm{H}_{2}\right)$ \\
\hline $\mathrm{Pd} / \mathrm{CBV} 720^{*}$ & 590 & $31 \%$ & $42 \%$ \\
\hline Pd-Pt(9:1)/CBV720* & 625 & n.d. & $51 \%$ \\
\hline Pd-Pt(4:1)/CBV720* & 623 & $42 \%$ & $52 \%$ \\
\hline $\operatorname{Pd}-\operatorname{Pt}(3: 2) / C B V 720 *$ & 583 & n.d. & $56 \%$ \\
\hline $\operatorname{Pd}-\operatorname{Pt}(3: 7) / C B V 720 *$ & 669 & n.d. & $36 \%$ \\
\hline Pt/CBV720* & 618 & $60 \%$ & $63 \%$ \\
\hline
\end{tabular}

The dispersion of the Pt/CBV720* catalyst is exceptionally high, which may explain why it performed slightly better than $\mathrm{Pd} / \mathrm{CBV} 720^{*}$. However, dispersion alone cannot be responsible for increased sulfur tolerance, as the bimetallic Pd-Pt catalysts outperformed the Pt catalyst, despite having lower dispersions.

The XPS spectra for the three spent catalyst samples are shown in Figure 3-9 through Figure 3-12. Binding energies from XPS analysis are shown in Table 3-10. The increase in the 
binding energy for both the $\mathrm{Pd} 3 \mathrm{~d}_{5 / 2}$ and $\mathrm{Pt} 4 \mathrm{f}_{7 / 2}$ in the bimetallic catalyst indicates a greater metal-support interaction compared with the individual monometallic catalysts. This is likely a contributing factor to the enhancement in sulfur tolerance observed with the bimetallic catalyst.

Table 3-10 Binding Energies from XPS analysis for Pd, Pt and Pd-Pt catalysts.

\begin{tabular}{|l|c|c|}
\hline \multicolumn{1}{|c|}{ Spent Catalyst Sample } & Pd 3d $_{\mathbf{5} / 2}$ Binding Energy (eV) & Pt $\mathbf{4 f}_{\mathbf{7} / 2}$ Binding Energy (eV) \\
\hline Pd/CBV720* & 336.4 & - \\
\hline Pt/CBV720* & - & 72.2 \\
\hline Pd-Pt(4:1)/CBV720* & 336.7 & 72.3 \\
\hline
\end{tabular}

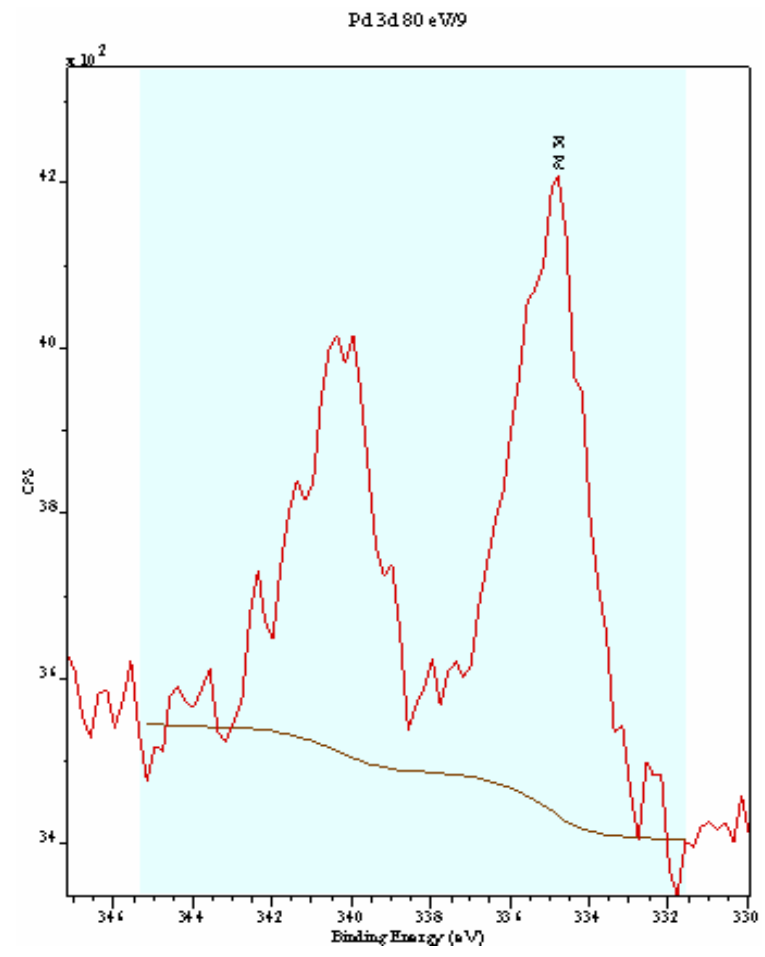

Figure 3-9. XPS Spectra of $\mathrm{Pd} 3 \mathrm{~d}_{5 / 2}$ for Pd/CBV720*. 


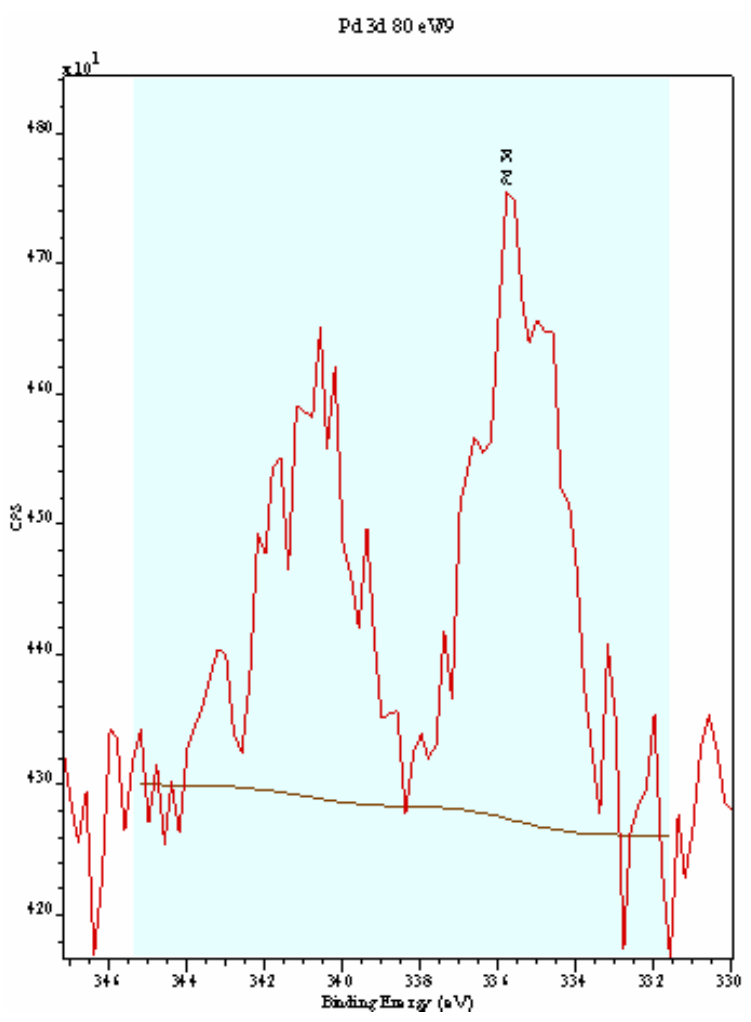

Figure 3-10. XPS Spectra of $\operatorname{Pd} 3 d_{5 / 2}$ for $\operatorname{Pd}-\operatorname{Pt}(4: 1) / C B V 720^{*}$.

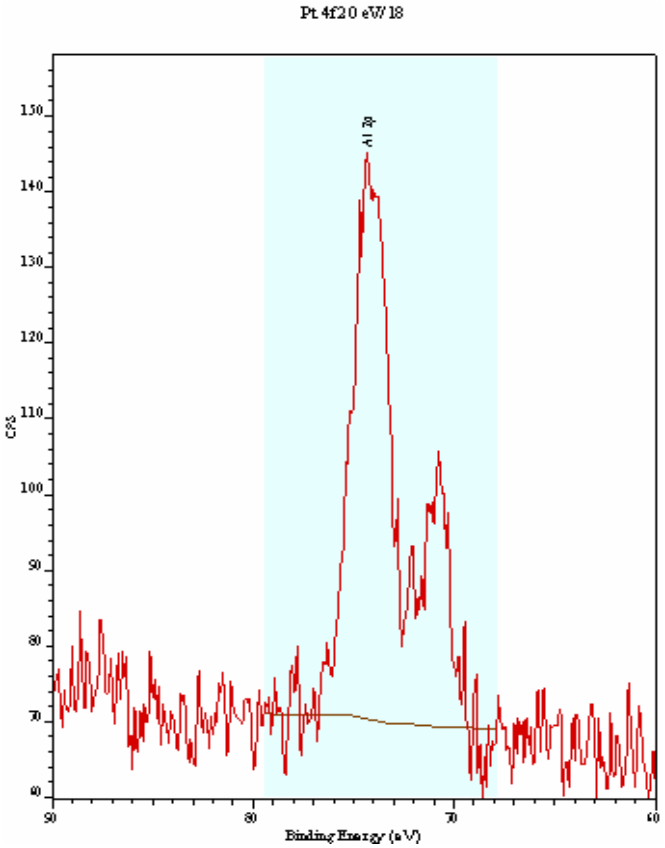

Figure 3-11 XPS Spectra of $\mathrm{Pt} 4 \mathrm{f}_{7 / 2}$ for Pt/CBV720*. 


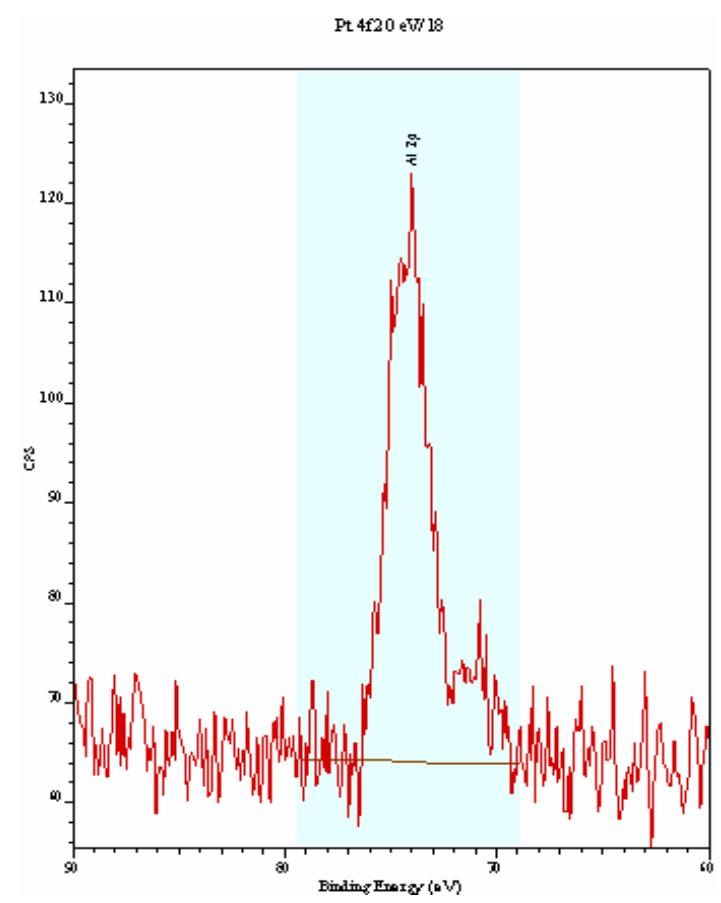

Figure 3-12. XPS Spectra of Pt $4 \mathrm{f}_{7 / 2}$ for Pd-Pt(4:1)/CBV720*.

\subsubsection{Summary}

The Pd-Pt bimetallic catalysts are more active and sulfur-resistant than the $\mathrm{Pd}$ monometallic catalysts. The increase in the binding energy for both the $\mathrm{Pd} 3 \mathrm{~d}_{5 / 2}$ and $\mathrm{Pt} 4 \mathrm{f}_{7 / 2}$ in the bimetallic catalyst indicates a greater metal-support interaction compared with the individual monometallic catalysts. This is likely a contributing factor to the enhancement in sulfur tolerance observed with the bimetallic catalyst.

\section{Subtask 3.3. Value-Added Chemicals from Naphthalene}

\subsubsection{Background}

In previous report, the methylation of 2-methylnaphthalene (2-MN) with methanol by using zeolitic catalysts was investigated [3-15]. Iron modified ZSM-5 zeolite (Fe-MFI molecular 
sieve) catalyst showed a high 2-MN conversion, 2,6-dimethylnaphthalene (2,6-DMN) yield and 2,6-DMN/2,7-DMN selectivity. Fe-MFI catalysts have been characterized by elemental analysis, XRD, TEM, and DMN adsorption experiment. The effect of sulfur compounds in the 2-MN feed stock on the performance of catalyst was examined.

In this report period, The main objective of this study is to conduct acidity studies to determine the relation between the acid property and the catalyst performance ( activity and selectivity).

\subsubsection{Experimental Description}

\subsubsection{Catalyst}

HZSM-5 (Supplied by Zeolyst International) with $\mathrm{SiO}_{2} / \mathrm{Al}_{2} \mathrm{O}_{3}$ ratio of 50 (CBV5524G) was used as the catalyst. For methylation of 2-MN, iron-modified ZSM-5 samples were tested as catalysts. Iron-modified ZSM-5 catalysts were prepared by modifying the HZSM-5 with iron fluoride $\left(\mathrm{FeF}_{3} \cdot 3 \mathrm{H}_{2} \mathrm{O}\right)$ and ammonium hydrogen fluoride $\left(\mathrm{NH}_{4} \mathrm{HF}_{2}\right)$ at elevated temperature.

\subsubsection{Catalyst Evaluation}

Catalytic testing was carried out in a down-flow fixed bed reactor system. In a typical run, 0.3 gram catalyst (10-18 mesh) loaded in reactor tube (Pyrex, I.D.: $1 / 2$ inch) was placed in the furnace center. The catalyst was activated at $450{ }^{\circ} \mathrm{C}$ for $1 \mathrm{~h}$ under the inert $\mathrm{N}_{2}$ gas flow (20 $\mathrm{ml} / \mathrm{min})$. Then the temperature was cooled down to the reaction temperature $\left(300{ }^{\circ} \mathrm{C}\right)$. Reactant dissolved in mesitylene solvent (2-MN:methanol:mesitylene $=1: 5: 5 \mathrm{~mol}$ ratio was fed into reactor through a HPLC pump at the flow rate of $1.98 \mathrm{ml} / \mathrm{min}$ together with $20 \mathrm{ml} / \mathrm{min}$ carrier $\mathrm{N}_{2}$ gas flow. The reaction product was collected at 1 hour intervals. Both the reactants and products 
were analyzed by HP 5890 gas chromatography (GC) with a $\beta$-Dex 120 capillary column (60m, $0.25 \mathrm{~mm}$ I.D. column with 0.25 micrometer coating film thickness). The Fe/Al ratio of the catalysts given in Table 3-11.

Table 3-11 Fe/Al Ratios in FE ZSM5 Catalysts

\begin{tabular}{|l|l|}
\hline Catalyst & Fe/Al ratio \\
\hline Fe ZSM 5 1 & $1 / 8$ \\
\hline Fe ZSM 5 2 & $1 / 4$ \\
\hline Fe ZSM 5 3 & $1 / 2$ \\
\hline Fe ZSM 5 4 & $3 / 4$ \\
\hline
\end{tabular}

\subsubsection{Results and Discussions}

\subsubsection{Characterization of Fe-ZSM 5 catalysts}

HZSM-5 and iron modified HZSM-5 catalysts, which were tested and characterized by $\mathrm{NH}_{3}$-TPD (temperature-programmed desorption) and their weak acid sites and strong acid sites were compared. The instrument used was a Micromeritics Auto Chem 2910 automated catalyst characterization system. The sample was pretreated at $450^{\circ} \mathrm{C}$ for 1 hour. The carrier gas used was Helium. The desorption temperature range was from 100 to $700^{\circ} \mathrm{C}$. Rate of heating was $10^{\circ} \mathrm{C} / \mathrm{min}$. The $\mathrm{NH}_{3}-\mathrm{TPD}$ profiles are shown in Figure 3-13. 


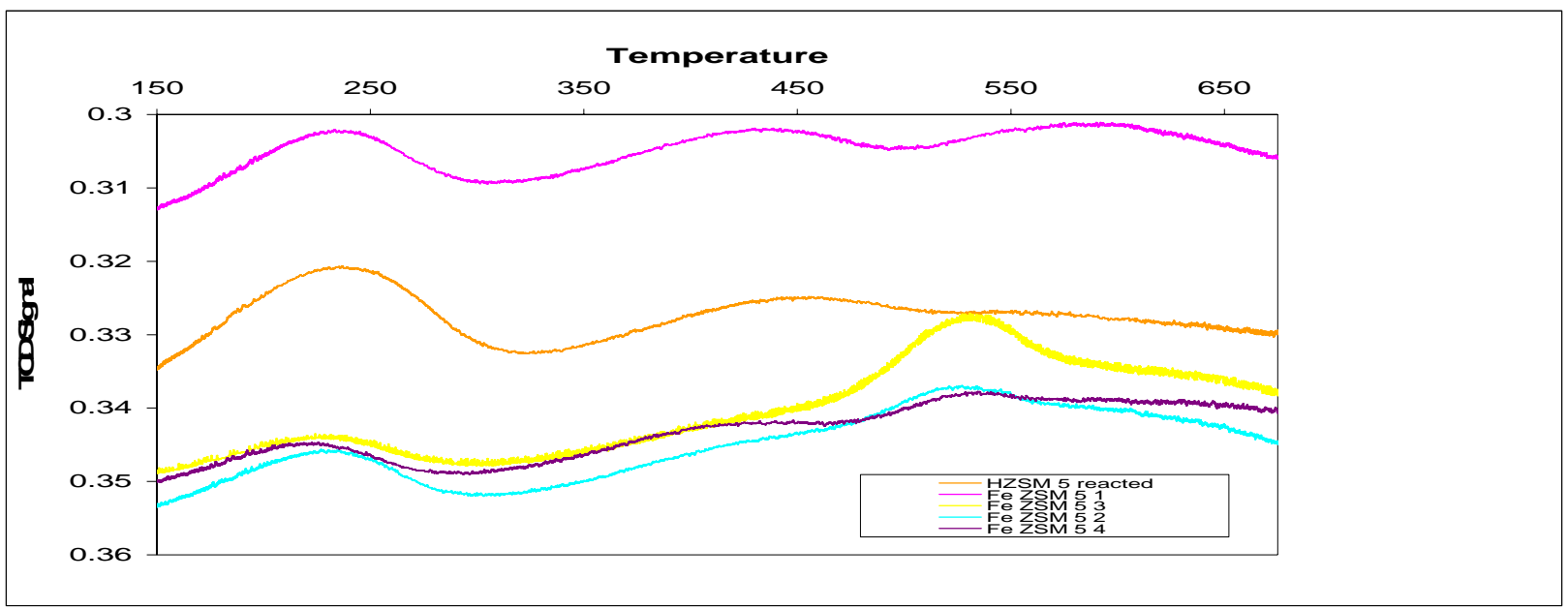

Figure 3-13. $\mathrm{NH}_{3}-$ TPD profiles of HZSM 5 and Iron modified ZSM 5 after reaction at 300 deg C Reaction conditions: temperature: $300{ }^{\circ} \mathrm{C}$; Feed (2-MN:methanol: mesitylene=1:5:5 mol ratio): $1.98 \mathrm{ml} / \mathrm{hr}$; Catalyst: $0.3 \mathrm{gram}$; Gas flow: $20 \mathrm{ml} / \mathrm{min}$

The above graph shows the ammonia TPD profile of Iron modified ZSM 5 and HZSM 5 analyzed after the methylation experiment was carried out at $300^{\circ} \mathrm{C}$. All the profiles have two ammonia desorption peaks. The peaks around the 200 to $250{ }^{\circ} \mathrm{C}$ correspond to the weak acid sites and those at a higher temperature, $\sim 450{ }^{\circ} \mathrm{C}$, correspond to the strong acid sites. Some of the profiles may have an additional peak around the temperature $550{ }^{\circ} \mathrm{C}$. Analysis of the peak by the mass spectroscopy determined it to be water, as shown in Figure 3-14. The sample Fe ZSM 5 1, Fe ZSM 5 2, Fe ZSM 54 and HZSM 5 have more weak acid sites than the strong acid sites and the Fe ZSM 53 has more strong acid sites. Most of the catalytic activity may be attributed to the presence of weak acid sites. 


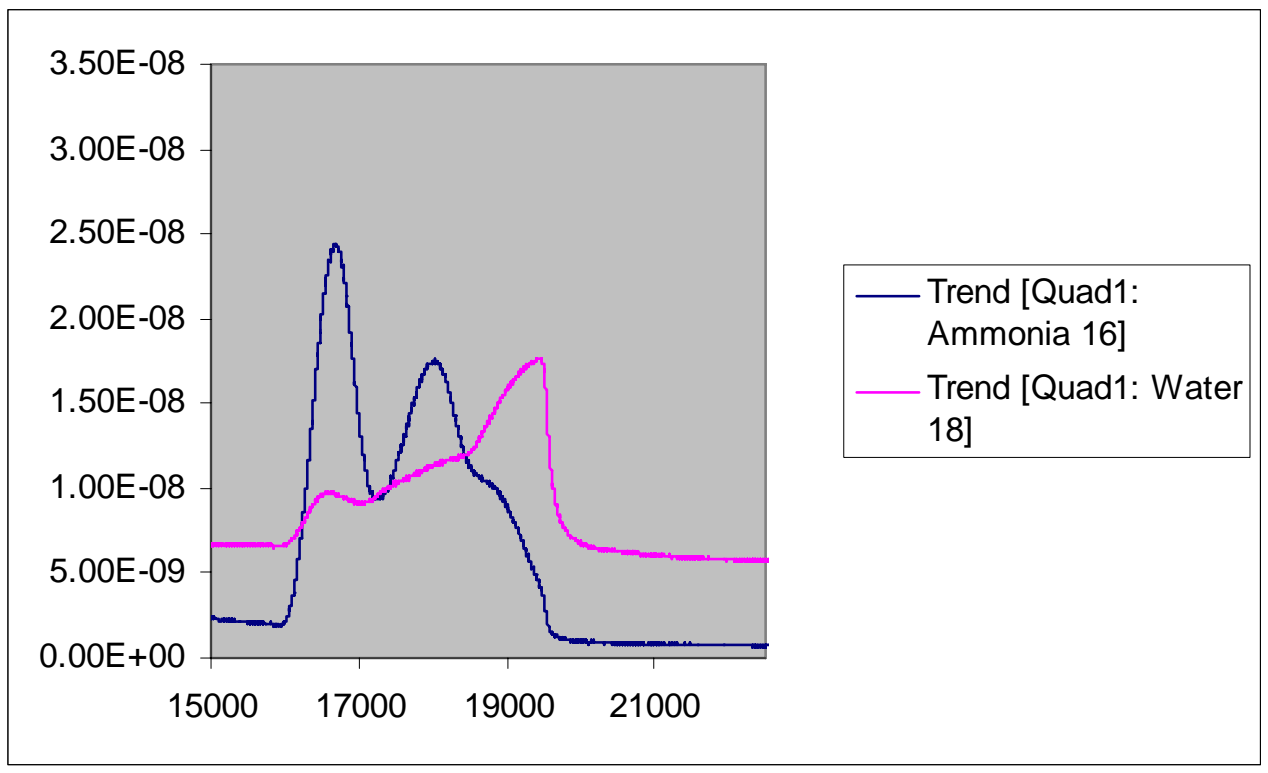

Figure 3-14. The Mass spectroscopy data indicating the peak for water after the $\mathrm{NH}_{3}$ desorption strong acid and weak acid sites

\subsubsection{Catalytic Conversion and Selectivity}

The catalytic conversion profiles are compared in the Figure 3-15.

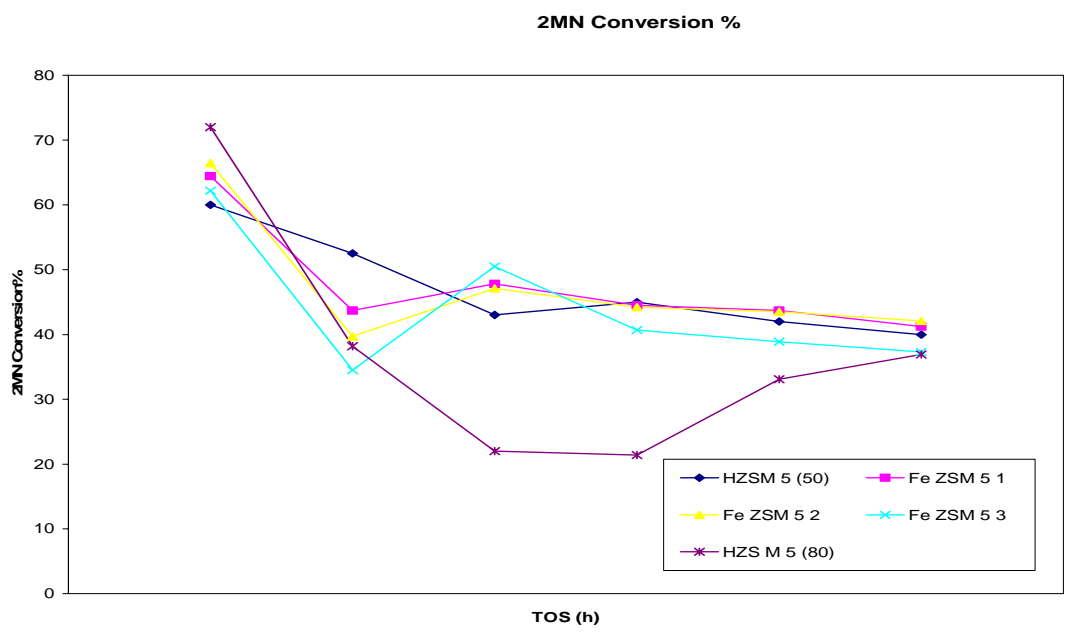

Figure 3-15. Comparison of the Conversion of 2-MN over Fe ZSM 5 catalysts.Reaction conditions: temperature: $300{ }^{\circ} \mathrm{C}$; Feed (2-MN:methanol: mesitylene=1:5:5 mol ratio): $1.98 \mathrm{ml} / \mathrm{hr}$; Catalyst: $0.3 \mathrm{gram}$; Gas flow: $20 \mathrm{ml} / \mathrm{min}$ 
We can observe that the highest conversion was obtained for the Fe ZSM $52(\mathrm{Fe} / \mathrm{Al}=1 / 4)$ and the conversion of all the iron modified samples was higher than that of the HZSM 5 $\left(\mathrm{SiO}_{2} / \mathrm{Al}_{2} \mathrm{O}_{3}=50\right)$ which shows that the conversion increases as the acidity decreases.

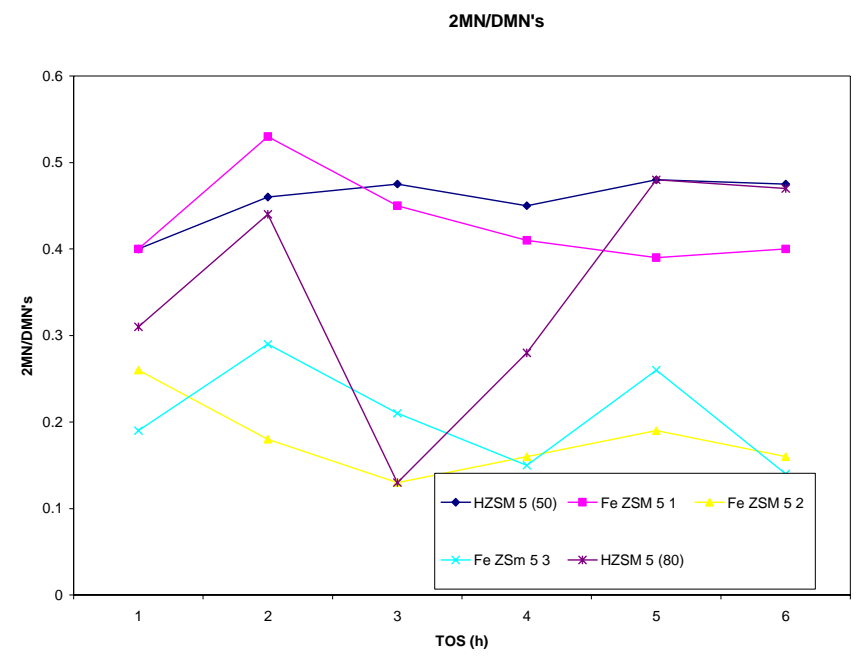

Figure 3-16. Comparison of the selectivity of 2,6DMN over Fe ZSM 5 catalysts.Reaction conditions: temperature: $300{ }^{\circ} \mathrm{C}$; Feed (2-MN:methanol: mesitylene $\left.=1: 5: 5 \mathrm{~mol} \mathrm{ratio}\right): 1.98 \mathrm{ml} / \mathrm{hr}$; Catalyst: $0.3 \mathrm{gram}$; Gas flow: $20 \mathrm{ml} / \mathrm{min}$

From Figure 3-16, we can observe that the selectivity of 2,6 DMN with other DMN isomers decreased with decrease in acidity. As the concentration of $\mathrm{Fe} / \mathrm{Al}$ ratio increased, the selectivity decreased. 


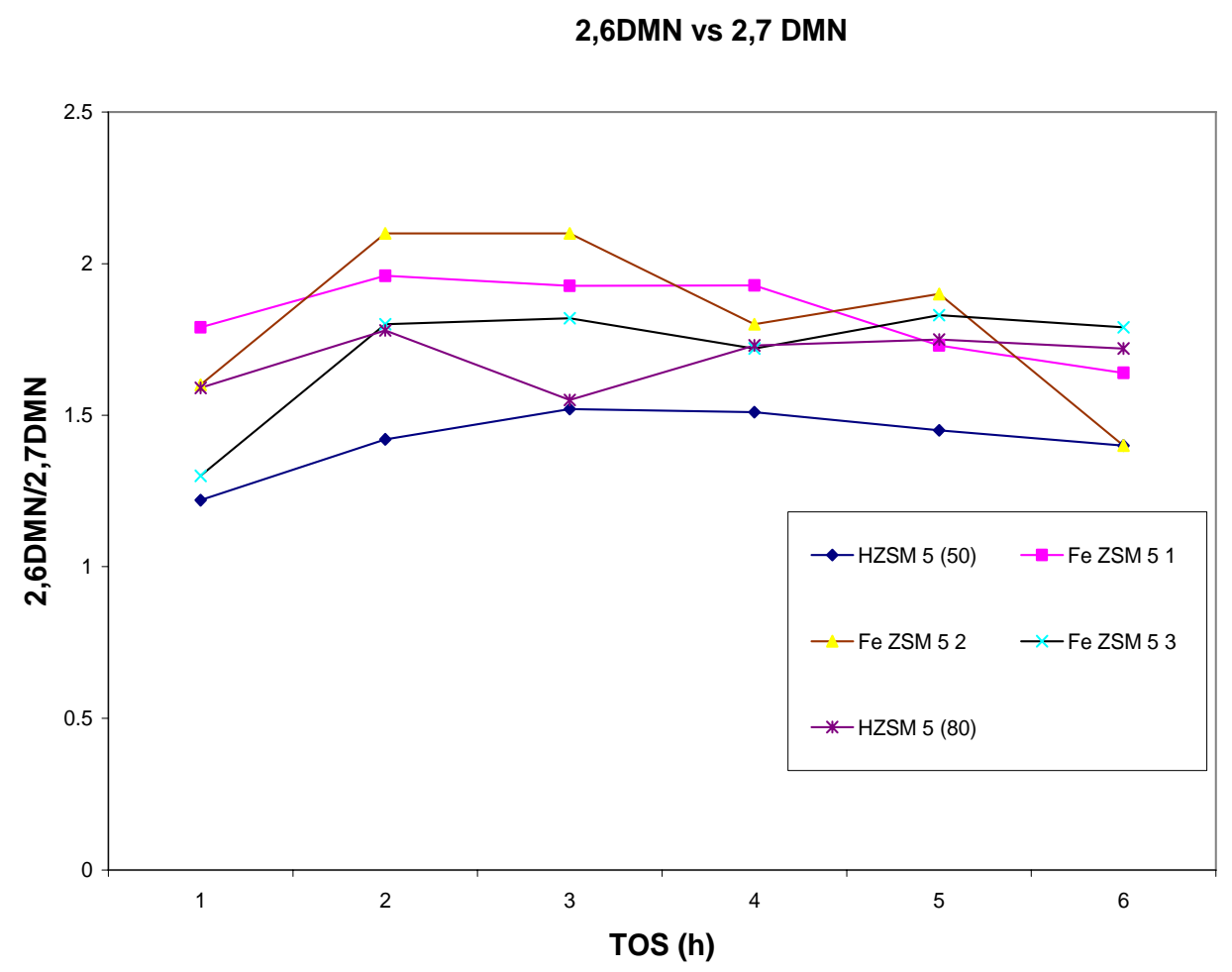

Figure 3-17. Comparison of the selectivity of 2,6DMN/2,7 DMN over Fe ZSM 5 catalysts.Reaction conditions: temperature: $300{ }^{\circ} \mathrm{C}$; Feed (2-MN:methanol: mesitylene $=1: 5: 5 \mathrm{~mol}$ ratio): $1.98 \mathrm{ml} / \mathrm{hr}$; Catalyst: $0.3 \mathrm{gram}$; Gas flow: $20 \mathrm{ml} / \mathrm{min}$

From Figure 3-17, we can infer that the 2,6/2,7 selectivity was the highest in the Fe ZSM $52(\mathrm{Fe} / \mathrm{Al}=1 / 4)$ followed by Fe ZSM $51(\mathrm{Fe} / \mathrm{Al}=1 / 8)$ and then by the Fe ZSM 5 3( $\mathrm{Fe} / \mathrm{Al}=1 / 2)$. The decrease in selectivity in Fe ZSM 53 may be due to the decrease in weak acid sites as shown in the TPD profile. All the iron modified ZSM 5 samples showed a higher ratio of 2,6/2,7 DMN when compared to that of $\mathrm{HZSM} 5\left(\mathrm{SiO}_{2} / \mathrm{Al}_{2} \mathrm{O}_{3}=50\right)$.

\subsubsection{Summary}

The conversion and selectivity are higher for iron-modified ZSM 5 when compared to the ZSM $5\left(\mathrm{SiO}_{2} / \mathrm{Al}_{2} \mathrm{O}_{3}=50\right)$. This means that the conversion and selectivity increase with the decrease in acidity. 
From the $\mathrm{NH}_{3}$ TPD profile, we can infer that most of the catalyst activity is due to the presence of weak acid sites.

\subsubsection{Future work}

Future work will focus on the development of high-quality catalyst and clarifying the relationship among acid property (strength, site, etc), transition metal species, pore structure and catalyst performance (activity and selectivity). The catalysts will be characterized by acidity measurement, XRD, XPS and FT-IR. 
Task 4. Evaluation of Coal-Based Fuel Oil Products (B. Miller, S. Miller)

The objective of the Task 4 activities is to evaluate the effect of introducing coal into an existing petroleum refinery on the fuel oil product. To accomplish this, the combustion performance and trace element emissions of a fuel oil produced during co-processing will be measured in Penn State's watertube research boiler. The combustion performance and trace element emissions for the fuel oil produced by further refining of the light cycle oil-refined chemical oil blend with that from a commercial/petroleum-based No. 6 fuel oil will be compared. The testing will be performed to determine if differences in the combustion behavior or emissions of the two fuel oils would result from variations in the API gravity, viscosity, or changes in composition including trace elements present in either fuel oil. No testing was performed during this reporting period as the project team is awaiting a test sample from the next PARC fuel production campaign. Near the end of March, Penn State did receive two drums of bottoms material from a previous Penn State/PARC campaign (i.e., 2002, Jet Fuels Program) where RCO (from Koppers) and LCO (from United Refining) were blended in a 1:1 ratio, hydrotreated, and fractionated. The $518^{\circ} \mathrm{F}$ plus bottoms fraction was sent and will be tested during the next reporting period.

The following describes the analyses and combustion testing to be performed on the fuel oil for the new batch of fuels. In the last report, work was described detailing the results of boiler testing of a fuel oil. [4-10] 


\section{Subtask 4.1 Fuel Analysis}

In this subtask, a fuel oil by-product produced during the preparation of a coal-based jet fuel will undergo a series of analyses. The analyses will be performed to: 1) ensure that the samples meet standardized fuel oil specifications; 2) determine the quantity of trace elements in the fuel oil; and 3) classify the fuel oil per established specifications. Testing will include evaluation of API gravity, viscosity, elemental composition, and heating value of the fuel. Results from the fuel oils will be compared to No. 6 fuel oil (Bunker C oil).

A drum of fuel oil was received from PARC in March, which will be analyzed during the next reporting period prior to the combustion and emissions testing. During Year 1 of the project, it became apparent that it was necessary to develop an analytical protocol when determining the inorganic analysis of oils since there is limited information available and there are few commercial laboratories that can satisfactorily analyze fuel oils for major, minor, and trace elements. Work on developing this protocol was performed during this reporting period. In addition, The Energy Institute recently purchased (separate from this project) a Leco mercury analyzer for solid fuels analysis and we are currently working with the manufacturer to modify this instrument or its analytical procedure for liquid fuel analysis as well.

\subsubsection{Mercury in Fuel Oil}

The distribution of mercury species in oil varies depending upon the sample source and history. These classes of compounds are not routinely analyzed when characterizing liquid hydrocarbons. What is important is that these mercury species have detrimental effects on people, equipment and catalysts. Mercury is detrimental to petroleum processing systems. In chemical manufacturing and refining, mercury poisons catalysts and can become a component of 
waste water which can impact regulatory compliance. Maintenance workers in the petroleum industry can be at risk due to the inhalation of mercury vapor and absorption of organic mercury compounds via the skin.

Crude oil and unprocessed gas condensates can contain significant amounts of mercuric sulfide. Organic mercury compounds are also found in raw produced liquids. Ionic mercury compounds are present in liquids but it is not known if they occur naturally or are produced as a byproduct due to post-collection conversion of other mercury species [4-1]. In addition, the partitioning of mercury into different products is a function of how it is processed.

The US EPA announced in December 2000 that emissions of hazardous air pollutants (HAPS), including mercury, from oil- and coal-fired power plants is necessary and appropriate. However, there were significant discrepancies in the precision and reproducibility of mercury analysis of liquid hydrocarbons.

Prior to 1995, emissions of mercury from oil-fired utility boilers were estimated based on emission factors. The emission factors were based on analytical data that was not entirely reliable. The following emission factors were used in the Mercury Study Report to Congress [4-

\section{2]:}

Residual Oil (No. 6): $2.9 \mathrm{~kg} / 10^{15} \mathrm{~J}$

Distillate Oil (No. 2): $3.0 \mathrm{~kg} / 10^{15} \mathrm{~J}$

However, the emission factors used in the Locating and Estimating Air Emissions Document are as follows [4-3]:

Residual Oil (no. 6): $2.7 \mathrm{~kg} / 10^{15} \mathrm{~J}$

Distillate Oil (No. 2): $30.02 \mathrm{~kg} / 10^{15} \mathrm{~J}$ 
It is evident that the estimates of air releases based on these emission factors would be inconsistent. Air releases from utility, non-utility, and residential combustion of oil vary as follows:

Utility: $\quad 0.2$ tons/yr

Non-utility: $\quad 5.0-7.7$ tons/yr

Residential: $\quad 2.8-3.2$ tons/yr

Studies conducted on the content of mercury in fuel oils since 1995 include: (1) Bloom [4-4] measured mercury concentrations in 32 samples of utility fuel oil and measured an average concentration of $0.67 \mathrm{ppb}$ and $1.32 \mathrm{ppb}$ in lighter distillates (gasoline, diesel). (2) Liang, Hovat, and Danilchik [4-5] measured 0.59 ppb mercury in one heating oil sample. (3) Rising, Sorurbakhsh and Wu [4-6] measured fuel oil from 13 sites and found mercury below detection limits $(<0.2 \mathrm{ppb})$. They also measured levels of other metals and found arsenic, cadmium, and selenium to be below detection limits. The detection limits for As, $\mathrm{Cd}$ and Se are 0.9, 0.1 and 6 ppb, respectively. The average concentration of chromium, lead, manganese and nickel was 242 , $16,5.5$ and $29 \mathrm{ppb}$, respectively.

According to Wilhelm [4-7], actual measurements of mercury discharged from utilities are 25 times less than non-utility discharges that were calculated based on mercury concentration measured in oil prior to 1995. Wilhelm [4-8] attributed this discrepancy to the fact that mercury levels in crude oil measured during the 1970's and 1980's were biased high due to analytical methods used at that time. The mean concentration of mercury in crude oil that was calculated in 2001 (based on studies published between 1995 and 2001) was estimated to be less than $5 \mathrm{ppb}$. Recent data for average mercury content in crude oil $(<5 \mathrm{ppb})$ and fuel oil (approx. $1 \mathrm{ppb})$ are in general agreement with one another. 
The US EPA, American Petroleum Institute (API) and National Petrochemical and Refiners Association (NPRA) recognize that discrepancies in the mean concentration and range of concentrations of total mercury measured in oils compromise the development of reliable mercury emission factors. To address this issue several projects are addressing the problem of analyzing total mercury in liquid hydrocarbons with statistical accuracy [4-7,4-8]. These newly developed methods of sampling and analyzing mercury in liquid hydrocarbons are capable of measuring mercury concentrations with good accuracy and precision.

At the end of the 1990's , 6.6 tons mercury/yr was being emitted by stationary oil combustion and 48 tons/yr was being emitted by stationary coal combustion. The greater emission rate of coal-fired plants is attributed to the higher levels of mercury in coals. The mercury content of coals can average from 0.07 to $0.12 \mathrm{ppm}$ depending upon the rank (lignite to bituminous coal). Most coals contain approximately $0.1 \mathrm{ppm}$ mercury (ten times as much mercury as in oil) whereas crude oil averages about $10 \mathrm{ppb}$. In February, 2002, the Bush Administration announced its Clear Skies Initiative for multipollutant controls. The proposal would require significant emission reductions of sulfur dioxide, nitrogen oxides, and mercury through an allowance-based cap-and-trade program. Specifically for mercury, the Clear Skies Initiative calls for a two-phase reduction in emissions below 1999 levels (48 tons) with an approximate 45 percent reduction beginning in 2010 and a 70 percent reduction beginning in 2018.

The mercury emitted from oil combustion represents about $10 \%$ of the US yearly emission rate of atmospheric mercury from coal and oil combustion combined. However, this could change with the integration of coal into the processing/production of liquid hydrocarbon fuels. The emissions from fuel oils derived from petroleum and coal will exhibit mercury 
concentrations that reflect the concentration of mercury in the parent crude oil as well as any mercury or other trace elements that are extracted from the coal during processing. Therefore it is essential that there be an accurate way to measure the levels of trace elements in these fuels to determine if the pose any environmental threat thereby compromising the fuel.

Efforts were made to evaluate how to best measure mercury in liquid hydrocarbons so that material balances could be conducted on the emissions measured during combustion testing. Efforts were initially made to address the measurement of mercury in a No. 6 fuel oil (as reported in last year's final report). The following discussion relates our efforts to address the problem of on-site mercury analysis in liquid hydrocarbons.

\subsubsection{Evaluation of LECO Mercury Analyzer for Liquid Hydrocarbons}

A model AMA254 mercury analyzer was purchased from the LECO Corporation. The primary reason for purchasing this instrument was to provide The Energy Institute with the capabilities of measuring the mercury content of test samples without relying on commercial labs. While the use of a commercial lab would present certain advantages, this instrument could provide an accurate and repeatable method for analyzing samples on short-term basis. Unlike ASTM Method D5184, the LECO AMA254 mercury analyzer is designed to determine total mercury content in various solids and certain liquids without sample pretreatment or sample preconcentration. The instrument is designed with a front-end combustion tube that is ideal for the decomposition of high carbon samples such as coal or petroleum coke. During this first stage of analysis, the samples are heated inside the front half of a combustion tube to approximately $750^{\circ} \mathrm{C}$ within a stream of pure oxygen. Following thermal decomposition, the gaseous products are carried through catalytic compounds pre-packed within the second half of the combustion 
tube. These compounds serve to remove all interfering impurities (i.e. ash, moisture, and halogens). The cleaned gases are then transported to the amalgamator, a small glass tube containing gold-plated ceramics, which collects the mercury vapor. The amalgamator is then heated to approximately $900^{\circ} \mathrm{C}$, releasing all the mercury vapor into the path of a standard Atomic Absorption Spectrometer. The Spectrometer uses an element-specific mercury lamp that emits light at a wavelength of $253.7 \mathrm{~nm}$ and a silicon UV diode detector for mercury quantitation [4-9]. Using this approach, the AMA254 has received ASTM Method Approval D-6722.

The instrument's performance was initially evaluated using NIST Standard Reference Material (SRM) 2685b (Sulfur and Mercury in Coal), SRM1633b (Constituent Elements in Coal Fly Ash), and additional standards produced in-house by diluting a 1000 parts per million (ppm) Inductively Coupled Plasma (ICP) certified standards of mercuric chloride. Following calibration, repeated analyses of these standards showed the instrument's performance was within the specified precision of 2.5 parts per billion (ppb) mercury. Several attempts were made to measure the mercury content in this instrument of the baseline fuel oil burned during the first year of this project. However, incomplete combustion of the heavy oil within the combustion tube produced carbon, which subsequently adsorbed the mercury prior to the amalgamator. We are presently working with the instrument's manufacturer to resolve this problem. Future efforts may include the following changes:

- addition of a combustion aid or accelerant to the sample to promote complete combustion;

- changing the instruments method of analyses (gas flow rate, temperatures, time intervals); and if necessary 
- spiking of the sample to increase the mercury level above the instruments detection limits.

Using the mercury analyzer, an effort is also being made to track the distribution of mercury in the gas, solid and liquid by-products formed during the co-coking process being considered as a possible method for stable jet fuel production. An initial coke sample produced during the co-coking of Powellton Eagle coal and decant oil was analyzed for mercury. An average value of $13.503 \mathrm{ppb}$ was measured for this by-product. Additional analysis of the coal feed stock will also be performed along with the liquid streams after the analytical limitations have been resolved.

\subsubsection{Other Techniques for Analysis of Trace Metals in Liquid Hydrocarbons}

Other methodologies for analyzing the mercury (and other trace elements) were investigated given that the LECO Mercury Analyzer has posed some problems. As a result of reviewing the literature and speaking to several commercial laboratories we will be examining the following analytical techniques during the next reporting period: instrumental neutron activation analysis (INAA), extraction/trap, isotope dilution and other types of combustion/trap techniques. A total mercury determination in crude oil by microwave digestion and cold vapor atomic absorption spectrometry (CVAAS) will also be investigated. This method was reviewed during the current reporting period and can be accomplished with in-house analytical equipment.

\section{Subtask 4.2 Fuel Atomization}

In the subtask, the fuel oil is to undergo atomization tests at the conditions (i.e., temperature and atomization pressures) it will be tested in the watertube boiler. However, due to 
the difficulty and cost of preparing large quantities of fuel oil, it is likely that atomization tests will not be performed in order to have sufficient quantities for the combustion and emissions testing.

\section{Subtask 4.3 Watertube Boiler Combustion Tests}

In this subtask, a combustion/emissions test will be performed firing the test fuel in Penn States watertube boiler. During the test, gaseous emissions $\left(\mathrm{CO}, \mathrm{SO}_{2}, \mathrm{NO}_{\mathrm{x}}, \mathrm{CO}_{2}\right.$, and $\left.\mathrm{O}_{2}\right)$ will be monitored using a continuous emissions monitoring system per EPA protocol, soot formation will be measured using EPA Method 5 stack sampling, trace elements and mercury (both total and speciated) emissions will be measured using a combined EPA Method 29/Ontario-Hydro sampling method, boiler efficiencies will be determined, and flame structure and intensity will be recorded using an in-furnace camera. 
Task 5. Pitch and Coke Material (G. Mitchell, C. Clifford, O. Gul, M. Escallon, Y. Suriyapraphadilok, J. Griffith)

Progress was made during the past five months in evaluating the quality of carbon products (coke and pitch materials) made in our laboratory-scale delayed coker using a blend of decant oil and a cleaned frother cell effluent sample of the Pittsburgh seam coal discussed in the Annual Report 2005 [5-1]. In particular, our efforts have been directed at generating coke and pitch products that may be suitable for anode-grade quality coke used by the aluminum industry. In addition, preliminary laboratory-scale work has been completed on the heat treatment of various hydrotreated decant oils coked alone and with coal. Basically, this work represents an extension of an investigation into the influence of hydrotreatment on the properties of liquid products and will explore what influence hydrotreatment might have on carbon product quality. The following is a summary of the research that has been completed during this performance period

\section{Subtask 5.1 Sample Procurement and Preparation}

Decant oil

A heavy petroleum stream (decant oil) from United Refining is being used for the cocoking experiments, which in addition to having no ash yield, has the gross chemical properties listing in Table 5-1. Results from vacuum distillation given in Table 5-2 show that about 27\% of the decant oil reports to the gasoline, jet fuel and diesel boiling point range which corresponds to about the same amount of alkane, alkene, and naphthalene compounds detected in distillates [5-2]. The remainder of the decant oil is composed of phenanthrenes through pyrenes and larger aromatic molecules. 
Table 5-1 Ultimate Analysis of Decant Oil [5-2]

$\begin{array}{cc}\text { Reading, dry basis } & \text { Decant Oil } \\ \text { Carbon } & 89.6 \\ \text { Hydrogen } & 7.3 \\ \text { Nitrogen } & 0.2 \\ \text { Sulfur } & 3.0 \\ \text { Oxygen } & -0.1 \\ \text { Ash yield } & -\end{array}$

Table 5-2 Product Distribution by Weight for Vacuum Distillation [5-2]

\begin{tabular}{ccccc}
\multicolumn{5}{c}{ Product Distribution by Weight from Vacuum Distillation } \\
Feed Material & IBP- $180^{\circ} \mathrm{C}$ & $180-270^{\circ} \mathrm{C}$ & $270-332^{\circ} \mathrm{C}$ & $332-\mathrm{FBP}^{\circ} \mathrm{C}$ \\
& gasoline & jet fuel & diesel & fuel oil \\
Decant Oil & 5.99 & 11.41 & 9.22 & 72.14
\end{tabular}

Coal

During this report period evaluation of the Pittsburgh seam froth flotation cell effluent (FCE) sample obtained from Mine No. 84/Eighty Four Mining owned and operated by CONSOL Energy Inc. in Washington Co., PA was completed and results are compared in Table 5-3 with the run-of-mine sample (DECS-34) collected at the beginning of this project. As can be seen, the final product for co-coking had a substantially reduced ash yield, whereas there were significant improvements in the thermoplasticity and petrographic composition. However, the ash mineral composition remained high in silica and iron which will have a negative influence on the quality of anode-grade coke. Unfortunately, the coal minerals most responsible for these high values, aluminosilicate clays and pyrite are intimately mixed on a micron-size scale with the vitrinite portion of the coal which has been concentrated by our cleaning techniques. It is likely that this is the absolute best that this particular Pittsburgh seam coal can be cleaned and still remain a viable raw material in terms of availability for co-coking. 
Table 5-3 Comparison of the Clean Coal Frother Cell Effluent with the Run-of-Mine Pittsburgh Seam Coal from Mine \#84

\begin{tabular}{|c|c|c|c|}
\hline $\begin{array}{l}\text { Analytical } \\
\text { Procedure }\end{array}$ & $\begin{array}{l}\text { Powellton/ } \\
\text { Eagle } \\
\text { El-106 }\end{array}$ & $\begin{array}{l}\text { Pittsburgh } \\
\text { Seam } \\
\text { DECS-34 }\end{array}$ & $\begin{array}{l}\text { 1.280 Float } \\
\text { FCE } \\
\text { El-186 }\end{array}$ \\
\hline \multicolumn{4}{|l|}{ Proximate Analysis: (dry) } \\
\hline Fixed Carbon, \% & 68.6 & 54.3 & 63.4 \\
\hline Volatile Matter, \% & 27.3 & 38.4 & 35.6 \\
\hline Ash, \% & 8.1 & 7.4 & 1.0 \\
\hline \multicolumn{4}{|l|}{ Ultimate Analysis: (dry) } \\
\hline Carbon, \% & 80.9 & 78.2 & 84.6 \\
\hline Hydrogen, \% & 4.6 & 5.2 & 5.3 \\
\hline Nitrogen, \% & 1.3 & 1.6 & 1.6 \\
\hline Sulfur, \% & nd & 1.6 & 1.1 \\
\hline Oxygen, \% (diff) & nd & 6.0 & 6.4 \\
\hline \multicolumn{4}{|l|}{ Gieseler Plastometer: } \\
\hline Softening Temperature, (C) & 397 & 381 & 385 \\
\hline Fluid Temperature Range (C) & 88 & 91 & 93 \\
\hline Maximum Fluidity (ddpm) & 7,002 & 16,418 & 29,527 \\
\hline Temperature at Maximum (C) & 446 & 435 & 436 \\
\hline \multicolumn{4}{|l|}{ Ash Mineral Composition: } \\
\hline Silicon Dioxide, \% & nd & 48.47 & 41.8 \\
\hline Aluminum Oxide, $\%$ & nd & 23.15 & 27.3 \\
\hline Ferric Oxide, \% & nd & 14.84 & 13.6 \\
\hline Titanium Oxide, $\%$ & nd & 1.00 & nd \\
\hline Phosphorus Pentoxide, \% & nd & 0.53 & 0.61 \\
\hline Calcium Oxide, $\%$ & nd & 2.49 & 5.65 \\
\hline Magnesium Oxide, \% & nd & 0.76 & 0.74 \\
\hline Sodium Oxide, $\%$ & nd & 0.69 & 0.72 \\
\hline Potassium Oxide, $\%$ & nd & 1.87 & 1.64 \\
\hline Sulfur Trioxide, $\%$ & nd & 1.95 & nd \\
\hline \multicolumn{4}{|l|}{ Organic Petrography: } \\
\hline Total Vitrinite, $\%$ & 86.5 & 82.8 & 96.2 \\
\hline Total Liptinite, $\%$ & 1.4 & 4.0 & 1.5 \\
\hline Total Inertinite, $\%$ & 12.1 & 13.2 & 2.3 \\
\hline
\end{tabular}

Two additional coals have been identified for evaluation in this study that have an appropriate rank, organic composition and thermoplastic properties that make them good prospects for co-coking and for the collection of a higher molecular weight pitch fraction compared with the particular Pittsburgh seam sample we have been investigating. Unfortunately, these coals and their associated cleaning plants are located in West 
Virginia and because of the recent mining tragedies in the State we thought it prudent to delay making sampling requests until mid-year. Furthermore, we were interested in completing our evaluation of the coke and pitch materials generated from the Pittsburgh co-coking runs to have some better understanding about the quality of our coal cleaning techniques.

\section{Subtask 5.2 Examination of Residual from Fractionation of the Deeply-Hydrogenated RCO/LCO as a Pitch Material}

Large quantities of higher boiling materials have been obtained as a result of the largescale production of different materials as described in previous Task 1 reports [5-1]. Because none of these heavy fractions have been made available for pitch preparation and we are still investigating how to make a suitable pitch of anode-grade quality (Task 5.5), the work has been delayed. However, small bench-scale testing continues into the effective use of variably hydrotreated decant oils to make carbon products in a three phase investigation.

1) The first phase of this investigation was designed to obtain and characterize the influence of hydrotreatment of the EI-107 decant oil to various levels of severity. Work was completed on the seven different feedstocks (original and hydrotreated derivatives of the decant oil) each having different chemical composition [5-3].

2) The second phase involves the heat-treatment of a decant oil and decant oil/ coal blends in a 4:1 ratio in tubing-bomb reactors. Past investigations [5-3, 5-4] at this scale were carried out at 2:1 decant oil and coal ratio. However, the decant oil to coal ratio was changed for the present work, due to the fact that in the scale-up to the pilot coker at The Energy Institute may be limited in coal loading into the coker. The fraction of coal cannot be higher than that limiting value, which is $20 \mathrm{wt} \%$. From the academic point of view, the reason to run 
experiments at $>20 \mathrm{wt} \%$ coal was to somehow duplicate experiments previously carried out at The Energy Institute; Fickinger [5-4] reported that when 33\% coal was added to the decant oil, the oils from the co-coking process contain coal components, which, after processing, were desirable in obtaining a thermally stable jet fuel.

3) In the third phase, the laboratory delayed coker will be employed to form much larger quantities of liquid and solid products for evalution.

The first phase has been finished and the results were submitted in a past report, whereas the second phase is coming to a close and constitutes the subject of the following report.

\section{Materials and Experimental}

Raw Materials

As described in a previous report [5-1], the United Refining decant oil (EI-107) was hydrotreated to six difference levels of severity by PARC Technical Services. Elemental analyses and average boiling point information from simulated distillation are compared in Table 5-4. Three of these decant oil products $(134,135$ and 138) along with the original were heat treated alone in the current study, whereas the original decant oil was used in co-coking experiments with the Powellton/Eagle raw froth flotation cell effluent product shown in Table 5-

3.

Table 5-4 Elemental Analysis and Simulated Boiling Point for Hydrogenated Decant Oils

\begin{tabular}{|c|c|c|c|c|c|c|c|}
\hline $\begin{array}{l}\text { Sample } \\
\text { Id. }\end{array}$ & $\begin{array}{l}\text { Carbon } \\
\text { (As Det.) }\end{array}$ & $\begin{array}{l}\text { Hydrogen } \\
\text { (As Det.) }\end{array}$ & $\begin{array}{l}\text { Nitrogen } \\
\text { (As Det.) }\end{array}$ & $\begin{array}{l}\text { Sulfur } \\
\text { (As Det.) }\end{array}$ & $\begin{array}{c}\text { Oxygen } \\
\text { (As Det.) }\end{array}$ & $\begin{array}{l}\mathbf{H} / \mathbf{C} \\
\text { Ratio }\end{array}$ & $\begin{array}{c}\text { Average } \\
\text { Boiling } \\
\text { Point, }{ }^{\circ} \mathrm{C}\end{array}$ \\
\hline EI 107 & $\begin{array}{c}89.59 \pm \\
0.27\end{array}$ & $\begin{array}{c}7.32 \pm \\
0.13\end{array}$ & $\begin{array}{c}0.22 \pm \\
0.08\end{array}$ & $\begin{array}{c}2.99 \pm \\
0.01\end{array}$ & -0.11 & 0.98 & 414.6 \\
\hline EI 133 & 90.09 & 8.40 & 0.18 & 1.39 & -0.05 & 1.12 & 400.7 \\
\hline EI 134 & 89.93 & 8.98 & 0.24 & 0.94 & -0.09 & 1.20 & 392.9 \\
\hline EI 135 & 90.80 & 8.71 & 0.17 & 0.44 & -0.12 & 1.15 & 391.4 \\
\hline EI 136 & 90.23 & 8.98 & 0.50 & 0.33 & -0.04 & 1.19 & 388.0 \\
\hline EI 137 & 90.02 & 10.00 & 0.10 & 0.03 & -0.15 & 1.33 & 370.1 \\
\hline EI 138 & 90.59 & 9.24 & 0.12 & 0.02 & 0.03 & 1.22 & 371.0 \\
\hline
\end{tabular}




\section{Coking Procedure}

The original decant oil and its hydrotreated versions were subjected to heat treatment using tubing bomb reactors. Five-gram samples of feedstock were immersed in a sand bath and held at a constant temperature of $465^{\circ} \mathrm{C}$ for periods of 6,12 and 18 hours in a closed system (sealed). Reaction time was varied to observe the impact on product yield and carbon textural elements using optical microscopy. The reactants (decant oil and blend, decant oil/coal 4:1 ratio) were loaded into a $25-\mathrm{mL}$ vertical microautoclave reactor, commonly referred to as a "tubing bomb". Figure 5-1 shows a schematic of the sealed reactor system which was constructed of 316 stainless steel tubing and fitted with Swagelok weld-on fittings on both ends [5-5]. Each test was run in duplicate and took place under autogenous pressure which reached as high as 1000$1500 \mathrm{psig}$ at the reaction temperature. After the desired reaction time, the reactor was quenched with cold water, the gas vented and contents were recovered by Soxhlet extraction separately with pentane and with THF.

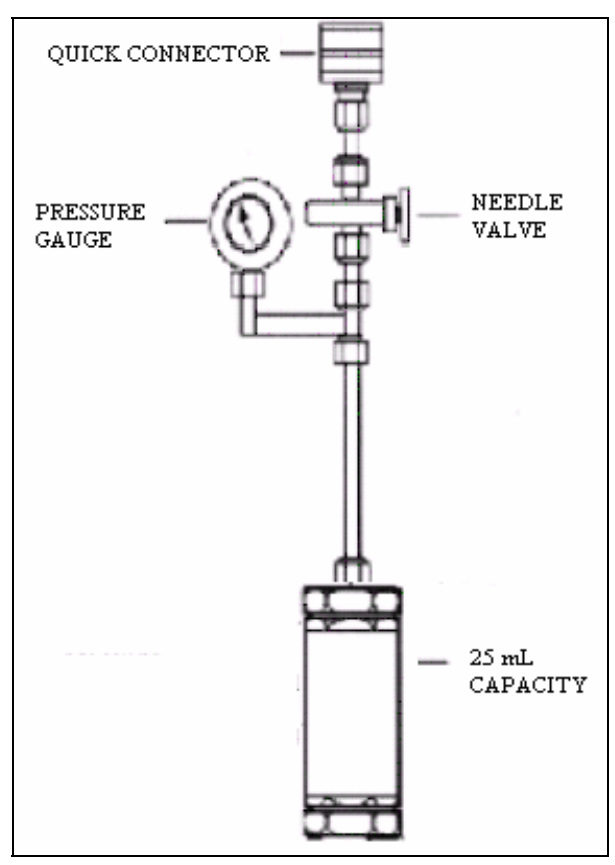

Figure 5-1 - Tubing Bomb Apparatus [5-5] 
Because evolved materials (gases and liquids) varied according to the nature of the feedstock and hence, the increase in pressure of the different experiments was variable, another set of experiments are underway, whereby gases are released during the course of the heat treatment. For this purpose, the same reactor (tubing bomb) will be used with a slight modification; the Swagelok weld-on tube fitting (female) will be coupled to the Swagelok weldon tube fitting (male) and the needle valve will be opened. This modification will allow releasing the gas in a controllable manner and will provide conditions closer to those found in delayed coking. Results of this work will be reported in the next performance period.

\section{Determination of Yields}

The yields were determined as follows:

Gases: Reactor weight (after finishing reaction and quenching in cold water) - reactor weight (after releasing gases).

Oils: Determined by the weight of the so-called pentane-soluble fraction. The extraction was carried out in the Soxhlet extraction system for $24 \mathrm{~h}$. Pentane was removed using the rotary evaporator.

THF-soluble: Weight of THF-extracted compounds. The extraction was carried out in the Soxhlet extraction system for $24 \mathrm{~h}$ using the pentane insoluble fraction. THF was removed using the rotary evaporator.

THF- insoluble: So-called semi-coke. This is the weight of the solid recovered in the thimble after extracting pentane-soluble and THF-soluble compounds. 


\section{Optical Microscopy}

The THF-extracted insoluble residue was divided in half, embedded in a cold-setting epoxy resin, placed under vacuum and then in a centrifuge to force a density/particle size gradient. After hardening, samples were cut in half longitudinally and mounted in $25 \mathrm{~mm}$ diameter molds. The hardened samples were polished for reflected light microscopy using a series of grit papers (400 and 600 grit) and alumina polishing slurries $(0.3 \mathrm{~mm}$ and $0.05 \mathrm{~mm})$. The carbon material was evaluated in white light using an oil immersion objective at a total magnification of $625 \mathrm{X}$ in polarized or cross-polarized light. Point count analysis was performed by traversing the sample based upon a $0.4 \times 0.4 \mathrm{~mm}$ grid and identifying the textural elements under a crosshair held in the microscope eyepiece. A total of 1000 counts was accumulated, 500 from each of two polished mounts.

Ten different textural elements as described below were identified in the decant oil and co-carbonization residues [5-6, 5-7].

Isotropic - a relatively low reflecting, dark gray carbon material derived from decant oil that displays little or no optical activity under polarized light.

Mosaic - a higher reflecting carbon textural element identified from decant oil materials that displays optical anisotropy and is characterized by isochromatic units of $<10 \mu \mathrm{m}$.

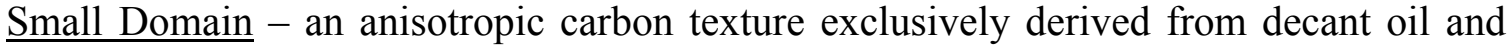
that exhibits isochromatic units of 10-60 $\mu \mathrm{m}$.

Domain - an anisotropic carbon derived from decant oil and having isochromatic units of greater than $60 \mu \mathrm{m}$.

Flow Domain - is an aligned anisotropic texture exhibiting elongated isochromatic areas of greater than $60 \mu \mathrm{m}$ in length and $<20 \mu \mathrm{m}$ wide. Generally, it is identified exclusively from decant oil.

Vitrinite-Derived Mosaic - the characteristic 0.5-2.0 $\mu \mathrm{m}$ diameter isochromatic units typically generated during the carbonization of vitrinite of high volatile bituminous coals. During co-carbonization with decant oil the isochromatic areas of bituminous rank vitrinite become enhanced to between 2.0 and $6.0 \mu \mathrm{m}$. In this investigation a distinction was made between enhanced (approximately $>2.0 \mu \mathrm{m}$ ) and non-enhanced (generally $<2.0$ $\mu \mathrm{m})$ isochromatic areas derived from vitrinite.

Isotropic Vitrinite - It is possible that some vitrinite may not develop a mesophase during carbonization and therefore may remain isotropic. 
Inertinite-Derived Texture - angular and irregular shaped particles trapped in the vitrinite or petroleum residua matrix, which may or may not display remnant cell structures and are mostly isotropic.

Mineral Matter - remnant particles of coal-derived mineral matter that usually includes clays, pyrite, quartz and carbonate minerals.

\section{Results and Discussion}

\section{Baseline Experiment}

\section{Original Decant Oil under Autogenous Pressure}

The influence of reaction time on the yields and carbon textural components of the original decant oil (DO107) under autogenous pressure are shown in Figures 5-2 and 5-3. Yield information shows that with increasing reaction time that the amount of gas and semi-coke increased at the expense of THF-soluble and oil within a sealed reactor and autogenous pressure. Under these conditions the nature of the insoluble residue

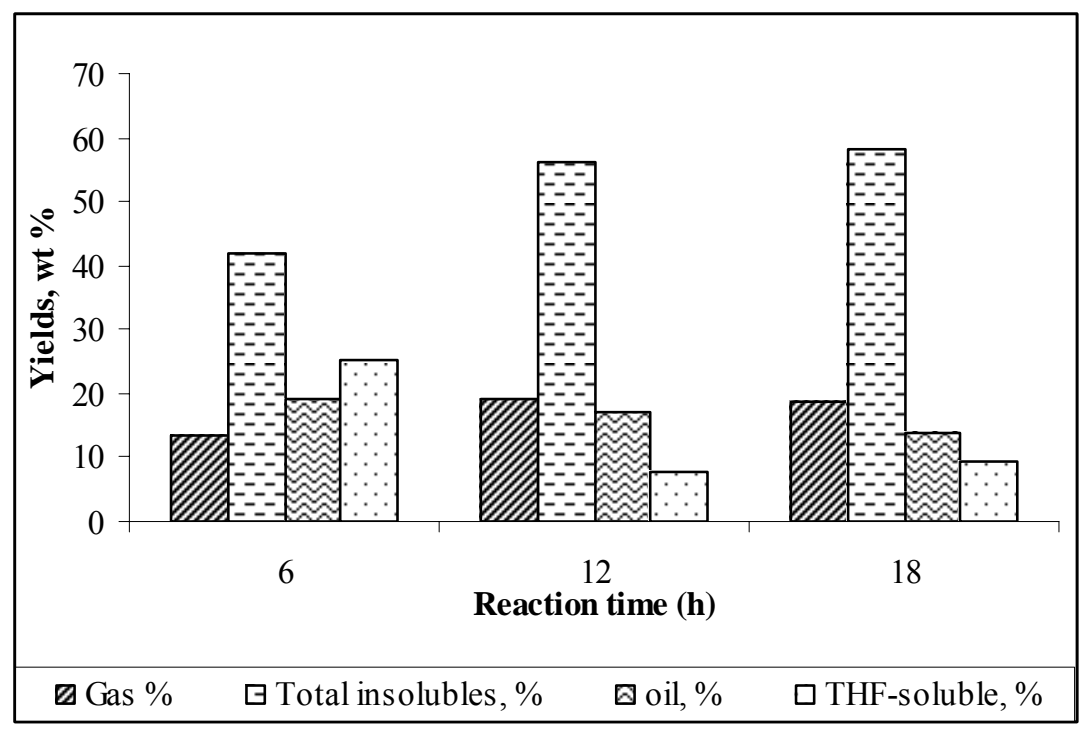

Figure 5-2 - Yields from Coking Original Decant Oil (DO107) Under Autogenous Pressure at $465^{\circ} \mathrm{C}$, wt. \%

showed a significant transformation. Figure 5-3 shows that autogenous pressure may impede the formation and coalescence of mesophase and the development of an anisotropic texture after 
$6 \mathrm{~h}$ of reaction, as it consisted mostly of isotropic carbon. With increasing reaction time more of the isotropic precursor developed a mesophase that resulted in anisotropic textures of mostly less than $60 \mu \mathrm{m}$. Although it is likely that the effect of confining pressure and of secondary reactions among primary volatile components contributed to the variation in yields and carbon textures, there is no doubt that reaction time has a significant influence. Results from experiments conducted under atmospheric pressure will be reported in the next performance period and will help to explain the current results.

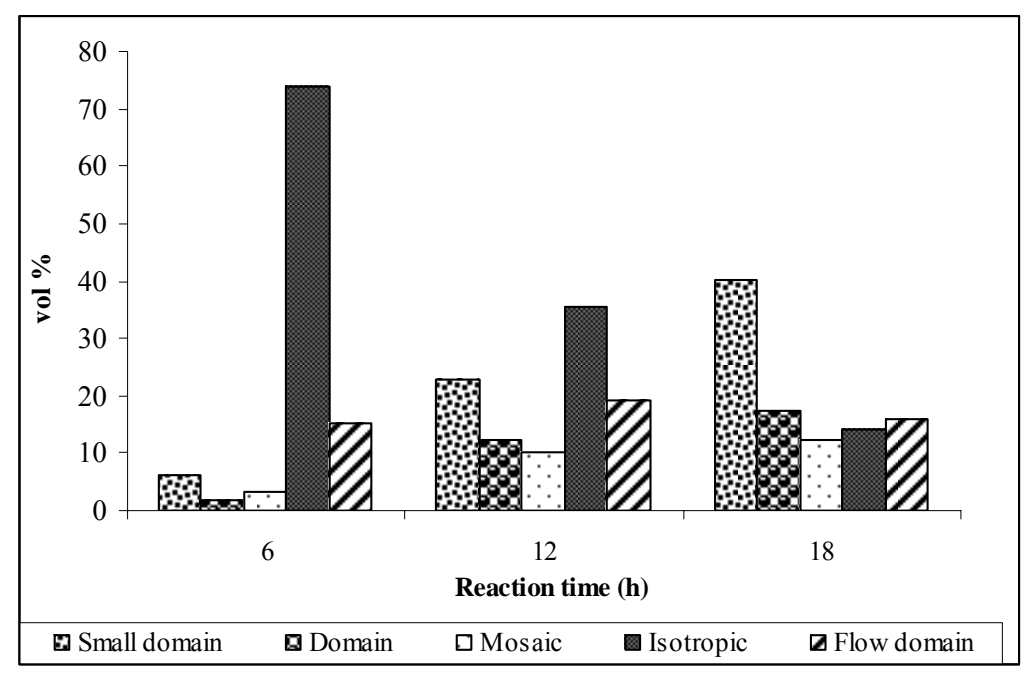

Figure 5-3 - Distribution of Carbon Textures in Cokes Derived from DO107, vol\%

\section{Decant Oil/Coal Blends under Autogenous Pressure}

With the addition of $20 \mathrm{wt} . \%$ coal, a marked change was observed in the distribution of product yields (Figure 5-4) and carbon textures (Figures 5-5 and 5-6) compared with when decant oil was heat treated alone. The THF-insoluble fraction was still observed in high concentration and with the addition of coal it increased about $10 \%$ at each reaction time. Although the gas make was nearly constant, there was a decrease in the amount of oil and THFsoluble concentration with reaction time, as was found with the decant oil alone. The carbon textures derived from coal and those derived from petroleum were normalized in Figures 5-5 
and 5-6, respectively and show that with increasing reaction time those components derived from coal were formed mainly from the enhancement of vitrinite and there was an increase in the concentration of relatively small $(<60 \mu \mathrm{m})$ anisotropic textures derived from the decant oil. Furthermore, there was much less isotropic carbon found after $6 \mathrm{~h}$ of reaction when coal was introduced compared with the decant oil coked alone. The sum of all the textures derived from coal ranges from $24.2-31.0$ vol. \% and generally increases in concentration with increasing hydrotreatment. Furthermore, the amount of enhanced vitrinite increases as well, which suggests that hyrdotreated decant oil while contributing more mass to the liquid and gas products also may improve the homogeneity of the coke product.

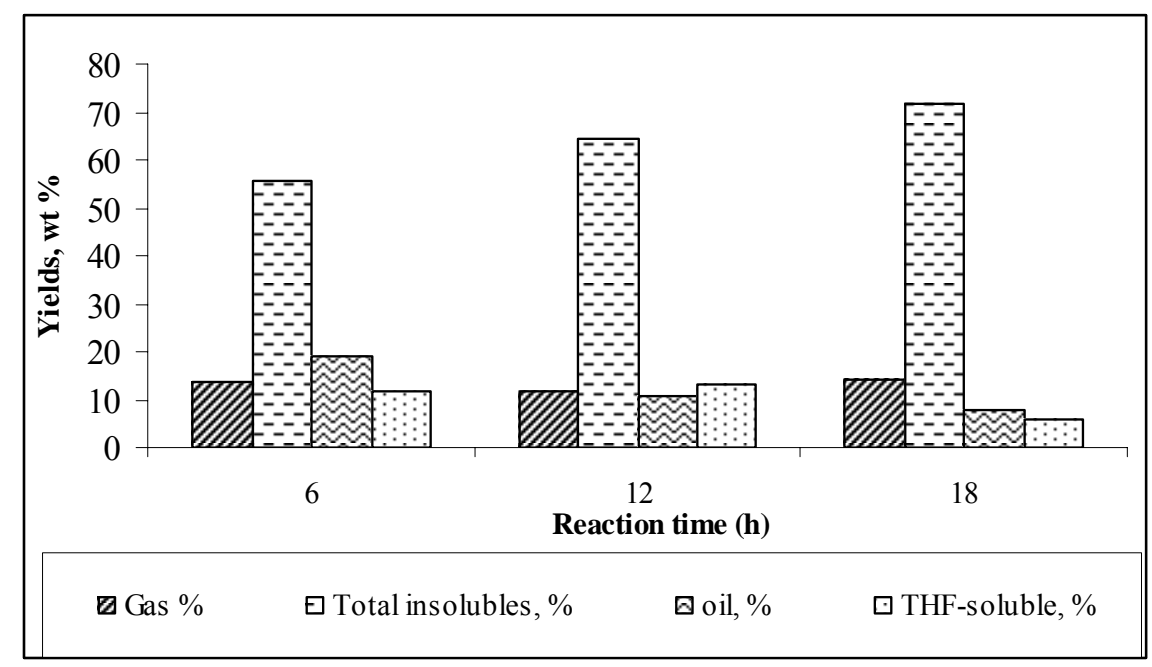

Figure 5-4 Yields from Coking Blends of DO107 and Powellton Coal Under Autogenous Pressure at $465^{\circ} \mathrm{C}$, wt. $\%$ 


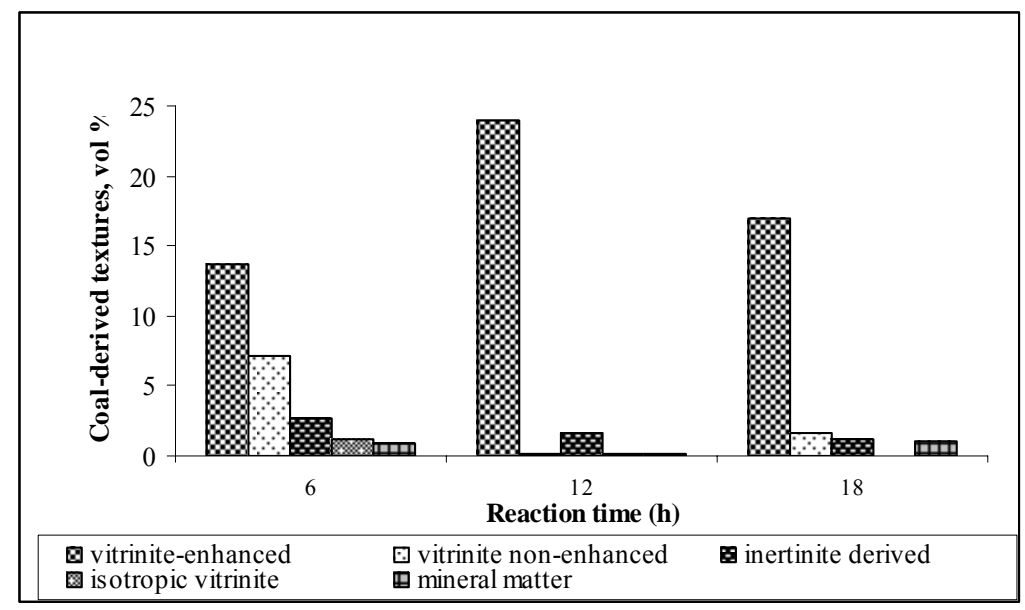

Figure 5-5 Distribution of Coal-derived Textures of Cokes from Decant Oil/ Coal Blends, vol. $\%$

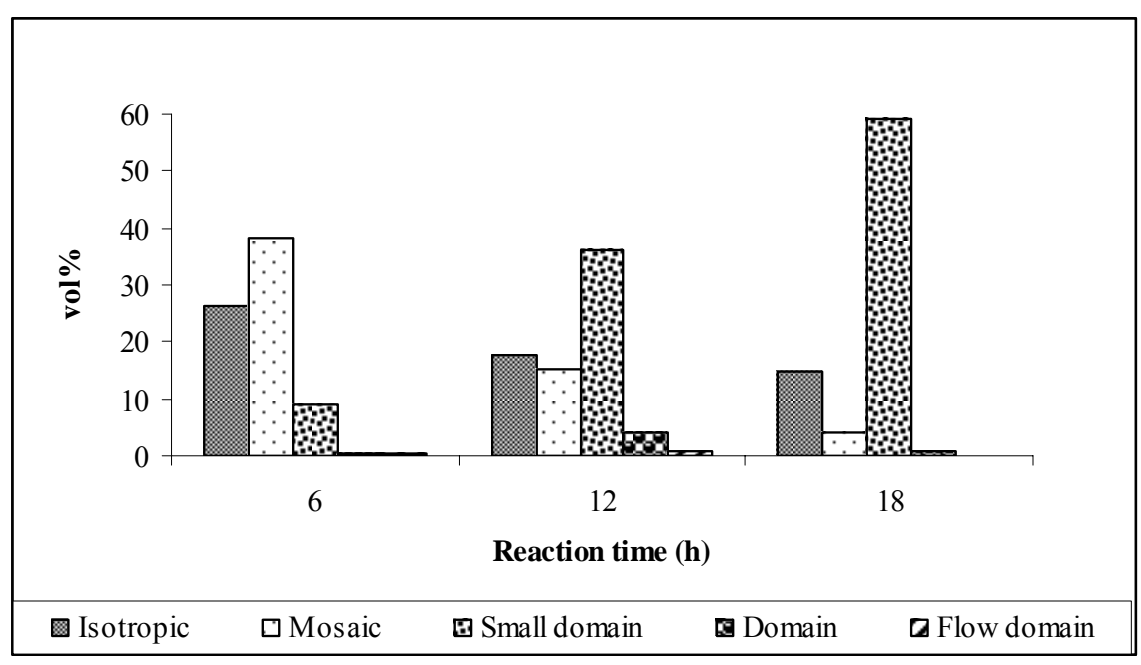

Figure 5-6 - Distribution of Petroleum-derived Textures in Cokes from Decant Oil/Coal Blends, vol. \% 
A more comprehensive comparison of yield and carbon textural information between decant oil and decant oil/coal blends for the different reaction times is provided in Figures 5-7 through 5-11. These three-dimensional figures show the variations and trends among the experiments as follows:

Gas and Oil: At $6 \mathrm{~h}$ reaction time the percentages of gas and oil were similar for DO107 alone and blended with coal; however, as reaction time was increased these produces were higher in runs using DO107 alone (Figure 5-7).

THF-soluble: Although the THF-soluble fraction was greater for DO107 alone at 6 and $18 \mathrm{~h}$, they were found in higher concentration at $12 \mathrm{~h}$ when blended with coal (Figure 5-7).

THF-insoluble: For all reaction times the amount of THF-insoluble was greater when coal was present (Figure 5-8).

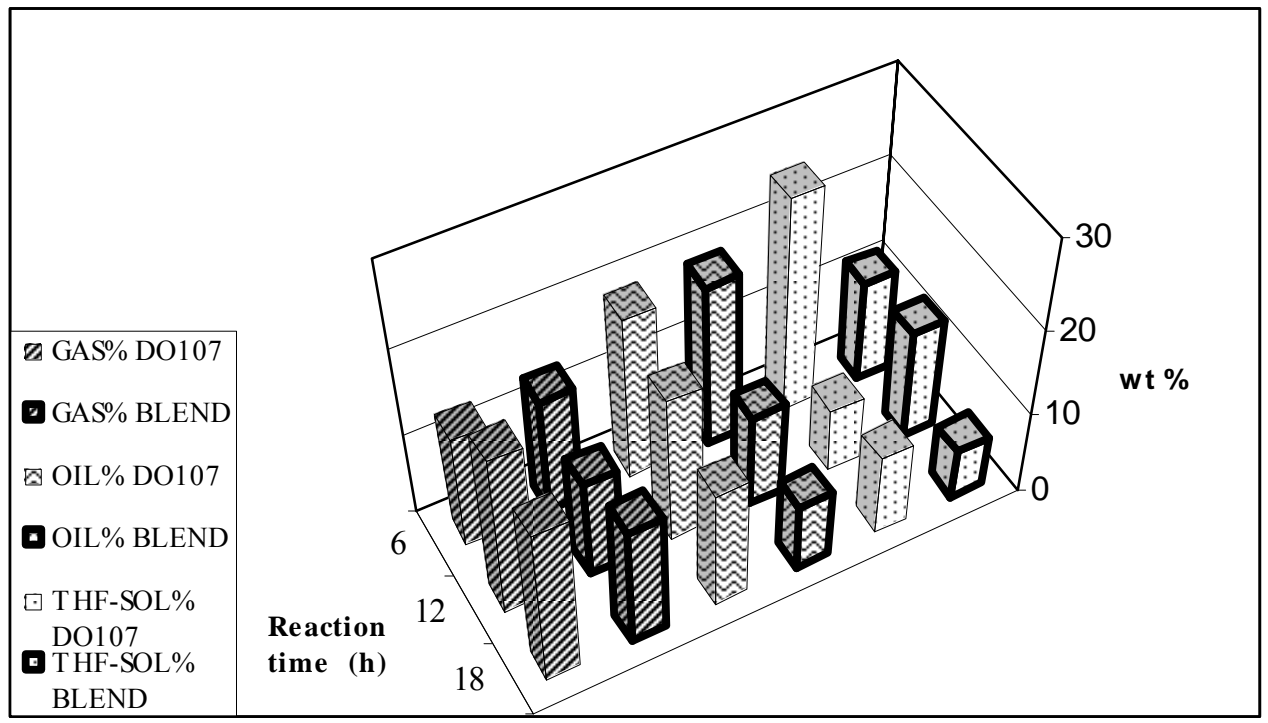

Figure 5-7 - Comparison of Yields for Gas, Oil and THF-soluble Fractions, from Experiments Using DO107 Alone and Blended with Coal under Autogenous Pressure, wt. \% 


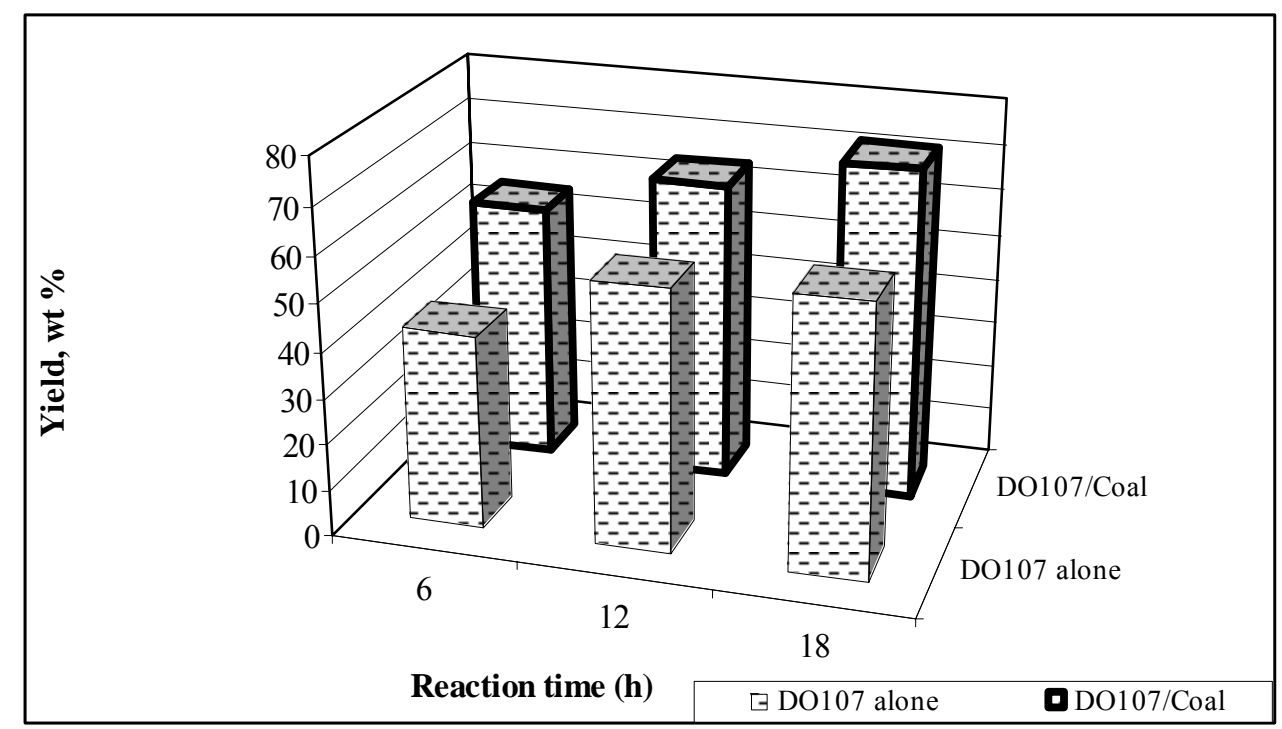

Figure 5-8 - Total Insoluble Yields for DO107 Alone and Blended with Coal under Autogenous Pressure, wt. \%

With regard to the influence of reaction conditions and the presence or absence of coal on carbon texture distribution, Figure 5-9 shows that the structures that are more desirable for premium carbon (domain and flow domain) were found in lower concentration when coal was employed at all reaction times. The textures often found in sponge coke (small domain) were higher for the blend and increased in concentration with increasing reaction time (Figure 5-10). Mosaic textures were initially higher for the blend $(6 \mathrm{~h})$, but decreased with reaction time and at $18 \mathrm{~h}$ was less than the decant oil reacted alone. Isotropic carbon was lower in concentration for the blend at 6 and $12 \mathrm{~h}$ and was comparable at $18 \mathrm{~h}$ (Figure 5-11). 


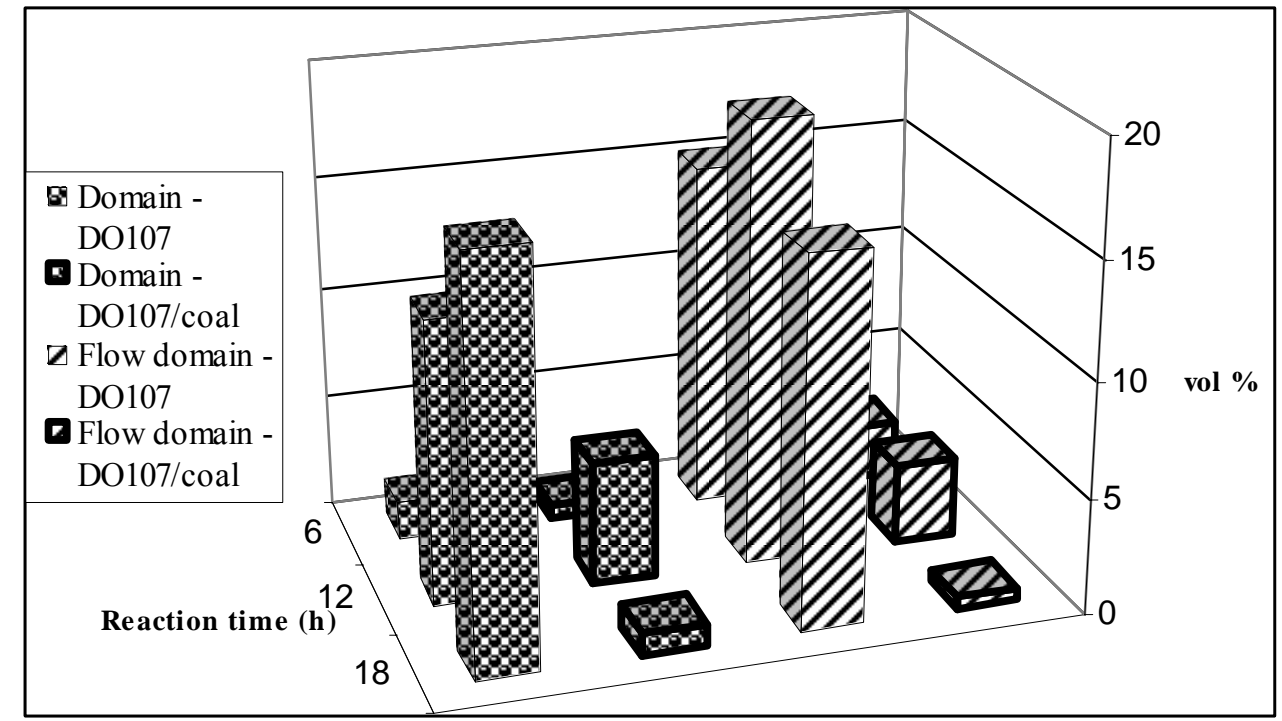

Figure 5-9 - Carbon Texture Comparison for Domain and Flow Domain, vol. \%

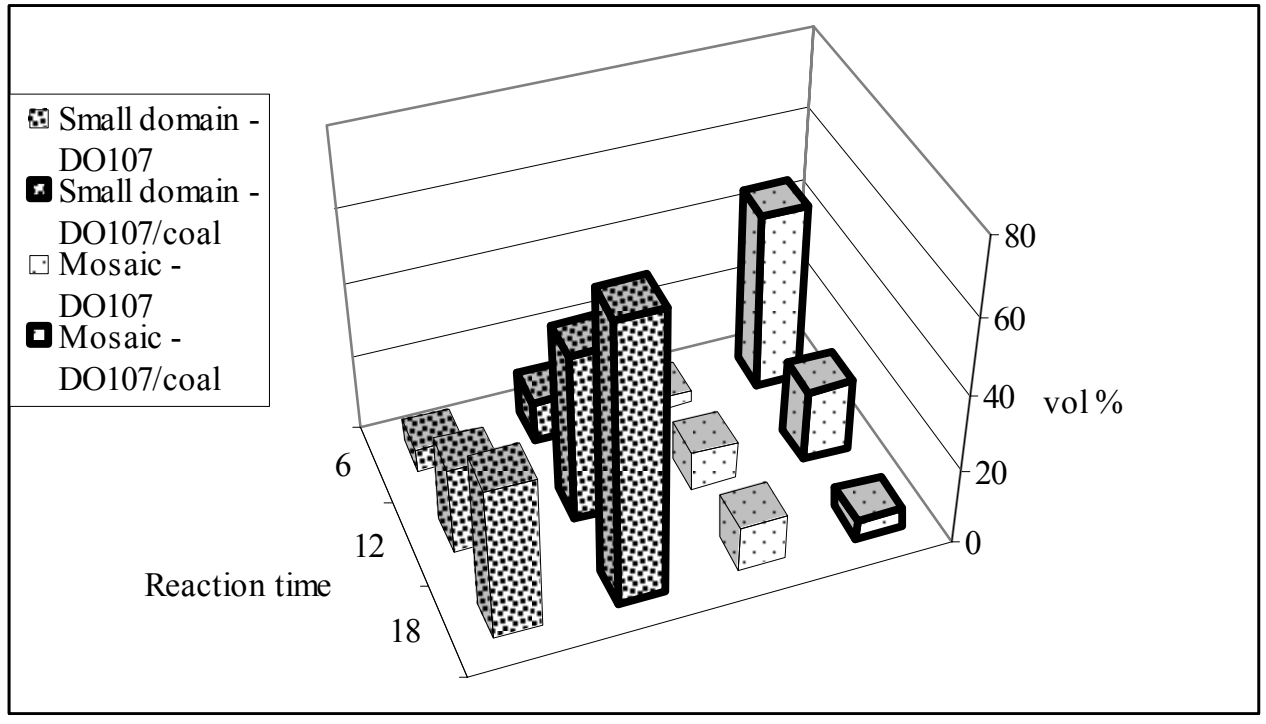

Figure 5-10 - Carbon Texture Comparison for Domain, Small Domain and Mosaic, vol. \% 


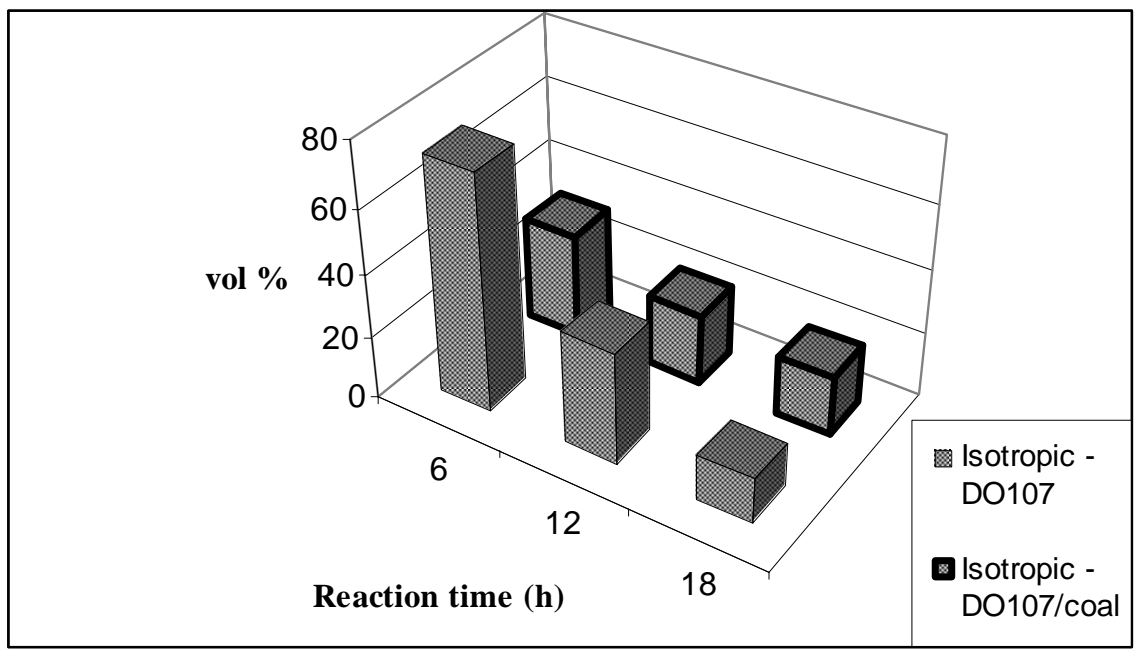

Figure 5-11 - Carbon Texture Comparison for Isotropic, vol. \%

\section{Comparison of Hydrogenated Decant Oils under Autogenous Pressure}

In preparation for making coke and pitch products from hydrogenated decant oils, a preliminary investigation into the influence of raw material quality and of reaction conditions was initiated. The results presented in Figures 5-12 through 5-15 represent the product yield information from heat treatment in tubing bombs similar to those that have been describe above. In comparison to the original decant oil (DO107, Figure 5-2), in general the yields of gas, oil and THF-soluble were greater and the amount of THF-insoluble lower for the hydrogenated samples. However, there was variation with regard to specific reaction conditions, as described below.

Gas yield: The highest yields were produced at 6 and $12 \mathrm{~h}$ from the three hydrogenated decant oils (Figure 5-12). The more severely hydrogenated decant oil (DO138) produced higher yields compared with the others which can be related to the nature of the feedstock. DO138 has the highest percentage of lighter components and compounds rich in hydrogen such as aliphatics, hydroaromatics and naphthenics [5-1]. 
Oil yield: Except for DO135, the highest yields of oil were formed at 6 and 12h and were greatest for DO138 for the reason the gas yields were higher, i.e., the presence of lighter components and compound rich in hydrogen produces more oils (Figure 5-13).

THF-soluble: The yields of the THF-soluble fraction were higher at $6 \mathrm{~h}$, but this time DO138 produced comparatively less THF-soluble than the other decant oils (Figure 5-15). This component may be less desirable for fuel or solid carbon products, but may contribute greatly to a pitch precursor.

THF-insoluble: The insoluble-fraction derived from the hydrotreated decant oils may be slightly lower in concentration than the original decant oil, but it increases with reaction time without regard for severity of hydrogenation (Figure 5-14). However, characterization of the carbon textures of these solids remains to be performed.

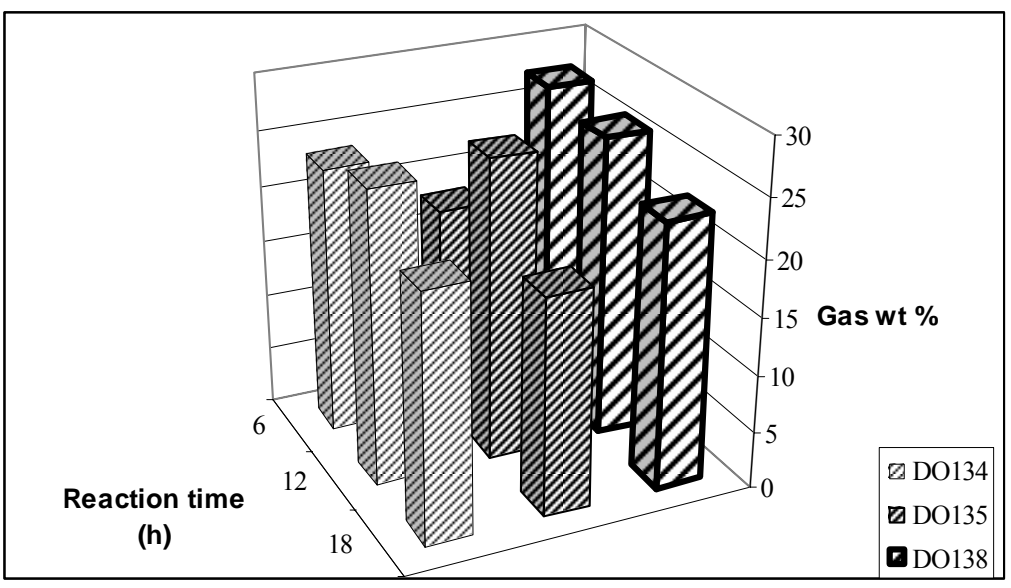

Figure 5-12 - Gas Yields from Three Hydrotreated Decant Oils 


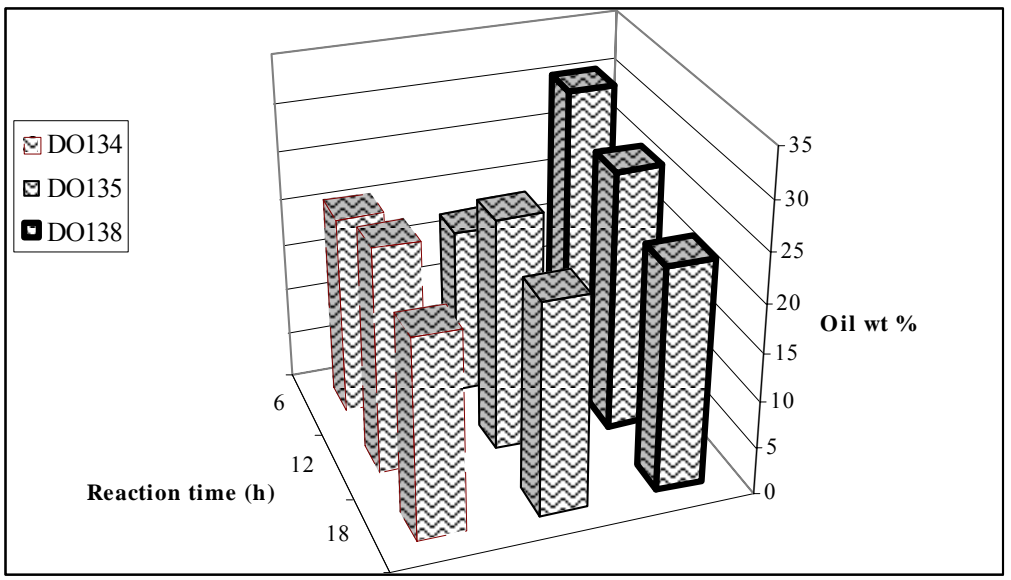

Figure 5-13 - Oil Yield from Three Hydrotreated Decant Oils

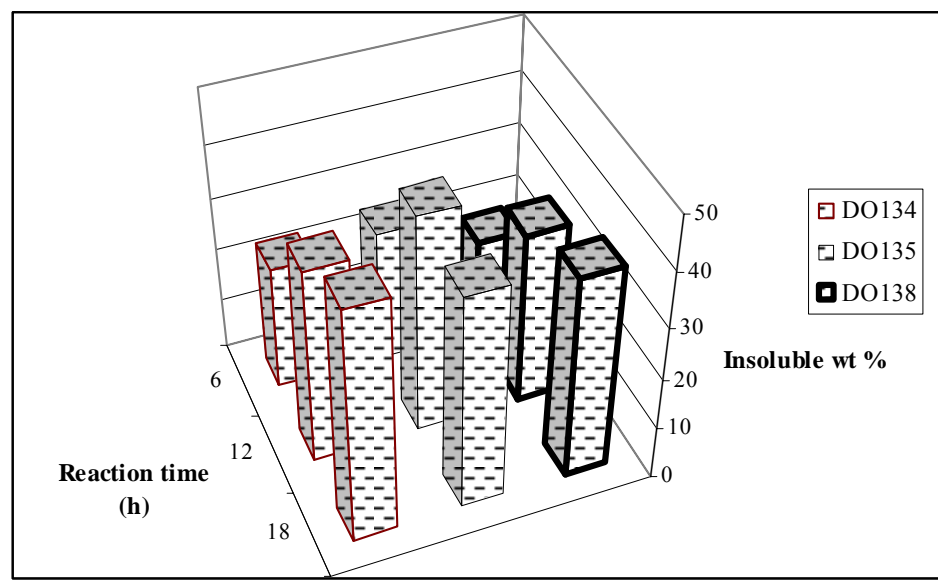

Figure 5-14 - THF-Insoluble Yield from Three Hydrotreated Decant Oils

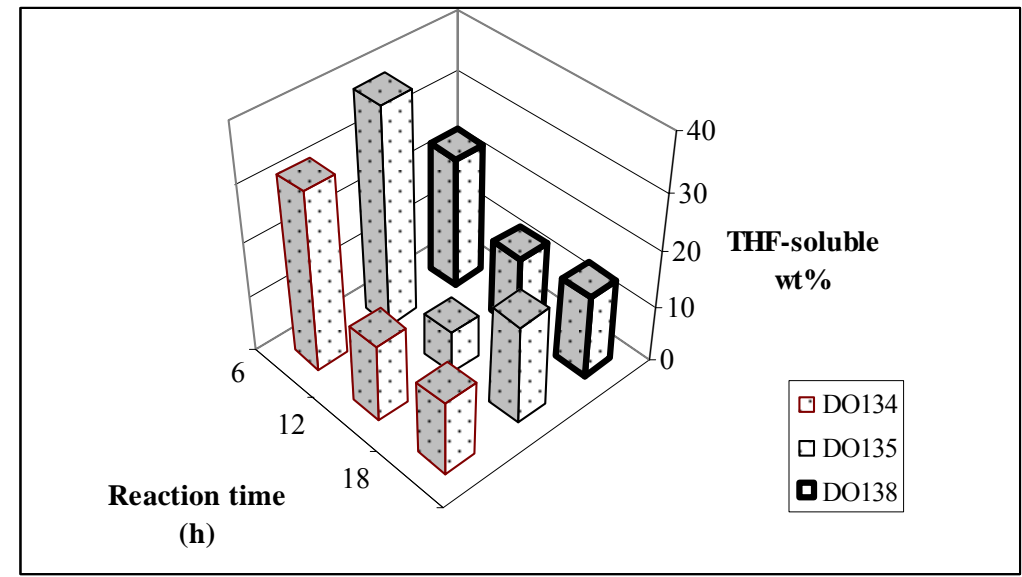

Figure 5-15 - THF-Soluble Yield from Three Hydrotreated Decant Oils 


\section{Future Work}

This on-going bench-scale investigation was designed to provide background information on the influence mildly hydrotreated decant oil might have on the quality of liquid and solid products during co-coking. To complete the work the following activities will be carried out;

1) Comparison of carbon textures for the hydrotreated decant oils.

2) Repeat the same analyses (decant oils and blends) completed for autogenous pressure, but under atmospheric pressure.

3) Compare yields and carbon textures for decant oils and blends for autogenous pressure vs. atmospheric pressure.

4) Conduct a more thorough investigation of cokes generated from decant oils and blends by X-ray diffraction (XRD) and temperature programmed oxidation (TPO).

5) Carry out characterization of the oils generated from decant oils and blend by GC-MS and NMR.

\section{Subtask 5.3 Co-Coking of Coal and Heavy Petroleum Stream}

A description of the laboratory scale coking apparatus and coking of hydrotreated versions of refinery produced decant oil and coking of coal/decant oil blends have been described in previous reports under Task 1.

In an effort to determine the reproducibility within the coker, twelve duplicate runs were completed. Characterization of the liquids will be described in this subtask, while characterization of the solids will be discussed in Subtask 5.4.

Due to issues with inhomogeneity in the carbon structures and ash left in the coke as well as the need to find an alternative source of RCO for Task 1, we have begun work on coal extraction. This will also be discussed in Subtask 5.3. 


\section{Subtask 5.3.1 Reproducibility of the Products from the Delayed Coker}

A series of runs were done to test the reproducibility of the process and to provide enough products for extensive testing. The coke generated from this work will be discussed in Subtask 5.4. The work in this subtask will focus on the liquids generated.

\section{EXPERIMENTAL}

Materials. The petroleum-based decant oil used in this study represents a typical decant oil with low sulfur content $(0.8 \mathrm{wt} \%)$. The coal used in this study was a Pittsburgh seam bituminous coal. Proximate and ultimate analyses for these feedstocks are shown in Table 1. The fluidity data and organic petrography (vitrinite, liptinite, inertinite) analyses results for the coal are also given in Table 5-5.

Apparatus. The delayed coking unit was designed after a unit developed at Intertek PARC Technical Services, Harmarville, PA. The Pilot-Scale Laboratory Coker (PSLC) consists of a $7.5 \mathrm{~cm}$ ID x $102.5 \mathrm{~cm}$ cylindrical reactor unit having an internal volume of approximately 4.5 liters. More information about PSLC can be found elsewhere. ${ }^{1}$

While this part of the report deals with liquid products isolated during co-coking, the solid products are mentioned here to completely describe the reaction system and the repeatability of the system. 
The system pressure, temperature and flow rates are monitored by a number of computer-controlled devices, and data from these devices is recorded throughout the experiment.

Table 5-5. Proximate and Ultimate Analysis of the Feeds Used in this Study

\begin{tabular}{|c|c|c|}
\hline & Coal & Decant Oil \\
\hline \multirow[t]{2}{*}{ Proximate Analysis } & $\begin{array}{l}\text { Pittsburgh } \\
\text { Seam }\end{array}$ & $\begin{array}{c}\text { United } \\
\text { Refining }\end{array}$ \\
\hline & EI-186 & EI-107 \\
\hline Ash $(\%)$ & 0.99 & 0.0 \\
\hline Volatile matter $(\%)$ & 35.6 & - \\
\hline Fixed carbon $(\%)$ & 63.4 & - \\
\hline \multicolumn{3}{|l|}{ Ultimate analysis $^{\mathrm{a}}$} \\
\hline Carbon $(\%)$ & 84.6 & 89.7 \\
\hline Hydrogen $(\%)$ & 5.3 & 7.3 \\
\hline Nitrogen $(\%)$ & 1.6 & 0.2 \\
\hline Sulfur $(\%)$ & 1.1 & 3.0 \\
\hline Oxygen (by diff.) (\%) & 6.4 & - \\
\hline \multicolumn{3}{|l|}{ Fluidity Data ${ }^{b}$} \\
\hline Fluid Temperature Range $\left({ }^{\circ} \mathrm{C}\right)$ & 93 & \\
\hline Maximum Fluidity (ddpm) & 29527 & \\
\hline Softening Temperature $\left({ }^{\circ} \mathrm{C}\right)$ & 385 & \\
\hline \multicolumn{3}{|c|}{ Organic Petrography:Volume $\%$ mineral matter free } \\
\hline Total Vitrinte (vol. \%) & 96.2 & \\
\hline Total Liptinite (vol. \%) & 1.5 & \\
\hline Total Inertinite (vol. \%) & 2.3 & \\
\hline
\end{tabular}

The preheater was a $2.5 \mathrm{~cm}$ OD x $51 \mathrm{~cm}$ stainless steel tube fitted directly to the bottom of the reactor. This was fed by a $0.953 \mathrm{~cm}(3 / 8$ ") O.D. feed line that was outside the furnace and was heated to $120^{\circ} \mathrm{C}$ using heating tape. This design configuration allows for essentially troublefree pumping of the coal-decant oil slurry over a wide temperature range. The temperature gradient through this $51 \mathrm{~cm}$ preheater is on the order of $200^{\circ} \mathrm{C}$, with an outlet temperature of 432 $441^{\circ} \mathrm{C}$. This was connected to a $0.635 \mathrm{~cm}\left(1 / 4^{\prime \prime}\right)$ O.D. line that carried feedstocks from the feed 107 
pump. A picture of the unit is shown in Figure 5-16a, and a schematic is shown in Figure 5-

$16 b$.

(a)

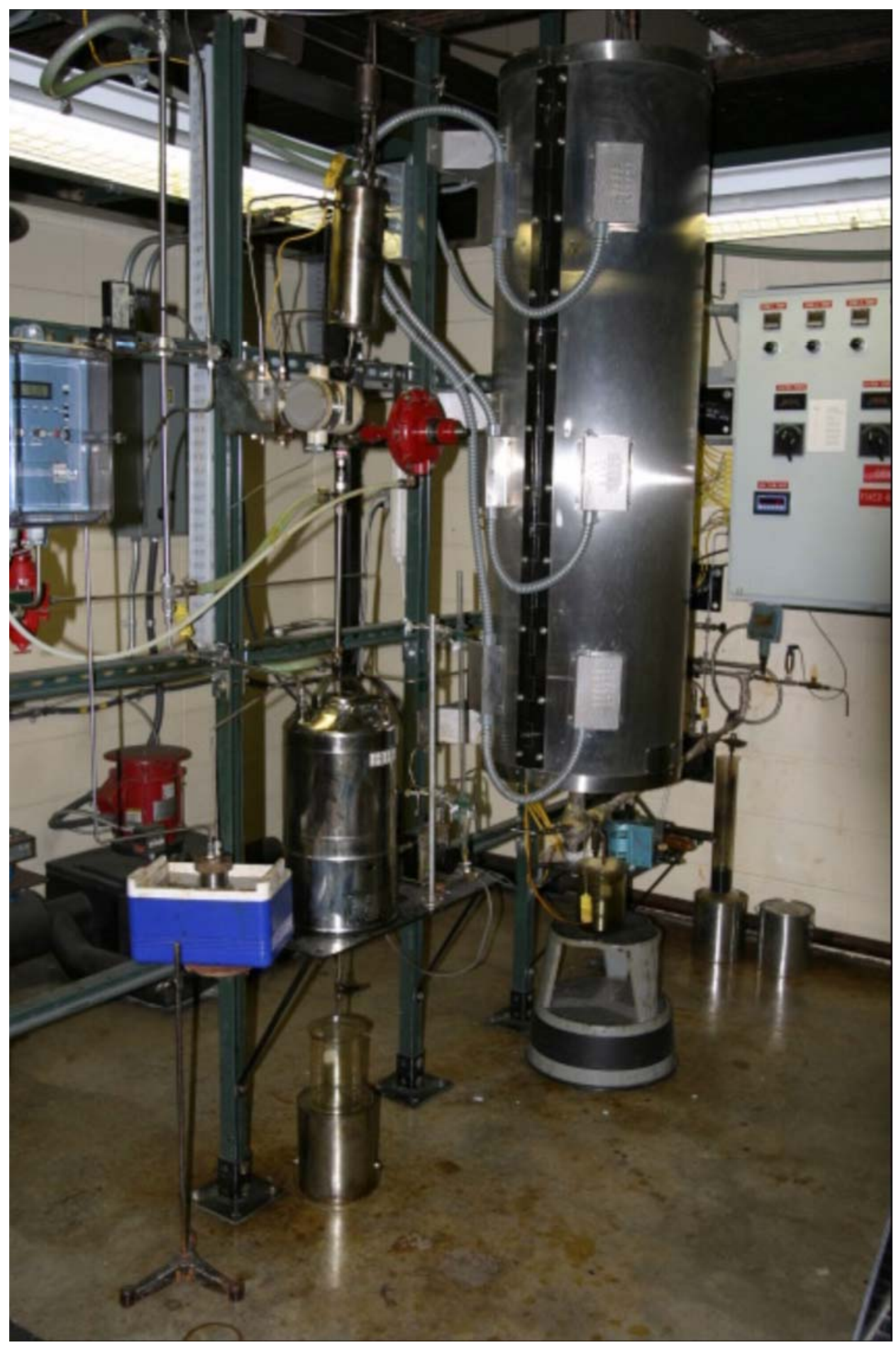


(b)

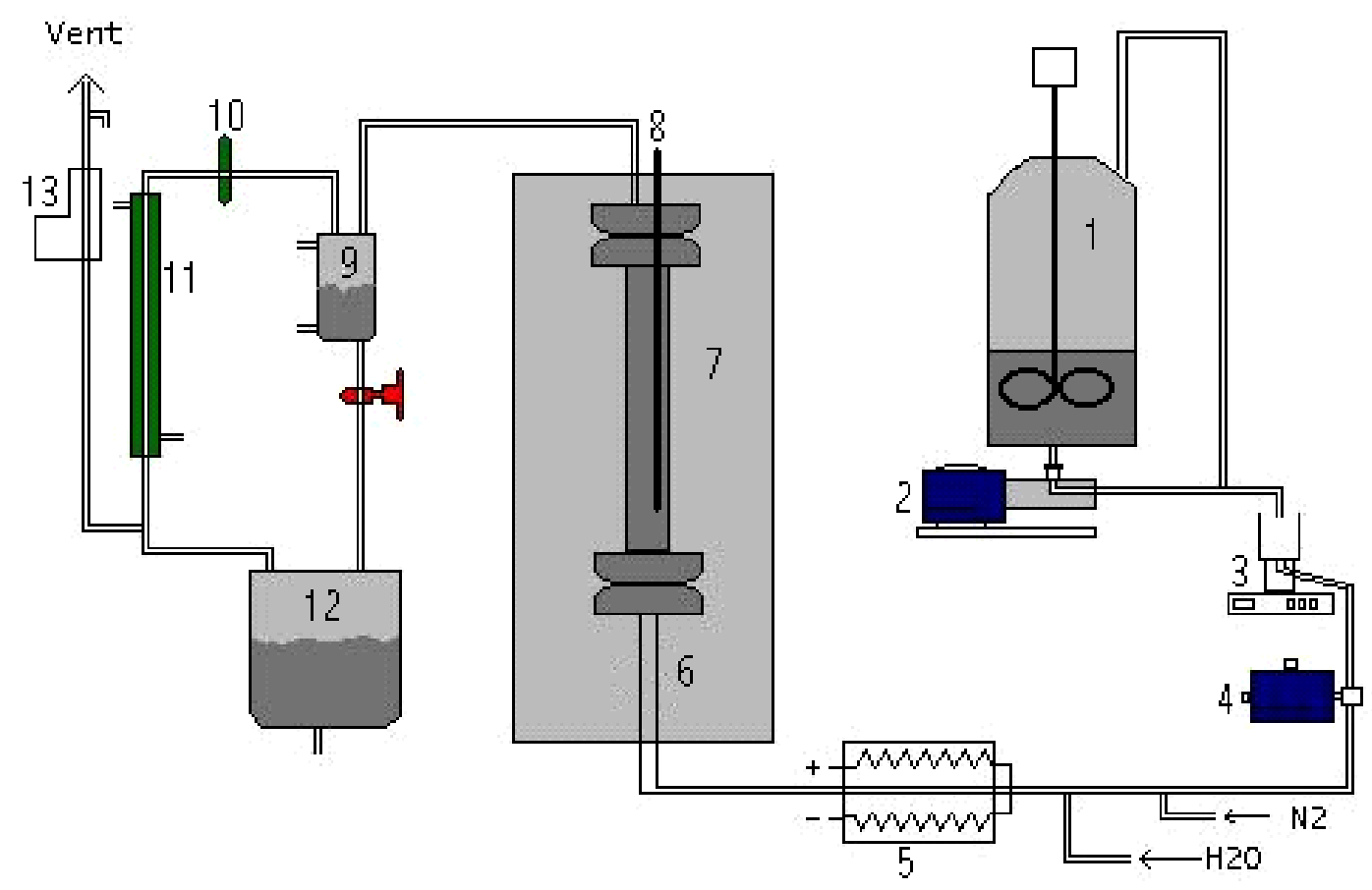

1. Heated Feedstock Tank 8. Thermocouple Well

2. Feedstock Pump 9. DP Cell

3. Balance

4. Metering Pump

10. Back Pressure Regulator

5. Superpreheater

11. Condenser

6. Preheater

12. Receiver Tank

7. Coker Drum

13. Mass Flow Meter

Figure 5-16: (a) Picture of delayed coking unit, (b) schematic of the units in the delayed coker. 
Reaction Procedures. The following operating conditions were used: coke drum inlet temperature $500^{\circ} \mathrm{C}$, coke drum pressure $25 \mathrm{psig}$, coal $/$ decant oil slurry feed rate $16.7 \mathrm{~g} / \mathrm{min}$, and feed introduction to the coker 6 hours. At the conclusion of each experiment, the coke drum was maintained at temperature for an additional 24 hours to insure carbonization of non-volatile components. The detailed conditions and product distributions for co-coking experiments are given in Table 2.

In the co-coking experiments, coal was fed in slurry form with the decant oil (coal/ decant oil ratio was 4:1) into the coker where the volatile components of the coal and decant oil were vaporized and subsequently condensed. The vented reactor system allowed for flash vaporization of the volatiles and subsequent carbonization of the heavy petroleum fraction and coal. In the delayed coking process, feedstock is pumped $(16.7 \mathrm{~g} / \mathrm{min})$ into the coker drum where reactions between the coke and the liquid lead to the formation of light desirable liquids and carbonaceous solid.

The feed is initially charged to a heated feedstock vessel that was continuously mixed throughout the co-coking experiment to achieve and maintain homogeneity. In these experiments, the feed vessel was placed on a balance for monitoring the feeding rate and the temperature of this vessel was kept at $66^{\circ} \mathrm{C}$. The slurry federate in these experiments was continuous and measured gravimetrically with time. The feed was incrementally heated along the feed line to the preheater. Feed was heated in the lines prior to the preheater to about $120^{\circ} \mathrm{C}$, and then to about $440^{\circ} \mathrm{C}$ in the preheater. Heated feedstock from the preheater was fed to the coker drum. Thermocouples attached at different positions along the coke drum were used to measure and to control the temperature during the experiment. Light hydrocarbons that vaporized exit 
from the top of coker drum and pass through a series of condensers. Gases went through a mass flow meter and were either collected or sent to vent.

In the experiments reported here, the liquid products from the reactions were passed through a series of condensers and valves that facilitate the isolation of liquid product as a function of reaction time. At the conclusion of the experiment the mass of the liquid condensate was weighed. In addition, the carbonaceous solid was removed from the coke drum and weighed. To have enough green coke to test an anode to be evaluated by industry and to make jet fuel from coal-based feedstock, twelve runs were conducted with PSLC. In this part of the report, we describe the characterization of the liquid products from co-coking and evaluated the work in terms of reproducibility. During each run, approximately $20-25 \mathrm{~mL}$ liquid samples were taken at 30 minutes intervals. In order to asses the liquid process repeatability, 4 of 12 runs $\left(3^{\text {rd }}, 5^{\text {th }}, 7^{\text {th }}\right.$, and $9^{\text {th }}$ runs) were selected randomly as representatives. Of each selected run, the first, the third, and the fifth hour samples and combined oils were characterized to probe process repeatability in one specific experiment as well as repeatability between runs. Since the pilot-scale vented reactor system is used for different coking or co-coking experiments at the Energy Institute at Penn State, this work has been carried out. The solids from these twelve runs will be evaluated and reported separately.

Analytical Procedures. ${ }^{1} \mathrm{H}$ and ${ }^{13} \mathrm{C}$ NMR analyses, using Bruker AMX 360 NMR spectrometer operating at 9.4 Tesla, were performed on liquid samples that had been taken previously at $1^{\text {st }}, 3^{\text {rd }}$, and $5^{\text {th }}$ hour during the run to study the compositional change during 6 hour feeding for 4 similar runs. 
The collected overhead liquids from each co-coking experiment were fractionated by vacuum distillation into refinery cuts corresponding to gasoline, jet fuel, diesel, and fuel oil. The distillations were performed on the bulk overhead liquid samples in order to obtain the true boiling point ranges. The use of vacuum minimizes sample decomposition. The distillations were conducted in a 2 L flask mounted in a heating mantle. A 1200 grams liquid sample was weighed in to the $2 \mathrm{~L}$ flask; the sample was stirred to assure a homogenous temperature in the liquid inside the flask. The flask, beaded-glass packed column, distillation head unit, condenser, vacuum application kit, and collection vessel were assembled. As the heating power was increased, the vapors came through the beaded-glass packed column and condensed in the condenser. Approximately 5-10 mm-Hg vacuum was used for distillation and a nomograph was used to correlate the temperature at a given pressure (vacuum pressure) and the temperature at atmospheric pressure. The pressure and temperature were constantly monitored during the distillation process.

The NMR analyses were also conducted for each refinery cut vacuum fractions that were obtained from each individual co-coking experiment. Samples were dissolved 1/1 volume ratio in $\mathrm{CDCl}_{3}$ containing $1 \mathrm{vol} \%$ of tetramethylsilane (TMS) as standard. For the ${ }^{1} \mathrm{H}$ NMR, the pulse width was $5 \mu \mathrm{sec}$ with a pulse delay of $5 \mathrm{sec}$ and a $90^{\circ}$ tip angle. For the ${ }^{13} \mathrm{C} \mathrm{NMR}$, the pulse width is $5 \mu \mathrm{sec}$ with a pulse delay of 45 seconds and a $70^{\circ}$ tip angle; these values were used to ensure quantitative results. In ${ }^{13} \mathrm{C}$ analyses, $\mathrm{Cr}(\mathrm{AcAc})_{3}(20 \mathrm{mg})$ was used for the $2 \mathrm{~mL}$ of overhead liquid/ $\mathrm{CDCl}_{3}$ mixture. Regions of the spectra were integrated and peaks were assigned based on literature chemical shift values for ${ }^{1} \mathrm{H}$ and ${ }^{13} \mathrm{C} .{ }^{2}$

GC/MS analysis, using a Shimadzu QP5000 spectrometer, was performed on vacuum fractionated liquid samples to study chemical composition. The GC/MS temperature program for 
gasoline was an initial temperature of $35^{\circ} \mathrm{C}(10$ minutes $)$, ramped at $4{ }^{\circ} \mathrm{C} / \mathrm{min}$ to $175^{\circ} \mathrm{C}$, and held at $175^{\circ} \mathrm{C}$ for an additional 5 minutes (total run time was 50 minutes). The temperature program for jet fuel was an initial temperature of $40{ }^{\circ} \mathrm{C}$ ( 4 minutes), ramped at $4{ }^{\circ} \mathrm{C} / \mathrm{min}$ to $220^{\circ} \mathrm{C}$, and held at $220{ }^{\circ} \mathrm{C}$ for an additional 10 minutes (total run time was 59 minutes). The temperature program for diesel was set as: an initial temperature of $40{ }^{\circ} \mathrm{C}(0$ minutes $)$, ramped to $120{ }^{\circ} \mathrm{C}$ at $15{ }^{\circ} \mathrm{C} / \mathrm{min}$, from $120{ }^{\circ} \mathrm{C}$ to $250{ }^{\circ} \mathrm{C}$ at $4{ }^{\circ} \mathrm{C} / \mathrm{min}$, and then held at $250{ }^{\circ} \mathrm{C}$ for an additional 8 minutes (total run time was 46 minutes). An XTI-5 ((Restek) $30 \mathrm{~m} \times 0.25 \mathrm{~mm} \times 0.25 \mu \mathrm{m}$ ) column was used for the GC/MS analyses.

Simulated distillation gas chromatography (Sim-Dis GC) was performed on the bulk overhead liquid samples to determine the boiling point distribution and weight percent yield of each refinery cut fraction. The simulated distillation measurements were made according to ASTM 2887 method by using an HP 5890 GC-FID fitted with an MXT-500 simulated distillation column (10 m, $0.53 \mathrm{~mm}$ ID and $2.65 \mu \mathrm{m}$ ) (Restek). Carrier gas flow rate was adjusted to $13 \mathrm{~mL} / \mathrm{min}$ for Sim-Dist GC analysis, and SimDis Expert 6.3 software was used to calculate the percentage of fractions.

\section{RESULTS AND DISCUSSION}

Product recovery. The aim of this research was to study the reproducibility of :

- pilot scale delayed coker yield distributions (gas, liquid, and coke),

- overhead liquid during 6 hours feeding period as well as reproducibility of overhead liquid between replicate experiments,

- vacuum distillation fractions from overhead liquids (gasoline, jet fuel, diesel, fuel oil). 
For this reason, a blend of Pittsburgh seam bituminous coal (EI-186) and low sulfur decant oil (EI-107) were co-coked in the pilot-scale delayed coker. In co-coking experiments, the coal was slurried with the decant oil, the coal added to $20 \%$ by weight; the slurry was continuously heated $\left(66^{\circ} \mathrm{C}\right)$ and stirred to assure homogeneity of the slurry during introduction to the coking reactor.

Table 5-5 shows the properties of the decant oil and coal used in the co-coking experiments. The conditions used in each of the coking and co-coking experiments are described in Table 5-6. Applied temperatures and feed material amounts were very close to each other for similar runs in our experiments (Table 5-6). The first principal objective was to determine that the process was reproducible in terms of the yields of green cokes, liquids, and gases from similar experiments that were conducted at different times using the similar feedstock and conditions. Reproducibility of co-coking of coal with decant oil in four separate experiments was shown to be excellent (Table 5-6, compare runs 52, 54, 56, 58). Average values (including the average deviation) of percent coke, liquid and gas are $27.82 \pm 0.60 \%, 62.82 \pm 0.62 \%$, and $9.36 \pm 0.0 .28 \%$, respectively. These values are typical for an industrial delayed coking operation. Liquids were obtained in suitable quantity for detailed chemical characterization, recombination and distillation into refinery cuts for evaluation.

Composition of liquid product as a function of reaction time. Samples were taken at 30 minute intervals during the six hours run time, for a total of 11 samples collected (in the first hour there was not enough material). Then $1^{\text {st }}, 3^{\text {rd }}$, and $5^{\text {th }}$ hour samples were chosen to monitor the compositional change. These 3 samples for 4 similar runs were analyzed using solution-state ${ }^{1} \mathrm{H}$ and ${ }^{13} \mathrm{C}$ NMR. Regions of spectra were integrated and peaks were assigned based on literature chemical shift values for both ${ }^{1} \mathrm{H}$ and ${ }^{13} \mathrm{C}$. ${ }^{2}$ Tables 5-7 and 5-8 show distribution of ${ }^{1} \mathrm{H}$ and ${ }^{13} \mathrm{C}$ 
signals as a function of time of delayed co-coking, respectively.

Table 5-6. Conditions and product distributions for co-coking experiments

\begin{tabular}{|c|c|c|c|c|}
\hline Run \# & 52 & 54 & 56 & 58 \\
\hline Conditions & $\begin{array}{c}\text { DO/Coal } \\
80 / 20 \\
\text { DO=EI-107 } \\
\text { C=Pitts. Seam }\end{array}$ & $\begin{array}{c}\text { DO/Coal } \\
80 / 20 \\
\text { DO=EI-107 } \\
\text { C=Pitts. Seam }\end{array}$ & $\begin{array}{c}\text { DO/Coal } \\
80 / 20 \\
\text { DO=EI-107 } \\
\text { C=Pitts. Seam }\end{array}$ & $\begin{array}{c}\text { DO/Coal } \\
80 / 20 \\
\text { DO=EI-107 } \\
\text { C=Pitts. Seam }\end{array}$ \\
\hline Feedstock, hours & 5.75 & 6 & 6 & 6 \\
\hline steam strip at $500 \mathrm{C}$, hrs & 0 & 0 & 0 & 0 \\
\hline hold at $500 \mathrm{C}$, hrs & 24 & 24 & 24 & 24 \\
\hline Feed rate, $\mathrm{g} / \mathrm{min}$ & 16.7 & 16.7 & 16.8 & 16.8 \\
\hline preheater inlet, $\mathrm{C}$ & 120 & 123 & 122 & 120 \\
\hline preheater outlet, C & 440 & 432 & 432 & 441 \\
\hline coke drum inlet, $\mathrm{C}$ & 495 & 500 & 500 & 505 \\
\hline $\begin{array}{l}\text { coke drum } \\
\text { lower/middle, C }\end{array}$ & 489 & 497 & 495 & 496 \\
\hline coke drum top, $\mathrm{C}$ & 472 & 481 & 479 & 476 \\
\hline Material Fed to Reactor & 5898 & 5984 & 5746 & 6022 \\
\hline \multicolumn{5}{|l|}{ Product } \\
\hline Coke & 1663 & 1714 & 1587 & 1616 \\
\hline Liquid & 3701 & 3691 & 3608 & 3858 \\
\hline Gas (by difference) & 534 & 579 & 551 & 548 \\
\hline coke + liquid product & 5364 & 5405 & 5195 & 5474 \\
\hline liquid/coke & 2.23 & 2.15 & 2.27 & 2.39 \\
\hline$\%$ coke & 28.20 & 28.64 & 27.62 & 26.83 \\
\hline \%liquid product & 62.75 & 61.68 & 62.79 & 64.07 \\
\hline \%gas & 9.05 & 9.68 & 9.59 & 9.10 \\
\hline
\end{tabular}


Table 5-7. Distribution of ${ }^{1} \mathrm{H}$ NMR signals as a function of time of delayed co-coking of Pittsburg Seam coal with decant oil (4:1 Ratio)

\begin{tabular}{|c|c|c|c|c|c|c|c|c|c|c|c|c|c|c|}
\hline & & & \#52 & & & $\# 54$ & & & \#56 & & & \#58 & & \\
\hline Assignments & Bands & $1 \mathrm{st}$ hr. & 3rd hr. & 5th hr. & $1 \mathrm{st}$ hr. & $3 \mathrm{rd} \mathrm{hr}$. & 5th hr. & $1 \mathrm{st} \mathrm{hr}$. & $3 \mathrm{rd} \mathrm{hr}$. & 5th hr. & $1 \mathrm{st} \mathrm{hr}$. & 3rd hr. & 5th hr. & Mean \\
\hline $\begin{array}{l}\mathrm{CH}_{3} \gamma \text { and further, some } \\
\text { naphthenic } \mathrm{CH} \text { and } \mathrm{CH}_{2}\end{array}$ & $1.0-0.5$ & 6.2 & 6.0 & 5.7 & 6.0 & 5.3 & 5.1 & 5.9 & 5.9 & 5.3 & 5.9 & 5.0 & 5.9 & 5.7 \\
\hline $\begin{array}{l}\mathrm{CH}_{2} \beta \text { and further, some } \\
\beta \mathrm{CH}_{3}\end{array}$ & $1.7-1.0$ & 15.5 & 13.6 & 13.4 & 14.0 & 11.7 & 11.5 & 13.3 & 12.7 & 12.1 & 12.8 & 11.3 & 12.8 & 12.9 \\
\hline $\begin{array}{l}\text { Most } \mathrm{CH}, \mathrm{CH}_{2} \beta \\
\text { hydroaromatic }\end{array}$ & $1.9-1.7$ & 1.0 & 1.4 & 1.2 & 1.2 & 1.3 & 1.1 & 1.3 & 1.6 & 1.0 & 1.6 & 1.2 & 1.6 & 1.3 \\
\hline$\alpha$ to olefinic & $2.1-1.9$ & 3.3 & 5.0 & 4.1 & 3.8 & 4.5 & 3.8 & 4.5 & 5.8 & 3.4 & 5.7 & 4.0 & 5.7 & 4.5 \\
\hline $\begin{array}{l}\mathrm{CH}_{3} \alpha \text { to aromatic } \\
\text { carbons }\end{array}$ & $2.4-2.1$ & 19.3 & 20.6 & 20.4 & 20.2 & 21.1 & 20.3 & 20.9 & 21.1 & 19.7 & 21.5 & 20.5 & 21.5 & 20.6 \\
\hline $\begin{array}{l}\mathrm{CH}, \mathrm{CH}_{2} \alpha \text { to aromatic } \\
\text { carbons }\end{array}$ & $3.5-2.4$ & 13.8 & 10.0 & 11.7 & 13.3 & 11.2 & 13.1 & 12.0 & 9.2 & 14.2 & 10.3 & 12.6 & 10.3 & 11.8 \\
\hline $\begin{array}{l}\mathrm{CH}_{2} \text { bridge } \\
\text { (diphenylmethane) }\end{array}$ & $4.5-3.5$ & 0.4 & 0.2 & 0.5 & 0.6 & 0.4 & 0.7 & 0.4 & 0.3 & 0.8 & 0.3 & 0.6 & 0.3 & 0.5 \\
\hline Olefinic & $\begin{array}{c}6.0-4.5 \\
\text { total } \\
\text { aliphatics }\end{array}$ & $\begin{array}{r}0.1 \\
59.6\end{array}$ & $\begin{array}{c}0.1 \\
56.8\end{array}$ & $\begin{array}{c}0.1 \\
57.1\end{array}$ & $\begin{array}{r}0.2 \\
59.2\end{array}$ & 55.5 & $\begin{array}{r}0.1 \\
55.7\end{array}$ & 58.4 & $\begin{array}{r}0.1 \\
56.6\end{array}$ & $\begin{array}{r}0.0 \\
56.6\end{array}$ & 58.1 & 55.3 & $\begin{array}{r}0.1 \\
58.1\end{array}$ & $\begin{array}{c}0.1 \\
57.3\end{array}$ \\
\hline Single ring aromatic & $7.2-6.0$ & 12.1 & 14.6 & 13.4 & 12.8 & 14.1 & 12.8 & 13.3 & 14.9 & 12.0 & 14.9 & 13.3 & 14.9 & 13.6 \\
\hline $\begin{array}{l}\text { Diaromatic and most of } \\
\text { tri- and tetraromatic } \\
\text { Some tri- and }\end{array}$ & $8.3-7.2$ & 26.7 & 27.6 & 28.2 & 26.6 & 29.2 & 29.7 & 27.1 & 27.5 & 29.3 & 26.2 & 29.8 & 26.2 & 27.8 \\
\hline tetraromatic rings & $8.9-8.3$ & 1.5 & 1.0 & 1.3 & 1.4 & 1.2 & 1.8 & 1.2 & 1.0 & 2.1 & 0.8 & 1.6 & 0.8 & 1.3 \\
\hline Some tetraromatic rings & $\begin{array}{c}9.3-8.9 \\
\text { total } \\
\text { aromatics }\end{array}$ & $\begin{array}{r}0.1 \\
\mathbf{4 0 . 4}\end{array}$ & $\begin{array}{r}0.0 \\
43.2 \\
\end{array}$ & $\begin{array}{r}0.0 \\
42.9\end{array}$ & $\begin{array}{r}0.0 \\
\mathbf{4 0 . 8}\end{array}$ & 0.0 & $\begin{array}{r}0.1 \\
44.3\end{array}$ & $\begin{array}{r}0.0 \\
41.6 \\
\end{array}$ & $\begin{array}{r}0.0 \\
43.4 \\
\end{array}$ & $\begin{array}{r}0.0 \\
43.5 \\
\end{array}$ & $\begin{array}{r}0.1 \\
\mathbf{4 1 . 9}\end{array}$ & $\begin{array}{r}0.0 \\
44.7 \\
\end{array}$ & $\begin{array}{r}0.1 \\
\mathbf{4 1 . 9}\end{array}$ & $\begin{array}{r}0.0 \\
\mathbf{4 2 . 8}\end{array}$ \\
\hline
\end{tabular}


Table 5-8. Distribution of ${ }^{13} \mathrm{C}$ NMR signals as a function of time of delayed co-coking of Pittsburg Seam coal with decant oil (4:1 Ratio)

\begin{tabular}{|c|c|c|c|c|c|c|c|c|c|c|c|c|c|c|}
\hline & & & $\# 52$ & & & $\# 54$ & & & $\# 56$ & & & \#58 & & \\
\hline $\begin{array}{r}\text { Assignments } \\
\end{array}$ & Bands & $1^{\text {st }} \mathrm{hr}$. & $3^{\text {rd }} \mathrm{hr}$. & $5^{\text {th }} \mathrm{hr}$. & $1^{\text {st }} \mathrm{hr}$. & $3^{\text {rd }} \mathrm{hr}$. & $5^{\text {th }} \mathrm{hr}$. & $1^{\text {st }} \mathrm{hr}$. & $3^{\text {rd }} \mathrm{hr}$. & $5^{\text {th }} \mathrm{hr}$. & $1^{\text {st }} \mathrm{hr}$. & $3^{\text {rd }} \mathrm{hr}$. & $5^{\text {th }} \mathrm{hr}$. & Mean \\
\hline $\begin{array}{l}\mathrm{CH}_{3} \gamma \text { and further from aromatic ring } \\
\mathrm{CH} 3 \text { in ethyl substituted cyclohexane }\end{array}$ & $12.5-11.0$ & 0.2 & 0.1 & 0.2 & 0.2 & 0.2 & 0.2 & 0.2 & 0.2 & 0.2 & 0.2 & 0.2 & 0.2 & 0.2 \\
\hline $\begin{array}{l}\mathrm{CH}_{3} \gamma \text { and further from aromatic ring } \\
\mathrm{CH}_{3} \alpha \text { shielded by two adjacent rings or groups }\end{array}$ & $15.0-12.5$ & 1.7 & 1.5 & 1.4 & 1.7 & 1.4 & 1.4 & 1.6 & 1.4 & 1.4 & 1.5 & 1.3 & 1.4 & 1.5 \\
\hline $\begin{array}{l}\mathrm{CH}_{3} \alpha \text { shielded by one adjacent ring or group } \\
\text { Some } \mathrm{CH}_{3} \text { a hydroaromatic and naphthenic } \mathrm{CH}_{2} \\
\mathrm{CH}_{2} \alpha \text { shielded by one adjacent rings or group }\end{array}$ & $18.0-15.0$ & 1.5 & 1.5 & 1.5 & 1.7 & 1.5 & 1.5 & 1.6 & 1.5 & 1.5 & 1.6 & 1.5 & 1.5 & 1.5 \\
\hline $\begin{array}{l}\mathrm{CH}_{3} \alpha \text { shielded by one adjacent rings or group } \\
\text { Some } \mathrm{CH}_{3} \text { a hydroaromatic and naphthenic } \mathrm{CH}_{2}\end{array}$ & $20.5-18.0$ & 4.7 & 4.4 & 4.4 & 4.8 & 4.4 & 4.6 & 4.7 & 4.4 & 4.4 & 4.6 & 4.3 & 4.5 & 4.5 \\
\hline $\begin{array}{l}\mathrm{CH}_{3} \text { not shielded by adjacent rings or groups } \\
\text { Some } \mathrm{CH}_{3} \text { a hydroaromatic and naphthenic } \mathrm{CH}_{2} \\
\mathrm{CH}_{2} \gamma \text { and further adjacent to terminal } \mathrm{CH}_{3}\end{array}$ & $22.5-20.5$ & 4.5 & 4.3 & 4.5 & 4.4 & 4.4 & 4.3 & 4.5 & 4.4 & 4.4 & 4.5 & 4.4 & 4.4 & 4.4 \\
\hline $\begin{array}{l}\mathrm{CH}_{2} \beta \text { in unsubstituted tetralin structures } \\
\text { Some } \mathrm{CH}_{2} \text { naphthenic, } \mathrm{CH}_{2} \alpha \text { not shielded }\end{array}$ & $24.0-22.5$ & 1.1 & 0.8 & 1.0 & 0.8 & 0.8 & 0.6 & 0.9 & 0.9 & 0.9 & 1.0 & 0.8 & 0.9 & 0.9 \\
\hline $\begin{array}{l}\mathrm{CH}_{2} \beta \text { in propyl and indan groups, } \mathrm{CH}_{3} \beta \text { in isopropyl } \\
\mathrm{CH}_{2} \text { not adjacent to } \mathrm{CH} \text { in alkyl groups } \\
\mathrm{CH}_{2} \text { adjacent to alkyl } \mathrm{CH} \text { in some } \mathrm{CH}_{2} \text { a and } \mathrm{CH}_{2} \text { adjacent to } \\
\text { terminal } \mathrm{CH}_{3} \text { in alkyl substituents with more than four carbons } \\
\mathrm{CH}_{2} \text { in ring joining ethylene groups, Some } \mathrm{CH}_{2} \text { naphthenic } \\
\text { Some ring joining methylene ( } 32-43 \mathrm{ppm})\end{array}$ & $27.5-24.0$ & 1.1 & 1.0 & 1.2 & 1.0 & 1.0 & 0.9 & 1.2 & 1.1 & 1.2 & 1.3 & 1.1 & 1.2 & 1.1 \\
\hline $\begin{array}{l}\mathrm{CH} \text { alkyl groups (except isoalkyl), } \mathrm{CH} \text { naphthenic } \\
\mathrm{CH}_{2} \text { alkyl groups adjacent to } \mathrm{CH}\end{array}$ & & & & & & & & & & & & & & \\
\hline Some ring joining methylene (32-43 ppm) & $60.0-37.0$ & 2.3 & 2.1 & 3.0 & 2.0 & 2.5 & 2.1 & 2.9 & 2.9 & 2.8 & 3.2 & 2.8 & 2.8 & 2.6 \\
\hline & total aliphatics & 24.4 & 22.3 & 23.9 & 23.0 & 22.1 & 20.9 & 24.3 & 23.3 & 22.9 & 24.5 & 22.3 & 23.3 & 23.1 \\
\hline Some olefinic (others spread through aromatic region) & $118.0-108.0$ & 1.1 & 1.0 & 1.7 & 1.2 & 1.4 & 1.4 & 1.5 & 1.5 & 2.0 & 1.5 & 1.9 & 2.0 & 1.5 \\
\hline $\begin{array}{l}\text { Protonated aromatic } \\
\text { Some internal (quaternary) aromatic }\end{array}$ & $129.5-118.0$ & 47.7 & 48.9 & 49.4 & 47.9 & 50.6 & 50.4 & 48.9 & 49.7 & 50.4 & 49.0 & 50.9 & 50.3 & 49.5 \\
\hline Most internal aromatic & $133.0-129.5$ & 10.9 & 11.1 & 10.5 & 10.9 & 10.8 & 11.0 & 10.4 & 10.5 & 10.5 & 10.3 & 10.5 & 10.3 & 10.6 \\
\hline Methyl substituted aromatic & $135.0-133.0$ & 3.9 & 3.9 & 3.7 & 4.1 & 3.8 & 3.9 & 3.8 & 3.9 & 3.7 & 3.9 & 3.7 & 3.8 & 3.8 \\
\hline \multirow{3}{*}{$\begin{array}{l}\text { Naphthenic substituted aromatic } \\
\text { Alkyl (other than methyl) substituted aromatic Heteroatom (N, } \\
\mathrm{O}, \mathrm{S} \text { ) aromatic }\end{array}$} & $138.0-135.0$ & 5.7 & 5.7 & 5.3 & 5.7 & 5.4 & 5.6 & 5.3 & 5.2 & 5.2 & 5.1 & 5.3 & 5.0 & 5.4 \\
\hline & $160.0-138.0$ & 6.4 & 7.1 & 5.6 & 7.2 & 6.0 & 6.7 & 5.8 & 6.0 & 5.4 & 5.7 & 5.5 & 5.3 & 6.1 \\
\hline & total aromatics & 75.6 & 77.7 & 76.1 & 77.0 & 77.9 & 79.1 & 75.7 & 76.7 & 77.1 & 75.5 & 77.8 & 76.7 & 76.9 \\
\hline
\end{tabular}


Even though there was no significant difference between ${ }^{1} \mathrm{H}$ NMR integration bands of samples (Table 5-7), when each individual run is evaluated separately, the first sample had always higher total aliphatic hydrogens than second and third samples. The reverse was true for the total aromatic hydrogen signals. One can conclude that at first stage mostly long carbonchain aliphatics or aliphatic side chain containing aromatics were thermally cleaved and distilled. Upon further thermal cracking, small distillable aromatics may come from trapped aromatic structures, and thermally cracked molecules from the coke artifact might have increased the aromatic hydrogen signals with time.

Aliphatic hydrogens from the ${ }^{1} \mathrm{H}$ NMR spectra consisted of hydrogens $\beta$ to $\mathrm{CH}_{2}$ and $\mathrm{CH}_{3}$ in the aliphatic hydrocarbon (12.9\%), $\mathrm{CH}_{3}$ hydrogens $\alpha$ to aromatic carbons $(20.6 \%)$, and $\mathrm{CH}$, $\mathrm{CH}_{2}$ hydrogens $\alpha$ to aromatic carbons (11.8\%). Aromatic hydrogens from the ${ }^{1} \mathrm{H}$ NMR spectra were mostly consisted of single ring aromatic hydrogens (13.6\%) and approximately two-fold higher 2-, 3-, and 4- fused ring aromatic hydrogens (27.8\%).

As determined by ${ }^{1} \mathrm{H}$ NMR, the average values were $57.3 \%$ for total aliphatics and $42.7 \%$ for total aromatics as calculated for 12 samples. These values are the same as original decant oil values that are $57.0 \%$ and $43.0 \%$.

${ }^{13} \mathrm{C}$ NMR results prove the total aliphatic hydrogens decrease with time for individual experiment (Table 5-8). First samples always had higher total aliphatic carbons signal in each individual experiment and this finding is consistent with ${ }^{1} \mathrm{H}$ NMR analyses results. Overhead liquid content was consisted of mainly aromatic carbons. Total aliphatic carbons and total aromatic carbons calculated as $23.1 \%$ and $76.9 \%$, respectively. Total aliphatic carbons content of original decant oil (25.0\%) was slightly higher than overhead liquid, but the reverse was true for the total aromatic carbons $(75.0 \%)$. 
Proton and carbon NMR analyses showed that even though there were slight changes in the integration of ${ }^{1} \mathrm{H}$ and ${ }^{13} \mathrm{C}$ NMR spectra that the standard deviation was low.

Simulated distillation gas chromatograph (Sim-Dis GC) was used to probe refinery boiling range materials change during six hours feeding. The refinery boiling ranges were gasoline (IBP- $\left.180^{\circ} \mathrm{C}\right)$, jet fuel $\left(180-270^{\circ} \mathrm{C}\right)$, diesel $\left(270-332^{\circ} \mathrm{C}\right)$, and fuel oil $\left(332^{\circ} \mathrm{C}-\mathrm{FBP}\right)$. A summary of all cut point ranges on samples of $1^{\text {st }}, 3^{\text {rd }}, 5^{\text {th }}$ hour for 4 replicate runs is found in Table 5. Interpretation of these data shows that there is very good agreement in between each fractions. Even though there were slight differences between Sim-Dis GC injections of each fraction for each separate run, these differences were in the experimental error range. The cut point ranges between replicate experiments were also in very good agreement. The average and average deviation values of gasoline, jet fuel, diesel, and fuel oil ranges were calculated as $2.26 \pm 0.40 \%, 4.64 \pm 0.35 \%, 6.05 \pm 0.13 \%$, and $86.12 \pm 0.15 \%$, respectively.

Boiling point distributions of these time-dependant samples of 4 replicate experiments are given in Table 5-10. First samples ( $1^{\text {st }}$ hour samples $)$ had lower boiling point distributions than second and third samples $\left(3^{\text {rd }}\right.$, and $5^{\text {th }}$ hour). It was generally true for all of replicate experiments that, after the first sample, an increase was observed for each percentage distilled; the percentage distilled values became stable. These boiling point data are consistent with proton and carbon NMR data. These two analyses with two different techniques offer that more polycondensed structures come out from the coker with time since the boiling point ranges and total aromatic hydrogens/carbons increase with time (Tables 5-7, 5-8, and 5-10). 
Table 5-9. Boiling point distributions by simulated distillation gas chromatography.

\begin{tabular}{|c|c|c|c|c|}
\hline \multicolumn{5}{|c|}{$\begin{array}{c}\text { BOILING POINT DISTRIBUTIONS BY SIM-DIST } \\
\text { OF TOTAL LIQUID PRODUCT }\end{array}$} \\
\hline & IBP $-180^{\circ} \mathrm{C}$ & $180-270{ }^{\circ} \mathrm{C}$ & $270-332{ }^{\circ} \mathrm{C}$ & 332-FBP ${ }^{\circ} \mathrm{C}$ \\
\hline & $\begin{array}{l}\text { IBP-356 } \\
\text { Gasoline }\end{array}$ & $\begin{array}{l}356-518^{\circ} \mathrm{F} \\
\text { jet fuel }\end{array}$ & $\begin{array}{c}518-630^{\circ} \mathrm{F} \\
\text { diesel }\end{array}$ & $\begin{array}{l}630-\mathrm{FBP}{ }^{\circ} \mathrm{F} \\
\text { fuel oil }\end{array}$ \\
\hline \multicolumn{5}{|l|}{$\# 1^{\text {st }}$ run } \\
\hline $1^{\text {st }} \mathrm{hr}$. & 1.76 & 6.33 & 6.56 & 84.40 \\
\hline $3^{\text {rd }} \mathrm{hr}$. & 1.27 & 4.88 & 5.87 & 87.03 \\
\hline $5^{\text {th }} \mathrm{hr}$. & 1.36 & 4.78 & 5.88 & 87.02 \\
\hline Mean (Sim-Dis) & 1.46 & 5.33 & 6.10 & 86.15 \\
\hline \multicolumn{5}{|l|}{$\# 2^{\text {nd }}$ run } \\
\hline $1^{\text {st }} \mathrm{hr}$. & 3.49 & 5.25 & 6.91 & 83.40 \\
\hline $3^{\text {rd }} \mathrm{hr}$. & 2.07 & 3.69 & 5.92 & 87.41 \\
\hline $5^{\text {th }} \mathrm{hr}$. & 2.21 & 3.73 & 5.84 & 87.29 \\
\hline Mean (Sim-Dis) & 2.59 & 4.22 & 6.22 & 86.03 \\
\hline \multicolumn{5}{|l|}{$\# 3^{\text {rd }}$ run } \\
\hline $1^{\text {st }} \mathrm{hr}$. & 2.62 & 4.98 & 6.46 & 84.99 \\
\hline $3^{\text {rd }} \mathrm{hr}$. & 2.66 & 5.04 & 6.17 & 85.23 \\
\hline $5^{\text {th }} \mathrm{hr}$. & 2.09 & 3.86 & 5.64 & 87.51 \\
\hline Mean (Sim-Dis) & 2.46 & 4.63 & 6.09 & 85.91 \\
\hline \multicolumn{5}{|l|}{$\# 4^{\text {th }}$ run } \\
\hline $1^{\text {st }} \mathrm{hr}$. & 2.82 & 4.71 & 6.04 & 85.47 \\
\hline $3^{\text {rd }} \mathrm{hr}$. & 2.28 & 4.01 & 5.49 & 87.26 \\
\hline $5^{\text {th }} \mathrm{hr}$ & 2.47 & 4.36 & 5.83 & 86.45 \\
\hline Mean (Sim-Dis) & 2.52 & 4.36 & 5.79 & 86.39 \\
\hline \multicolumn{5}{|c|}{ Mean values for 4 replicate runs } \\
\hline & 2.26 & 4.64 & 6.05 & 86.12 \\
\hline \multicolumn{5}{|c|}{ Average Deviation Values for 4 replicate runs } \\
\hline & 0.40 & 0.35 & 0.13 & 0.15 \\
\hline
\end{tabular}


Table 5-10. Simulated distillation boiling point distributions of coker distillates

\begin{tabular}{|c|c|c|c|c|c|c|c|c|c|c|c|c|}
\hline & \multicolumn{3}{|c|}{ \#52 } & \multicolumn{3}{|c|}{$\# 54$} & \multicolumn{3}{|c|}{$\# 56$} & \multicolumn{3}{|c|}{ \#58 } \\
\hline$\% \operatorname{Dis}^{\mathrm{a}}$ & $1^{\text {st }} \mathrm{hr}$. & $3^{\text {rd }} \mathrm{hr}$. & $5^{\text {th }} \mathrm{hr}$. & $1^{\text {st }} \mathrm{hr}$. & $3^{\mathrm{rd}} \mathrm{hr}$. & $5^{\text {th }} \mathrm{hr}$. & $1^{\text {st }} \mathrm{hr}$. & $3^{\text {rd }} \mathrm{hr}$. & $5^{\text {th }} \mathrm{hr}$. & $1^{\text {st }} \mathrm{hr}$. & $3^{\text {rd }} \mathrm{hr}$. & $5^{\text {th }} \mathrm{hr}$. \\
\hline IBP & 43.9 & 48.5 & 45.1 & 39.5 & 40.7 & 40.2 & 38.3 & 38.5 & 38.5 & 37.9 & 38.0 & 39.1 \\
\hline 20 & 339.9 & 346.5 & 343.5 & 341.6 & 350.8 & 350.6 & 341.9 & 342.3 & 349.4 & 342.3 & 349.6 & 345.6 \\
\hline 30 & 378.2 & 391.4 & 387.7 & 380.3 & 392.4 & 392.6 & 385.0 & 387.5 & 391.9 & 385.6 & 391.9 & 391.4 \\
\hline 40 & 392.8 & 399.0 & 398.1 & 394.1 & 400.1 & 400.7 & 394.6 & 396.5 & 399.9 & 394.7 & 400.3 & 399.4 \\
\hline 60 & 409.4 & 416.3 & 415.5 & 410.1 & 417.3 & 418.4 & 411.2 & 414.7 & 417.3 & 411.1 & 419.2 & 417.0 \\
\hline 70 & 419.6 & 429.1 & 427.6 & 420.0 & 429.2 & 431.1 & 421.4 & 426.7 & 429.8 & 420.9 & 431.9 & 429.3 \\
\hline 80 & 432.1 & 442.4 & 443.1 & 432.8 & 443.7 & 446.5 & 433.8 & 440.5 & 445.5 & 432.7 & 446.6 & 444.9 \\
\hline 90 & 448.7 & 461.1 & 462.3 & 450.8 & 462.2 & 467.1 & 450.3 & 459.7 & 466.0 & 448.8 & 468.4 & 464.1 \\
\hline FBP & 495.9 & 510.2 & 515.2 & 499.2 & 511.2 & 524.6 & 497.4 & 510.3 & 523.5 & 491.9 & 524.4 & 511.8 \\
\hline
\end{tabular}

a Percent Distilled 
Comparison of fraction yields and characterization of liquid product. Bulk overhead liquids were injected to Sim-Dis GC as described above in terms of repeatability. Product distributions by weight from Sim-Dis GC are given in Table 5-11. Repeatability of Sim-Dis GC analyses of replicate experiments was excellent and the values were all in experimental error. According to simulated distillation GC analyses, the averages and average deviations of the refinery boiling ranges were calculated as $2.10 \pm 0.05 \%$ gasoline, $3.59 \pm 0.15 \%$ jet fuel, $4.55 \pm 0.18 \%$ diesel, and $88.81 \pm 0.29 \%$ fuel oil.

The bulk overhead liquids were also vacuum-fractionated into refinery boiling ranges. For vacuum distillation, approximately $1200 \mathrm{~g}$ liquid sample was taken in to $2 \mathrm{~L}$ flask as described in Section 2.4. Vacuum fractionation results by weight are found in Table 5-12. Repeatability of vacuum distillation fractions for 4 replicate runs was in very good agreement. Average values for vacuum fractions as follows: gasoline 2.33\%, jet fuel 3.98\%, diesel 5.04\%, and fuel oil $87.70 \%$. There is excellent agreement between the results obtained by simulated distillation GC and the actual isolated yields of the fractions from the vacuum distillation (Table 5-11 and 5-12).

Table 5-11. Product distributions by weight from simulated distillation.

\begin{tabular}{|c|c|c|c|c|}
\hline $\begin{array}{r}\text { PRODUCT DI } \\
\text { FI }\end{array}$ & $\begin{array}{l}\text { STRIBUT } \\
\text { OM SIMUI }\end{array}$ & $\begin{array}{l}\text { NS BY W } \\
\text { TED DISTI }\end{array}$ & $\begin{array}{l}\text { IGHT } \\
\text { LATION GC }\end{array}$ & \\
\hline & IBP- $180^{\circ} \mathrm{C}$ & $180-270{ }^{\circ} \mathrm{C}$ & $270-332^{\circ} \mathrm{C}$ & 332-FBP ${ }^{\circ} \mathrm{C}$ \\
\hline Run No & $\begin{array}{l}\text { IBP-356 }{ }^{\circ} \mathbf{F} \\
\text { Gasoline }\end{array}$ & $\begin{array}{c}356-518^{\circ} \mathrm{F} \\
\text { jet fuel }\end{array}$ & $\begin{array}{c}518-630^{\circ} \mathrm{F} \\
\text { diesel }\end{array}$ & $\begin{array}{l}\text { 630-FBP }{ }^{\circ} \mathrm{F} \\
\text { fuel oil }\end{array}$ \\
\hline$\# 52$ & 2.09 & 3.42 & 4.42 & 89.13 \\
\hline \#54 & 2.02 & 3.40 & 4.37 & 89.23 \\
\hline$\# 56$ & 2.23 & 3.72 & 4.40 & 88.71 \\
\hline$\# 58$ & 2.05 & 3.83 & 5.01 & 88.18 \\
\hline Mean & 2.10 & 3.59 & 4.55 & 88.81 \\
\hline Average Deviation & 0.05 & 0.15 & 0.18 & 0.29 \\
\hline
\end{tabular}


Table 5-12. Product distributions by weight from vacuum distillation.

\begin{tabular}{|c|c|c|c|c|}
\hline \multicolumn{5}{|c|}{$\begin{array}{l}\text { PRODUCT DISTRIBUTIONS BY WEIGHT } \\
\text { FROM VACUUM DISTILLATION }\end{array}$} \\
\hline & IBP $-180^{\circ} \mathrm{C}$ & $180-270{ }^{\circ} \mathrm{C}$ & $270-332{ }^{\circ} \mathrm{C}$ & 332-FBP ${ }^{\circ} \mathrm{C}$ \\
\hline Run No & $\begin{array}{l}\text { IBP-356 }{ }^{\circ} \mathrm{F} \\
\text { Gasoline }\end{array}$ & $\begin{array}{l}356-518^{\circ} \mathrm{F} \\
\text { jet fuel }\end{array}$ & $\begin{array}{l}518-630^{\circ} \mathrm{F} \\
\text { diesel }\end{array}$ & $\begin{array}{l}630-\mathrm{FBP}^{\circ} \mathrm{F} \\
\text { fuel oil }\end{array}$ \\
\hline$\# 52$ & 2.59 & 4.99 & 4.96 & 87.26 \\
\hline$\# 54$ & 1.96 & 3.79 & 5.54 & 87.35 \\
\hline$\# 56$ & 2.35 & 3.64 & 4.83 & 87.87 \\
\hline$\# 58$ & 2.41 & 3.51 & 4.84 & 88.32 \\
\hline Mean & 2.33 & 3.98 & 5.04 & 87.70 \\
\hline Average Deviation & 0.17 & 0.43 & 0.21 & 0.34 \\
\hline
\end{tabular}

Comparison of fraction yields and characterization of liquid product. Collected vacuum fractions (gasoline, jet fuel, diesel, fuel oil) were characterized using ${ }^{1} \mathrm{H}$ and ${ }^{13} \mathrm{C}$ NMR and GC/MS techniques in terms of vacuum distillation repeatability, chemical composition distribution, and compositional differences between fractions. Tables 5-13 and 5-14 show ${ }^{1} \mathrm{H}$ and ${ }^{13} \mathrm{C}$ NMR results of collected vacuum fractions of overhead liquids of co-coking experiments. Proton and carbon NMR results of original overhead liquid were also given in these tables. Aliphatic protons showed a decrease from gasoline to fuel oil $(89.3 \% \rightarrow 52.9 \%)$, and the reverse was true for the aromatic protons $(10.7 \% \rightarrow 47.1 \%)$. Fuel oil fraction had less aliphatic hydrogen and more aromatic hydrogen than original overhead liquid. Carbon NMR results (Table 5-14) show proton NMR (Table 5-13) observations in which aliphatic carbon percentages decrease and aromatic carbon percentages increase from gasoline to fuel oil.

Proton and carbon NMR spectra, signal intensities and changes for gasoline, jet fuel, diesel, and fuel oil are given in Figures 5-17 and 5-18, respectively. As expected, gasoline proton NMR spectra showed one- and two-ring aromatic hydrogens in low intensity (Figure 517). Jet fuel had a wider aromatic proton signal than gasoline, but the signal intensities were low 
when compared to aliphatic proton signals. Diesel and fuel oil proton NMR spectra similar to each other but the peak intensities were different, e.g. peaks at higher than 8 ppm frequency was more intense in fuel oil spectra. In fuel oil spectra, the intensity of aromatic hydrogens was increased and also poly-condensed aromatic carbon hydrogens were observed. Carbon NMR spectra also confirms proton NMR results that aliphatic carbon peak intensities decrease from gasoline to fuel oil. When aromatic carbon to aliphatic carbon peak intensity ratios are compared for each fraction, it increases from gasoline to fuel oil (Figure 5-17). These observations are consistent with Tables 5-13 and 5-14.

Vacuum fractions from distillation were analyzed using GC/MS and the compositions of the fractions were grouped as: paraffins, saturated cyclics, indanes, alkyl benzenes, naphthalenes, and polycyclic aromatic compounds. No tetralins and decalins were observed with GC/MS, and they were not included to the related table. The results are given in Table 5-15. The percentage of each group was calculated by comparing the areas of each group to total area. Table 5-15 reports that gasoline fraction mostly consisted of paraffins, cycloparaffins and benzenes, including small amount of indanes and naphthalenes. Jet fuel had a higher percentage of paraffins and naphthalenes, but lower benzenes and cycloparaffins than gasoline. Jet fuel also had very small quantity of polycyclic aromatics. If naphthalenes and benzenes are hydrogenated enough to obtain cyclostructures, hydrogenated fuel can be used as thermally stable jet fuel, since cyclo-structures have been shown as the highest thermally stable molecules at higher temperatures. ${ }^{3}$ The diesel fraction had the least paraffins and cycloparaffins, but the most polycyclic aromatics (54\%). These findings are consistent with proton NMR results. 
Table 5-13. Distribution of ${ }^{1} \mathrm{H}$ NMR signals of delayed co-coking of Pittsburgh Seam coal with decant oil (4:1 Ratio)

\begin{tabular}{|l|c|c|}
\hline & Mean & Std. Dev. \\
\hline Overhead Liq. $\left(\mathrm{H}_{\mathrm{Al}}\right)$ & 57.26 & 1.43 \\
Overhead Liq. $\left(\mathrm{H}_{\mathrm{Ar}}\right)$ & 42.74 & 1.43 \\
\hline Gasoline $\left(\mathrm{H}_{\mathrm{Al}}\right)$ & 89.32 & 0.98 \\
Gasoline $\left(\mathrm{H}_{\mathrm{Ar}}\right)$ & 10.68 & 0.98 \\
\hline Jet Fuel $\left(\mathrm{H}_{\mathrm{Al}}\right)$ & 85.72 & 1.85 \\
Jet Fuel $\left(\mathrm{H}_{\mathrm{Ar}}\right)$ & 14.28 & 1.85 \\
\hline Diesel $\left(\mathrm{H}_{\mathrm{Al}}\right)$ & 67.49 & 1.19 \\
Diesel $\left(\mathrm{H}_{\mathrm{Ar}}\right)$ & 32.51 & 1.19 \\
\hline Fuel Oil $\left(\mathrm{H}_{\mathrm{Al}}\right)$ & 52.92 & 0.10 \\
Fuel Oil $\left(\mathrm{H}_{\mathrm{Ar}}\right)$ & 47.08 & 0.10 \\
\hline
\end{tabular}

Table 5-14. Distribution of ${ }^{13} \mathrm{C}$ NMR signals of delayed co-coking of Pittsburgh Seam coal with decant oil (4:1 Ratio)

\begin{tabular}{|l|c|c|}
\hline & Mean & Std. Dev. \\
\hline Overhead Liq. $\left(\mathrm{C}_{\mathrm{Al}}\right)$ & 23.10 & 1.09 \\
Overhead Liq. $\left(\mathrm{C}_{\mathrm{Ar}}\right)$ & 76.90 & 1.09 \\
\hline Gasoline $\left(\mathrm{C}_{\mathrm{Al}}\right)$ & 66.38 & 1.72 \\
Gasoline $\left(\mathrm{C}_{\mathrm{Ar}}\right)$ & 33.62 & 1.72 \\
\hline Jet Fuel $\left(\mathrm{C}_{\mathrm{Al}}\right)$ & 58.61 & 1.70 \\
Jet Fuel $\left(\mathrm{C}_{\mathrm{Ar}}\right)$ & 40.56 & 1.70 \\
\hline Diesel $\left(\mathrm{C}_{\mathrm{Al}}\right)$ & 35.49 & 0.21 \\
Diesel $\left(\mathrm{C}_{\mathrm{Ar}}\right)$ & 64.51 & 0.21 \\
\hline Fuel Oil $\left(\mathrm{C}_{\mathrm{Al}}\right)$ & 21.14 & 0.26 \\
Fuel Oil $\left(\mathrm{C}_{\mathrm{Ar}}\right)$ & 78.86 & 0.26 \\
\hline
\end{tabular}




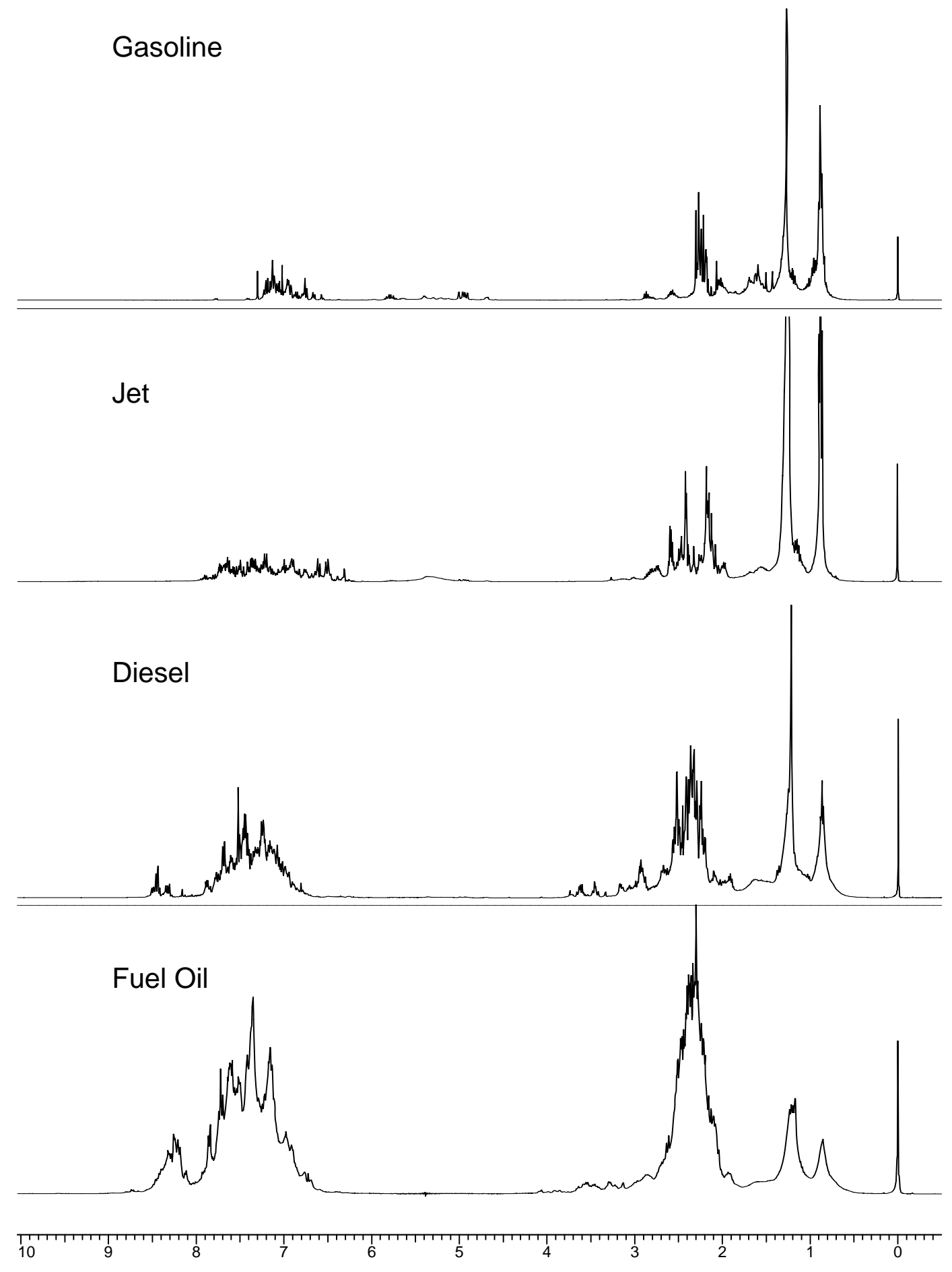

Figure 5-17. ${ }^{1} \mathrm{H}$ NMR spectra of vacuum distillation fractions. 


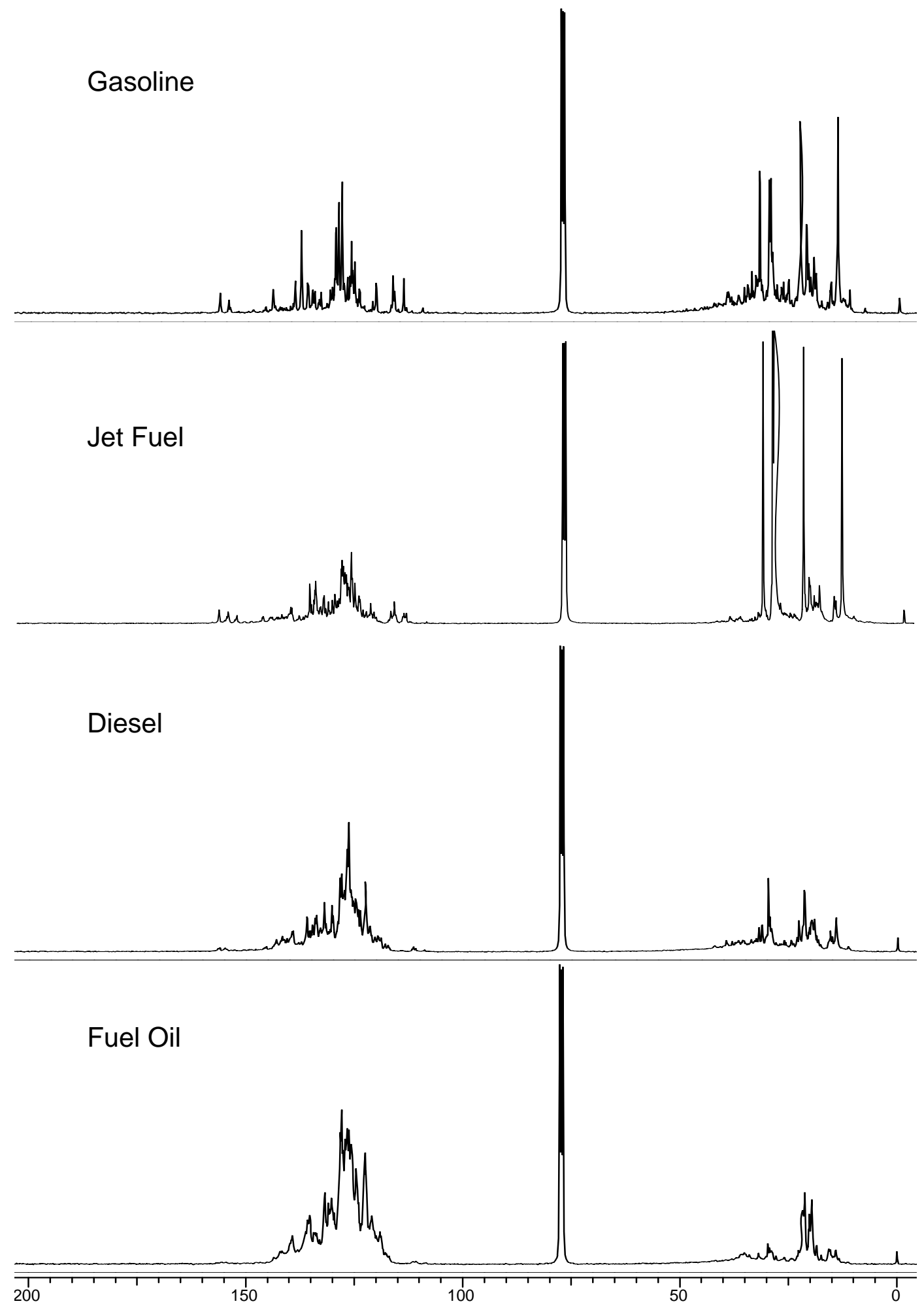

Figure 5-17. ${ }^{13} \mathrm{C}$ NMR spectra of vacuum distillation fractions. 
Table 5-15. Chemical compositions of vacuum fractions based on semi-quantitative GC/MS results

\begin{tabular}{lccc}
\hline Chemical Groups & Gasoline & Jet Fuel & Diesel \\
\hline paraffins & 40.10 & 50.33 & 3.30 \\
cyclo paraffins & 18.17 & 3.79 & 2.11 \\
benzenes & 38.30 & 15.98 & 18.62 \\
indanes & 2.42 & 5.30 & 2.20 \\
naphthalenes & 1.01 & 24.45 & 19.47 \\
tri-ring + & 0.00 & 0.08 & 54.29 \\
\hline
\end{tabular}

\section{Subtask 5.3.2 Production of RCO from Coal Extraction}

There are two problems that need resolution if RCO is to be used within the refinery. The first has to do with potential limitations in future supply of RCO from coal tar processing within the US. It is important to consider alternative ways to produce the chemical equivalent of RCO from coal in an inexpensive process, particularly not involving a coke oven.

The second issue is due to some inhomogenity within the coke when co-coking. The cocoking process can produce carbon products with different properties than those produced in the current delayed coker. However, to generate a premium carbon product, the mineral matter from coal must be minimized (certainly below 1.0\%) and the carbonaceous solid residue derived from coal must be homogenized with that being generated from petroleum residua during delayed coking. ${ }^{13}$ As will be described in Subtask 5.4, one of the issues in producing coke from this process is the ash content of the resulting product. Another issue is that within the carbon artifact from co-coking, there is some separation of the coal and decant oil so that the carbon is not as homogenized as we would like.

The alternative RCO process should be able to be integrated into a refinery, so it should use unit operations, chemical reagents and/or solvents that are used or produced in a refinery. The processes expected to be used should not require expensive reagents like catalysts and 
hydrogen consumption. Potential processes that could possibly produce useful two-ring compounds from coal and meet these criteria involve some form of solvent extraction of coal.

Yoshida et al. ${ }^{14-17}$ reported that an ashless coal with less than $0.1 \%$ in ash content, referred as "Hypercoal", can be produce from bituminous coals by mean of an extraction process using a cost-effective industrial solvent like LCO or decant oil. Based on this research, we are beginning to investigate the co-coking behavior of a material produced from coal extraction of bituminous coal using decant oil or LCO as a solvent.

In previous work, we have shown that LCO can extract up to $50 \%$ of coal using a singlestage batch process, but solvent to coal ratios of 10:1 had to be used in order to get these yields [ref]. Based on this work and research by others, we believe that a multistage process that can filter the products while hot will significantly increase this yield and provide significant conversion of bituminous coal using industrial refinery solvents. We are in the process of building a high temperature extraction/filtration device which could be used to extract coal using refinery streams like LCO and/or DO. We aim to switch between LCO and DO to produce a feedstock for hydrotreating or a feedstock for the co-coking, respectively. In the first case, using LCO as a solvent for the extraction will allow us to produce liquid material from coal (extract) suitable as feedstock for hydrotreating in the JP-900 production. In the second case, using DO as a solvent for the extraction will allow us to produce a clean (hypercoal) coal that will be used as feedstock for the co-coking process. In both cases the solvent extraction process will save us the steps of blending the extract with these solvents before sending this material for either hydrotreating or co-coking. Figure 5-18 is a schematic of the unit we are building. 


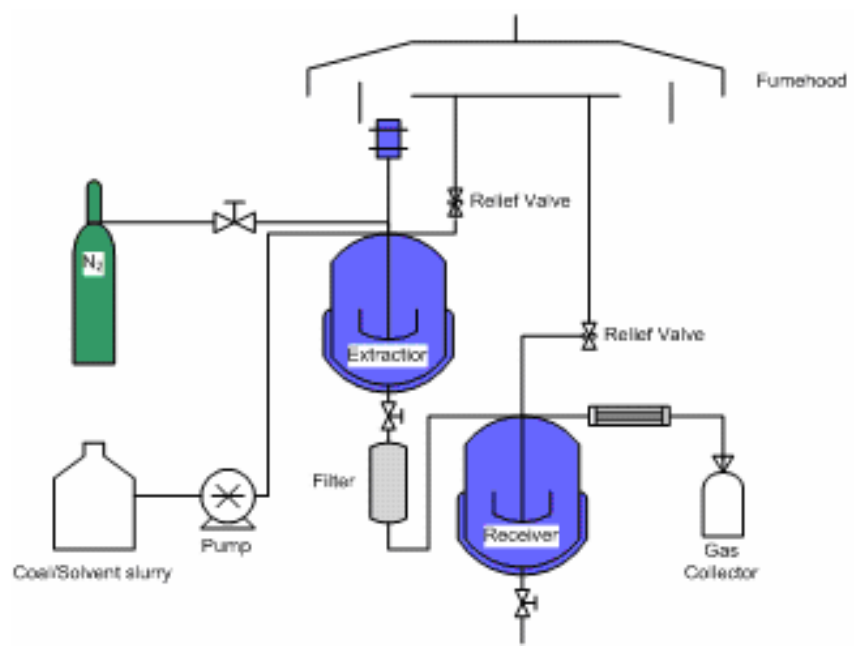

Figure 5-19: Schematic of 2-stage coal extraction reactor, with hot in-line filter. 


\section{Subtask 5.4 Analysis of Co-Coking Coke}

In an effort to determine the value of our Pittsburgh seam co-coke, Alcoa, Inc. agreed to perform cursory laboratory tests using our coke in place of their "standard petroleum coke" for laboratory evaluation of calcined coke, production of bench-scale anodes, and measurement of baked apparent density and electrical resistivity. All that was required for this service was to provide $19 \mathrm{~kg}$ of calcined coke. Alcoa provided the name of a company that they employ for this work, A.J. Edmond. Consequently, in July 2005 about $20 \mathrm{~kg}$ of clean FCE Pittsburgh coal (EI186) was split into $141.3 \mathrm{~kg}$ aliquots and sealed under argon in foil multilaminate bags to be used for 12 consecutive delayed coker runs (\#50-\#61), for analytical evaluation and for reserve. Coking runs were conducted between the last week of July through October, 2005. Toward the end of the coking runs one of the coke artifacts was selected (Run \#55) for subsampling for both optical microscopy and proximate analysis; it was returned to the group of twelve shipped to A.J. Edmond to be crushed, homogenized and calcined. We requested a representative sample of both the green and calcined cokes to be returned to Penn State for evaluation and the remaining calcined coke was shipped to Dr. Angelique Adams at Alcoa for evaluation. In addition, we requested that A.J. Edmond perform the same suit of analyses on our coke that are normally provided to the aluminum industry [Appendix 5-1]. Calcination was completed by 11/8/05 and the sample was supplied to Alcoa shortly thereafter. A report of investigate from Dr. Adams was provided in February 2006 and is included in this report as Appendix 5-2.

\section{Evaluation of Pittsburgh FCE Co-Coke}

Although there were differences among each of the twelve consecutive coker runs in terms of feed duration and amount, various temperatures and amounts of products collected, run 
\#55 represented a point where unit operations were running smoothly and so it was selected to be sectioned for petrography and proximate analysis. Table 5-16 shows some differences with previous coker runs, in that the decant oil/coal mixture was preheated and blended at $121^{\circ} \mathrm{C}$ and the coke was held at $500^{\circ} \mathrm{C}$ for 24 hours. These changes were made to improve the physical and thermal homogeneity of the coke product as was discussed in the last annual report [5-1].

One centimeter thick sections were cut from the $36 \mathrm{~cm}$ long $8.0 \mathrm{~cm}$ diameter coke artifact at the 1-2 cm, 6-7 cm, $12-13 \mathrm{~cm}, 18-19 \mathrm{~cm}, 24-25 \mathrm{~cm}$ and $30-31 \mathrm{~cm}$ levels above the inlet. Subsections from each disk of coke were cut from the outer rim (A) and interior (B), oriented to expose the direction of material flow, imbedded in epoxy and polished for optical microscopy. In addition, outer and interior subsections of the $1-2 \mathrm{~cm}, 12-13 \mathrm{~cm}$ and $24-25 \mathrm{~cm}$ disks were obtained, crushed and homogenized for proximate analysis. Results are shown in Tables 5-17 5-19.

Table 5-16 - Conditions and Yields from the Experimental Delayed Coker

\begin{tabular}{|l|c|}
\hline Conditions & Run \#55 \\
\hline Date & $8 / 30 / 05$ \\
\hline Components & $\begin{array}{c}\text { 4:1Decant Oil/1.280 float of } \\
\text { Pittsburgh FCE EI\#186 }\end{array}$ \\
\hline Feed, hrs & 6 \\
\hline Held at $500{ }^{\circ} \mathrm{C}$, hrs & 24 \\
\hline Feed Rate, g/min & 16.8 \\
\hline Preheater inlet, ${ }^{\circ} \mathrm{C}$ & 121 \\
\hline Preheater Outlet, ${ }^{\circ} \mathrm{C}$ & 439 \\
\hline Coke Drum Inlet, ${ }^{\circ} \mathrm{C}$ & 499 \\
\hline Coke Drum Low $/ \mathrm{mid} .,{ }^{\circ} \mathrm{C}$ & 498 \\
\hline Coke Drum Top, ${ }^{\circ} \mathrm{C}$ & 479 \\
\hline Total Feed, g & 6054 \\
\hline Coke Product, g $(\%)$ & 1660 \\
\hline Liquid Product, g, $(\%)$ & $(27.4 \%)$ \\
\hline Gas Product, g, $(\%)$ & 3813 \\
& $(63.0 \%)$ \\
\hline \hline
\end{tabular}


The raw petrographic data shown in Tables 5-17 and 5-18 for different sections of run \#55, although incomplete, were very similar in some respects to earlier runs using the Pittsburgh seam coal; that is, there was some concentration of coal-derived textures near the bottom-center above the inlet. However, the distinction between the fine-size carbon textures (enhanced vitrinite and mosaic) was difficult to make because of the homogeneity of the carbon. Coalderived carbon textures decreased in concentration between 1-2 and 6-7 cm above the inlet and then diminish significantly at the $12-13 \mathrm{~cm}$ level only to be found to increase again in the $24-25$ $\mathrm{cm}$ section. The ash and volatile matter yields showed the same trend as the petrography (Table 5-19), which suggests a different type of component segregation than has been observed previously. The greater amount of flow domain and domain textures found in section $12-13 \mathrm{~cm}$ above the inlet demonstrates that decant oil-derived carbon was concentrated in this region of the reactor. The coal that passed through this region and deposited above was mostly enhanced vitrinite. Overall the small domain texture $(10-60 \mu \mathrm{m})$ tended to be on the small size approaching $10 \mu \mathrm{m}$ compared with cokes reported on previously [5-1]. Once the petrographic analyses are completed on sections $18-19 \mathrm{~cm}$ and 30-31 cm above inlet perhaps we will have a better understanding of what has occurred in run \#55.

\section{Pittsburgh Composite Samples}

Proximate and petrographic results for the green and calcined composite samples returned from A.J. Edmond are compared with run \#55 in Tables 5-19 - 5-21. Overall the composite coke was very low in ash yield (1.25\%), but higher than anticipated from the $1.0 \%$ ash yield reported from the coal at a $20 \%$ blend ratio with decant oil, the value should have been slightly less than $0.6 \%$. At this time we have no explanation for a higher than anticipated ash 
yield. The main influence of calcination at $1275^{\circ} \mathrm{C}$ was a loss of volatile matter which also served to increase the ash yield further (Table 5-19).

Petrographic analyses (Tables 5-20 and 5-21) of the green and calcined coke show that they were similar. Calcination may tend to cause some aligned domain textures to be seen as flow domains and there may be some enlargement of mosaics into small domain textures, but basically they were the same coke. What is remarkable was that only $13-14 \%$ of the coke textures can be identified as having been derived from coal, whereas by calculation and past experience they should represent about $55 \%$ of the coke. The only explanations for this observation is that 1) the coal and decant oil are being effectively homogenized into small size isochromatic textures and that a portion of the mosaic and perhaps even some of the smaller small domain textures were really coal-derived, or 2) that 20 weight percent coal did not find its way into the reactor in most of the twelve runs. Because of the fairly uniform small size of the carbon textures and the materials balance that was performed after each run, the former is more likely than the latter. If less coal were somehow employed in each run, then the ash yield and concentration of inertinite-derived carbon textures would be much less than has been measure. However, in future runs we will filter the remaining influent to determine the amount of coal actually remaining in the feed bath.

To make a premium anode-grade carbon low ash yield is not the only requirement, but for metal purity there is a requirement to have low silica and iron contents. Consequently, a spectrochemical analysis of the feed coal as well as the green and calcined composite samples was performed and the results are shown in Table 5-22. An aliquot of the cleaned FCE Pittsburgh sample (EI\#186) was evaluated for some important major and minor elements. As shown the greatest contributions to the ash from the coal were $\mathrm{Si}, \mathrm{Al}, \mathrm{Fe}, \mathrm{Ca}$ and $\mathrm{K}$ that are 
derived from aluminosilicate clay minerals, pyrite and calcite which were observed in the bulk coal sample. Most of these minerals were intimately distributed as $<5 \mu \mathrm{m}$ size discrete particles trapped in the vitrinite matrix and which can only be liberated completely by crushing the sample below their particle size. If they are not removed during cleaning they are passed along to the coke as shown in the analyses of the green and calcined coke in Table 5-22. 
Table 5-17 - Petrographic Analysis of Carbon Textures in Coker Sample \#55 by Size and Origin, Vol. \%

\begin{tabular}{|c|c|c|c|c|c|c|c|c|c|c|c|}
\hline \multirow{2}{*}{$\begin{array}{l}\text { Long. } \\
\text { Interval, } \\
\text { cm }\end{array}$} & \multirow{2}{*}{$\begin{array}{c}\text { Cross } \\
\text { Section, } \\
\text { mm }\end{array}$} & \multicolumn{2}{|c|}{ "Vitrinite-derived } & \multirow{2}{*}{$\begin{array}{c}\text { Inert- } \\
\text { derived }\end{array}$} & \multirow{2}{*}{$\begin{array}{l}\text { Isotropic } \\
\text { Vitrinite }\end{array}$} & \multirow{2}{*}{$\begin{array}{c}\text { Min. } \\
\text { Matter }\end{array}$} & \multirow{2}{*}{$\begin{array}{c}\text { Isotropic } \\
\text { Petroleum } \\
\text { derived }\end{array}$} & \multirow{2}{*}{$\begin{array}{c}\text { Mosaic, } \\
<10 \mu \mathrm{m}\end{array}$} & \multirow{2}{*}{ 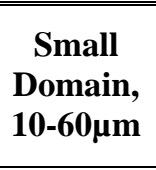 } & \multirow{2}{*}{$\begin{array}{l}\text { Domain } \\
>60 \mu \mathrm{m}\end{array}$} & \multirow{2}{*}{$\begin{array}{c}\text { Flow } \\
\text { Domain, } \\
>60 \mu \mathrm{m} \mathrm{L}, \\
<10 \mu \mathrm{m} \mathrm{W} \\
\end{array}$} \\
\hline & & Enhanced & Non- enhan. & & & & & & & & \\
\hline $1.0-$ & $0.0-19.5$ & 15.1 & "0.0 & 0.8 & 0.0 & 0.0 & 0.2 & 58.2 & 25.3 & 0.4 & 0.0 \\
\hline 2.0 & $19.5-43.0$ & 32.3 & 17.3 & 3.7 & 0.0 & 0.3 & 0.2 & 45.2 & 1.0 & 0.0 & 0.0 \\
\hline $6.0-$ & $0.0-19.0$ & 19.2 & 0.0 & 1.2 & 0.0 & 0.0 & 0.1 & 54.9 & 24.2 & 0.1 & 0.3 \\
\hline 7.0 & $19.0-40.0$ & 16.3 & 11.9 & 1.9 & 0.0 & 0.1 & 0.2 & 41.8 & 26.8 & 0.1 & 0.9 \\
\hline $12.0-$ & $0.0-21.0$ & 1.9 & 0.0 & 0.0 & 0.0 & 0.0 & 0.8 & 12.2 & 71.0 & 8.3 & 5.8 \\
\hline 13.0 & $21.0-43.0$ & 7.3 & 0.0 & 0.4 & 0.0 & 0.0 & 0.2 & 14.1 & 60.7 & 10.2 & 7.1 \\
\hline $18.0-$ & & nd & nd & nd & nd & nd & nd & nd & nd & nd & nd \\
\hline 19.0 & & nd & nd & nd & nd & nd & nd & nd & nd & nd & nd \\
\hline $24.0-$ & $0.0-24.0$ & 15.6 & 0.0 & 1.0 & 0.0 & 0.0 & 0.2 & 43.8 & 37.6 & 0.4 & 1.4 \\
\hline 25.0 & $24.0-42.0$ & 8.5 & 0.0 & 0.7 & 0.0 & 0.0 & 0.5 & 26.2 & 58.8 & 3.7 & 1.6 \\
\hline $30.0-$ & & nd & nd & nd & nd & nd & nd & nd & nd & nd & nd \\
\hline 31.0 & & nd & nd & nd & nd & nd & nd & nd & nd & nd & nd \\
\hline
\end{tabular}

Table 5-18 - Proportion of Textures Derived from Pittsburgh Seam Coal and Decant Oil Compared with the Normalized Concentration of Decant Oil Textures in Coke from Run \#55, Vol. \%.

\begin{tabular}{|c|c|c|c|c|c|c|c|c|}
\hline $\begin{array}{c}\text { Long. } \\
\text { Interval, } \\
\text { cm }\end{array}$ & $\begin{array}{c}\text { Cross } \\
\text { Section, } \\
\text { mm }\end{array}$ & $\begin{array}{c}\% \\
\text { Coal- } \\
\text { derived }\end{array}$ & $\begin{array}{c}\% \\
\text { Petroleum- } \\
\text { derived }\end{array}$ & $\begin{array}{c}\text { Isotropic } \\
\text { Petroleum- } \\
\text { derived }\end{array}$ & $\begin{array}{c}\text { Mosaic, } \\
<10 \mu m\end{array}$ & 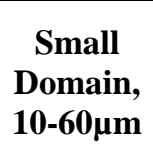 & $\begin{array}{l}\text { Domain } \\
>60 \mu \mathrm{m}\end{array}$ & $\begin{array}{c}\text { Flow } \\
\text { Domain, } \\
>60 \mu \mathrm{m} \mathrm{L,} \\
<10 \mu \mathrm{m} \mathrm{W}\end{array}$ \\
\hline $1.0-$ & $0.0-19.5$ & 15.9 & 84.1 & 0.2 & 69.2 & 30.1 & 0.5 & 0.0 \\
\hline 2.0 & $19.5-43.0$ & 53.6 & 46.4 & 0.4 & 97.4 & 2.2 & 0.0 & 0.0 \\
\hline $6.0-$ & $0.0-19.0$ & 20.4 & 79.6 & 0.1 & 69.0 & 30.4 & 0.1 & 0.4 \\
\hline 7.0 & $19.0-40.0$ & 30.2 & 69.8 & 0.3 & 59.9 & 38.4 & 0.1 & 1.3 \\
\hline $12.0-$ & $0.0-21.0$ & 1.9 & 98.1 & 0.8 & 12.4 & 72.4 & 8.5 & 5.9 \\
\hline 13.0 & $21.0-43.0$ & 7.7 & 92.3 & 0.2 & 15.3 & 65.8 & 11.0 & 7.7 \\
\hline $18.0-$ & & nd & nd & nd & nd & nd & nd & nd \\
\hline 19.0 & & nd & nd & nd & nd & nd & nd & nd \\
\hline $24.0-$ & $0.0-24.0$ & 16.6 & 83.4 & 0.2 & 52.5 & 45.1 & 0.5 & 1.7 \\
\hline 25.0 & $24.0-42.0$ & 9.2 & 90.8 & 0.6 & 28.8 & 64.7 & 4.1 & 1.8 \\
\hline $30.0-$ & & nd & nd & nd & nd & nd & nd & nd \\
\hline 31.0 & & nd & nd & nd & nd & nd & nd & nd \\
\hline
\end{tabular}


Table 5-19 - Proximate Analysis of Run \#55 from Different Levels above Inlet Compared with the Green and Calcined Coke Composite Provided by A. J. Edmond.

$\begin{array}{cccccc}\text { Sample Id. } & \text { \% Moisture } & \text { \% Ash, dry } & \begin{array}{c}\text { \% Volatile } \\ \text { Matter, dry }\end{array} & \begin{array}{c}\text { \% Fixed } \\ \text { Carbon, dry }\end{array} & \begin{array}{c}\text { Sulfur } \\ 1-2 \mathrm{~cm}, \mathrm{~A}\end{array} \\ 1.26 & 1.38 & 7.44 & 91.18 & \text { nd } \\ 1-2 \mathrm{~cm}, \mathrm{~B} & 1.42 & 3.25 & 7.55 & 89.20 & \text { nd } \\ 12-13 \mathrm{~cm}, \mathrm{~A} & 1.27 & 0.39 & 6.97 & 92.64 & \text { nd } \\ 12-13 \mathrm{~cm}, \mathrm{~B} & 1.17 & 0.53 & 8.89 & 90.58 & \text { nd } \\ 24-25 \mathrm{~cm}, \mathrm{~A} & 1.15 & 0.69 & 7.03 & 92.28 & \text { nd } \\ 24-25 \mathrm{~cm}, \mathrm{~B} & 1.25 & 1.06 & 6.64 & 92.30 & \text { nd } \\ \text { Green Composite } & \mathbf{0 . 5 5} & \mathbf{1 . 2 5} & \mathbf{6 . 6 5} & \mathbf{9 2 . 1 0} & \mathbf{1 . 2 9} \\ \text { Calcined Composite } & \mathbf{0 . 0 5} & \mathbf{1 . 5 2} & \mathbf{1 . 5 1} & \mathbf{9 6 . 9 7} & \mathbf{1 . 3 4}\end{array}$

Table 5-20 - Petrographic Analysis of Carbon Textures in Composite of Twelve Coker Runs Provided by A.J. Edmond, both Green and Calcined Coke by Size and Origin, Vol. \%.

\begin{tabular}{|c|c|c|c|c|c|c|c|c|c|c|}
\hline \multirow[b]{2}{*}{$\begin{array}{c}\text { Sample } \\
\text { Id. }\end{array}$} & \multicolumn{2}{|c|}{ Vitrinite-derived } & \multirow[b]{2}{*}{$\begin{array}{l}\text { Inert- } \\
\text { derived }\end{array}$} & \multirow[b]{2}{*}{$\begin{array}{l}\text { Isotropic } \\
\text { Vitrinite }\end{array}$} & \multirow[b]{2}{*}{$\begin{array}{c}\text { Min. } \\
\text { Matter }\end{array}$} & \multirow{2}{*}{$\begin{array}{c}\text { Isotropic } \\
\text { Petroleum } \\
\text { derived }\end{array}$} & \multirow[b]{2}{*}{$\begin{array}{c}\text { Mosaic, } \\
<10 \mu \mathrm{m}\end{array}$} & \multirow{2}{*}{$\begin{array}{c}\text { Small } \\
\text { Domain, } \\
10-60 \mu m\end{array}$} & \multirow[b]{2}{*}{$\begin{array}{l}\text { Domain } \\
>60 \mu \mathrm{m}\end{array}$} & \multirow{2}{*}{$\begin{array}{c}\text { Flow } \\
\text { Domain, } \\
>60 \mu \mathrm{m} \mathrm{L} \text {, } \\
<10 \mu \mathrm{m} \mathrm{W} \\
\end{array}$} \\
\hline & Enhanced & Non-enhanced & & & & & & & & \\
\hline Green & 10.7 & 1.4 & 0.8 & 0.0 & 0.3 & 0.3 & 29.4 & 52.4 & 3.5 & 1.2 \\
\hline Calcined & 10.4 & 2.8 & 1.0 & 0.0 & 0.0 & 0.2 & 37.4 & 43.9 & 2.0 & 2.3 \\
\hline
\end{tabular}

Table 5-21 - Proportion of Textures Derived from Coal and Decant Oil Compared with the Normalized Concentration of Decant Oil Textures in Composite Green and Calcined Cokes, Vol. \%

\begin{tabular}{|c|c|c||c|c|c|c|c|}
\hline \hline $\begin{array}{c}\text { Sample } \\
\text { Id. }\end{array}$ & $\begin{array}{c}\text { \% Coal- } \\
\text { derived }\end{array}$ & $\begin{array}{c}\text { \% } \\
\text { Petroleum- } \\
\text { derived }\end{array}$ & $\begin{array}{c}\text { Isotropic } \\
\text { Petroleum- } \\
\text { derived }\end{array}$ & $\begin{array}{c}\text { Mosaic, } \\
<\mathbf{1 0 \mu m}\end{array}$ & $\begin{array}{c}\text { Small } \\
\text { Domain, } \\
\mathbf{1 0 - 6 0 \mu m}\end{array}$ & $\begin{array}{c}\text { Domain } \\
>\mathbf{6 0 \mu m}\end{array}$ & $\begin{array}{c}\text { Flow } \\
\text { Domain, } \\
>\mathbf{6 0} \boldsymbol{\mu m} \mathbf{L}, \\
<\mathbf{1 0} \boldsymbol{\mu m} \mathbf{W}\end{array}$ \\
\hline \hline Green & 13.2 & 86.8 & 0.3 & 33.9 & 60.4 & 4.0 & 1.4 \\
\hline Calcined & 14.2 & 85.8 & 0.2 & 43.6 & 51.2 & 2.3 & 2.7 \\
\hline
\end{tabular}


Table 5-22 - Spectrochemical Analysis of Ash Derived from Green and Calcined Coke Composite Provided by A. J. Edmonds Compared with the Coal (EI-186)

$\begin{array}{cccc}\begin{array}{c}\text { Element as } \\ \text { \% Oxide }\end{array} & \begin{array}{c}\text { Cleaned FCE Pittsburgh Seam } \\ \text { EI-186 }\end{array} & \begin{array}{c}\text { Green Coke } \\ \text { Composite }\end{array} & \begin{array}{c}\text { Calcined Coke } \\ \text { Composite }\end{array} \\ \text { High Temp Ash, } \mathbf{9 0 0}^{\circ} \mathbf{C} & 1.04 & 0.79 & 1.14 \\ \mathbf{S i O}_{2} & 41.8 & 41.5 & 40.0 \\ \mathbf{A l}_{2} \mathbf{O}_{3} & 27.3 & 27.9 & 23.5 \\ \mathbf{F e}_{2} \mathbf{O}_{3} & 13.6 & 14.0 & 18.5 \\ \mathbf{C a O} & 5.65 & 5.08 & 7.36 \\ \mathbf{K}_{2} \mathbf{O} & 1.64 & 1.43 & 1.46 \\ \mathbf{N a}_{2} \mathbf{O} & 0.72 & 0.72 & 0.72 \\ \mathbf{M g O} & 0.74 & 0.90 & 0.70 \\ \mathbf{B a O} & 0.24 & 0.21 & 0.18 \\ \mathbf{P}_{2} \mathbf{O}_{5} & 0.61 & 0.52 & 0.24 \\ \mathbf{S r O} & 0.58 & 0.52 & 0.39 \\ \mathbf{M n O} & 0.01 & 0.01 & 0.07\end{array}$




\section{Subtask 5.5: Analysis of Co-Coking Binder Pitch}

As discussed in the Annual Report 2005 [5-1] the liquid product from the cocoking Run \#35 was further distilled to yield a pitch material. About 13\% was in the pitch boiling point range (cut-point temperature of $\sim 250^{\circ} \mathrm{C}$ at $\sim 3 \mathrm{mmHg}$ or equivalent to $\sim 450^{\circ} \mathrm{C}$ at ambient pressure). The distilled pitch was named co-coking pitch-2 or CCP-2. It was shown by a Laser Desorption Mass Spectrometry (LDMS) that the majority of compounds in CCP-2 range from 200-350 amu, while most of the compounds in commercial coal tar pitch (CTP) and petroleum pitch (PP) were in the range of 200-800 amu. These results showed that deep vacuum distillation to produce co-coking pitch was not enough and that a heat treatment was needed to produce more condensed aromaticfused-ring compounds. Details of structural analysis of CCP-2 are shown in this report to confirm the need for improvement of the co-coking pitch. During the period of May 2005 to November 2005, twelve batches of liquid distillates from co-coking process of decant oil and the new Pittsburgh Seam coal (EI-186) were produced. Our aim was to prepare new co-coking pitch samples using these new batches of liquids from the cocoker runs. A heat treatment was applied to add more condensed aromatic compounds and increase the softening point of the sample to obtain a mass distribution closer to that of the Standard Coal Tar Pitch (SCTP) and the Petroleum Pitch (PP) being used for comparison in this study.

\section{Materials and Experimental:}

The material for generating co-coking pitch was obtained by using a laboratoryscale vacuum distillation apparatus. The distillates from co-coking were placed in a 
round-bottom flask, which was connected to a riser and condenser assembly. The temperature of the boiling liquid was measured by a thermocouple. A cold trap immersed in liquid nitrogen was used to collect any light product not condensed in the collection flask. After the pressure was reduced to $5 \mathrm{mmHg}$ using a rotary-vane vacuum pump, the heating mantle was switched on. The temperature was increased and the distillates were collected until the desired cut-point temperature was reached. CCP-2 was obtained directly as a material leftover in the round-bottom flask after a final cut point at $450^{\circ} \mathrm{C}$. Note that all the cut-point temperatures are the equivalent temperatures after converting the experimental conditions to atmospheric pressure. The temperature was controlled carefully to minimize overheating and thermal degradation. The standard coal tar pitch, i.e. SCTP-2, and the commercial petroleum pitch, i.e. PP-1, obtained from the Koppers Co., Ltd. were used as reference materials.

There are two main methods of producing heavy compounds from petroleum fractions: heat soaking and oxidation (or polymerization with oxygen) [5-17]. These methods combined with distillation and solvent extraction have been widely used to produce petroleum pitch [5-17]. As a preliminary study, the co-coking liquid from run \#50 was distilled to obtain a fraction of $320-360^{\circ} \mathrm{C}$ and $360^{\circ} \mathrm{C}-\mathrm{FBP}$ (Final Boling Point); only heat soaking was conducted in this report period. The aforementioned two fractions of co-coking liquid were heat soaked at temperatures of $420^{\circ} \mathrm{C}$ and $475^{\circ} \mathrm{C}$; pressures of 0 psig (atmospheric pressure) and 300 psig; and heat soaking times ranging from 1 to 24 hours as described in Table 5-23. Five grams of sample were placed in a $20 \mathrm{~mL}$ reactor and purged with UHP $\mathrm{N}_{2}$. UHP $\mathrm{N}_{2}$ was also used to pressurize the samples. A pressure gauge was attached to each reactor to monitor the pressure before, during and after the 
reactions. All the reactor parts containing the sample were totally immersed in a fluidized-sand bath which was equipped with a temperature controller. After the reaction, the reactor was quenched in water. All original samples and their derived materials were characterized by Laser Desorption Mass Spectrometry (LDMS) to determine the mass distribution.

Table 5-23 - Heat Soaking Conditions of Co-coking Liquid Distillate Run \#50

\begin{tabular}{|c|l|c|c|c|c|}
\hline \multirow{2}{*}{ Sample \# } & \multirow{2}{*}{ Original } & \multirow{2}{*}{$\begin{array}{c}\text { Cut Temperatures of } \\
\text { Original }\end{array}$} & \multicolumn{3}{|c|}{ Heat Soaking Conditions } \\
\cline { 4 - 6 } & & $\begin{array}{c}\text { Temp. } \\
\left({ }^{\circ} \mathrm{C}\right)\end{array}$ & $\begin{array}{c}\text { Time } \\
(\mathrm{hr})\end{array}$ & $\begin{array}{c}\mathrm{P}_{\text {ini }} \\
(\mathrm{psig})\end{array}$ \\
\hline HT01 & Run \#50 & $360^{\circ} \mathrm{C}-\mathrm{FBP}$ & 475 & 1 & 300 \\
\hline HT02 & Run \#50 & $360^{\circ} \mathrm{C}-\mathrm{FBP}$ & 475 & 1 & 0 \\
\hline HT03 & Run \#50 & $360^{\circ} \mathrm{C}-\mathrm{FBP}$ & 475 & 3 & 300 \\
\hline HT04 & Run \#50 & $360^{\circ} \mathrm{C}-\mathrm{FBP}$ & 475 & 3 & 0 \\
\hline HT05 & Run \#50 & $360^{\circ} \mathrm{C}-\mathrm{FBP}$ & 475 & 6 & 300 \\
\hline HT06 & Run \#50 & $360^{\circ} \mathrm{C}-\mathrm{FBP}$ & 475 & 6 & 0 \\
\hline HT07 & Run \#50 & $360^{\circ} \mathrm{C}$-FBP & 425 & 5 & 0 \\
\hline HT08 & Run \#50 & $360^{\circ} \mathrm{C}-\mathrm{FBP}$ & 425 & 16.5 & 0 \\
\hline HT09 & Run \#50 & $360^{\circ} \mathrm{C}-\mathrm{FBP}$ & 425 & 20 & 0 \\
\hline HT10 & Run \#50 & $320-360^{\circ} \mathrm{C}$ & 475 & 1 & 0 \\
\hline HT11 & Run \#50 & $320-360^{\circ} \mathrm{C}$ & 475 & 2 & 0 \\
\hline HT12 & Run \#50 & $320-360^{\circ} \mathrm{C}$ & 475 & 3 & 0 \\
\hline
\end{tabular}

\section{Laser Desorption Mass Spectrometry (LDMS)}

LD mass spectra were obtained using a Micromass MALDI-L/R. The samples were analyzed by the Huck Institute, Department of Chemistry, PSU. No matrix assistance was used on any samples. A $20 \mathrm{mg}$ whole pitch with $>200$ mesh size was dissolved in $1 \mathrm{~mL}$ toluene and sonicate for 1 hour. The pitch solution was deposited on a sample cell and dried before insertion in the mass spectrometer ion source. 


\section{Solid State ${ }^{13}$ C NMR Spectroscopy}

All the solid state ${ }^{13} \mathrm{C}$ NMR results shown in this report were characterized at the School of Chemical, Environmental and Mining Engineering, University of Nottingham, UK. Cross-polarization (CP) and standard Bloch decay or single-pulse excitation (SPE) measurements were carried out at $50.46 \mathrm{MHz}$ on a Bruker MSL200 spectrometer with magic-angle-spinning (MAS) at $5.5 \mathrm{kHz}$. Tetrakis(trimethlysilyl)silane (TKS) was used as a standard. The $90^{\circ}{ }^{13} \mathrm{C}$ pulse width was $6 \mu$ s and a recycle delay of 5 seconds was used. Dipolar dephasing (DD) experiments were performed in both CP/MAS and SPE techniques using dephasing times of $1-500 \mu$ s to determine the fraction of non-protonated carbon and further calculation of bridgehead aromatic carbons $\left(\mathrm{C}_{\mathrm{BR}}\right)$.

\section{Solution State ${ }^{1} \mathrm{H}$ NMR Spectroscopy}

Samples were analyzed on a Bruker AMX 360 NMR operating at 9.4 Tesla and $360 \mathrm{MHz}$ at $27^{\circ} \mathrm{C}$. About $30 \mathrm{mg}$ of whole pitch sample ground to $>200$ mesh size was dissolved in $1 \mathrm{ml}$ of $99.8 \%$ atom deuterated chloroform which contains $1 \%(\mathrm{v} / \mathrm{v})$ tetramethylsiloxane (TMS). The pitch solution was placed in a $5 \mathrm{~mm}$ o.d. NMR tube without filtering. A recycle time of 5 seconds was used with a $90^{\circ} \mathrm{C}$ pulse length of $5 \mu$ s.

\section{Solution State ${ }^{13}$ C NMR Spectroscopy}

The solution state ${ }^{13} \mathrm{C}$ NMR measurements were acquired at $90.56 \mathrm{MHz}$ using a Bruker AMX 360 NMR operating at 9.4 Tesla. About $400 \mathrm{mg}$ of $>200$ mesh size whole pitch sample was dissolved in $4 \mathrm{~mL}$ of deuterated chloroform (99.8\% purity with $1 \%$ 
(v/v) TMS). The pitch solution was filtered and placed in a 5-mm o.d. NMR tube. The ${ }^{1} \mathrm{H}$ decoupling and spin-lock field was ca $3 \mathrm{kHz}$ and a $70^{\circ}{ }^{13} \mathrm{C}$ pulse width of $5.0 \mu \mathrm{s}$ was employed. Chromium (III) acetylacetonate $\left(\mathrm{Cr}(\mathrm{AcAc})_{3}\right)$ was added to ensure complete relaxation. A recycle delay of 2.5 seconds was used and at least 15,000 scans were acquired for each sample.

Table 5-24 - Properties of SCTP-2, PP-1 and CCP-2

\begin{tabular}{|c|c|c|c|}
\hline Property & SCTP-2 & PP-1 & CCP-2 \\
\hline \multicolumn{4}{|l|}{ Elemental Analysis } \\
\hline $\mathrm{C}$ & $93.83 \pm 0.20^{\dagger}$ & $93.48 \pm 0.21^{\dagger}$ & $91.62 \pm 1.09^{\dagger}$ \\
\hline $\mathrm{H}$ & $3.87 \pm 0.16^{\dagger}$ & $5.55 \pm 0.44^{\dagger}$ & $5.91 \pm 0.65^{\dagger}$ \\
\hline $\mathrm{N}$ & $1.03 \pm 0.05^{\dagger}$ & $0.20 \pm 0.07^{\dagger}$ & $0.34 \pm 0.02^{\dagger}$ \\
\hline S & $0.56 \pm 0.01^{\dagger}$ & $1.21 \pm 0.08^{\dagger}$ & $3.34 \pm 0.09^{\dagger}$ \\
\hline $\mathrm{O}$ (by calculation) & 0.71 & -0.45 & -0.28 \\
\hline Atomic H/C & 0.50 & 0.71 & 0.77 \\
\hline \multicolumn{4}{|l|}{ Other Properties } \\
\hline Softening Point $\left({ }^{\circ} \mathrm{C}\right)$ & $114^{*}$ & $111.9^{*}$ & $\sim 50-60^{\dagger \dagger}$ \\
\hline Quinoline Insolubles (wt\%) & $15^{\ddagger}$ & $0.1^{\ddagger}$ & $0.1^{\dagger}$ \\
\hline Toluene Insolubles (wt\%) & $32.59 \pm 2.05^{\dagger}$ & $3.89 \pm 0.80^{\dagger}$ & $0.0^{\dagger}$ \\
\hline Moisture (wt\%, dry) & $0.08 \pm 0.06^{\dagger}$ & $0.00 \pm 0.00^{\dagger}$ & $0.04 \pm 0.04^{\dagger}$ \\
\hline Volatile Matter (wt $\%$, dry) & $40.56 \pm 0.22^{\dagger}$ & $53.46 \pm 0.12^{\dagger}$ & $89.30 \pm 2.04^{\dagger}$ \\
\hline Fixed Carbon (wt\%) & $59.12 \pm 0.34^{\dagger}$ & $46.51 \pm 0.06^{\dagger}$ & $10.36 \pm 1.99^{\dagger}$ \\
\hline Ash Content (wt\%) & $0.25 \pm 0.06^{\dagger}$ & $0.04 \pm 0.06^{\dagger}$ & $0.29 \pm 0.08^{\dagger}$ \\
\hline
\end{tabular}

N.D. $=$ Not Detectable; N.A. $=$ Not Available; ${ }^{\dagger}$ Data obtained from The Energy Institute;

${ }^{\dagger \dagger}$ Approximated by viscosity measurement; ${ }^{\ddagger}$ Data provided by Koppers Co., Ltd 


\section{Results and Discussion}

\section{Structural Analysis of SCTP-2, PP-1 and CCP-2}

Analytical data for SCTP-2, PP-1 and CCP-2 are shown in Table 5-24. Although the carbon content of PP-1 was similar to that of SCTP-2, the H/C ratio of SCTP-2 was significantly lower. The softening points of SCTP-2 and PP-1 were about $110-115^{\circ} \mathrm{C}$ while the softening point of the laboratory $\mathrm{CCP}-2$ was $c a .50-60^{\circ} \mathrm{C}$. SCTP-2 and PP-1 were highly aromatic with few heteroatoms. The properties of CCP-2 were similar to petroleum pitch rather than coal tar pitch as can be seen form the solution state NMR results shown in Table 5-25. The LDMS results show that the majority of masses in SCTP-2 and PP-1 were distributed in the ranges of 200-800 amu and some heavier compounds were found up to ca. 1400 amu. CCP-2 contains masses mainly in the range of 225-400 amu and a small fraction of compounds in the range of 400-600 amu. A comparison of the mass distribution of these three pitches is shown in Figure 5-19.

Due to the complexity of the materials, solution state and solid state NMR were used to study the average structural parameters. This average structure may only be a minor component if it exists at all and will probably not adequately represent the variety of components in the samples [5-18]. However, the average structure could be very useful especially when comparing complex compounds such as pitch from different origins and processes. The details of carbon and hydrogen present in different forms in SCTP-2, PP-1 and CCP-2 are shown in Table 5-26 along with their average molecular weights. Based on data from the solution state NMR combined with the average molecular weight data from LDMS and heteroatomic data from the elemental analysis, the structural parameters for SCTP-2, PP-1 and CCP-2 were calculated in Table 5-25 
based on the methods described by Kershaw and Black [5-18] and other references [5-19, 5-20]. 

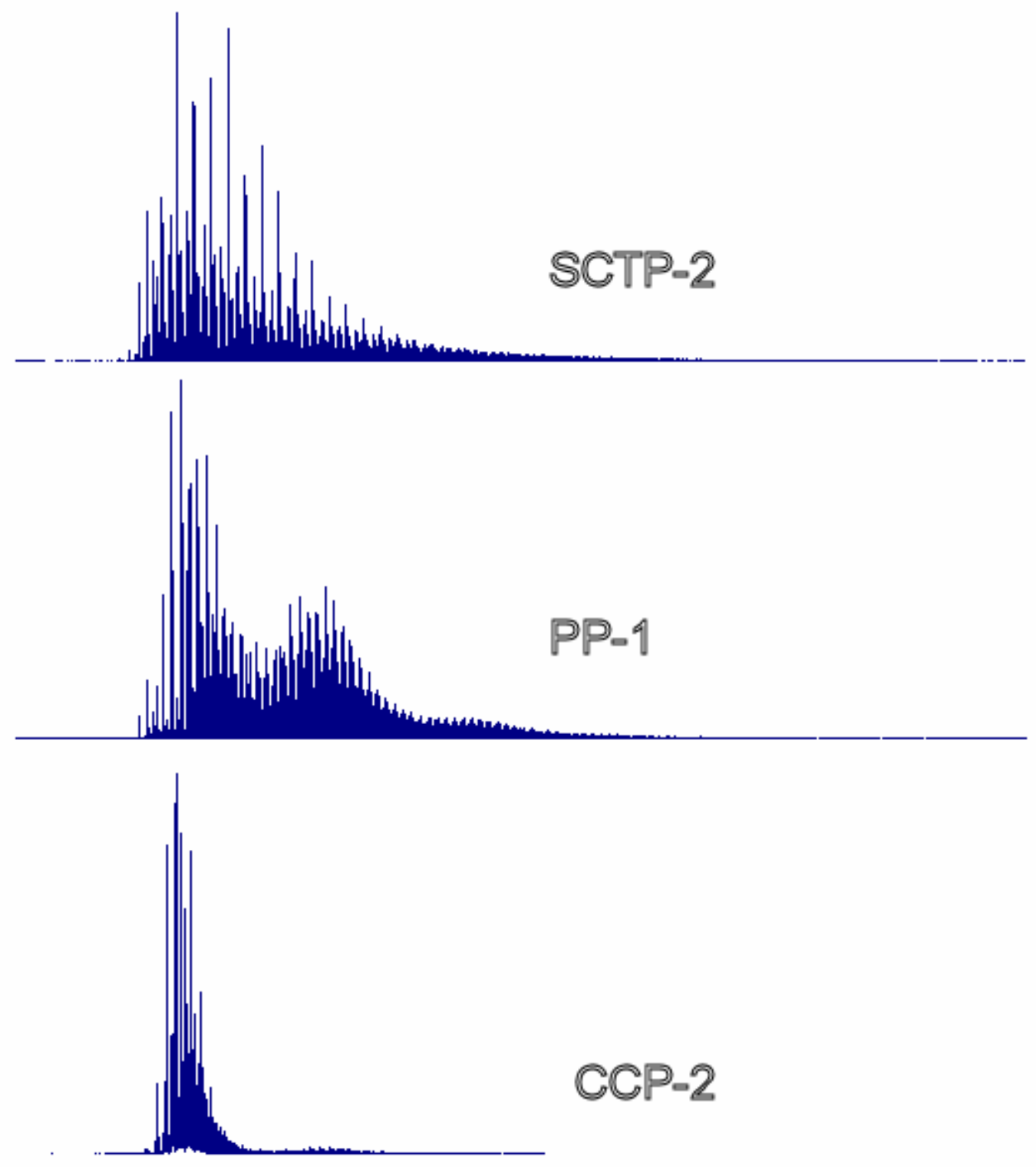

Figure 5-20 - Mass Distribution of SCTP-2, PP-1 and CCP-2 Analyzed by LDMS 
Table 5-25 - NMR and LDMS Data for SCTP-2, PP-1 and CCP-2

\begin{tabular}{|c|c|c|c|}
\hline & SCTP-2 & PP-1 & CCP-2 \\
\hline \multicolumn{4}{|l|}{ Solution state ${ }^{1}$ H NMR } \\
\hline$\overline{\text { Total aromatic hydrogen }}(\% \mathrm{H})$ & 83.89 & 56.61 & 55.40 \\
\hline Total aliphatic hydrogen $(\% \mathrm{H})$ & 16.11 & 43.39 & 44.60 \\
\hline - Ring joining methylene, methine $\mathrm{H}(3.5-5.0 \mathrm{ppm})(\% \mathrm{H})$ & 2.30 & 3.15 & 2.11 \\
\hline - Benzylic H (1.9-3.5 ppm) $(\% \mathrm{H})^{\mathrm{A}}$ & 8.21 & 32.20 & 35.92 \\
\hline - Aliphatic $\mathrm{H}(<1.9 \mathrm{ppm})(\% \mathrm{H})^{\mathrm{B}}$ & 5.60 & 8.05 & 6.57 \\
\hline \multicolumn{4}{|l|}{ Solution state ${ }^{13} \mathrm{C}$ NMR } \\
\hline Total aromatic carbon & 96.30 & 86.16 & 85.15 \\
\hline - Non-protonated aromatic carbon (130-160 ppm) (\%C) & 20.53 & 28.85 & 23.43 \\
\hline - Protonated aromatic carbon (111-130 ppm) (\%C) & 75.78 & 57.31 & 61.72 \\
\hline Total aliphatic carbon $(\% \mathrm{C})$ & 3.70 & 13.84 & 14.85 \\
\hline$-\mathrm{CH}, \mathrm{CH}_{2}(24.0-60.0 \mathrm{ppm})(\% \mathrm{C})$ & 3.16 & 6.71 & 3.90 \\
\hline$-\mathrm{CH}_{3}(11.0-24.0 \mathrm{ppm})(\% \mathrm{C})$ & 0.53 & 7.13 & 10.95 \\
\hline \multicolumn{4}{|l|}{ LDMS } \\
\hline - Number average molecular weight $(\mathrm{MW})_{\mathrm{n}}(\mathrm{amu})$ & 399 & 434 & 298 \\
\hline - Weight average molecular weight $(\mathrm{MW})_{\mathrm{w}}(\mathrm{amu})$ & 504 & 517 & 324 \\
\hline - Polydispersity & 1.27 & 1.19 & 1.09 \\
\hline
\end{tabular}

${ }^{A}$ Benzylic hydrogen is hydrogen on a carbon atom adjacent to an aromatic ring other than ring-joining methylene or methane groups [5-18].

${ }^{\mathrm{B}}$ Aliphatic hydrogen is hydrogen on a $\beta$-carbon or further from an aromatic ring [5-18].

The average molecular weights (number average) calculated from LDMS for SCTP-2 and PP-1 is 399 and 434, respectively. The mass values range from 175-1400 amu for SCTP-2 and 175-1300 amu for PP-1. This indicates that there are 31 and 34 carbon atoms in an average molecule in SCTP-2 and PP-1, respectively. However, PP-1 contains a higher degree of alkyl and naphthenic substituents, whereas SCTP-2 consists of large and highly condensed fused-aromatic rings. On average the structural parameters from Table 5-26 suggest that SCTP-2 contained one $\mathrm{CH}_{3}$ and one $-\mathrm{CH}_{2}$ - for every 1-2 molecules. Nitrogen atoms exist on an average of one atom for every three molecules, while a ring joining methylene group was present for every 5 molecules. PP-1 contained two $-\mathrm{CH}_{3}$ and one $-\mathrm{CH}_{2-}$ per one molecule. The portion of aliphatic $\mathrm{H}$, 
hydrogen on a $\beta$-carbon or further from an aromatic ring [5-18], indicates that PP-1 contained two $-\mathrm{CH}_{2}-\mathrm{CH}_{3}$ for every three molecules on average. One in three molecules of PP-1 contained a ring joining methylene group. Compared to SCTP-2 and PP-1, the co-coking pitch, CCP-2, contained two $-\mathrm{CH}_{3}$ for every molecule and one $-\mathrm{CH}_{2}-\mathrm{CH}_{3}$ for every three molecules on average. A ring joining methylene was present for every 5 molecules. Because sulfur content was high, CCP-2 contained one sulfur atom for every 3 molecules. Some representative average structures of these three pitches are shown in

Figure 5-21.

Table 5-26 - Number of Various Atoms in Average Molecule and Structural Parameters for SCTP-2, PP-1 and CCP-2 Derived from Solution State NMR and LDMS.

\begin{tabular}{|l|l|l|l|}
\hline & SCTP-2 & PP-1 & CCP-2 \\
\hline $\mathrm{C}$ & 31.20 & 33.66 & 22.52 \\
$\mathrm{H}$ & 15.45 & 23.99 & 17.44 \\
$\mathrm{~N}$ & 0.29 & 0.06 & 0.07 \\
$\mathrm{~S}$ & 0.07 & 0.16 & 0.31 \\
$\mathrm{O}$ & 0.18 & 0.00 & 0.00 \\
Average MW calculated from elemental analysis & 399.00 & 434.00 & 298.48 \\
Hydrogen & & & \\
Total aromatic hydrogen & 12.96 & 13.58 & 9.66 \\
Total aliphatic hydrogen & 2.49 & 10.41 & 7.78 \\
- Ring joining methylene, methine H (3.5-5.0 ppm) & 0.36 & 0.76 & 0.37 \\
- Benzylic H (1.9-3.5 ppm) & 1.27 & 7.73 & 6.26 \\
- Aliphatic H (<1.9 ppm) & 0.87 & 1.93 & 1.15 \\
Carbon & & & \\
Total aromatic carbon & 30.05 & 29.00 & 19.17 \\
- Non-protonated aromatic carbon $(130-160$ ppm) & 6.40 & 9.71 & 5.28 \\
- Protonated aromatic carbon $(111-130$ ppm) & 23.64 & 19.29 & 13.90 \\
Total aliphatic carbon & 1.15 & 4.66 & 3.34 \\
- CH, CH $(24.0-60.0$ ppm) & 0.99 & 2.26 & 0.88 \\
- CH $H_{3}(10.0-24.0$ ppm) & 0.17 & 2.40 & 2.47 \\
Average alkly chain length of alkyl substituents & 1.96 & 1.35 & 1.24 \\
Aliphatic H/C & 2.16 & 2.24 & 2.33 \\
\hline
\end{tabular}




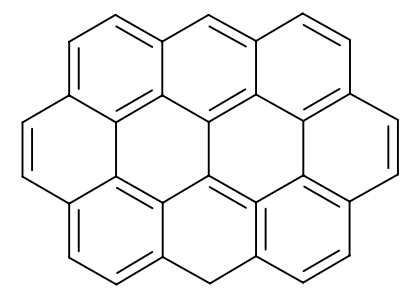

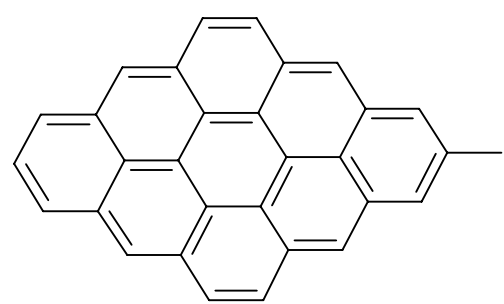

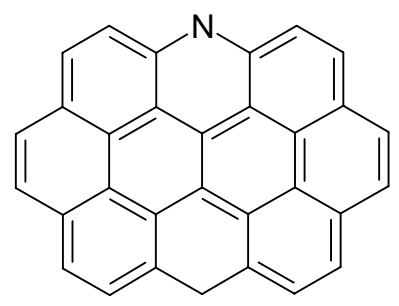<smiles>CCc1ccc2c(c1)CCc1c-2cc2c3c1c(c1cccc4cc5ccccc5c3c41)=CC=C2</smiles>

PP-1<smiles>Cc1ccc2c(c1)sc1c(C)c3ccc4ccccc4c3cc12</smiles>

\section{CCP-2}<smiles></smiles>

Figure 5-21 - Average Structures for SCTP-2, PP-1 and CCP-2 Suggested by the Solution State NMR Analyses

The degree of condensation of the aromatic structure is often obtained by the relative proportion of bridgehead and peripheral aromatic carbons [5-21]. The ${ }^{13} \mathrm{C}$ solid state dipolar dephasing experiments were employed for this purpose. It is generally accepted that SPE or Bloch decay measurements are the best approach for obtaining quantitative ${ }^{13} \mathrm{C}$ NMR results [5-22]. The procedure for calculating the fraction of nonprotonated aromatic carbon, $f_{\text {non-prot. }}$, is the same as that used previously for coals [5-22]. 
Table 5-27 Comparison of Results from ${ }^{13} \mathrm{C}$ Solid State (CP and SPE) and ${ }^{13} \mathrm{C}$ Solution State NMR for SCTP-2 and PP-1

\begin{tabular}{|c|c|c|c|c|c|c|}
\hline & \multicolumn{3}{|c|}{ SCTP-571 } & \multicolumn{3}{|c|}{ PP-1 } \\
\hline & \multicolumn{2}{|c|}{${ }^{13} \mathrm{C}$ Solid State } & \multirow[t]{2}{*}{$\begin{array}{c}{ }^{13} \text { C Solution } \\
\text { State }\end{array}$} & \multicolumn{2}{|c|}{${ }^{13} \mathrm{C}$ Solid State } & \multirow[t]{2}{*}{$\begin{array}{c}{ }^{13} \mathrm{C} \text { Solution } \\
\text { State }\end{array}$} \\
\hline & $\mathrm{CP}$ & SPE & & $\mathrm{CP}$ & SPE & \\
\hline $\begin{array}{l}\text { Aromaticity } \\
\left(\mathrm{f}_{\mathrm{a}}, \mathrm{C}_{\mathrm{AR}} / \mathrm{C}\right)\end{array}$ & $97.32 \%$ & $98.68 \%$ & $96.30 \%$ & $85.62 \%$ & $86.98 \%$ & $86.16 \%$ \\
\hline $\begin{array}{l}\mathrm{f}_{\text {non-protonated }}\left(\mathrm{C}_{\text {non- }}\right. \\
\left.\text { prot. } / \mathrm{C}_{\mathrm{AR}}\right)\end{array}$ & & $61.91 \%$ & & & $33.20 \%$ & \\
\hline $\mathrm{f}_{\mathrm{BR}}\left(\mathrm{C}_{\mathrm{BR}} / \mathrm{C}_{\mathrm{AR}}\right)$ & & $58.53 \%$ & & & $12.98 \%$ & \\
\hline $\mathrm{C}_{\mathrm{ar}}$, unit & & 35 & & & 8 & \\
\hline $\mathrm{N}_{\text {peri }}$ & & 10.7 & & & 1.7 & \\
\hline Average MW & & 448 & & & 193 & \\
\hline
\end{tabular}

Recycle delays of up to $500 \mu$ s were used to take account of the pitch fractions having considerably long ${ }^{13} \mathrm{C} \mathrm{T} 1$ [5-23]. Note that CCP-2 was not measured by ${ }^{13} \mathrm{C}$ solid state due to its low softening point, i.e. the material could flow at room temperature which could damage the analyzing probe. Table 5-27 lists the values of fnon-prot. calculated from SPE and CP dipolar dephasing experiments for SCTP-2 and PP-1. The $f_{\text {non-prot. }}$ calculated from CP was considerably lower than the data obtained from the SPE experiments. The value of $f_{\text {non-prot. }}$ for SCTP- 2 is 0.62 , while this fraction was 0.33 for PP-1.

The fraction of bridgehead aromatic carbon $\left(f_{B R}\right)$ can be derived by subtracting the fraction of aromatic carbons bound to aliphatic carbon and heteroatoms from the total fraction of non-protonated aromatic carbon [5-21, 5-23]. It is assumed that half of the oxygen was phenolic with the remainder being condensed furans [5-23]. Hence, on average each oxygen was bound to ca. 1.5 non-protonated aromatic carbons. For nitrogen, it was assumed that half of them were aromatic secondary amines (carbazoles) and the remainder were basic (aza) compounds [5-23]. An average attachment to non- 
protonated aromatic carbons for nitrogen was assumed to be one. For aliphatic carbons, there was a small difference between SCTP-2 and PP-1. It was assumed that one aliphatic carbon in SCTP-2 was bound to one aromatic group. This assumption has been verified by the ${ }^{13} \mathrm{C}$ solution state experiment where the amount of $\mathrm{CH}_{3}$ not bound to aromatic groups (10-15 ppm chemical shift) was nil for SCTP-2. For PP-1, it was assumed that at least $70 \%$ of aliphatic carbons were bound to aromatic groups. The values of $f_{B R}$ were 0.59 for SCTP-2 and 0.13 for PP-1.

The average ring structure can be calculated from the $f_{B R}$ value by assuming the structure to be fully peri-condensed as described by Solum [5-24]. It was suggested that an average molecular mass of SCTP-2 was 448 which contains ca. 11 peri-condensed aromatic rings. However, using the same calculation, PP-1 consisted on average of only ca. 2 peri-condensed aromatic rings. These results were not consistent with those obtained from the solution state NMR, LDMS, and elemental analysis as described previously. The disagreement of the average structure of PP-1 can be explained by an inappropriate assumption of using peri-condensed structure for petroleum-derived compounds in SPE experiments since PP-1 contained a high fraction of alkyl substituents. The average structure model for PP-1 should be more appropriately described by cata-condensation. For SCTP-2, results from the solution state NMR (Table 5-26) and from the SPE experiments (Table 5-27) explain that SCTP-2 contains highly condensed aromatic compounds, i.e. very low fraction of alkyl substituents with peri-condensed structure. The average highly condensed structure suggested by SPE may derive from a high value of QI content [5-23] in this sample, i.e. 15 wt.\%. From the LDMS analysis, although a whole pitch dissolved in toluene was analyzed without 
filtration, the QI fraction which was not dissolved in toluene may not be fully ionized by a laser. This may result in an underestimation of the average molecular mass from this technique. The average molecular mass obtained from LDMS for the PP-1 was less questionable since $c a .98 \%$ of the pitch sample was soluble in toluene, hence, the average molecular mass from the TS fraction could be realistic.

Structural analysis of SCTP-2, PP-1 and CCP-2 clearly shows that CCP-2 needs to be improved to obtain higher mass components in order to be comparable with SCTP-2 and PP-1. The development of the co-coking pitch is explained in the following section.

\section{Development of Co-Coking Pitch}

There are three parameters for the heat soaking conditions applied to the 320 $360^{\circ} \mathrm{C}$ and $360^{\circ} \mathrm{C}-\mathrm{FBP}$ fractions of the co-coking liquid from run $\# 50$ : temperature, pressure and time. From the LDMS analysis, samples which were previously pressurized to 300 psig gave lower mass ranges than the sample without previously pressurization, e.g. Run50_HT01 v.s. Run50_HT02, Run50_HT03 v.s. Run50_HT04, and Run50_HT05 v.s. Run50_HT06 (the LDMS spectra are not shown in this report). Therefore, pressurized condition could be ruled out from this study.

Table 5-28 lists the visual observation of the heat-soaked materials as compared to the original material. All conditions give liquid materials except those of $475^{\circ} \mathrm{C}$ for 6 hours reaction time. Presumably, coke was formed at these conditions, but its type and nature have yet to be determined by optical microscopy. 


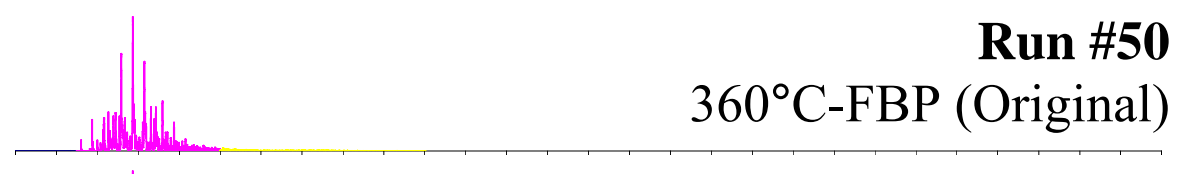

Run\#50 HT02 $475^{\circ} \mathrm{C}, 1 \mathrm{hr}$

Run\#50 HT04 $475^{\circ} \mathrm{C}, 3 \mathrm{hr}$

Run\#50 HT06 $475^{\circ} \mathrm{C}, 6 \mathrm{hr}$
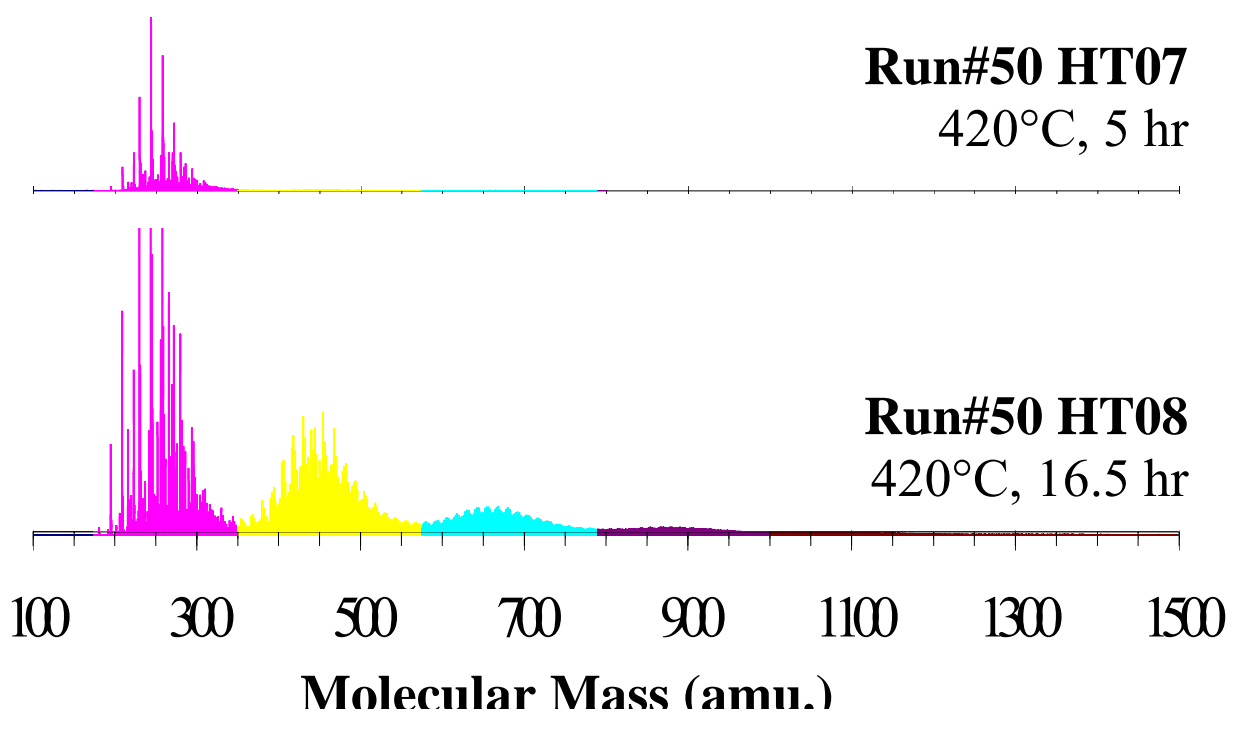

Figure 5-22 - LDMS Spectra of Original Run\#50 and Its Derived Materials HT02, HT04, HT06, HT06, HT07 and HT08. 
Table 5-28 - Conditions of Heat Soaking and Visual Observation of Reacted Materials as Compared to the Original Run\#50 (360 $\left.{ }^{\circ} \mathrm{C}-\mathrm{FBP}\right)$, SCTP-2 and PP-1.

\begin{tabular}{|c|c|c|c|c|}
\hline Sample & $\begin{array}{c}\text { Temp. } \\
\left({ }^{\circ} \mathrm{C}\right)\end{array}$ & $\begin{array}{c}\text { Initial } \\
\text { pressure } \\
\text { (psig) }\end{array}$ & $\begin{array}{l}\text { Time } \\
\text { (hrs) }\end{array}$ & Visual Observation \\
\hline SCTP-2 & & & & $\begin{array}{l}\text { Black and shiny solid at room } \\
\text { temperature }\end{array}$ \\
\hline PP-1 & & & & $\begin{array}{l}\text { Black and shiny solid at room } \\
\text { temperature }\end{array}$ \\
\hline $\begin{array}{l}\text { Run50 } \\
\left(360^{\circ} \mathrm{C}-\mathrm{FBP}\right)\end{array}$ & & & & Black and viscous liquid \\
\hline Run50 HT01 & 475 & 300 & 1 & Black and viscous liquid \\
\hline Run50_HT02 & 475 & 0 & 1 & Black and viscous liquid \\
\hline Run50_HT03 & 475 & 300 & 3 & Black and very sticky liquid \\
\hline Run50_HT04 & 475 & 0 & 3 & Black and very sticky liquid \\
\hline Run50_HT05 & 475 & 300 & 6 & $\begin{array}{l}\text { Black solidified and shiny material with a } \\
\text { little gummy part }\end{array}$ \\
\hline Run50_HT06 & 475 & 0 & 6 & $\begin{array}{l}\text { Black solidified and shiny material with a } \\
\text { little gummy part }\end{array}$ \\
\hline Run50_HT07 & 420 & 0 & 5 & Brown viscous liquid \\
\hline Run50_HT08 & 420 & 0 & 16.5 & Black and sticky liquid \\
\hline
\end{tabular}

Figure 5-22 shows the mass distribution of original $360^{\circ} \mathrm{C}-\mathrm{FBP}$ fraction of run \#50, and its derived materials HT02, HT04, HT06, HT06, HT07 and HT08 from the LDMS analysis. The pattern of these materials is similar to oligomers. If we consider a group of the original materials ranging from $175-350^{\circ} \mathrm{C}$ as monomers, the heat-soaked materials contain di-, tri-mers and so on. Varying temperatures and reaction times give the same mass ranges of these oligomers but different yields of each fraction.

Table 5-29 and Figure 5-23 show fractions of each oligomer. It can be seen that as reaction time was increased, more heavy compounds were produced at the expense of lower mass materials. Only HT06 did not follow this trend since the materials may have 
formed cokes and as can be seen that the amount of di- and tri-mers decreased significantly. The amount of monomer was high in the HT06 sample which may result

Table 5-29 - Mass Distribution of SCTP-2, PP-1, Run\#50 and Its Derivatives.

\begin{tabular}{|l|l|l|l|l|l|l|}
\hline Sample & $\begin{array}{l}\mathbf{1 7 5 - 3 5 0} \\
\text { amu. }\end{array}$ & $\begin{array}{l}\mathbf{3 5 0 - 5 7 5} \\
\text { amu. }\end{array}$ & $\begin{array}{l}\mathbf{5 7 5 - 7 9 0} \\
\text { amu. }\end{array}$ & $\begin{array}{l}\mathbf{7 9 0 - 1 0 0 0} \\
\text { amu. }\end{array}$ & $\begin{array}{l}\mathbf{1 0 0 0 - 1 5 0 0} \\
\text { amu. }\end{array}$ & $\begin{array}{l}\mathbf{1 5 0 0 - 2 0 0 0} \\
\text { amu. }\end{array}$ \\
\hline SCTP-2 & $55 \%$ & $31 \%$ & $8 \%$ & $3 \%$ & $3 \%$ & - \\
\hline PP-1 & $42 \%$ & $42 \%$ & $10 \%$ & $3 \%$ & $2 \%$ & - \\
\hline Run50 & $94 \%$ & $6 \%$ & - & - & - & - \\
\hline Run50_HT02 & $46 \%$ & $33 \%$ & $12 \%$ & $5 \%$ & $3 \%$ & - \\
\hline Run50_HT04 & $47 \%$ & $24 \%$ & $13 \%$ & $7 \%$ & $7 \%$ & $3 \%$ \\
\hline Run50_HT06 & $68 \%$ & $17 \%$ & $7 \%$ & $3 \%$ & $3 \%$ & $2 \%$ \\
\hline Run50_HT07 & $81 \%$ & $11 \%$ & $7 \%$ & $0 \%$ & - & - \\
\hline Run50_HT08 & $53 \%$ & $30 \%$ & $10 \%$ & $4 \%$ & $3 \%$ & $1 \%$ \\
\hline
\end{tabular}

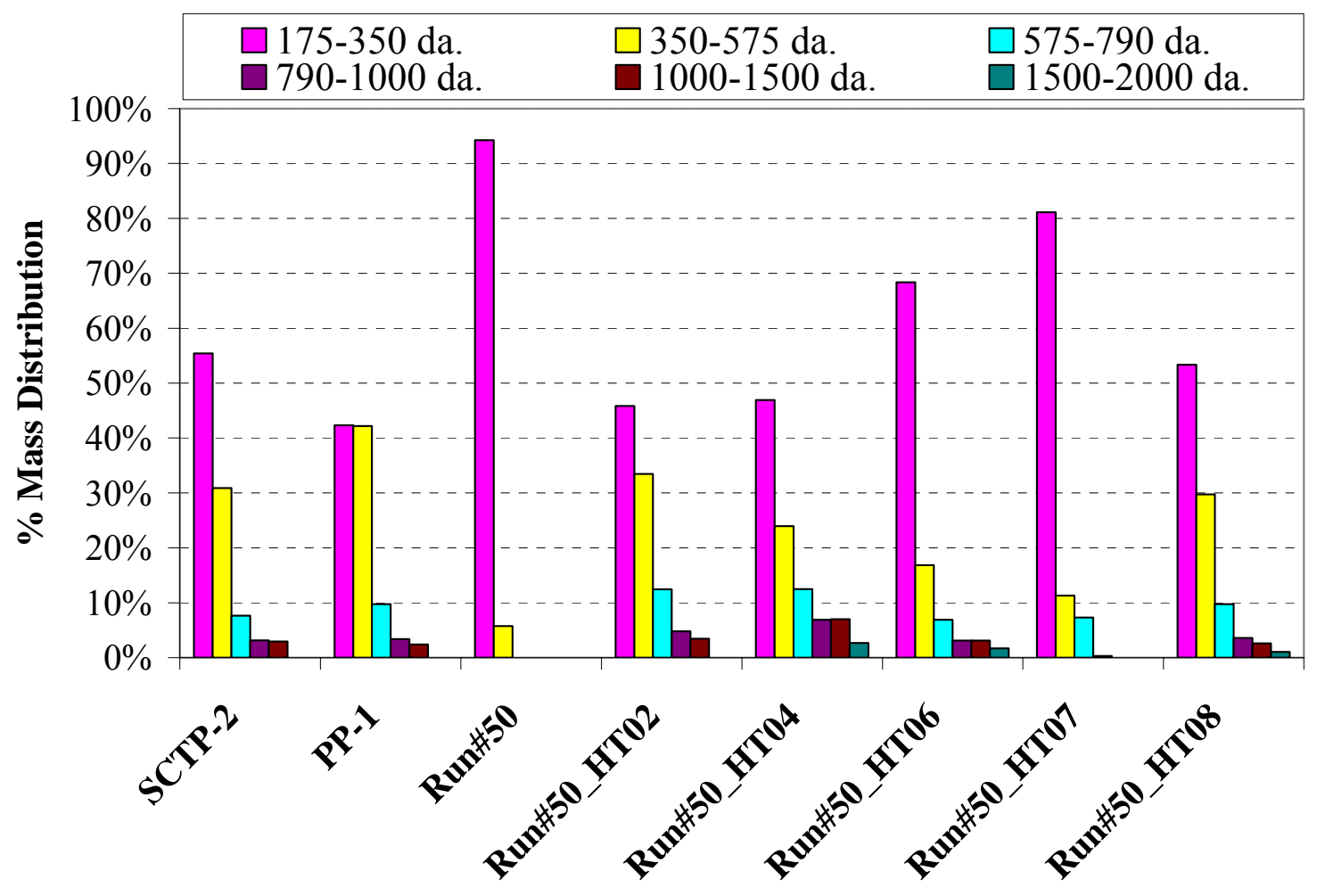

Figure 5-23 - Mass Distribution of SCTP-2, PP-1, Run\#50 and Its Derivatives. 
from a relatively low fraction of di-and tri-mers while the cracking to form 1-mer radicals was still active.

Number average, weight average and polydispersity of the heat-soaked materials

Table 5-30 - Number and Weight Averages of SCTP-2, PP-1, Run\#50 and Its Derivatives

\begin{tabular}{|l|c|c|c|}
\hline & $(\mathbf{M W})_{\mathbf{n}}$ & $(\mathbf{M W})_{\mathbf{w}}$ & Polydispersity \\
\hline SCTP-2 & 398.73 & 504.49 & 1.27 \\
\hline PP-1 & 434.18 & 517.06 & 1.19 \\
\hline Run50 & 364.43 & 395.87 & 1.09 \\
\hline Run50_HT02 & 441.04 & 563.56 & 1.28 \\
\hline Run50_HT04 & 495.32 & 746.28 & 1.51 \\
\hline Run50_HT06 & 380.47 & 596.29 & 1.57 \\
\hline Run50_HT07 & 312.81 & 365.32 & 1.17 \\
\hline Run50_HT08 & 416.81 & 571.24 & 1.37 \\
\hline
\end{tabular}

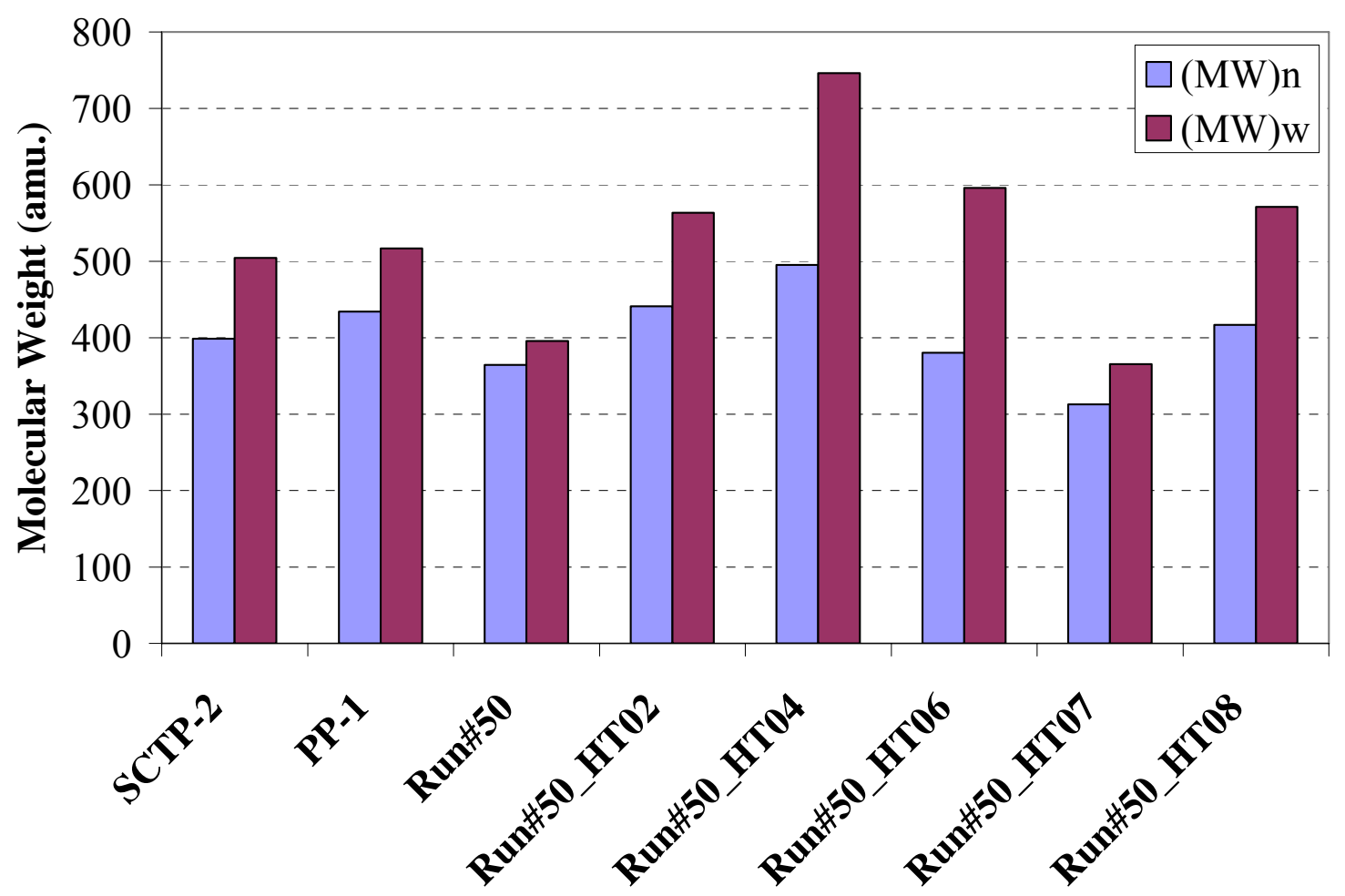

Figure 5-24 - Number and Weight Averages of SCTP-2, PP-1, Run\#50 and Its Derivatives. 
SCTP-2

PP-1

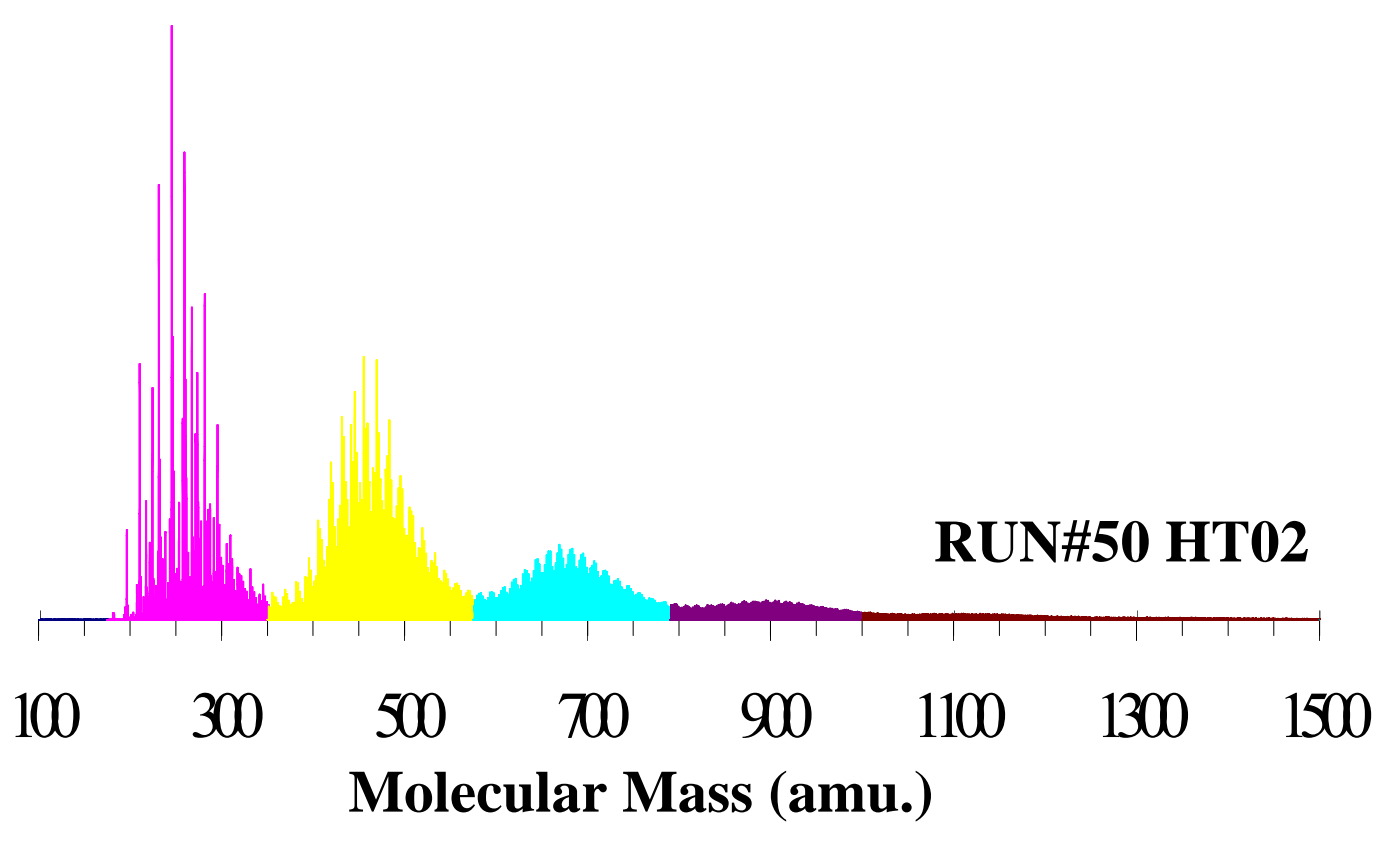

Figure 5-25 - Comparison of a mass distribution of Run\#50_HT02 to that of SCTP-2 and PP-1. 
were compared with its original, SCTP-2 and PP-1 as shown in Table 5-30 and Figure 5-

24. HT02 is closer to those commercial pitches and was chosen for further study.

Figure 5-25 shows a comparison of mass distribution of run\#50_HT02 to that of SCTP-2 and PP-1. HT02 contained heavy enough compounds as compared to SCTP-2 and PP-1; however, gaps between oligomers need to be filled in order to have a continuous distribution of masses from 200-800 amu. To achieve this distribution, one idea would be to heat-soak a lower mass range fraction of run \#50 in order to form oligomers that could fill those gaps. The fraction of $320-360^{\circ} \mathrm{C}$ was chosen and heat soaking experiments were performed at $475^{\circ} \mathrm{C}$ for 1,2 , and 3 hours. An obvious drawback of the $320-360^{\circ} \mathrm{C}$ fraction was that it contained a significant amount of long chain alkanes which were not supposed to appear in the binder pitch material. These long alkanes also can be polymerized to form polymers. A better approach to using this fraction would be to remove the alkanes before heat soaking. However, in this preliminary study the $320-360^{\circ} \mathrm{C}$ fraction was used directly without prior treatment.

Mass ranges of the resulted oligomers were different from those of the $360^{\circ} \mathrm{C}$ FBP fraction as shown in Figure 5-26. Figure 5-27 shows that there may be a possibility of approaching the mass range materials of SCTP-2 and PP-1 by mixing HT02 and HT10 together at a specific ratio before distilling to remove the light compounds. This task will be done in the future along with an oxidation method to obtain heavy compound materials. 


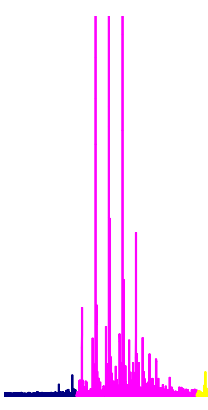

\section{Run \#50 \\ $320-360^{\circ} \mathrm{C}$ (Original)}

\section{Run\#50 HT10}

$475^{\circ} \mathrm{C}, 1 \mathrm{hr}$

\section{Run\#50 HT11}

$475^{\circ} \mathrm{C}, 2 \mathrm{hr}$

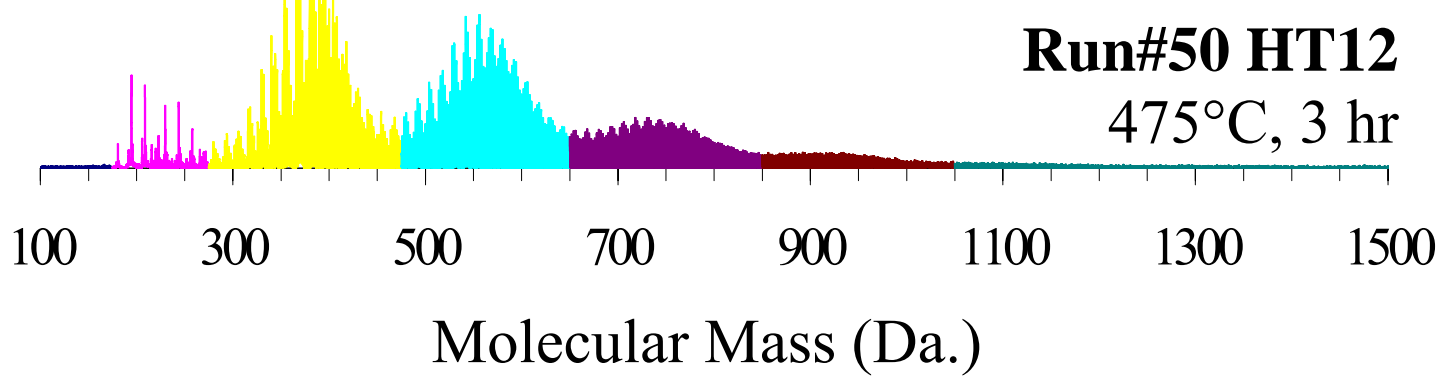

Figure 5-26 - Comparison of a Mass Distribution of the 320-360 ${ }^{\circ}$ Fraction and Its Derived Materials HT10, HT11 and HT12. 


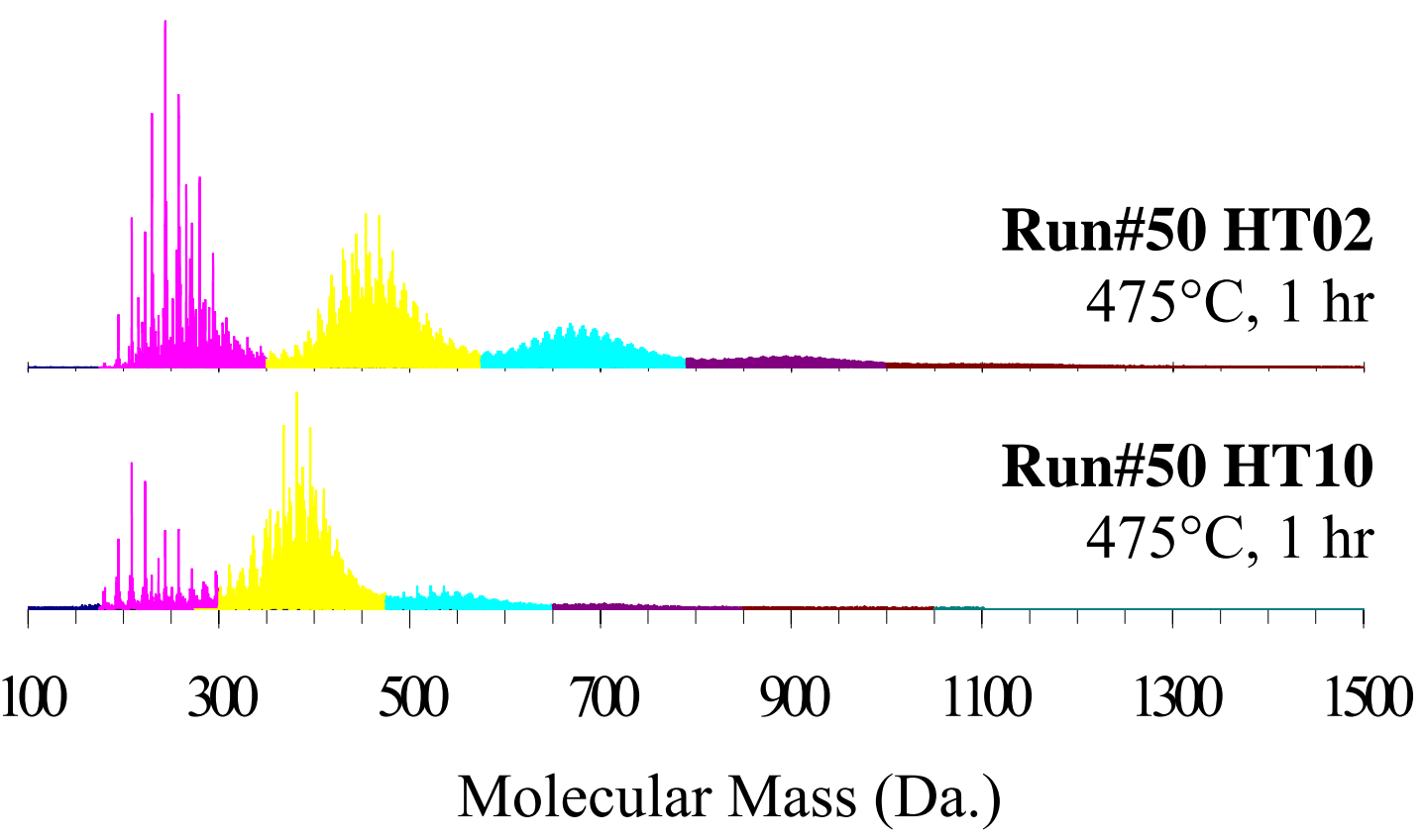

Figure 5-27 - Comparison of the mass distribution of HT02 and HT10. A possibility of mixing these two samples at a specific ratio to obtain a more continuous mass distribution.

\section{Future Work}

1. At least two co-coking pitches will be developed by heat soaking and/or oxidation for an application of binder pitch for the Aluminum Industry.

2. Understand the wetting behavior between pitch and coke from the high temperature solid state ${ }^{1} \mathrm{H}$ NMR spectra.

\section{Subtask 5.6: Manufacture and Testing of Carbon Artifacts}

As discussed previously, a large amount of cleaned Pittsburgh FCE was used to prepare about $19 \mathrm{~kg}$ of coke (20\% coal and $80 \%$ decant oil) to be employed in laboratoryscale testing by Alcoa using their routine analytical procedures. The coke was crushed and sized to Alcoa's specification and calcined by A.J. Edmond, who also performed a 
variety of analytical tests that are commonly used for coke assessment by the aluminum industry [Appendix 5-1]. The coke was calcined in $3.5 \mathrm{~kg}$ batches at $1275^{\circ} \mathrm{C}$ to a real density of $2.08 \mathrm{~g} / \mathrm{cc}$, homogenized and shipped to Alcoa for laboratory-scale anode preparation.

Comparison of analytical information obtained from A.J. Edmond (Appendix 51) with those obtained from Penn State (Tables 5-17 and 5-22) for proximate analysis (moisture, volatile matter and ash) and elemental analysis of ash show the Penn State values to be greater. The reason for this is that Penn State uses ASTM techniques and equipment designed to investigate coal and coke (ASTM vol. 05.06), whereas A.J. Edmond employs ASTM (vol. 05.02) techniques designed specifically for petroleum coke. Differences in particle size distribution and heating procedures are sufficient to explain the variation, but insufficient to require Penn State to invest in new equipment. Currently, we will accept the variation inhouse and purchase the services when require.

Production of bench-scale anodes was conducted at the Alcoa Technical Center using the following procedure (Appendix 5-2). About 74\% of our properly sized and calcined co-coke sample (replacing the standard petroleum coke) was mixed with $26 \%$ sized, recycled anode butts from an Alcoa smelter and an increasing concentration of coal-tar pitch represents standard procedure. Samples were mixed in an R \& D Carbon, Bench Scale Unit designed to produce 1:1000 scale electrodes. One of these units was purchased from $\mathrm{R} \& \mathrm{D}$ Carbon during this performance period and will arrive in September so that we may prepare anodes to our specifications. Test anodes were prepared using pitch concentrations from 15.5 to 20.0 weight percent at $0.5 \%$ intervals to determine the optimum amount to use for a given coke blend. Mixtures were pressed into 
cylindrical molds at 600 bar and then baked for about 100 hours at $1125^{\circ} \mathrm{C}$ in an inert atmosphere.

In an initial evaluation, baked apparent density and electrical resistivity were determined using procedures discussed in Appendix 5-2 and compared with Alcoa's standard petroleum coke anodes. Results show that a pitch concentration of $17.0 \%$ provided the optimum baked apparent density, corresponding well with the standard anode, but the anodes using co-coke were significantly higher in density. Alcoa reported that if the increase in density were achieved in commercial production, that anode life would be extended. Furthermore, at $17 \%$ pitch a significant reduction in the electrical resistivity was observed that if realized in production would result in energy savings. However, owing to excessively high concentrations of silicon (2 times greater) and iron ( 5 times greater) the coke is unacceptable for use as a replacement for petroleum coke. Because of this no further testing was performed by Alcoa, although if the co-coke had met the above initial requirements additional testing including air and $\mathrm{CO}_{2}$ reactivity, compression and flexural strength, air permeability, and thermal conductivity, would have been determined. Currently, we are discussing the prospects of having these test completed for the Pittsburgh co-coke for comparison with future co-coke samples.

Future work in this area will be to prepare a coal of higher quality and prepare sufficient coke material for laboratory anode testing. In addition, we are working toward the point where we will be able to generate our own pitch material to use as binder for our co-coke product. Consequently, we will produce and test carbon artifacts (i.e. carbon anodes) using both co-coke and pitch made from the co-coking runs of future 
experiments to be compared with carbon artifacts made from SCTP and PP. Table 5-31 shows the type of carbon artifacts that will be produced for this study.

Table 5-31 - Samples of Manufacturing of Carbon Artifacts.

\begin{tabular}{|l|l|}
\hline Pitch & Coke \\
\hline SCTP & Commercial cokes \\
\hline SCTP & Co-coking cokes \\
\hline PP & Commercial cokes \\
\hline PP & Co-coking cokes \\
\hline Co-coking pitch & Commercial cokes \\
\hline
\end{tabular}




\section{REFERENCES}

1-1 Schobert, H. H., Advanced Thermally Stable Coal-Based Jet Fuels, Annual Progress Report, AFOSR Grant F49620-99-1-0290, 2001-2002

1-2 Schobert, H. H., Advanced Thermally Stable Coal-Based Jet Fuels, Annual Progress Report, AFOSR Grant F49620-99-1-0290, 2000-2001

1-3 Schobert, H. H., Advanced Thermally Stable Coal-Based Jet Fuels, Annual Progress Report, AFOSR Grant F49620-99-1-0290, 1999-2000

1-4 Coleman, M. M., Fearnley, S. P., Kumar, S. and Sobkowiak, M., Fuel Stabilization, AFRL-PR-WP-TR-2000-2007, Final Report for 07/01/1995 12/31/1998, September 1999.

1-5 Song, C., Lai, W.-C., Schobert, H.H. Hydrogen-Transferring Pyrolysis of Long-Chain Alkanes and Thermal Stability Improvement of Jet Fuels by Hydrogen Donors. Ind. Eng. Chem. Res., 1994, 33 (3), 548-557

1-6 Lai, W.-C and Song, C., Prepr. Pap.- Amer. Chem. Soc. Div. Fuel Chem. 1996a $41: 524$

1-7 Lai, W.-C and Song, C., Fuel Processing Technology, 1996b 48:1

1-8 Selvaraj, L., Sobkowiak, M., Song, C., Stallman, J., Coleman, M. M. A Model System for the Study of Additives Designed to Enhance the Stability of Jet Fuels at Temperatures Above $400^{\circ} \mathrm{C}$. Energy \& Fuels, 1994, 8 (4), 839845.

1-9 Yoon, E.M., Selvaraj, L., Song, C., Stallman, J., Coleman, M. M., High Temperature Stabilizers for Jet Fuels and Similar Hydrocarbon Mixtures. 1. Comparative Studies of Hydrogen Donors. Energy \& Fuels, 1996a, 10 (3), 806-811.

1-10 Yoon, E.M., Selvaraj, L., Eser, S. and Coleman, M. M., High Temperature Stabilizers for Jet Fuels and Similar Hydrocarbon Mixtures. 2. Kinetic studies, Energy \& Fuels, 1996a, 10 (3), 812-815.

1-11 Andrésen, J.M., Strohm, J.J., Boyer, M.L., Song, C, Schobert, H.H. and Butnark, S., Am. Chem. Soc. Div. Petrol. Chem. Prepr., 2001a, 46(1), 208209.

1-12 Andrésen, J.M., Strohm, J.J., Sun, L., Song, C. Energy \& Fuels, 2001b, 15(3), 714-723. 
1-13 Badger, M. W., Fickinger, A. E.,Martin, S. C.,Mitchell, G. D. and Schobert, H. H., Proc. $8^{\text {th }}$ Austrlian Coal Science Conference, 1998, 245.

1-14 Badger, M. W., Fickinger, A. E., Mitchell, G. D., Adams, A. N. and Schobert, H. H., Proc. $205^{\text {th }}$ International Technical Conference on Coal Utilization and Fuel Systems (in press).

1-15 Butnark, S., Badger, M.W. and Schobert, H.H., Amer. Chem. Soc., Div. Fuel Chem. Prepr., 1999, 44 (3), 662-665.

1-16 Butnark, S., Badger, M. W. and Schobert, H. H., Prepr. Pap.- Amer. Chem. Soc. Div. Petrol. Chem., 2000 45:493.

1-17 Fickinger, A. E., 2000, M. S. Thesis, The Pennsylvania State University, University Park, PA.

1-18 Fickinger, A. E., Badger, M. W., Mitchell, G. D. and Schobert, H. H., , Prepr. Pap.- Amer. Chem. Soc. Div. Fuel Chem, 1999, 44:106.

1-19 Fickinger, A. E., Badger, M. W., Mitchell, G. D. and Schobert, H. H., , Prepr. Pap.- Amer. Chem. Soc. Div. Fuel Chem, 2000, 45:299.

1-20 Song, C., and Schobert, H. H., , Prepr. Pap.- Amer. Chem. Soc. Div. Fuel Chem., 2000, 45:819.

1-21 Butnark, S., Badger, M. W. and Schobert, H. H., Determining the Desired Chemical Composition for Thermally Stable Jet Fuel, Amer. Chem. Soc., Div. Fuel Chem. Prepr., 2001, 46 (2), 492-494.

1-22 Butnark, S., Badger, M. W. and Schobert, H. H. and Wilson, G. R., Selection of Prototype Thermally Stable Jet Fuels 3. Jet Fuel Boiling Range and its Affect on Pyrolytic Stability, Prepr. Pap.- Amer. Chem. Soc. Div. Petrol. Chem., 2002, 47(3), 201.

1-23 Schobert, H. H., Badger, M. W. and Santoro, R. J., Progress Toward CoalBased JP-900, Prepr. Pap.- Amer. Chem. Soc. Div. Petrol. Chem., 2002, 47:192.

1-24 Wilson, G. R., Project Report on AFOSR-Subcontract for Advanced Thermally Stable Coal-Based Jet Fuels for the Pennsylvania State University, PARC Technical Services Inc., Pittsburgh, PA. August 2002.

1-25 Rudnick, L. R., et al. "Refinery Integration of By-Products from Coal-Derived Jet Fuels", Year Annual Progress Report, Grant No. DE-FC26-03NT41828, November 17, 2005. 
2-1 Heywood, J. B. Internal Combustion Engine Fundamentals, McGraw-Hill: New York, 1988.

2-2 Yang, Y., J. P. Szybist, and A. L. Boehman, "Low Temperature Oxidation of Methylcyclohexane in an SI Engine," Prepr. Pap.-Am. Chem. Soc., Div. Fuel Chem. 2006, 51(1), 329-330.

2-3 Tanaka, S.; Ayala, F.; Keck, J. C.; Heywood, J. B., Combustion and Flame 2003, 132, (1-2), 219-239.

2-4 Szybist, J., A.L. Boehman, D. C. Haworth, and H. Koga. "Premixed Ignition Behavior of Alternative Diesel Fuel-Relevant Compounds in a Motored Engine Experiment," Submitted to Combustion and Flame, 2005.

2-5 Kirby, S.R., A. L. Boehman, and D. J. Clifford, "Evaluation of coal-based diesel products affect on fuel quality," Prepr. Pap.-Am. Chem. Soc., Div. Fuel Chem. 2005, 50 (2), 732-733.

2-6 Rudnick, L. R., et al. "Refinery Integration of By-Products from Coal-Derived Jet Fuels", Year Annual Progress Report, Grant No. DE-FC26-03NT41828, November 17, 2005.

2-7 Boehman, A.L., J. Song, and M. Alam, "Impact of biodiesel blending on diesel soot and the regeneration of particulate filters." Energy \& Fuels, 2005. 19(5), 1857-1864.

2-8 Tuinstra, F. and J.L. Koenig, "Raman Spectrum of Graphite." Journal of Chemical Physics, 1970. 53(3), 1126-1130.

2-9 Chen, H.X. and R.A. Dobbins, "Crystallogenesis of particles formed in hydrocarbon combustion," Combustion Science and Technology, 2000. 159, 109-128.

2-10 VanderWal, R., "Soot Nanostructure: Dependence upon Synthesis Condition," Combustion and Flame, 2004, 136, 129-140.

2-11 Escribano, R., et al., "Raman spectroscopy of carbon-containing particles," Vibrational Spectroscopy, 2001. 26(2), 179-186.

2-12 Liu, F.S., et al., "The chemical effects of carbon dioxide as an additive in an ethylene diffusion flame: Implications for soot and NOx formation," Combustion and Flame, 2001, 125(1-2), 778-787.

2-13 Du, D. X., Axelbaum R. L., and Law, C. K., "The Influence of Carbon Dioxide and Oxygen as Additives on Soot Formation in Diffusion Flames," $23^{\text {rd }}$ Symposium (International) on Combustion/ The Combustion Institute, 1990, 1501-1507.

2-14 Kim, C.H., et al., "Soot surface growth and oxidation in laminar diffusion flames at pressures of 0.1-1.0 at,". Combustion and Flame, 2004. 136(1-2), 191-207. 
3-1 Song, C.S.; Ma, X. Appl. Catal. B: Env., 2003, 41, 207; Song, C.S. Catal. Today, 2003, 86, 265.

3-2 Whitehurst, D.D., Isoda, T. Mochida, I. Adv. Catal. 1998, 42, 345.

3-3 Lee, S.-W.; Ryu, J. W.; Min, W. Catal. Surv. Asia 2003, 7, 271.

3-4 Sano, Y.; Choi, K.-H.; Korai, Y.; Mochida, I. Appl. Catal. B 2004, 49, 219.

3-5 Oyama, S. T., Wang, X., Lee, Y.-K., Bando, K. and Requejo, F. G., J. Catal. 210 (2002) 207.

3-6 Stinner, C., Prins, R. and Weber, Th., J. Catal. 202 (2001) 187.

3-7 Oyama, S. T., J. Catal. 216 (2003) 343.

3-8 Sie, S. T., Fuel Proc. Tech. 61 (1999) 149.

3-9 Sano, Y.; Choi, K.-H.; Korai, Y.; Mochida, I. Energy \& Fuels 2004, 18, 644.

3-10 Kulprathipanja, S., Nemeth, L. T., Holmgren, J. S., Process for Removing Sulfur Compounds from Hydrocarbon Stream, U.S. Patent 5,807,475, 1998.

3-11 (a) Y. Yoneyama; C. Song, Catal Today, 1999, 50, 19; (b) Y. Yoneyama; C. Song, Energy \& Fuels, 2002, 16, 767; (c) C.S. Song, Y. Yoneyama and K. M. Reddy. U.S. Patent, 6,451,729, 2002; (d) C.S. Song, Y. Yoneyama and K. M. Reddy. U.S. Patent, 6,156,693, 2000.

3-12 Kim, J.H. Ma, X, Song, C.S., Lee, Y.-K. and Oyama, S.T., Energy \& Fuels, 2005, 19, 353.

3-13 J. Tauster, T.A. Pecoraro, R.R. Chianelli, J. Catal. 63 (1980) 515.

3-14 R. Burch, A. Collins, Appl. Catal. 17 (1985) 273.

3-15 Rudnick, L. R., et al. "Refinery Integration of By-Products from Coal-Derived Jet Fuels", Year Annual Progress Report, Grant No. DE-FC26-03NT41828, November 17, 2005.

3-16 E. Devers; P. Afanasiev; B. Jouguest; M. Vrinat, Catal Lett 82 (2002) 13.

3-17 N.-Y. Topsøe and H. Topsøe, J. Catal. 84 (1983) 386.

3-18 Z. Hong, and J.R. Regalbuto, J. Phys. Chem. 99 (1995) 9452.

4-1 Wilhelm, S.M. and Bloom, N., Mercury in petroleum, Fuel Processing Technology, March, 2000. 
4-2 U.S. EPA, Mercury study report to Congress, Volume II: An inventory of anthropogenic mercury emissions in the United States, US Office of Air Quality, Planning and Standards; Research Triangle, NC, EPA-452/R-97004,1997a.

4-3 U.S. EPA, Locating and estimating air emission from sources of mercury and mercury compounds, US Office of Air Quality, Planning and Standards; Research Triangle, NC, EPA-454/R-97-012, December, 1997b.

4-4 Bloom, N.S., Analysis and stability of mercury speciation in petroleum hydrocarbons, Fresenius J. Anal. Chem., vol 366(5), 2000.

4-5 Liang, L., Horvat, M. and Danilchik, P., A novel analytical method for determination of pictogram levels of total mercury in gasoline and other petroleum-based products, Sci. Tot. Environ., 187, 57, 1996.

4-6 Rising, B., Sorurbakhsh, P., Wu., J., Survey of ultra-trace metals in gas turbine fuels, $11^{\text {th }}$ Annual International Petroleum Environmental Conference, Proceedings, Albuquerque, NM, October, 2004

4-7 Wilhelm, S.M., Mercury in fuel oil, www.hstech.com/Data/Oil?Fuel\%20Oil.htm, March 25, 2005.

4-8 Wilhelm, S.M. and Kirchgessner, D.A., Mercury in US crude oil: A study by US EPA, API and NPRA, SPE/EPA/DOE Exploration and Production Environmental Conference, San Antonio, TX, Society of Petroleum Engineers Paper 80573, 2003.

4-9 LECO Corporation, AMA254 Instruction Manual, October 2003.

4-10 Rudnick, L. R., et al. "Refinery Integration of By-Products from Coal-Derived Jet Fuels", Year Annual Progress Report, Grant No. DE-FC26-03NT41828, November 17, 2005.

5-1 Rudnick, L.R., Boehman, A., Song, C., Miller, B.G., Mitchell, G., "Refinery Integration of By-Products from Coal-Derived Jet Fuels," Semi-Annual Progress Report for Grant DE-FC26-03NT41828, November 17, 2005.

5-2 Gul, O., Rudnick, L.R. and Schobert, H.H., Delayed Coking of Decant Oil and Coal in a Laboratory Scale Coking Unit, to be submitted to Energy \& Fuels.

5-3 Escallón, M.M., M.S. Thesis. Reaction of decant oil and bituminous coal at $465^{\circ} \mathrm{C}$ in a laboratory scale coker, Pennsylvania State University, 2004. 
5-4 Fickinger, A.E., M.S. Thesis. Laboratory-scale coking of coal/petroleum mixtures, The Pennsylvania State University, 2000.

5-5 Song, C., Eser, S., Schobert, H.H., Hatcher, P.G. Pyrolysis degradation studies of a coal-derived and a petroleum-derived aviation jet fuel, Energy and Fuels, 1993, 7, 234-243.

5-6 Gül, Ö., Rudnick, L.R. and Schobert, H. H., "Delayed Coking of Decant Oil and Coal In A Laboratory Scale Coking Unit," In Press, Energy \& Fuels, July 2006

5-7 Rodriguez J.; Tierney J.W.; Wender I., "Evaluation of a Delayed Coking Process by ${ }^{1} \mathrm{H}$ and ${ }^{13} \mathrm{C}$ NMR Spectroscopy: 2. Detailed Interpretation of Liquid NMR Spectra," Fuel 1994, 73(12), 1870-1875.

5-8 Gül, Ö., Rudnick, L.R. and Schobert, H. H., The Effect of Chemical Composition of Coal-Based Jet Fuels on the Deposit Tendency and Morphology, Submitted for publication (Energy \& Fuels).

5-9 Yoshida, T.; Li, C.; Takanohashi, T.; Matsumura, A.; Sato, S.; Saito, I., Fuel Processing Technology 2004, 86, 61-72.

5-10 Yoshida, T.; Takanohashi, T.; Katoh, K., Fuel 2000, 79, 399-404.

5-11 Yoshida, T.; Takanohashi, T.; Sakanishi, K.; Saito, I., Energy\&Fuels 2002, 16, 1006-1007.

5-12 Yoshida, T.; Takanohashi, T.; Sakanishi, K.; Saito, I.; Fujita, M.; Mashimo, K., Fuel 2002, 81, 1463-1469.

5-13 Griffith, J.G., Rudnick, L.R., Schobert, H.H., Preprint Pap., Amer. Chem. Soc. Div. Petr. Chem., 2006, 51 (1-2).

5-14 Griffith, J.G., Clifford, C.E.B., Rudnick, L.R., Schobert, H.H., Preprint Pap., Amer. Chem. Soc. Div. Petr. Chem., 2006, 51 (3-4), submitted.

5-15 Oya, A., Qian, Z. and Marsh, H. Structural study of cokes using optical microscopy and X-ray diffraction. Fuel, 1983, 62, 274-278.

5-16 Eser, S. In Supercarbon: Synthesis, Properties and Applications; Yoshimura, S., Chang, R., Eds. Springer-Verlag, Berlin, 1998; 147.

5-17 Newman, J.W., and Newman, K.L. (1997). A History of Pitch Technologies. In Introduction to Carbon Technologies, H. Marsh, Heintz, E. A., and Rodriguez-Reinoso, F., ed. (Secretariado de Publicaciones), pp. 269-328. 
5-18 Kershaw, J.R., and Black, K.J.T. (1993). Structural Characterization of CoalTar and Petroleum Pitches. Energy \& Fuels 7, 420-425.

5-19 Attalla, M.I., Vassallo, A.M., and Wilson, M.A. (1989). Nuclear Magnetic Resonance Studies of Coal Liquifaction. In Spectroscopic Analysis of Coal Liquids, J.R. Kershaw, ed. (NY: Elsevier), pp. 195-245.

5-20 Kershaw, J.R. (1989). Average Structure Determinations. In Spectroscopic Analysis of Coal Liquid, J.R. Kershaw, ed. (NY: Elsevier), pp. 247-265.

5-21 Snape, C.E., Kenwright, A.M., Bermejo, J., Fernandez, J., and Moinelo, S.R. (1989). Evaluation of the aromatic structure of coal tar pitch by solid and solution state NMR. Fuel 68, 1605-1608.

5-22 Love, G.D., Law, R.V., and Snape, C.E. (1993). Determination of nonprotonated aromatic carbon concentrations in coals by single pulse excitation carbon-13 NMR. Energy \& Fuels 7, 639-644.

5-23 Andresen, J.M., Luengo, C.A., Moinelo, S.R., Garcia, R., and Snape, C.E. (1998). Structural uniformity of toluene-insolubles from heat-treated coal tar pitch as determined by solid state C-13 NMR spectroscopy. Energy \& Fuels $12,524-530$.

5-24 Solum, M.S., Pugmire, R.J., and Grant, D.M. (1989). Energy \& Fuels 3, 187 193. 


\section{List of Acronyms and Abbreviations}

$\begin{array}{ll}\text { 1THQ } & \text { 1,2,3,4-tetrahydroquinoline } \\ \text { 5THQ } & \text { 5,6,7,8-tetrahydroquinoline } \\ \text { AFOSR } & \text { Air Force Office of Scientific Research } \\ \text { ADN } & \text { Adsorptive Denitrogenation } \\ \text { ADS } & \text { Adsorptive Desulfurization } \\ \text { ATTM } & \text { Ammonium Tetrathiomolybdate } \\ \text { API } & \text { American Petroleum Institute } \\ \text { BT } & \text { benzothiophene } \\ \text { CFR } & \text { Cooperative Fuels Research } \\ \text { DBT } & \text { dibenzothiophene } \\ \text { DDC } & \text { Detroit Diesel Corporation } \\ \text { DDS } & \text { direct desulfurization } \\ \text { DHQ } & \text { decahydroquinoline } \\ \text { DMBP } & \text { dimethyl biphenyl } \\ \text { DMDBT } & \text { dimethyldibenzothiophene } \\ \text { DMDCH } & \text { dimethyl dicyclohexyl } \\ \text { DMN } & \text { dimethyl naphthalene } \\ \text { EN } & \text { ethyl naphthalene } \\ \text { EPA } & \text { Environmental Protection Agency } \\ \text { FBP } & \text { final boiling point } \\ \text { FCC } & \text { fluid catalytic cracking } \\ \text { FID } & \text { flame ionizaton detector } \\ \text { FTIR } & \text { Fourier Transform Infrared } \\ \text { GCMS } & \text { gas chromatography-mass spectrometry } \\ \text { HDMDBT } & \text { hydrodimethyl dibenzothiophene } \\ \text { HDS } & \text { hydrodesulfurization } \\ \text { HDT } & \text { hydrotreated } \\ \text { HM } & \text { H-mordenite } \\ \text { HPLC } & \text { high performance liquid chromatography } \\ \text { HY } & \text { H Y-type zeolite } \\ \text { HYD } & \text { hydrogenation pathway } \\ \text { HZSM } & \text { H-synthetic zeolite material } \\ \text { IBP } & \text { initial boiling point } \\ \text { IC } & \text { internal combustion } \\ \text { IQT } & \text { ignition quality test } \\ \text { JP-900 } & \text { jet fuel prototype stable to 900 F } \\ \text { LCO } & \text { light cycle oil } \\ \text { LDMS } & \text { laser desorption mass spectrometry } \\ \text { LHSV } & \text { liquid hourly space velocity } \\ \text { LTHDA } & \text { low temperature hydrotreating and dearomatization } \\ \text { MCHT } & \text { methyl cyclohexyl toluene } \\ \text { MCM } & \text { mesopourous catalytic material } \\ \text { NTP } & \text { mothyl naphthalene } \\ & \end{array}$




$\begin{array}{ll}\text { PARC } & \text { Pennsylvania Applied Research Corporation } \\ \text { PB } & \text { propyl benzene } \\ \text { PCH } & \text { propyl cyclohexane } \\ \text { PCHE } & \text { propyl cyclohexene } \\ \text { PP } & \text { petroleum pitch } \\ \text { PSU } & \text { Penn State University } \\ \text { RCO } & \text { refined chemical oil } \\ \text { SI } & \text { spark ignited } \\ \text { SpGr } & \text { specific gravity } \\ \text { SwRI } & \text { Southwest Research Institute } \\ \text { TLP } & \text { total liquid product } \\ \text { TOS } & \text { time on stream } \\ \text { WHSV } & \text { weight hourly space velocity } \\ \text { XPS } & \text { x-ray photoelectron spectroscopy }\end{array}$




\section{Appendix 5-1}

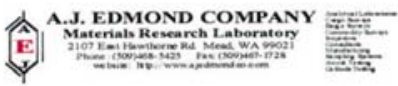

\begin{tabular}{|c|c|c|c|c|c|}
\hline MRL ID\# & 05.300 .01 & 05.305 .01 & & & \\
\hline Origin & PSU & PSU & & & \\
\hline Type & Green Coke & Calcined Coke & & & \\
\hline Description & $\begin{array}{c}80 \% \text { EI-107 } \\
\text { Oil } 20 \% \text { EI-186 } \\
\text { Pitts Seam Coal }\end{array}$ & $\begin{array}{c}80 \% \text { EI-107 } \\
\text { Oil } 20 \% \text { EI-186 } \\
\text { Pits Seam Coal }\end{array}$ & & & \\
\hline \multicolumn{6}{|l|}{ Sieve Analysis Wt.\% (USM) } \\
\hline$+3 / 4^{\prime \prime}$ & 37.19 & 19.86 & & & \\
\hline$-3 / 4^{\prime \prime}+1 / 2 "$ & 36.23 & 33.91 & & & \\
\hline$-1 / 2 "+4$ & 12.61 & 20.24 & & & \\
\hline$-4+8$ & 5.90 & 10.13 & & & \\
\hline$-8+14$ & 2.47 & 5.10 & & & \\
\hline$-14+20$ & 1.58 & 3.48 & & & \\
\hline$-20+30$ & 0.87 & 1.86 & & & \\
\hline$-30+60$ & 1.56 & 2.97 & & & \\
\hline$-60+100$ & 0.54 & 0.96 & & & \\
\hline$-100+200$ & 0.47 & 0.81 & & & \\
\hline$-200+325$ & 0.23 & 0.28 & & & \\
\hline-325 & 0.35 & 0.40 & & & \\
\hline Moisture \% & 0.54 & & & & \\
\hline \multicolumn{6}{|l|}{ De-Dust Oil Content \% } \\
\hline Hg Porosity@15K (cu. mm/g) & & 58.6 & & & \\
\hline $\begin{array}{l}\text { Isotropic Coke } \% \\
\end{array}$ & & 1.71 & & & \\
\hline Spec.Elec. Resistivity (ohm-in.) & & 0.035 & & & \\
\hline $\begin{array}{c}\text { HGI } \\
\end{array}$ & 26.0 & 23.7 & & & \\
\hline \multicolumn{6}{|l|}{ VBD (g/ce) (USM) } \\
\hline \multicolumn{6}{|l|}{$-8+16$} \\
\hline \multicolumn{6}{|l|}{$-20+40$} \\
\hline$-30+50$ & & 0.925 & & & \\
\hline \multicolumn{6}{|l|}{$-30+50$ Natural } \\
\hline Real Density (g/cc-He) & & 2.082 & & & \\
\hline Hg Apparent Density (g/cc) & & 1.830 & & & \\
\hline Volatile Content Matter \% & 5.18 & 0.71 & & & \\
\hline Ash $\%$ & 0.71 & 0.89 & & & \\
\hline \multicolumn{6}{|l|}{ Elemental Analysis \% } \\
\hline $\begin{array}{r}\text { Calcium (Ca) } \\
\end{array}$ & 0.0226 & 0.0262 & & & \\
\hline Iron (Fe) & 0.0571 & 0.0684 & & & \\
\hline Nickel (Ni) & 0.0005 & 0.0007 & & & \\
\hline Silicon (Si) & 0.0863 & 0.1013 & & & \\
\hline Sodium (Na) & $<0.0030$ & 0.0054 & & & \\
\hline Sulfur (S) & 1.31 & 1.34 & & & \\
\hline Vanadium (V) & 0.0015 & 0.0018 & & & \\
\hline
\end{tabular}




\section{Appendix 5-2}

FROM A. ADAMS

HALL PROCESS IMPROVEMENT

TENNESSEE OPERATIONS
TO G. MITCHELL THE PENNSYLVANIA STATE UNIVERSITY

2006-02-14

RE: EVALUATION OF COKE DERIVED FROM THE CO-COKING OF COAL AND
PETROLEUM FRACTIONS FOR USE IN HALL CELL ANODES Letter Report No. 06-038

\section{Summary}

At the request of Gareth Mitchell and Les Rudnick of the Pennsylvania State University, a preliminary evaluation of carbonaceous material produced from the delayed coking of a blend of $20 \%$ coal and $80 \%$ decant oil was conducted. This assessment was made as part of the Refinery Integration Project. The evaluation included a quantitative comparison of the properties of the calcined coke, production of bench-scale anodes, and measurement of the baked apparent density and electrical resistivity of the anode specimens.

The calcined coke product produced from the co-coking process had an ash content too high to be suitable for use in anodes. Specifically, the silicon and iron content of the calcined co-coke were well above current specifications, and would result in unacceptable metal purity for a commercial smelter. This finding would eliminate the material from being a candidate coke source for anodes. Other results were more encouraging. Concentrations of other undesirable oxidation catalysts were lower than standard petroleum coke. Additionally, the properties of the baked anodes (baked apparent density and electrical resistivity) were improved with utilization of the co-coked carbon. If the silicon and iron levels can be sufficiently decreased to $<300 \mathrm{ppm}$ each, it is recommended that the co-coked material be reevaluated as a potential coke source for anodes.

\section{Experimental}

\section{$\underline{\text { Coke Analysis }}$}

The green coke was analyzed by A.J. Edmond Company using standard industrial practices. Tests included in the evaluation are listed below:

1. Vibrated bulk density (g/cc)

2. Moisture (\%)

3. Mercury porosity $\left(\mathrm{mm}^{3} / \mathrm{g}\right)$

4. Isotropic coke $(\%)^{*}$

5. Specific electrical resistance $(\Omega$-in)

6. Hardgrove grindability index 
7. Volatile matter $(\%)$

8. Ash (\%)

9. Elemental analysis
a. Calcium
b. Iron
c. Sodium
d. Nickel
e. Silicon
f. Vanadium
g. Sulfur

*It should be noted that in this case the term isotropic coke refers to the presence of shot coke. This material is identified by its spherical BB-type appearance. It does not refer to the microtexture of the coke as observed by ASTM optical light microscopy procedures.

\section{Coke Calcining and Sizing}

The green coke was also calcined at A.J. Edmond Company using a stagnant calciner. A schematic of the coke calciner used is given in Figure 1. $3.5 \mathrm{~kg}$ of coke was loaded into the calciner, heated to the desired calcination temperature, and allowed to soak for 10 minutes. The standard practice for A.J. Edmond is to calcine the material to a temperature of $1325^{\circ} \mathrm{C}$. For typical petroleum cokes, this results in a real density of 2.06 $\mathrm{g} / \mathrm{cc}$. For the co-coke material, $1325^{\circ} \mathrm{C}$ resulted in a real density of $2.11 \mathrm{~g} / \mathrm{cc}$. A.J. Edmond decided to back off on temperature to $1275^{\circ} \mathrm{C}$, which resulted in a real density of $2.78 \mathrm{~g} / \mathrm{cc}$. They decided not to reduce the temperature any further. The reported density is an average of the different runs needed to calcine the $19 \mathrm{~kg}$ of coke shipped from Penn State. 


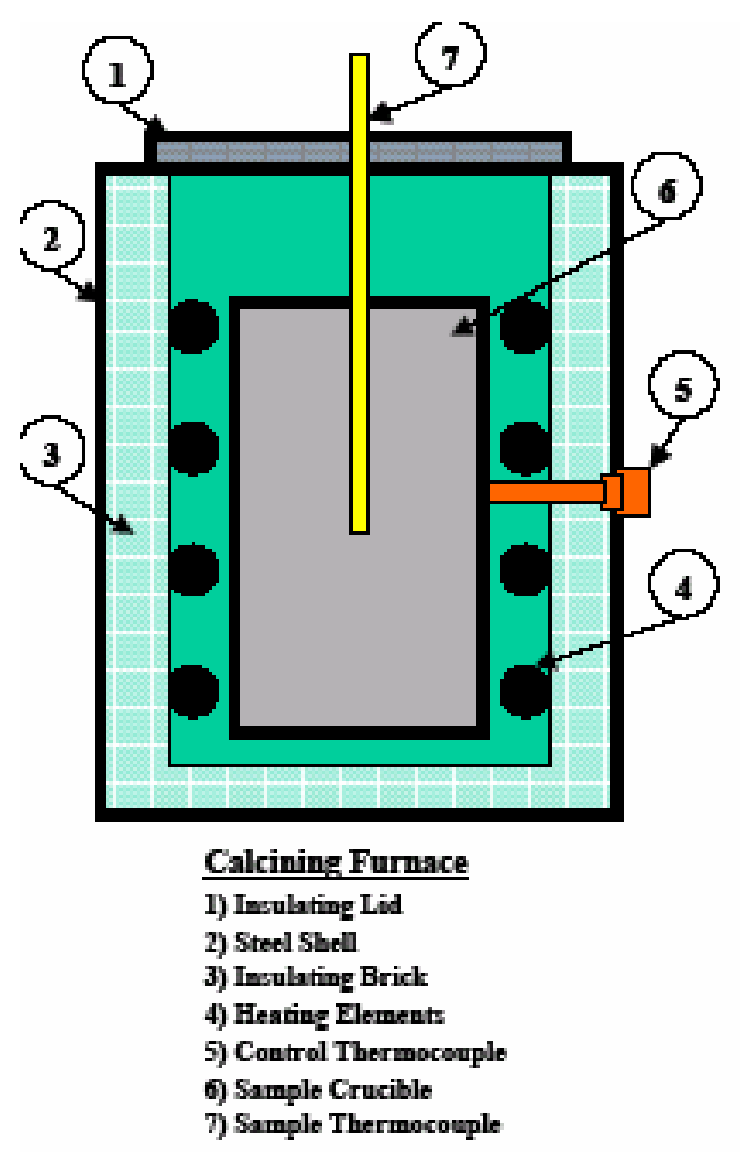

Figure 1: Schematic of A.J. Edmond Stagnant Coke Calciner Operation

A.J. Edmond crushed and sized the calcined co-coke to a sieve analysis that ATC specified. The sieve analysis was based on work currently going on at the lab. For laboratory anode production, recycled butts from an Alcoa smelter were added to the aggregate. The sieve analysis for the total dry aggregate is given in Table 1.

Table 1: Sieve Analysis of Total Dry Aggregate

\begin{tabular}{|c|c|c|c|c|}
\hline & $\mathbf{2 6 \%}$ & $\mathbf{2 8 \%}$ & $\mathbf{7 \%}$ & $\mathbf{3 9 \%}$ \\
\hline & Butts & Coarse & Intermediates & Fines \\
\hline$-3 / 4,+1 / 2$ & $6.2 \%$ & & & \\
\hline$-1 / 2,+1 / 4$ & $38.9 \%$ & $1.1 \%$ & & \\
\hline$-1 / 4,+4$ & $10.1 \%$ & $1.0 \%$ & & \\
\hline$-4,+8$ & $16.8 \%$ & $17.7 \%$ & & \\
\hline$-8,+12$ & $9.8 \%$ & $41.0 \%$ & & \\
\hline$-12,+20$ & $6.5 \%$ & $27.0 \%$ & $21.9 \%$ & $0.1 \%$ \\
\hline$-20,+28$ & $3.5 \%$ & $10.0 \%$ & $10.9 \%$ & $0.5 \%$ \\
\hline$-28,+60$ & $4.7 \%$ & $2.3 \%$ & $49.4 \%$ & $3.4 \%$ \\
\hline$-60,+100$ & $1.5 \%$ & & $10.3 \%$ & $8.4 \%$ \\
\hline$-100,+200$ & $1.3 \%$ & & $6.0 \%$ & $23.8 \%$ \\
\hline
\end{tabular}




\begin{tabular}{|c|c|c|c|c|}
\hline$-200,+325$ & $0.4 \%$ & & $1.1 \%$ & $16.1 \%$ \\
\hline-325 & $0.4 \%$ & & $0.3 \%$ & $47.7 \%$ \\
\hline & $100.0 \%$ & $100.0 \%$ & $100.0 \%$ & $100.0 \%$ \\
\hline
\end{tabular}

\section{Production of Laboratory-Scale Anodes}

Bench-scale anodes were produced using the facilities at the Alcoa Technical Center. The aggregate was preheated overnight at the mixing temperature of $160^{\circ} \mathrm{C}$. A batch of 4,500 grams of the aggregate was charged to a 10-liter sigma blade mixer and mixed dry for three minutes. The desired amount of pitch was then added to the aggregate. The green paste was mixed for 30 minutes. Four hundred grams of mix were removed from the mixer for pressing into green anodes. The material was pressed into an anode specimen in a $50 \mathrm{~mm}$ diameter mold preheated to $135^{\circ} \mathrm{C}$. The mix was pressed to 600 bar $(8,820$ psig) and held at that pressure for 20 seconds.

The amount of pitch needed to increase the pitch level by $0.5 \%$ was added then to the mixer and mixed for 3 minutes. Another anode was made. The process was repeated until 10 anodes of varying pitch concentration were produced. The anodes were then baked to a finishing temperature of $1125^{\circ} \mathrm{C}$ using the temperature profile shown in Figure 2. Once cooled, several measurements were taken to determine the baked apparent density and electrical resistivity of the anode specimens.

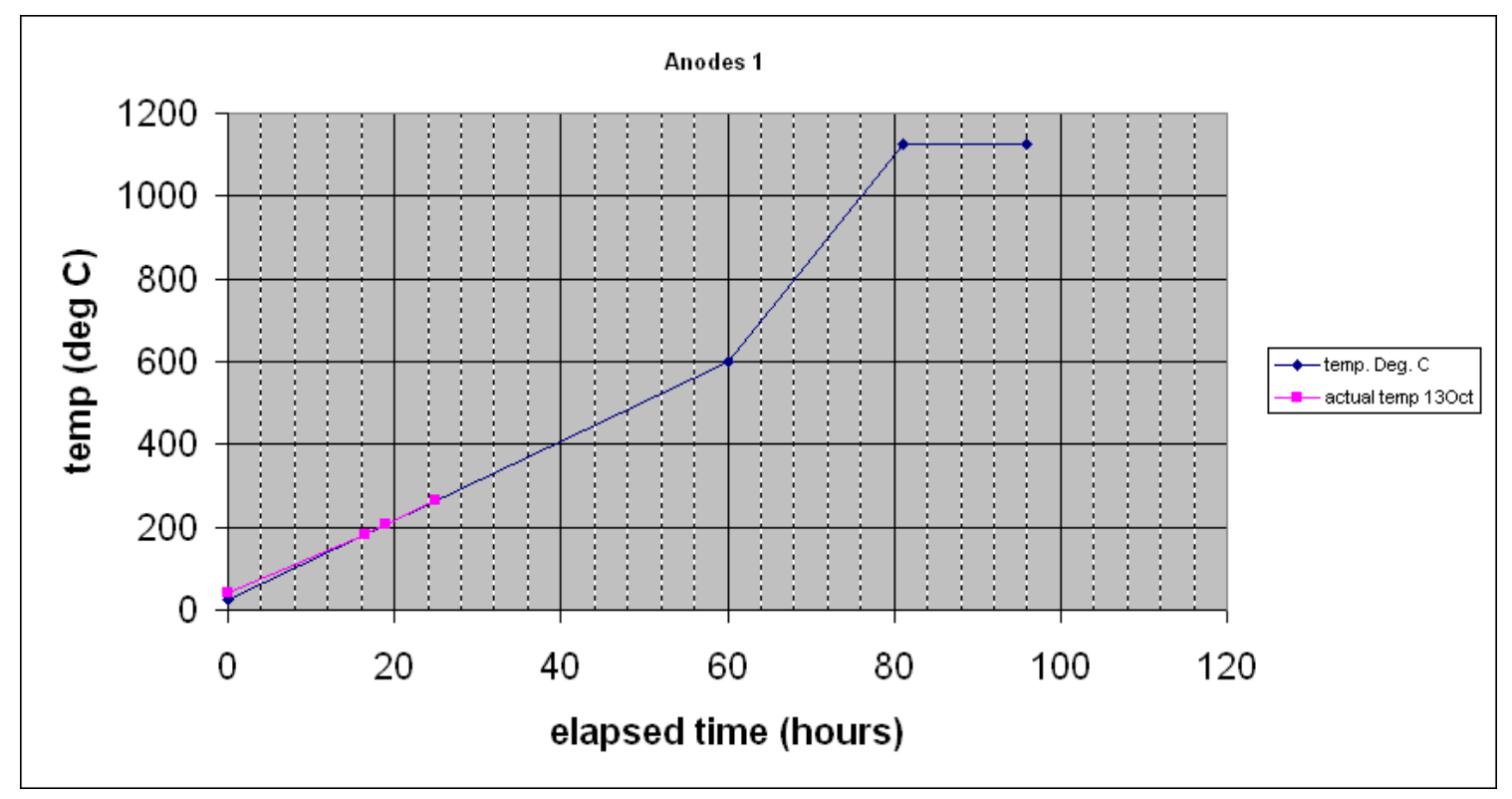

Figure 2: Heat Curve for Anode Baking 


\section{Testing of Laboratory-Scale Anodes}

\section{Baked Apparent Density}

The baked apparent density of the anodes was calculated based on weight and volume measurements. Digital calipers were used to measure the volume of the anode. Four diameter measurements were made $90^{\circ}$ apart from each other at the top, center, and bottom of the anode. Four length measurements were taken $90^{\circ}$ apart from each other and averaged. Equation 1 was used to calculate the baked apparent density of the anode specimens.

\section{Equation 1: Bake Apparent Density}

$$
\begin{aligned}
& \text { Where: } \\
& \text { BAD, Baked apparent density }\left(\mathrm{g} / \mathrm{cm}^{3}\right) \\
& \mathrm{W}_{\mathrm{b}} \text {, weight of baked specimen }(\mathrm{g}) \\
& \mathrm{V}_{\mathrm{b}} \text {, volume of baked specimen }\left(\mathrm{cm}^{3}\right)
\end{aligned}
$$$$
B A D=\frac{W_{b}}{V_{b}}
$$

\section{Electrical Resistivity}

The room-temperature electrical resistivity of the carbon anode specimens was determined using an eight-point method. The ends of the cylindrical specimens were first flattened using a belt sander. The specimen was then placed between two copper plates and nine amps of DC current were applied. A $7.15 \mathrm{~cm}$ millivoltmeter probe was placed in eight different spots, $45^{\circ}$ apart, around the anode. The voltage drop across the probe was measured, and the electrical resistivity was calculated using Equation 2.

\section{Equation 2: Electrical Resistivity}

$$
\text { Re sistivity }=\frac{A x B}{C x D}
$$

Where:
A, millivolts reading
$\mathrm{B}$, average cross sectional area $\left(\mathrm{cm}^{2}\right)$
$\mathrm{C}$, probe length $(\mathrm{cm})$
D, current supplied to sample (amps) 


\section{$\underline{\text { Results }}$}

\section{Coke}

The calcined coke analysis from A.J. Edmond is summarized below. To put the results into context, an analysis from the calcined coke used to make the standard anodes in this study are included along with a list of ideal specifications. It should be noted that coke specifications are plant-dependent and are a function of the type of metal produced and the environmental regulations in effect at each location. A coke that could meet the desired specification limits listed below would have wide-spread applicability across the Alcoa smelting system.

Table 2: Calcined Coke Analysis

\begin{tabular}{|c|c|c|c|}
\hline Origin & Alcoa & Alcoa & PSU \\
\hline Type & Calcined coke & Calcined Coke & Calcined Coke \\
\hline Description & $\begin{array}{c}\text { Ideal target } \\
\text { specifications }\end{array}$ & $\begin{array}{c}\text { Calcined coke used } \\
\text { in production of } \\
\text { "standard" anodes }\end{array}$ & $\begin{array}{c}80 \% \text { EI-107 } \\
\text { Oil/20\% EI-186 } \\
\text { Pitts Seam Coal }\end{array}$ \\
\hline VBD -30+50 (g/cc) (USM) & $>0.85$ & 0.86 & 0.925 \\
\hline Real Density (g/cc-He) & $>2.04$ & 2.06 & 2.082 \\
\hline Sulfur (S) & $<2.5$ & 2.5 & 1.34 \\
\hline Ash\% & $<0.5$ & 0.3 & 0.89 \\
\hline Calcium (Ca) & $<200$ & 200 & 262 \\
\hline Iron (Fe) & $<300$ & 350 & 684 \\
\hline Nickel (Ni) & $<250$ & 250 & 1013 \\
\hline Silicon (Si) & $<250$ & 200 & 54 \\
\hline Sodium (Na) & $<200$ & 75 & 18 \\
\hline Vanadium (V) & $<200$ & 350 & ND \\
\hline Moisture \% & $<0.5$ & ND & 0.71 \\
\hline Volatile Content Matter \% & $<0.5$ & ND & 0.035 \\
\hline Spec. Elec. Resistivity (ohm-in.) & $<0.05$ & ND & 23.7 \\
\hline HGI & $\sim 30$ & ND & \\
\hline
\end{tabular}

The results show that co-coke is a very hard, dense material. Concentrations of the aluminum mental contaminants silicon and iron are significantly higher than currentlyused anode grade coke, and would negatively impact metal purity. On the other hand, concentrations of nickel and vanadium, oxidation catalysts, are well under the desired limit of $200 \mathrm{ppm}$, and would likely contribute to increase anode life. Additionally, the sulfur level of $1.34 \%$ is less than the typical $2.0-2.5 \%$ of most anode grade material, and would assist plants in meeting environmental specifications. 


\section{Anodes}

As a first-cut evaluation, the baked apparent density and electrical resistivity of the anodes were considered. The baked apparent densities of anodes made from standard and co-coke coke are shown below in Figure 3. It is estimated that the maximum baked apparent density is achieved at $17.0 \%$ pitch for both sets of test anodes. The maximum density achieved for the standard and co-coke anodes is 1.57 and $1.63 \mathrm{~g} / \mathrm{cc}$, respectively. The density of the co-coke anodes is considered significantly higher and, if realized in commercial production, would extend the life of the anode.

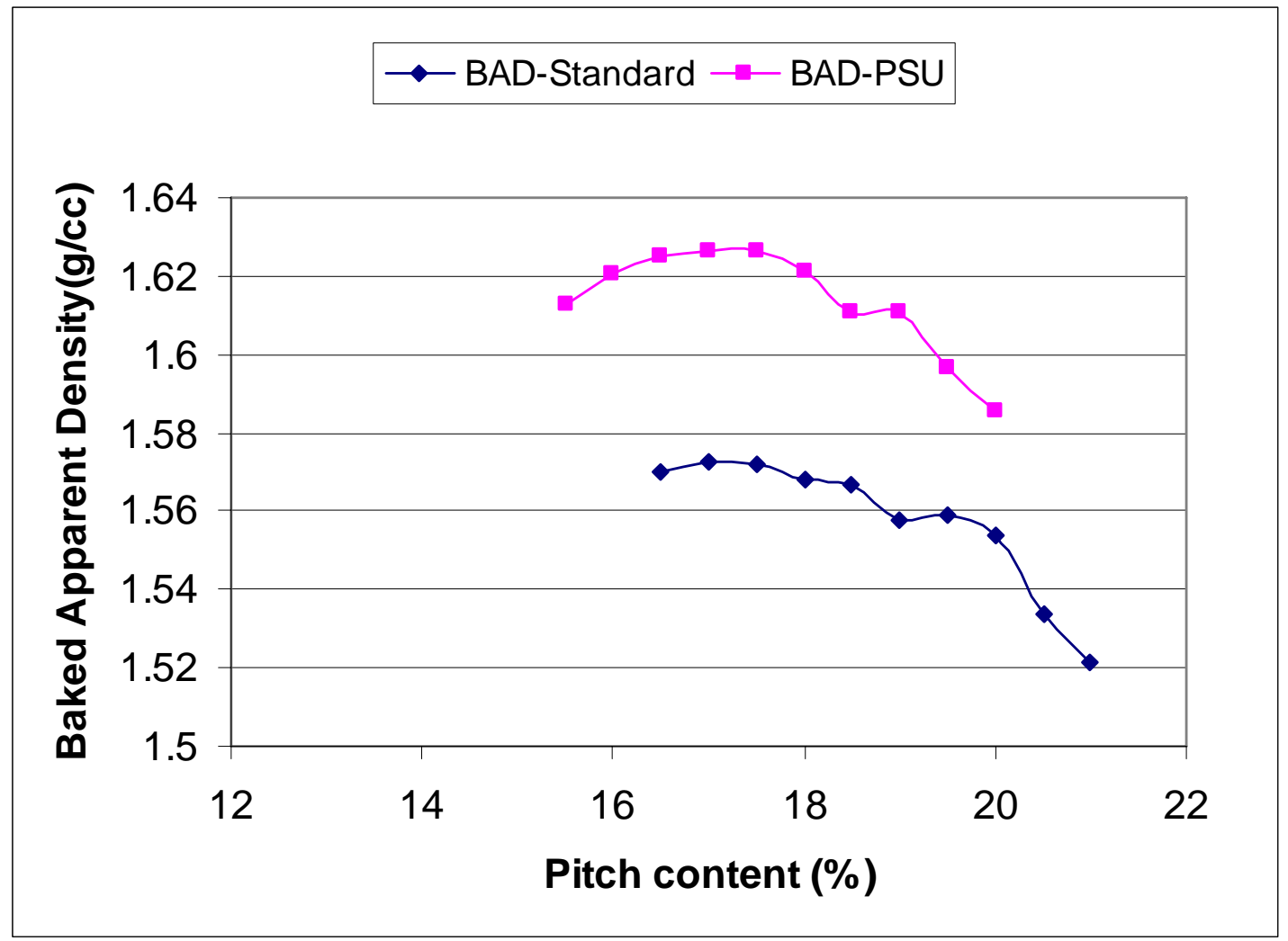

Figure 3: Baked Apparent Density of Penn State and Standard Anode Specimens

At $17 \%$ pitch the electrical resistivities of the Penn State and standard anodes are 53 and $64 \mu \Omega$-m respectively. This is also a significant difference between the two types of anodes. If realized in commercial production, energy savings in the form of reduced voltage drop across the anodes could be realized with the co-coke material. 


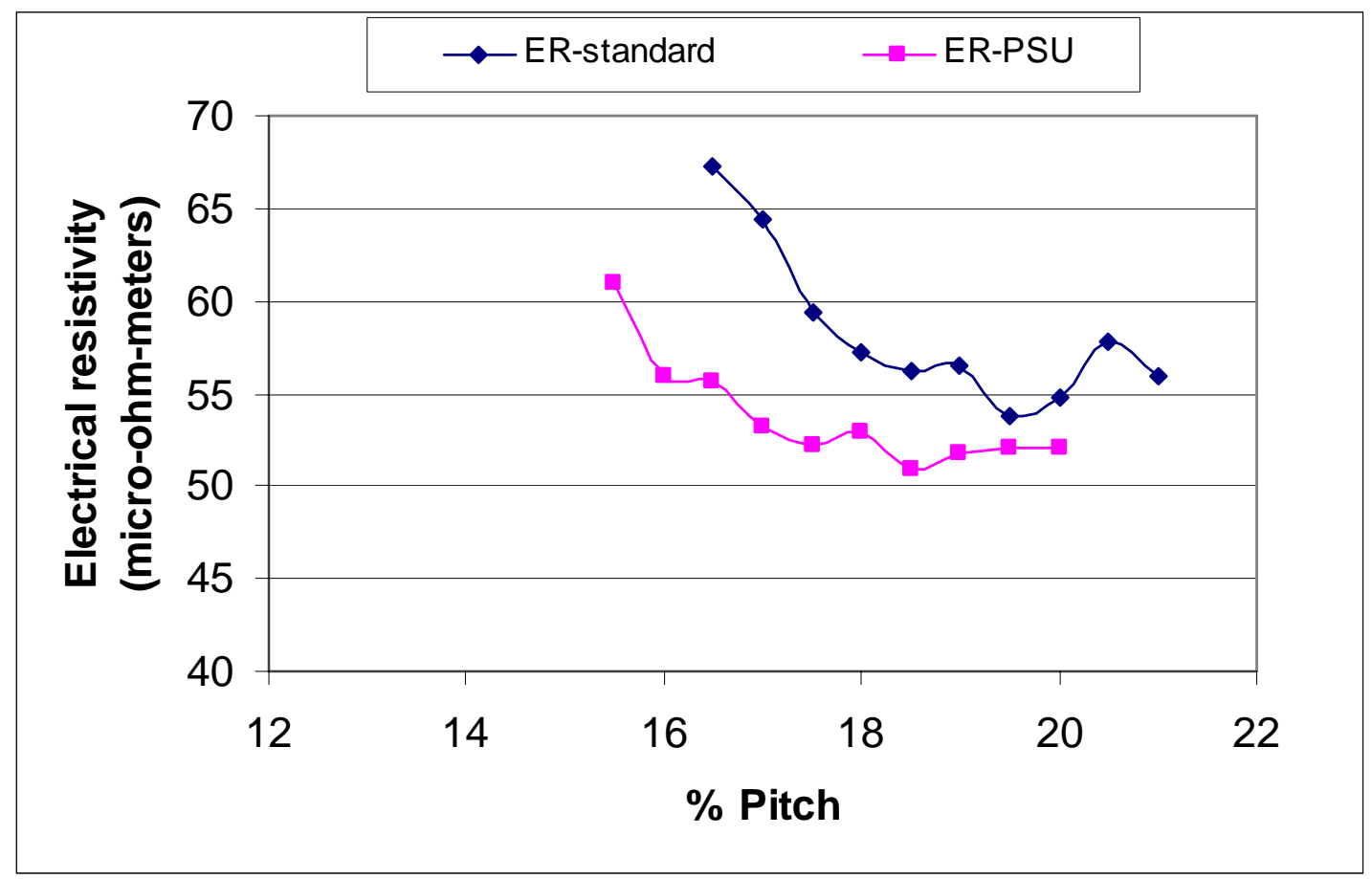

Figure 4: Electrical Resistivity of Penn State and Standard Anodes

\section{Conclusions}

The iron and silicon content of the calcined co-coke material evaluated would immediately rule it out as a candidate coke source for use in anodes. The concentration of silicon and iron were 1013 and 684 ppm, respectively, where the target specification limit is $<300 \mathrm{ppm}$ for both elements. However, if these two impurities could be reduced to below $300 \mathrm{ppm}$ each, a more comprehensive evaluation of the material would be warranted because of other favorable characteristics. The high density and low concentration of oxidation catalysts in the coke could contribute to increased anode life. The low sulfur content could assist plants in meeting their environmental requirements for $\mathrm{SO}_{2}$ emissions.

A full evaluation of the coke would include production of several batches of anodes and testing of the cores for air and $\mathrm{CO}_{2}$ reactivity, compressive and flexural strength, air permeability, and thermal conductivity.

\section{Acknowledgements}

Doug Bruce is gratefully acknowledged for conduction of the bench anode production and testing. Mark Wyborney from A.J. Edmond Company is acknowledged for calcining the coke and providing the coke analysis. 